\title{
EXPERT SPINDLE DESIGN SYSTEM
}

By

Osamu Maeda

B.A.Sc. (Mechanical Engineering)

Kobe University, Japan, 1996

A THESIS SUBMITTED IN PARTIAL FULFILLMENT OF

THE REQUIREMENTS FOR THE DEGREE OF

MASTER OF APPLIED SCIENCE

in

THE FACULTY OF GRADUATE STUDIES

MECHANICAL ENGINEERING

We accept this thesis as conforming

to the required standard

THE UNIVERSITY OF BRITISH COLUMBIA

August 2003

(C) Osamu Maeda, 2003 
In presenting this thesis in partial fulfilment of the requirements for an advanced degree at the University of British Columbia, I agree that the Library shall make it freely available for reference and study. I further agree that permission for extensive copying of this thesis for scholarly purposes may be granted by the head of my department or by his or her representatives. It is understood that copying or publication of this thesis for financial gain shall not be allowed without my written permission.

Department of Mechanical Engineening

The University of British Columbia Vancouver, Canada

Date Sept. 15.2003 


\begin{abstract}
Machine tool spindle is the most important mechanical component in removing metal during machining operations. The structural dynamics of the spindle are evaluated at the tool tip since it directly affects the material removal rate. Flexible spindles lead to unstable chatter vibrations, which can be avoided only by reducing the material removal rate. In addition, the spindle motor must have sufficient torque and power to overcome the cutting resistance of work materials to be machined. The spindles are currently designed based on accumulated experience, basic laws of machine design, and metal cutting mechanics. This thesis presents an expert spindle design system strategy which is based on the efficient utilization of past design experience, the laws of machine design and metal cutting dynamics.

The configuration of the spindle is decided by identifying the work material, desired cutting conditions and most common tools which will be used on the machine tool. The spindle drive mechanism, drive motor, bearing types, and spindle shaft dimensions are selected based on the target application. The thesis provides a set of fuzzy design rules which lead to interactive and automatic design of spindle drive configurations. The structural dynamics of the spindle are automatically optimized by distributing the bearings along the spindle shaft. The proposed strategy is to iteratively predict the Frequency Response Function (FRF) of the spindle at the tool tip using the Finite Element Method (FEM) based on Timoshenko Beam elements. Predicted FRF of the spindle is integrated to the chatter vibration stability law which indicates whether the design would lead to chatter vibration free cutting operation at the desired speed and depth of cut. The bearing spacings are iteratively optimized without violating the design constraints of the spindle.

The proposed expert system design is demonstrated by automatically designing several spindles which are found on industrial machine tools.
\end{abstract}




\section{Table of Contents}

Abstract $\quad$ ii

Table of Contents

List of Tables

List of Figures

Acknowledgment $\quad$ xiv

Nomenclature $\quad$ xv

$\begin{array}{lr}\text { 1. Introduction } & 1\end{array}$

$\begin{array}{lc}\text { 2. Literature Review } & 4\end{array}$

$\begin{array}{ll}\text { 2.1. Overview } & 4\end{array}$

2.2. Basics of Spindle Design 4

2.3. Expert System for Spindle Design 5

2.4. Chatter Vibrations $\quad 6$

2.5. Spindle Analysis $\quad 9$

$\begin{array}{lr}\text { 3. Design Principle for the Milling Spindle } & 11\end{array}$

$\begin{array}{ll}\text { 3.1. Introduction } & 11\end{array}$

3.2. Transmission 13

3.2.1. Gear Type $\quad \cdot 13$ 
3.2.2. Belt-Pulley Type

3.2.3. Direct Coupling Type 15

$\begin{array}{ll}\text { 3.2.4. Motorized type } & 15\end{array}$

3.3. Bearings 16

3.3.1. Number of the Bearings 16

3.3.2. Bearing Types 17

3.3.3. Contact Rolling Bearings for Machine Tools 20

3.3.4. High Speed Angular Contact Ball Bearings 23

3.3.5. Preload 26

3.3.6. Bearing Arrangement 28

3.3.7. Lubrication System 33

3.4. Tool Interface 36

4. Expert System for Spindle Design 4

4.1. Introduction 41

4.2. Expert System for Spindle Design $\quad 42$

4.3. Fuzzy Logic 43

4.4. Application of Expert System to Spindle Design 52

4.4.1. Transmission Type Selection 53

4.4.2. Lubrication Type Selection $\quad 66$

4.5. Validation 71

5. Bearing Spans' Optimization $\quad 84$

$\begin{array}{lr}\text { 5.1. Introduction } & 84\end{array}$

$\begin{array}{lc}\text { 5.2. Chatter Free Spindle } & 85\end{array}$ 
5.3. Finite Element Analysis for Bearing Spans' Optimization

5.3.1. Beam Elements

5.3.2. Frequency Response Function $\quad 89$

5.3.3. Suitable Beam Element for Spindle Analysis _ 93

5.3.4. Spindle Analysis 96

5.4. Optimization Methods $\quad 102$

5.4.1. Introduction 102

$\begin{array}{ll}\text { 5.4.2. Sequential Quadratic Programming . } & 104\end{array}$

5.4.3. SQP Application to Bearing Spans' Optimization 107

5.4.4. Bearing Spans' Optimization with Expert Spindle Design System 116

5.4.5. Validation 123

$\begin{array}{lr}\text { 6. Conclusions } & 125\end{array}$

$\begin{array}{lr}\text { Appendix A } & 128\end{array}$

$\begin{array}{ll}\text { Appendix B } & 130\end{array}$

$\begin{array}{ll}\text { Appendix C } & 131\end{array}$

$\begin{array}{ll}\text { Appendix D } & 132\end{array}$

$\begin{array}{ll}\text { Appendix E } & 135\end{array}$

$\begin{array}{ll}\text { Appendix F } & 151\end{array}$

$\begin{array}{lr}\text { Appendix G } & 154\end{array}$

$\begin{array}{ll}\text { Appendix H } & 155\end{array}$ 


\section{List of Tables}

3.1: The Comparison of Bearings [36]

3.2: The Properties Comparison of Contact Bearings [36]

3.3 : Symbols for Bearing Arrangement

4.1 : Logic Connectives in Fuzzy Logic

4.2 : Rules for Transmission Selection (Gear/Belt-pulley)

4.3 : Rules for Transmission Selection (Direct Coupling/Motorized)

4.4 : Bearing Types and DmNGmax Values

4.5 : Rules for Lubrication Selection

4.6 : Validation List

4.7 : Most common cutting conditions for SH-403 CNC MachineCutting Conditions

4.8 : The Results of the Expert System for Spindle Design

5.1 : Iteration Process to Identify Optimized Bearing Spans

5.2 : Modification Parameters

C.1 : Specifications of VMC 2216 


\section{List of Figures}

1.1 : Flow Chart of Expert Spindle Design System 2

2.1: Chatter Mechanism in Turning [2] 7

2.2 : Dynamic Modeling for Milling 8

2.3: Transfer Function Measurement Setup 9

3.1 : Typical Spindle Model 12

3.2 : Gear Type Spindle $\quad 13$

3.3 : Gear Ratio Difference (a) Same gear size, (b) Gear ratio is $3: 1$

3.4 : Belt-Pulley Type Spindle 14

3.5 : Direct Coupling Type Spindle 15

3.6: Motorized Spindle 16

3.7 : Front Bearings and Rear Bearings $\quad 17$

3.8 : Lubricant Film Difference $\quad 18$

3.9 : Types of Rolong Bearings for Machine Tool Spindle (a) Angular Contact Ball Bearings,

(b)Cylindrical Roller Bearings, (c) Double-Row Cylindrical Roller Bearings, (d) Double-

Direction Angular Contact Trust Ball Bearings, (e) Taper Roller Bearings 22

3.10 : Angular Contact Ball Bearing Model [36] 24

3.11 : Properties Comparison of Șilicon Nitride and Bearing Steel [41] 25

3.12 : Setting Preload 26

3.13 : Fixed Position Preload 27

3.14 : Constant Preload 28

3.15 : "Face" and "Back" 29

3.16 : Back-to-back Mounting 29

$3.17:$ Face-to-face Mounting 30 
3.18: Tandem Mouting $\quad 30$

3.19 : Bearing Arrangement (DB-R) 32

3.20 : Bearing Arrangement (2TB-DB) 32

3.21 : Bearing Arrangement (QB-DT) 33

$3.22: \mathrm{DmN} \quad 34$

3.23 : Grease Lubrication $\quad 35$

3.24 : Oil Air Lubrication 36

$3.25: \operatorname{CAT}(7 / 24)$ Toolholder 37

3.26 : HSK Toolholder 38

$3.27:$ KM Toolholder 39

3.28 : NC5 Toolholder 39

$4.1:$ Internal Structure of Basic Expert System 43

4.2 : Classical Set 44

$4.3:$ Fuzzy Set 44

4.4 : Classical Set for Spindle Speed 45

4.5 : Fuzzy Set for Spindle Speed 45

4.6: Characteristic Function of Spindle Speed with Classical Sets 46

4.7 : Membership Function of Spindle Speed with Fuzzy Sets 46

4.8 : Typical Shapes of Membership Functions [23] 47

4.9 : Input Fuzzification 49

$4.10:$ Logic Operation and Implication $\quad 50$

4.11: Aggregation [19] 50

4.12 : Defuzzification 51

4.13 : Internal Structure of Expert System for Spindle Design 53

4.14 : Process of Transmission Type Selection $\quad 54$

4.15 : Power and Torque Diagrams, (a) Normal Type, (b) Winding Switching Type 56

4.16 : Membership Function of Torque 59 
4.17: Membership Function of Spindle Speed $\quad 60$

4.18 : Membership Function of Low Cost vs. High Accuracy $\quad 61$

4.19 : Membership Function of Gear vs. Belt-pulley 61

4.20: Whole Process for Transmission Selection 63

4.21 : Process of Lubrication Type Selection $\quad 66$

4.22 : Spindle Specifications of SH-403 [47] 72

4.23 : Tool Geometry Input Interface $\quad 73$

4.24: Workpiece Database $\quad 73$

4.25 : Cutting Conditions Input Interface $\quad 74$

4.26: Motor Specification Input Interface $\quad 74$

4.27: The Specifications for Spindle Design (Available Case) 75

4.28: The Specifications for Spindle Design (Not Available Case) 76

4.29 : Transmission Selection $\quad 76$

4.30 : Design Factor Input Interface for Transmission Selection 77

4.31 : Lubrication Selection · 78

4.32 : Bearing Specification Set Interface $\quad 78$

4.33 : Design Factor Input Interface for Lubrication Selection 79

4.34 : Result from Expert System $\quad$. 80

4.35 : Selection Results for Starragheckert 260-50-24 80

4.36 : Selection Results for Weiss MAL UBC Version $\quad 81$

4.37 : Selection Results for Mitsui Seiki VU65A 82

4.38 : Selection Results for Matsuura H.Max-500 82

5.1 : Stable and Unstable Conditions (a) Stable Cutting, (b) Unstable Cutting 86

5.2 : Variable Parameters

5.3 : Degree of Freedom of Euiler-Bernoulli Beam Element 88

5.4 : Simple Pipe Test 93 
5.5 : Comparison of Measured Mode Shapes against FE Models with the Euler-Bernoulli Beam, the Euler-Bernoulli Beam + Rotary Inertia, and Timoshenko Beam, (a) Mode 1, (b) Mode 2, (c) Mode 3

5.6 : Comparison of FRFs $\quad 96$

5.7 : FE Model for Spindle Model $\quad 97$

5.8: Tool Mode Shape $\quad 98$

5.9 : Direct FRF Comparison at the Tool Tip Between Original Model and Neglected Tool Mode Model

5.10 : Rotor Mass Division, (a) One Mass, (b) Five Divided Mass 100

5.11 : FRF Comparison With Different Mass Divisions 101

5.12 : Modes Comparison $\quad 101$

5.13 : Global Minimum and Local Minimum 103

5.14 : Optimization Algorithm with SQP for Bearing Spans' Optimization 107

5.15 : Stability Lobes 108

5.16 : Design Variables $\quad 109$

5.17 : Design Constants $\quad 110$

5.18: Bearing Dimensions and Stiffnesses $\quad 110$

5.19 : Design Constraints $\quad 111$

$5.20:$ Initial Conditions $\quad 112$

5.21 : Change of FRF 113

5.22 : Comaprison of the Three Results 115

5.23 : Interface for Setting Number of Front Bearings 116

5.24 : Interface for Setting Rear Bearings $\quad 116$

$\begin{array}{ll}5.25: \text { Interface for Setting Spindle Shaft Dimensions } & 117\end{array}$

5.26 : Interface for Setting Bearing Parameters 117

$5.27:$ Interface for Setting Mass Properties 118

5.28 : Interface for Setting Bearing Span Constraints $\quad 118$ 
5.34 : (a) Validation of Final Optimum Stability Lobes, (b) Figure That Zooms in the Rectangle Box at (a)

A. 1 : DB-DB

A.2 : DT-DT

A. $3: 2$ TB-R 128

A.4 : QB-R 128

A.5 : QB-A 129

A.6 : QB-DB 129

A.7 : RDB-DB 129

B.1 : Inserting Angle Comparison 130

D.1 : Membership Function of High Dynamic Stiffness vs. Balancing Vibration 132

D. 2 : Membership Function of Low Replacement Operation Cost vs. Low Replacement Parts Cost

D. 3 : Membership Function of Low Thermal Effect vs. Small Noise

D.4 : Membership Function of Direct Coupling vs. Motorized

D. 5 : Membership Function of $\mathrm{DmN}$

D.6 : Membership Function of Low Cost vs. Less Contamination

D.7 : Membership Function of Less Maintenance vs. Long Life

D.8 : Membership Function of Grease vs. Oil-air

E.1: Degree of Freedom of Euiler-Bernoulli Beam Element

E.2 : Deformation of Euler-Bernoulli Beam

E.3 : Inertia Force Worked in Euler-Bernoulli Beam 
E.4 : Inertia Force Worked in Euler-Bernoulli + Rotary Effects Beam $\quad 140$

E.5 : Deformation of Timoshenko Beam 142

E.6 : Inertia Force Worked in Timoshenko Beam 148

F.1 : Minimum Value of Curves, (a) Quadratic Function, (b) High Order Function 152

H.1 : Modeling for Spindle Analysis 155 


\section{Acknowledgment}

Completion of this work would not have been possible without the support of my colleagues, friends, and family. Firstly, I would like to express my gratitude to my research supervisor Dr. Yusuf Altintas for the valuable instruction, guidance, and support which he has provided throughout my research and coursework. I wish to thank to my colleagues in the Manufacturing Automation Laboratory at UBC, as not only did they offer their constant help with technical issues, but provided a highly enjoyable and rewarding graduate study experience.

Finally, I would like to thank my beloved family for their unwavering support and patience regarding my graduate study abroad. I dedicate this work to my family, especially to my wife, Eri. 


\section{Nomenclature}

$a$

A

$a_{\text {lim }}$

$a_{\text {Clim }}$

[C]

$\left[C_{\mathrm{q}}\right]$

$d$

D

$D M$

$D m N$

$D m N_{G \max }$

$d_{m}$

E

$F_{C}$

$f_{o b}$

$F_{t}$

$G B$

$G_{m o}$

$G_{s}$

$h$

$h_{11}$ axial depth of cut

section area of spindle shaft

critical depth of cut

critical depth of cut at cutting speed

damping matrix

generalized damping matrix

search direction for optimization

diameter of milling cutter

defuzzified value for transmission type selection (Direct coupling/Motorized)

DmN number

maximum $\mathrm{DmN}$ number with grease lubrication

bearing pitch diameter

modulus of elasticity

centrifugal force

objective function

tangential cutting force

defuzzified value for transmission type selection (Gear/Belt-pulley)

gear size on motor

gear size on spindle

chip thickness

direct frequency response function at position 1 
Hessian matrix

[I] identity matrix

$I, J \quad$ mass moment of inertia

$k_{c}$

cross section factor

K

cutting force coefficient

stiffness matrix

$\left[K_{q}\right]$

generalized stiffness matrix

$L U B$

defuzzified value for lubrication type selection

$m$

mass

$[M]$

mass matrix

$\left[M_{q}\right]$

generalized mass matrix

$M_{g}$

gyroscopic moment

$n$

cutting spindle speed

$n_{\text {acmax }}$

actual maximum spindle speed

$n_{m o}$

motor speed

$n_{\max }$

maximum motor speed

$N$

number of teeth.

$[P]$

eigenvector matrix (mode shape matrix)

$P_{m o}$

motor power

$\{R\}$

generalized force vector

$S$

Laplace operator

$T_{a c}$

actual spindle torque

$T_{c}$

instantaneous cutting torque

$T_{m o}$

motor torque

$T_{\operatorname{maxc}}$

maximum cutting torque

$v$

deflection in y direction 


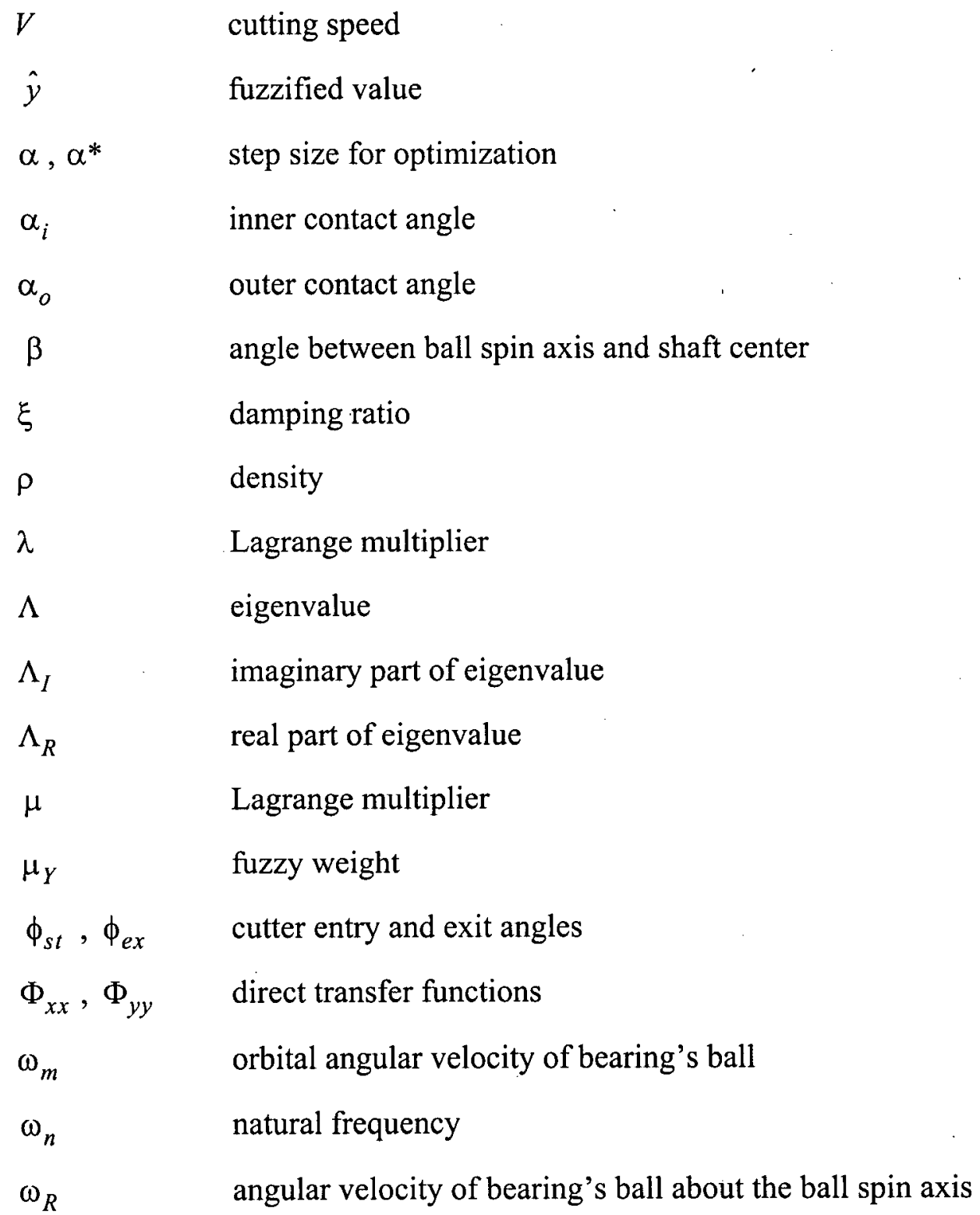




\section{Chapter 1}

\section{Introduction}

The spindle is one of the most important mechanical parts in machining centers. The spindle shaft rotates at different speeds and holds a cutter which machines a material attached to the machine tool table. The structural properties of the spindle directly affect the machining productivity and finish quality of the workpieces. The structural properties of the spindle depend on the dimensions of the shaft, motor, tool holder, bearings, and the design configuration of the overall spindle assembly.

The spindle is generally designed from the designers' accumulated experience, by utilizing successes and failures experienced previously. However, once the experienced design engineers retire or move to other positions, the accumulated design knowledge vanishes with them. Therefore, the knowledge needs to be accumulated in a digital knowledge-base. This research therefore considers spindle component selection and configuration using a proposed expert system based on the digital knowledge base. The expert system with fuzzy logic is implemented as the selection system.

On the other hand, significant numbers of spindles are damaged in industry due to selfexcited chatter vibrations during machining. Most spindle failures are due to dynamic overloading of the bearings, except for spindle collisions due to mistakes in Numerical Control (NC) programs. This research considers the chatter stability law in designing a spindle with optimum bearing spacings along the shaft. The overall expert spindle design system is outlined in Fig. 1.1. 


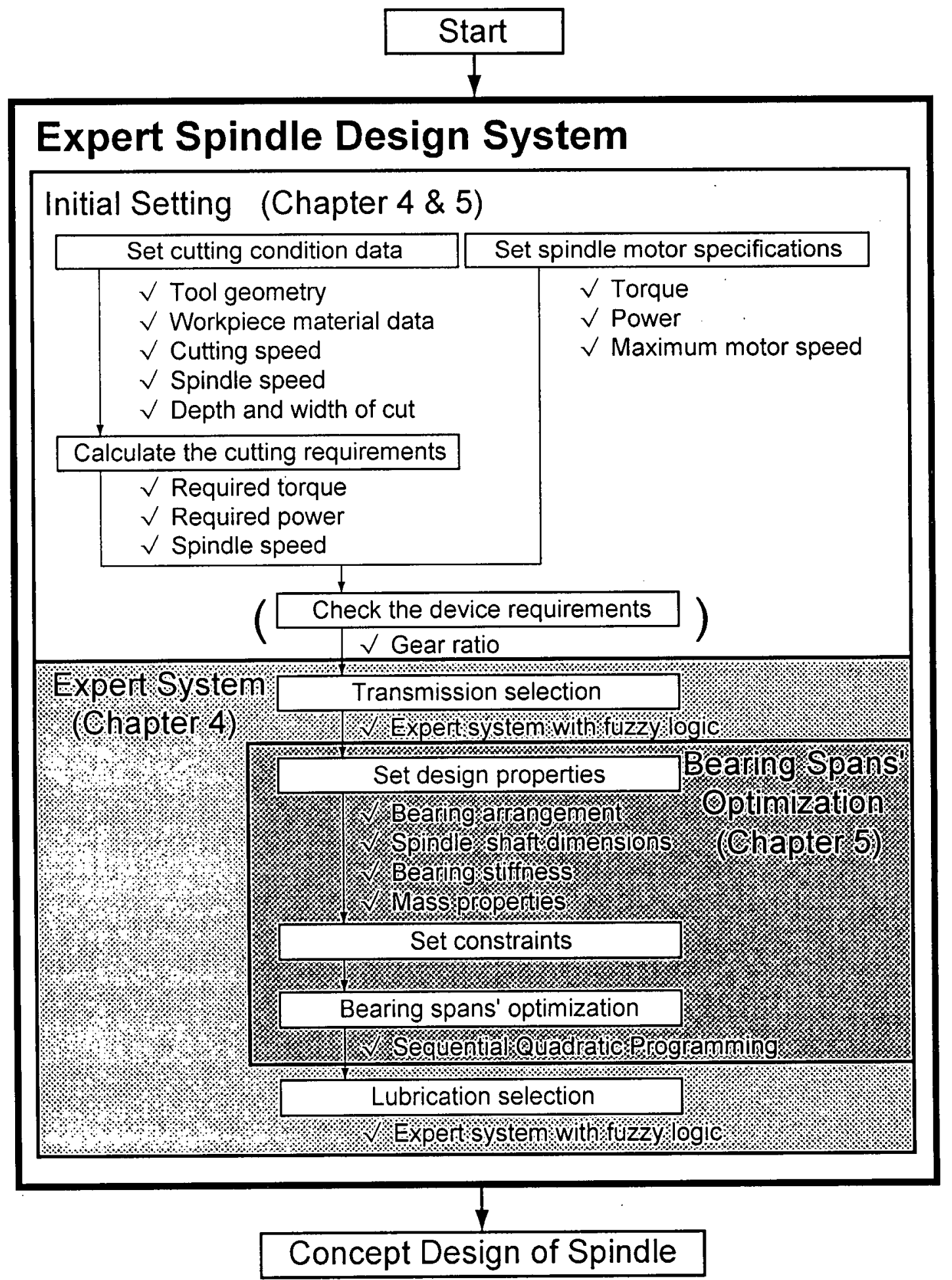

Figure 1.1 : Flow Chart of Expert Spindle Design System 
The thesis is organized as follows.

The literature review covering the spindle design, expert systems, metal cutting, chatter vibration stability and structural analysis is presented in Chapter two. The design principles of machine tool spindles are presented in Chapter three. The types of bearings, whether the spindle is driven by an integral or external motor, drive train and power transmission configurations are presented based on torque, power, and speed requirements from the machine tool. Chapter four presents a proposed expert spindle design strategy, which classifies the selection of spindle components and configurations using fuzzy logic sets. Once the spindle configuration is selected by the expert design system, the bearing spacing along the shaft is optimized using a Finite Element based analysis algorithm presented in Chapter five. The thesis is concluded with the summary of contributions and recommended future work in Chapter six. 


\section{Chapter 2}

\section{Literature Review}

\subsection{Overview}

The concept of chatter free spindle design at certain ranges of spindle speeds is becoming important since the spindle damage due to chatter vibrations often occurs in industry. Therefore, a significant amount of work has been done regarding spindle design and analysis. In this chapter, a literature survey related to a spindle design, expert system for spindle design, chatter vibrations, and spindle analysis is presented.

\subsection{Basics of Spindle Design}

The market demands of cutting for machine tools, especially for milling operations, are favoring to high speed cutting. The meaning of high speed machining (HSM) is changing; HSM meant $8,000[\mathrm{rpm}]$ in the early $1990 \mathrm{~s}$, but now it indicates 30,000 to 40,000 [rpm] [26].

Bearing catalogs $[16,40]$ and several papers $[3,31,43,44]$ show the fundamental knowledge about spindle design and survey the recent trends in spindle design.

For HSM, the spindle design must be carefully decided by the designers [9]. Ceramic ball bearings, which are also called hybrid bearings, are commonly used for high speed spindles because of their small density, high modulus of elasticity, low thermal expansion property, and high hardness $[4,40,42]$. In addition, if the ball size is reduced, the rotation speed achieved by the spindle increases due to the mass reduction of each ball $[6,31]$. Not only the bearing balls, but the ring material [10] and the shape of the ball cage [7] must also be taken into account for high speed spindles. 
The main lubrication systems for bearings are grease and oil air lubrication. The advantage of the grease lubrication is that the rotation speed can be quite high without high cost and maintenance. However, for advanced high speed spindles, the oil air lubrication system is required because of its low viscosity and exhaust system [5, 42]. Weck and Koch [62] introduced the oil air minimum quantity lubrication using a new oil air supply. They developed the oil air supply system through a bore in the outer bearing ring. Tsutsumi and Tada [59] proposed the proper oil air supply angle for an angular contact ball bearing.

The preload for the bearings is also an important issue for high speed spindles. The preload tends to increase with the increase of the rotation speed of the spindle, and the over preload causes the bearings to break. Therefore, the preload must be applied and adjusted properly, with a suitable preload system depending on the spindle specifications [8].

From a HSM point of view, the tool holder must also be taken into account. Rivin [45] surveyed tooling structures; tool life, stiffness, damping, tool interface technologies. Weck et al. [64] proposed a way to increase the damping of a long overhang tool by using squeeze-film fluid.

Moriwaki et al. [36] summarized a study of the machine tool design, which includes the spindle design principle, basics of bearing, tool interface, etc. They showed not only theoretical design principles, but also practical design issues as well.

\subsection{Expert System for Spindle Design}

An expert system is a useful tool in the decision making system. One of the first practical expert systems was MYCIN built by Shortliffe [52, 53]. The MYCIN is the system used for assisting in the decisions involved in the selection of appropriate therapy for patients with infections.

For the spindle designs, Shinno et al. [51] proposed a decision-making methodology for a lathe spindle design which included the knowledge and thinking pattern of experienced designers. This decision-making system can prioritize the rules based on the input specifications. Eskicioglu 
et al. [15] developed a rule-based algorithm for spindle bearing arrangement selection by PROLOG, which is a programming language for expert systems. The bearing arrangements are determined by the cutting operation type, the required cutting force, the required life of bearings, and so on. The number of the final bearing arrangement result becomes plural depending on the input data, and it is similar to human design process. Wong and Atkinson [65] demonstrated a knowledge cell approach for diverse designs. They divided the knowledge cell into four parts, Function

cell, Selection cell, Graphics cell, and Logic cell. Lately, Myung and Han [37] presented a knowledge-based parametric design system using the function of the commercial CAD software. This system is not a decision making system for spindle components' selection, but an automated geometry changing system which varies due to the dimension change of the surrounding part.

\subsection{Chatter Vibrations}

Chatter vibrations produce an uneven and poor surface and lead to an increase in cutting forces, which may destroy the workpiece, tool, tool holder and even the spindle. Therefore, the chatter vibrations must be taken into account in spindle design.

Chatter is a self-excited type of vibration which occurs in the milling process due to the dynamic characteristics of the machine tool, workpiece, and cutting process, and can be best explained by a phenomenon called Regeneration of Waviness. When one of the flutes is in cut, it starts to leave a wavy surface behind due to the transient vibrations and that wavy surface is cut by the next flute, which also vibrates and leaves another wavy surface (Fig. 2.1). Depending on the phase shift between the two successive waves, the maximum chip thickness may grow exponentially while oscillating at a chatter frequency that is close, but not equal to, a dominant structural mode in the system [2].

The regeneration phenomenon was first explained by Tlusty [57] and Tobias [58]. Later, Merritt [34] used a feedback control theory to verify the theory developed by Tlusty and Tobias. 


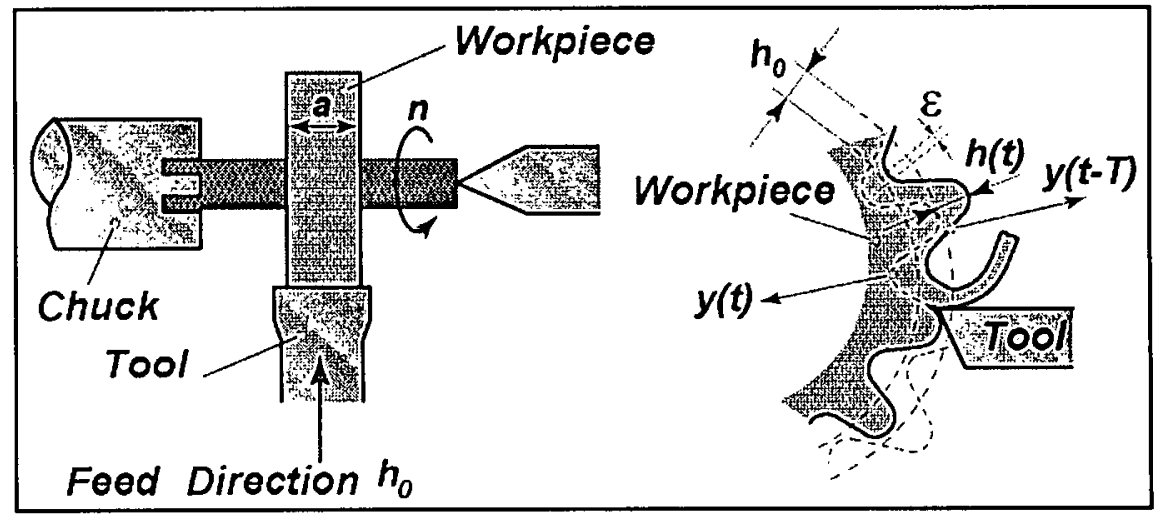

Figure 2.1 : Chatter Mechanism in Turning [2]

Tlusty approached the problem of chatter vibrations in milling by applying his orthogonal cutting stability formulation to milling with an average directional coefficient, as well as an oriented transfer function. However, there are some difficulties in this solution of milling stability, such as directional coefficients which orient the cutting forces and change the direction of excitation. Instead of using a one dimensional solution for milling like Tlusty did, two dimensional approaches were developed by Minis and Yanushevsky [35], and Altintas and Budak [1]. They obtained a chatter free axial depth of cut as;

$$
a_{\text {lim }}=\frac{-2 \pi \Lambda_{R}}{N K_{s}}\left(1+\left(\frac{\Lambda_{I}}{\Lambda_{R}}\right)^{2}\right)
$$

where, $K_{s}$ is the cutting coefficient, and $N$ is the number of teeth. $\Lambda_{R}$ and $\Lambda_{I}$ are real and imaginary values of $\Lambda$, which is obtained as an eigenvalue of the following equation:

$$
\operatorname{det}\{[I]+\Lambda[G][\alpha]\}=0
$$

where $[G][\alpha]$ is the oriented transfer function of the machine tool and workpiece in feed direction, and the one perpendicular to it. In order to solve the eigenvalue $\Lambda$, Minis and Yanushevsky 
used iterative techniques, and Altintas and Budak used a direct solution based on the physics of chatter.

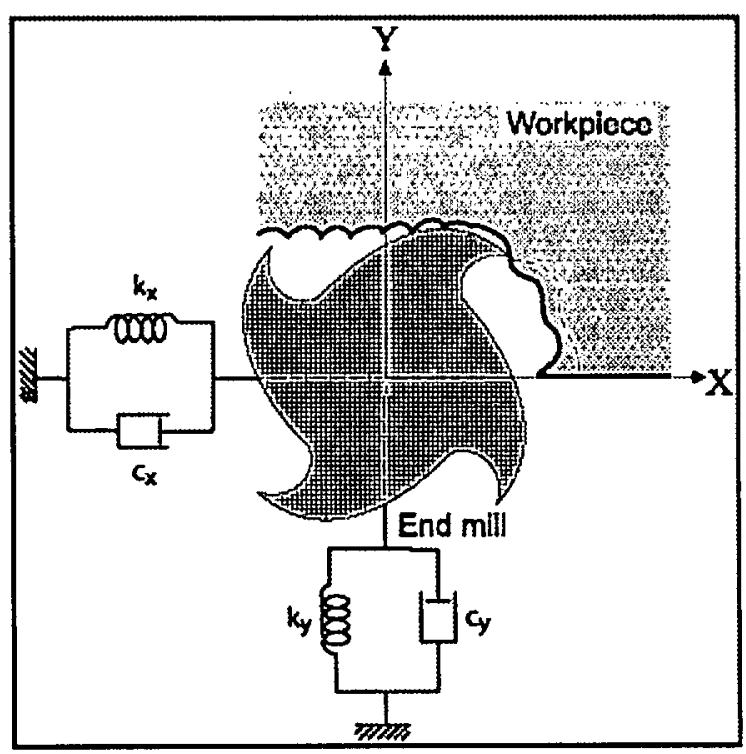

Figure 2.2 : Dynamic Modeling for Milling

The eigenvalue $\Lambda$ in Eq. (2.2) can be solved by the following equation:

$$
a_{0} \Lambda^{2}+a_{1} \Lambda+1=0
$$

where,

$$
\begin{gathered}
a_{0}=\Phi_{x x}\left(i \omega_{c}\right) \Phi_{y y}\left(i \omega_{c}\right)\left(\alpha_{x x} \alpha_{y y}-\alpha_{x y} \alpha_{y x}\right) \\
a_{1}=\alpha_{x x} \Phi_{x x}\left(i \omega_{c}\right)+\alpha_{y y} \Phi_{y y}\left(i \omega_{c}\right)
\end{gathered}
$$

where, $\Phi_{x x}\left(i \omega_{c}\right)$ and $\Phi_{y y}\left(i \omega_{c}\right)$ are the direct transfer functions at the tool tip in the $\mathrm{x}$ and $\mathrm{y}$ directions. $\alpha_{x x}, \alpha_{y y}, \alpha_{x y}$, and $\alpha_{y x}$ are constant values that are determined by the immersion conditions. In practice, in order to obtain transfer functions $\Phi_{x x}\left(i \omega_{c}\right)$ and $\Phi_{y y}\left(i \omega_{c}\right)$, the transfer function measurement must be conducted, as shown in Fig. 2.3 [2]. 


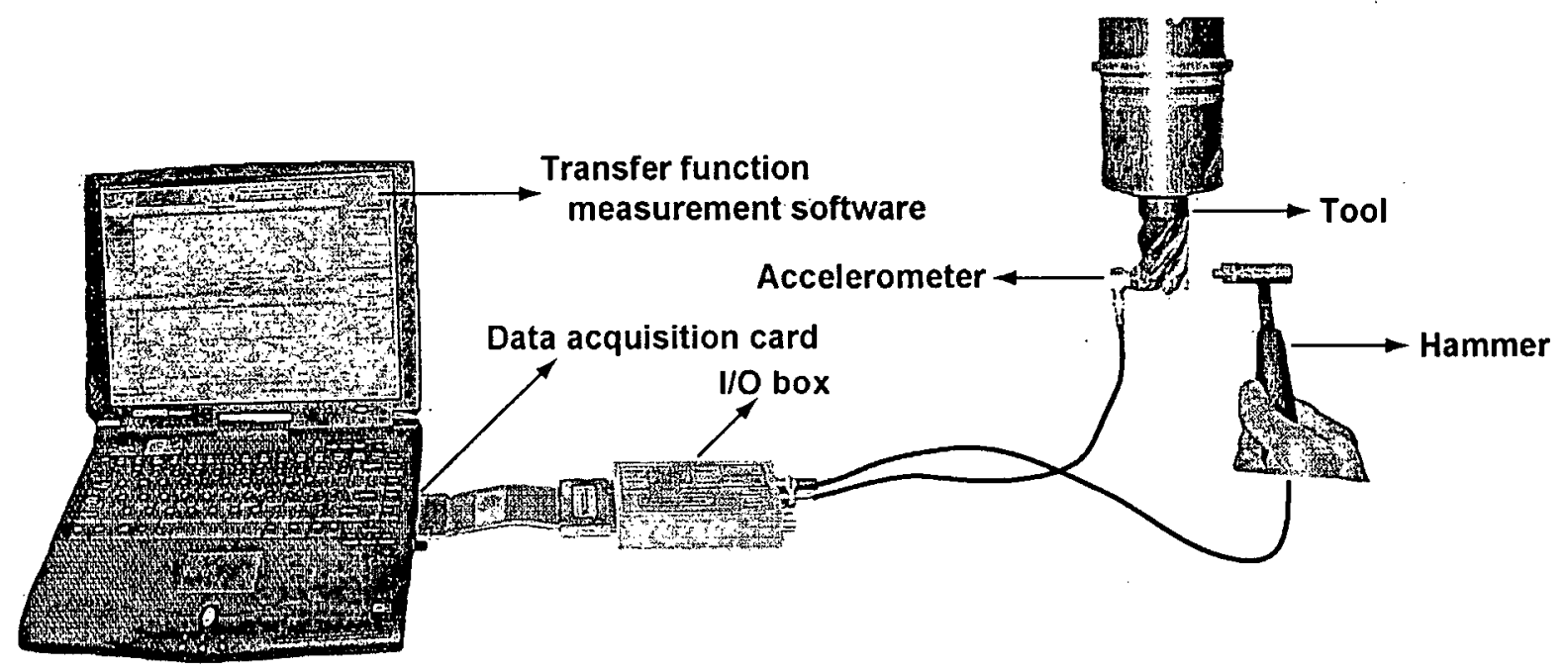

Figure 2.3 : Transfer Function Measurement Setup

Shin [50] presented the change of chatter stability due to the speed-varying characteristics of angular contact bearings. Chen and Wang [12] presented a rotor/bearing structure with a high speed spindle system. They derived chatter stability lobes with a one dimensional method, like Tlusty et al., by using an analytical spindle model including nonlinear bearings.

\subsection{Spindle Analysis}

Finite element analysis (FEA), also called the finite element method (FEM), has become a popular method for the numerical solution of the practical engineering analysis with advanced computer technologies. Although there are several element types, such as solid, plane, and beam, the beam element is the simplest and most suitable element for spindle analysis because the spindle consists of symmetric cylindrical parts.

Ruhl [46] is one of the first researchers who used a finite element method for modeling rotor systems. Ruhl's FE model includes translational inertia and bending stiffness, but neglects rotary inertia and shear deformation. Yang [66] conducted static stiffness analysis with analytical solu- 
tions. Yang optimized a bearing span using two bearings, and described the methods used to solve the multi-bearing spans' optimization method with an analytical solution. Nelson [39] compared the calculation results of natural frequencies among Euler-Bernoulli beam, Rayleigh beam, shear effects beam, and Timoshenko beam. Nelson concluded that the Timoshenko beam is the most accurate model. Brandon and Al-Shareef [11] compared the results of mode shapes and natural frequencies between the Euler-Bernoulli beam and the Timoshenko beam. They found that some modes cannot be detected with the Euler-Bernoulli beam. Taylor et al. [55] developed a program which optimizes the spindle shaft diameters to minimize the static deflection with constrained shaft mass. They used the Downhill Simplex Method to find the optimum value. Lee and Choi [30] conducted the optimization design in which they minimized the weight of the rotor-bearing system with the augmented Lagrange multiplier method. Chen et al. [13] demonstrated the optimization results to minimize the forces transmitted by the bearings to the supports. Nataraj and Ashrafiuon [38] expanded Chen's research to be realistic systems. Wang and Chang [63] simulated a spindle-bearing system with finite element model and compared it to the experimental results. They concluded that the optimum bearing spacing for system static stiffness does not guarantee an optimum system dynamic stiffness of the spindle. Hagiu and Gafiranu [22] demonstrated the system in which the bearing preload of the grinding machine is optimized. Kang et al. [29] conducted static and dynamic spindle analysis by using ANSYS with an added rigid disk and nonlinear bearing model.

The works shown above are all great works but most of their spindles are modeled with only two support bearings; none of them use more than two bearings for their analysis. In addition, most of them optimize design parameters, such as shaft diameters, bearing span, and bearing preload, to minimize the static deflection. In this thesis, more than two bearings can be considered in the spindle model and, the chatter stability that is totally related to the dynamic properties of the spindle is taken into account. 


\section{Chapter 3}

\section{Design Principle for the Milling Spindle}

\subsection{Introduction}

Machine tools are used to manufacture the machines, including machine tools. Machine tool is the generic name for turning, milling, drilling, and other type of metal cutting machines. The milling machine is one of the most frequently used machines for metal cutting.

The spindle of a machine, which is rotated by the spindle motor, can be considered as the most important component. The spindle holds the cutting tool, which cuts the workpiece, so that it influences the accuracy directly (see Fig. 3.1). However, the spindle is also the weakest part among the machine's elements, because it is just supported by several bearings at high speeds. Therefore, a poor spindle design leads directly to low productivity, and in the worst case, the spindle will fail because of the poor spindle design or its poor usage. The spindle specification is basically decided by market needs, which are for example, higher accuracy, higher productivity, and lower cost. Some users need a very stiff and accurate spindle; others, who care little for performance, may just need a low cost spindle.

In manufacturing industries which use the spindle heavily, such as the aerospace industry, high numbers of spindles are damaged, mostly due to bearing failure. The bearings are damaged due to self-excited chatter vibrations, life of bearings, and faulty operation. The chatter vibrations have been analytically investigated to optimize chatter free cutting operations. Most industries usually use a machining center with certain cutting conditions, like the cutting speed, and depth and width of cut. The objective of this thesis research is to identify design parameters of a spindle to perform most optimally for a given set of cutting conditions. 


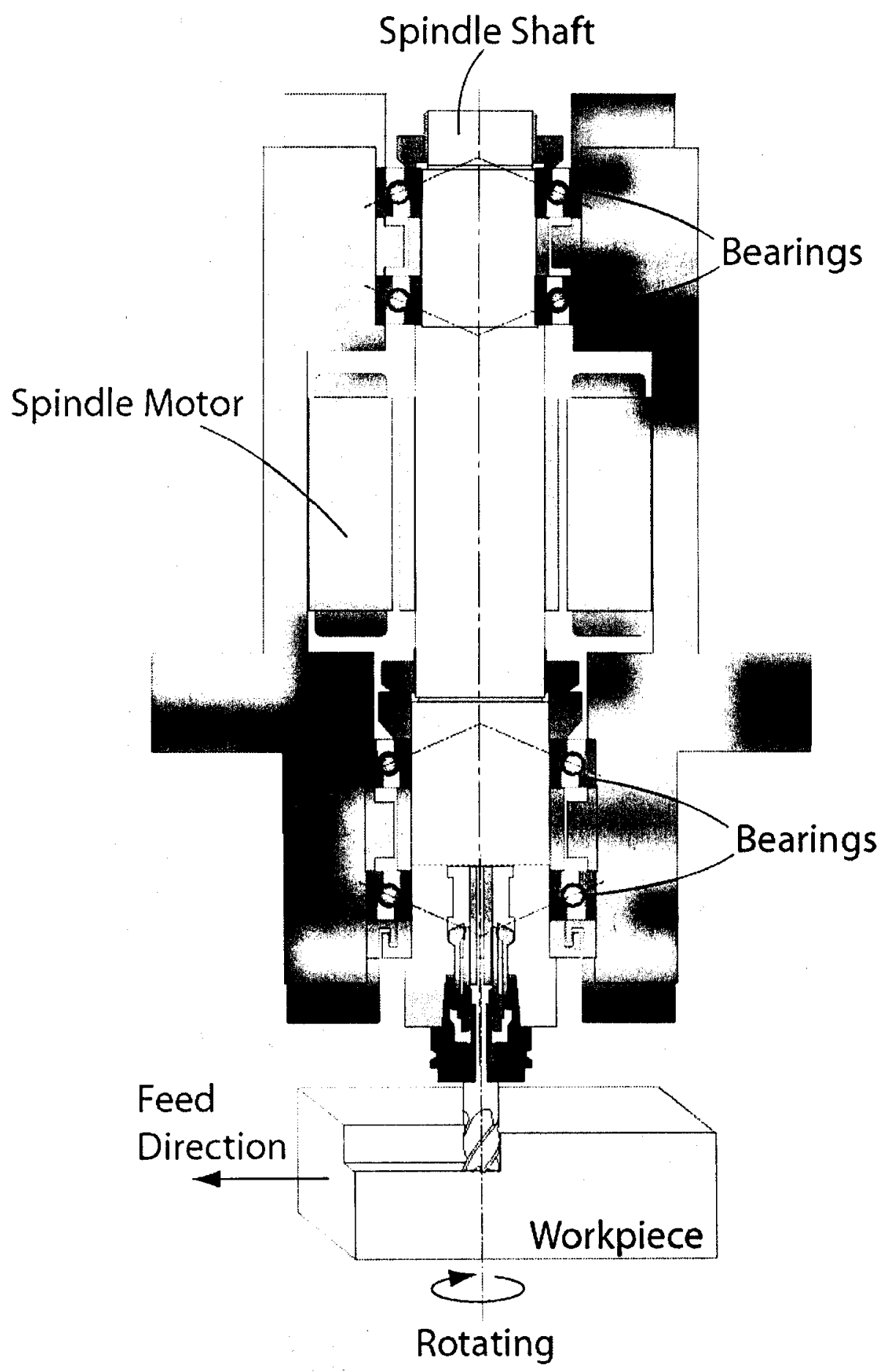

Figure 3.1 : Typical Spindle Model 


\subsection{Transmission}

Torque has to be transmitted from the spindle motor to the spindle. There are number of transmission types, and the main design configurations are summarized as follows [36].

\subsubsection{Gear Type}

A wide range of spindle speeds and torque are needed to suit a cutting condition. Heavy milling operations require very high torque, for example more than $600[\mathrm{Nm}]$ at a low spindle speed range. The spindle motor itself seldom has such a high torque. Therefore, torque reduction via a gear system is used (see Figure 3.2). The torque transmitted to the motor is reduced proportional to the gear or speed reduction.

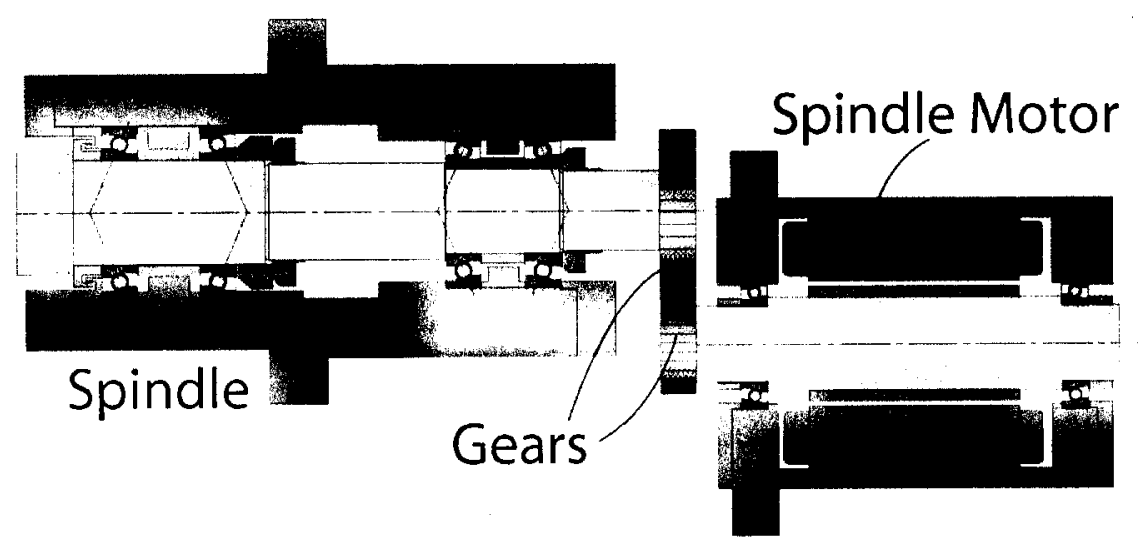

Figure 3.2 : Gear Type Spindle

By changing the gear ratio, the torque range of the spindle can be increased proportionally to the gear ratio, without changing the spindle motor power. If both spindle and motor gear size are exactly the same, as shown in Fig. 3.3 (a), the torque of the spindle becomes the same as the torque generated by the spindle motor. On the other hand, Fig. 3.3 (b) shows a case where the gear size is different, the spindle gear is three times bigger than the motor gear. In this case, the spindle torque is three times greater than motor torque. For example, even if the maximum motor torque is $200[\mathrm{Nm}], 600[\mathrm{Nm}]$ of cutting torque can be obtained at the spindle. 


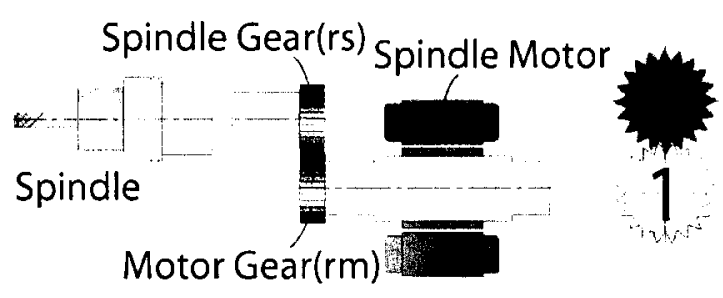

(a)

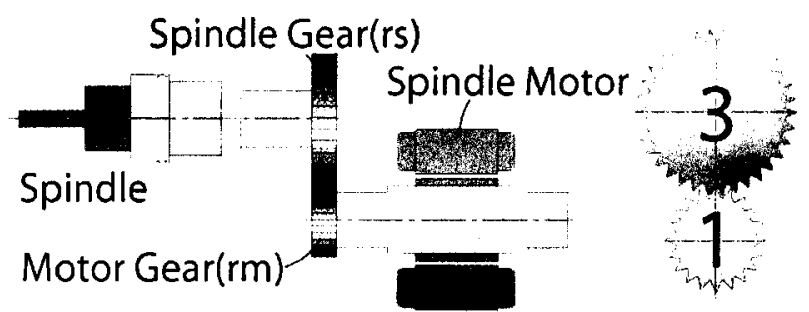

(b)

Figure 3.3 : Gear Ratio Difference (a) Same gear size, (b) Gear ratio is $3: 1$

\subsubsection{Belt-Pulley Type}

Belt-pulley type spindles (Fig. 3.4) are commonly used at high spindle speed ranges, i.e. up to $15,000[\mathrm{rpm}]$. Compared with the gear type spindle, the vibrations at the transmission point lower due to damping characteristics of the belt drive mechanism. However, belt cannot transmit much torque because of the slip between the belt and pulley interface. Moreover, at the spindle range of more than $15,000[\mathrm{rpm}]$, the belt heats up and expands, leading to loosening of the transmission tension, and the sufficient torque cannot be transmitted. Therefore, the belt-pulley type spindle is basically used at the middle spindle speed range (from 8000 to 15000 [rpm]). Belt driven spindles are used in machines with low cost. From the design point of view, belt drives are easier to manufacture than the gear type spindles.

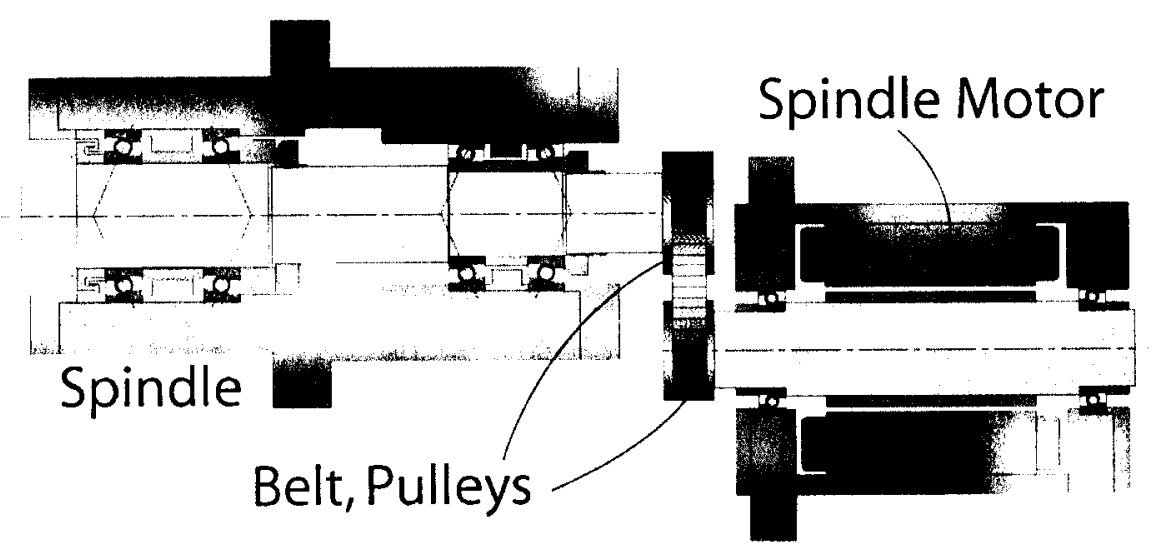

Figure 3.4 : Belt-Pulley Type Spindle 


\subsubsection{Direct Coupling Type}

For the spindle torque and speed range which cannot be driven by the belt-pulley mechanism, the direct coupling type spindle, shown in Fig. 3.5, is used. The maintainability of a separated motor for the spindle is advantageous since either the spindle or the spindle motor can be repaired separately when one of the bearings is broken. However, at high spindle speed range (more than $30,000[\mathrm{rpm}])$, the misalignment between the coupling and spindle motor or/and the coupling and the spindle shaft lead to forced vibrations.
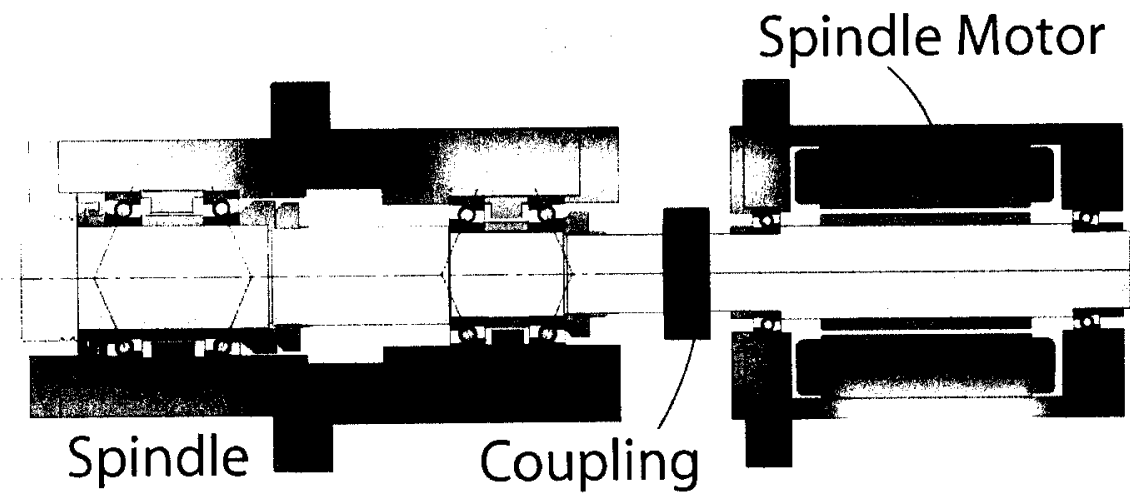

Figure 3.5 : Direct Coupling Type Spindle

\subsubsection{Motorized type}

The motorized type spindle where the motor is integrated to the spindle shaft, shown in Fig. 3.6, is used. Since there is no transmission linkage between the motor and the spindle, there is less vibration due to unbalance and misalignment. However, heat generated at the rotor is conducted to the spindle shaft leading to its thermal expansion. The cooling system has to be carefully considered to minimize the thermal growth. Besides, because of the built-in motor structure, the bearing span between the front and rear bearings tends to be wider and the spindle shaft also tends to be longer. Therefore, the natural frequency and the dynamic stiffness of the motorized spindles are lower. 


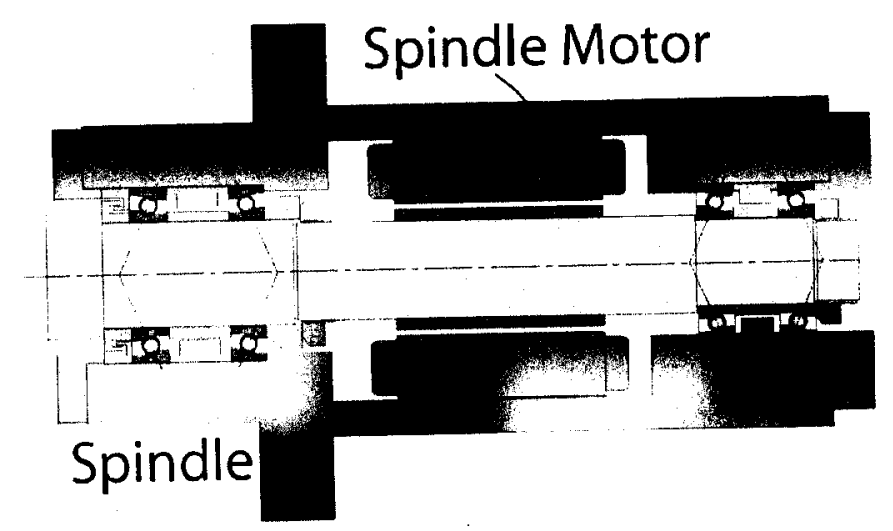

Figure 3.6 : Motorized Spindle

\subsection{Bearings}

\subsubsection{Number of the Bearings}

Basically, the stiffness of the spindle increases with higher number of bearings. However, because of the resistance from the bearings, the maximum rotation speed is more limited. Therefore, depending on the market needs, designers have to compromise between spindle stiffness and spindle speed, and determine the number of the bearings.

Most of the cutting forces are transmitted as bending loads to the front bearings because the cutting forces act from the front side. Especially, radial forces are mostly supported by the front bearings. Although it may differ depending on the amount of preload, the high speed spindles use two front bearings, and the spindle that has a capability for high load needs to use more bearings. The maximum number of the front bearings is found to be four.

The purpose of the rear bearings is to resist against the bending vibration of the spindle shaft. The number of rear bearings is dependent on how much designers want to reduce the vibration. In order to decide on the number of bearings, designers need to compute and figure out the dynamic properties of the spindle, i.e. by using finite element analysis. If the rear part of the spindle shaft 
vibrates extensively with a bearing, designers should basically increase the number of the bearings up to three.

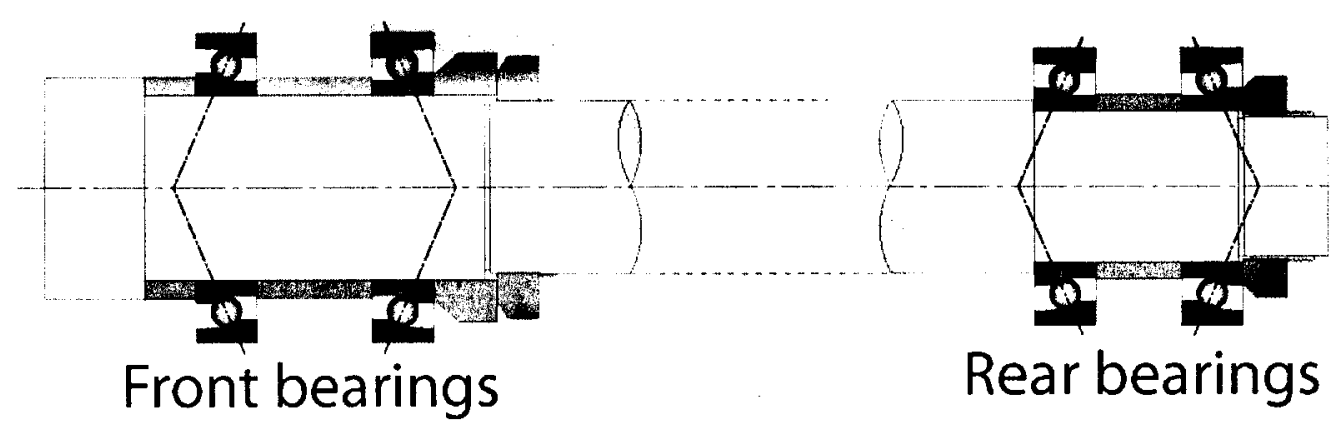

Figure 3.7 : Front Bearings and Rear Bearings

\subsubsection{Bearing Types}

The required features for spindle bearings are; to support the load applied as cutting forces with enough stiffness, to achieve a high rotation speed smoothly. These features are achieved with the setting up of the lubrication system in the bearings.

The types of bearings can be roughly classified as contact bearings and non-contact bearings. The contact bearings are for example, ball bearings and roller bearings, and the non-contact bearings are for instance, hydrostatic and hydrodynamic bearings, aerostatic and aerodynamic bearings, and magnetic bearings. A comparison of the properties of each bearing is shown in Table 3.1 [36].

\section{(1) Rotational Accuracy}

The precision cutting requires high rotational accuracy which can be delivered by static bearings, such as hydrostatic and aerostatic bearings. The lubricant film formed in the static bearings is thicker compared with the contact and dynamic bearings. Therefore, the lubricant can absorb the geometric errors of bearings, and the bearings can rotate smoothly. The contact bearings, in contrast, directly contacts with roller and rings (in fact, very thin lubricant is formed between the 
roller and the rings because of the dynamic pressure that occurs by rotation of the spindle) so that the geometric errors of bearings directly affects the rotational accuracy.

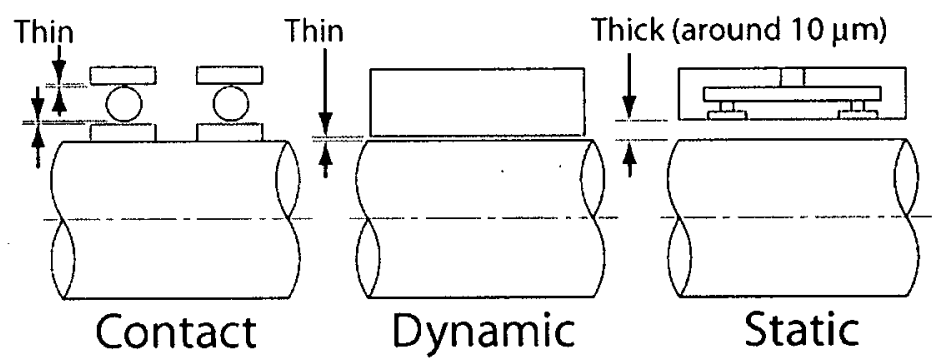

Figure 3.8 : Lubricant Film Difference

\section{(2) Load Capacity and Static Stiffness}

These properties are very important for the cutting operation since the deflection at the tool tip due to the bearing stiffness is directly transmitted as the geometric errors on the workpiece. Contact bearings essentially have better properties against the load than non-contact bearings. The air bearings are not suitable for the cutting operation that needs a high load capacity because of their higher compressibility and the low viscosity. The hydrostatic bearings, however, can have the same load capacity as the contact bearings, if the static pressure is applied properly.

\section{(3) Damping}

Damping is one of the factors which determine the dynamic stiffness of the spindle. If the dynamic stiffness is not high enough, chatter vibration occurs easily during cutting operations, and the workpiece may be damaged by the unstable machining. The rolling element and the bearing rings are contacted directly so that there is less damping performance, with contact bearings. The air bearings, although they are better than contact bearings, also do not have very damping performance since air has a low viscosity and a high compressibility. The hydro static and dynamic bearings however, have a high damping performance because of the property of the oil, which acts as the lubricant. 


\section{(4) High Speed and Temperature rise}

The air and magnetic bearings can be applied from a low speed to super high speed range. The hydro bearings generate high heat and consume energy due to the viscous resistance of the lubricant. Hence, the hydro bearings are not suitable for the high speed spindle drives. At high rotational speed range, the contact bearings generate high heat and will also suffer from the centrifugal forces.

\section{(5) Maintainability}

The contact bearings are the most advantageous because they are relatively simple to replace. Static hydro and air bearings need auxiliary equipment, such as a compressor and hydraulic power unit, to supply the lubricant.

\section{(6) Life}

The non-contact bearings, except hydro and air dynamic bearings, have a long life since the wear on the bearings is negligible. On the other hand, the contact bearings have shorter life because of the friction wear. The hydro and air dynamic bearings are in a non contact condition during air cutting, but do contact if the load exceeds the capacity of the lubricant in the bearings. Hence, the life of the hydro and air dynamic bearings may also not be very long if the loads are high.

\section{(7) Cost}

The contact bearing has the lowest cost relative to other types of bearing. The magnetic bearings are most costly bearing system because of the difficulty of the bearing position control. The air bearings need more precise manufacturing techniques so these are more costly than the hydro 
bearings. The hydro and air static bearings require the peripheral devices; therefore they are more costly than dynamic type bearings.

Table 3.1 : The Comparison of Bearings [36]

\begin{tabular}{|c|c|c|c|c|c|c|}
\hline & \multirow{3}{*}{ Contact } & \multicolumn{5}{|c|}{ Non-Contact } \\
\hline & & \multicolumn{2}{|c|}{ Hydro } & \multicolumn{2}{|c|}{$\therefore$ Aero } & \multirow{2}{*}{ Magnetic } \\
\hline & & Dynamic & Static & Dynamic & Static & \\
\hline Rotational Accuracy & 0 & 0 & (C) & 0 & (a) & 0 \\
\hline Load Capacity & (a) & 0 & (a) & $\bar{x}$ & 0 & $\bar{x}$ \\
\hline Static Stiffness & (C) & 0 & (C) & $\bar{x}$ & 0 & $\bar{x}$ \\
\hline Damping & $x$ & (a) & (a) & $\triangle$ & $\Delta$ & $\triangle$ \\
\hline High Speed & $\triangle$ & $x$ & $\triangle$ & 0 & (a) & (a) \\
\hline Temperature Rise & 0 & $\bar{x}$ & $\Delta$ & (a) & (C) & (a) \\
\hline Maintainability & (a) & 0 & $\triangle$ & 0 & $\triangle$ & 0 \\
\hline Life & $\triangle$ & $\triangle$ & (a) & $\triangle$ & (a) & (a) \\
\hline Cost & (a) & 0 & $x$ & $\triangle$ & $x$ & $x$ \\
\hline
\end{tabular}

Practically, most of the bearings for machine tool spindles are contact rolling bearings because of the cost-effectiveness and the maintainability. The grinding machine needs high damping performance; therefore hydrostatic or hydrodynamic bearings are more common to implement. The spindle with air bearings is used for ultra precision machining because of its high rotational accuracy and low temperature rise.

\subsubsection{Contact Rolling Bearings for Machine Tools}

Since the contact rolling bearings are frequently used for machine tool spindles, more details will be discussed in this section. As shown in Fig. 3.9, there are a number of bearing types for machine tools. The spindle speed range has been speedily increasing for high speed machining. Only the bearings suitable for high speed spindle, such as angular ball bearings and cylindrical roller bearings, are used for machine tools, especially for milling machine spindles. Table 3.2 [36] shows a comparison of the properties of contact bearings. 


\section{(a) Angular Contact Ball Bearings}

Angular Contact Ball Bearings are the most suitable and most frequently used in the machine tools, particularly milling spindles. This type of bearing has balanced essential properties for the high speed and high accuracy spindle. Because of the structure, it only supports an axial load in one direction; thus it has to be applied to at least two angular bearings in the spindles. Also, the stiffness of the angular contact ball bearing itself is not high enough for the milling operations. Therefore, designers may need to use a multiple number of bearings in order to compensate for the disadvantage.

\section{(b) Cylindrical Roller Bearings}

Although the cylindrical roller bearings have no stiffness in the axial direction, the stiffness in the radial direction is quite large because they carry the radial load with the edges rather than the points, like angular contact ball bearings. In addition, this type of bearing operates well at high rotation speeds. The cylindrical roller bearings are usually used on the lathe spindles, which need high stiffness in the radial direction. The rear bearing of milling spindles employ the cylindrical roller bearings, since it does not need much axial stiffness. Recently, they are used for the front bearing of milling spindle, with a set of angular ball bearings because the high radial stiffness of cylindrical bearings is adequate for heavy milling machining operation, which requires the capacity for high radial loads. Moreover the rotation capacity of this type of bearings has been increasing enough for the front bearings with advanced technologies.

\section{(c) Double-Row Cylindrical Roller Bearings}

Double-row cylindrical roller bearings have more stiffness against the radial loads than single-row cylindrical roller bearings. They do not carry an axial load same as the single-row bearings. Although the stiffness of double-row is more than that of single-row, the rotation capacity is less. Therefore, the double-row cylindrical roller bearings are mostly used on the lathe spindles. 


\section{(d) Double-Direction Angular Contact Trust Ball Bearings}

Contrary to the cylindrical roller bearings, double-direction angular contact trust ball bearings have no capability to carry the radial loads. So, these are used with cylindrical roller bearings in order to make up the disadvantage of each. This type of bearing is not suitable for a high speed spindle due to the high contact angle, so it has not recently been applied to milling machines.

\section{(e) Taper Roller Bearings}

The advantage of taper roller bearings is, best of all, high stiffness. Although they can carry an axial load in the one direction, a very high stiff spindle in both radial and axial directions can be achieved by supplying them in matched pairs. However, the taper roller bearings are no longer used for the milling spindles due to the low rotation capacity.

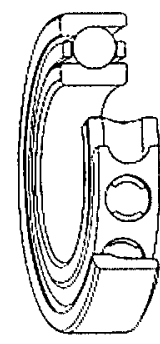

(a)

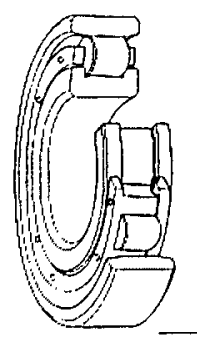

(b)

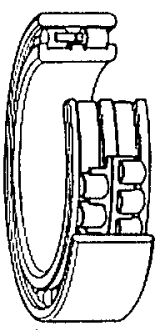

(c)

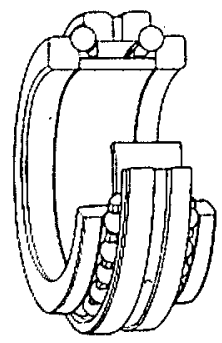

(d)

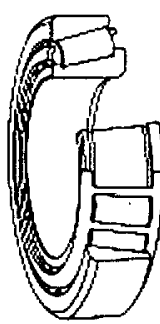

(e)

Figure 3.9: Types of Rolong Bearings for Machine Tool Spindle

(a) Angular Contact Ball Bearings, (b)Cylindrical Roller Bearings, (c) Double-Row Cylindrical Roller Bearings, (d) Double-Direction Angular Contact Trust Ball Bearings, (e) Taper Roller Bearings 
Table 3.2 : The Properties Comparison of Contact Bearings [36]

\begin{tabular}{|c|c|c|c|c|c|c|}
\hline & \begin{tabular}{|c} 
Angular \\
Contaat \\
Ball Bearing
\end{tabular} & $\begin{array}{l}\text { Cylindrical } \\
\text { Roller } \\
\text { Bearing }\end{array}$ & $\begin{array}{l}\text { Double-Row } \\
\text { Cylindrical } \\
\text { Roller } \\
\text { Bearing }\end{array}$ & $\begin{array}{l}\text { Double-Direction } \\
\text { Angular Contact } \\
\text { Trust Ball Bearing }\end{array}$ & $\begin{array}{l}\text { Taper } \\
\text { Roller } \\
\text { Bearing }\end{array}$ \\
\hline & & (O) & $\square$ & $\pi$ & खि & 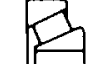 \\
\hline \multirow{3}{*}{ Load } & Radial Load & 0 & (0) & (C) & $x$ & (1) \\
\hline & Axial Load & $\overline{0}$ & $x$ & X & (0) & (0) \\
\hline & Combined Load & (0) & X & $x$ & $x$ & (9) \\
\hline \multicolumn{2}{|r|}{ High Speed } & (9) & (0) & 0 & 0 & 0 \\
\hline \multicolumn{2}{|c|}{ Rotational Accuracy } & (a) & (0) & (9) & (0) & 0 \\
\hline \multicolumn{2}{|c|}{ Low Noise/Low Torque } & (a) & (1) & $\bigcirc$ & 0 & 0 \\
\hline \multicolumn{2}{|r|}{ Stiffness } & 0 & (O) & (Q) & (O) & (O) \\
\hline
\end{tabular}

The angular contact ball bearings and cylindrical roller bearings are mostly used for the milling spindle. In particular, the angular contact ball bearings are used for almost all milling spindles because of its high rotational capacity.

\subsubsection{High Speed Angular Contact Ball Bearings.}

In the high rotation speed range, ball gyroscopic moments and ball centrifugal forces cause the inner raceway contact angles to increase $\left(\alpha_{i}\right)$, and the outer raceway contact angles to decrease $\left(\alpha_{o}\right)$ [24]. This leads the spindle being hard to rotate at high speed. Centrifugal force $F_{C}$ and gyroscopic moment $M_{g}$ can be described as follows;

$$
\begin{gathered}
F_{C}=m \cdot \frac{d_{m}}{2} \cdot \omega_{m}{ }^{2} \\
M_{g}=J \omega_{R} \omega_{m} \sin \beta
\end{gathered}
$$

where $m$ is the mass of the bearing ball, $d_{m}$ is the bearing pitch diameter, $\omega_{m}$ is the orbital angular velocity of the ball, $\omega_{R}$ is the angular velocity of the ball about the ball spin axis, $J$ is the mass moment of inertia, and $\beta$ is the angle between the ball spin axis and the shaft center. 


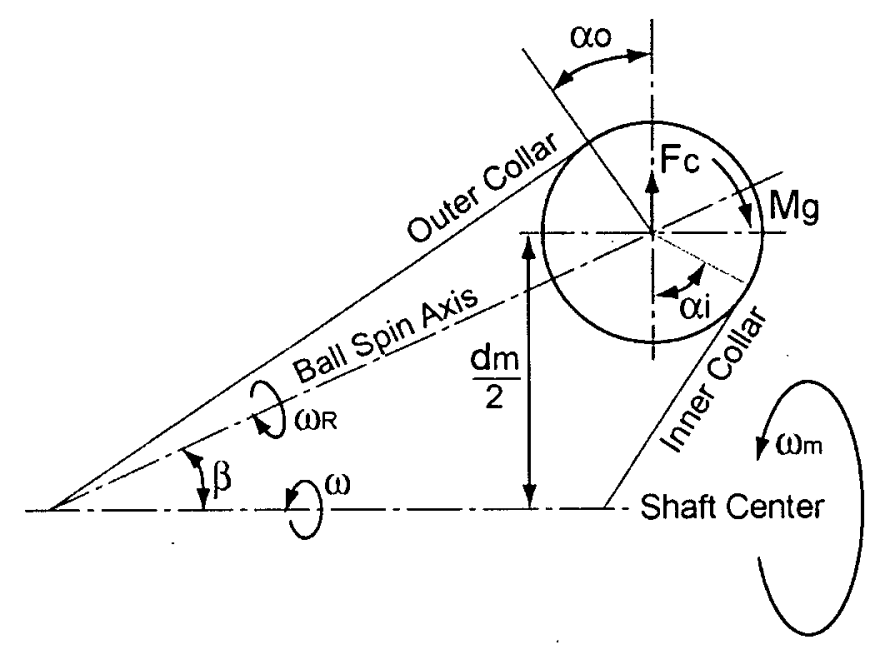

Figure 3.10 : Angular Contact Ball Bearing Model [36]

\section{(1) Small Size Ball Bearing}

The small size of the bearing balls means that the diameter, the mass, and the mass moment of inertia are small. Therefore, considering Eq. (3.1) and Eq. (3.2), both the centrifugal force and the gyroscopic moments can be reduced with the small size ball bearing. Besides, the reduction of the ball size leads to more number of balls in the bearings, therefore the rigidity of the small size ball bearing is higher than that of the normal size bearings. [31] The disadvantage is that the fatigue life is shortened due to the low load capacity of the small size ball bearings; however it may not be a serious problem because the cutting load is generally small at high speed cutting. [40]

\section{(2) Hybrid Angular Contact Ball Bearing}

A silicon nitride (ceramic) is used for the material of the high speed bearing balls. This ceramic bearing is called a hybrid bearing (hybrid of ceramic ball and steel raceway collar). Figure 3.11 [41] shows the properties comparison between the ceramic and the bearing steel, which is normally used for bearing balls. The density of ceramic is $40 \%$ of the bearing steel, so that the 
centrifugal forces and gyroscopic moments become small. The higher modulus of elasticity of the ceramic leads to a high stiffness spindle. The low co-efficient of thermal expansion of the ceramic can keep the temperature rise down compared with the bearing steel. In addition, the small friction coefficient of ceramic leads to lower power consumption and lower temperature rise.

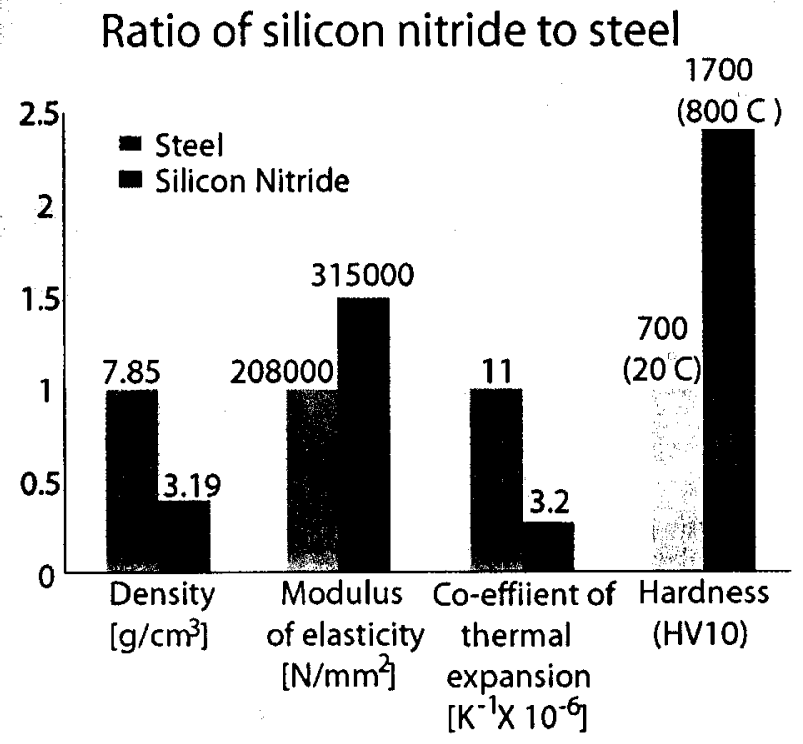

Figure 3.11 : Properties Comparison of Silicon Nitride and Bearing Steel [41]

\section{(3) Special Material for Bearing Collars}

The new steel material for the bearing collars also has a beneficial effect for the high speed bearing. Cronidur ${ }^{\circledR} 30$, which is a brand of the FAG/Barden Corporation [10] is one of the advanced steel materials. The rotation capacity of the new steel material can be increased by $30 \%$ more than the current steel collars.

Another factor for high rotation capacity is contact angle, which needs to be small. For machine tool bearings, the contact angles $12,15,25,30$, and 40 degrees are usually implemented. For the high speed spindle, the contact angles 12, 15, and 25 degrees are employed. Furthermore, 
the cage which positions the bearing balls at the proper place also important factor for high speed bearings [7].

\subsubsection{Preload}

Preload is the external axial load applied to bearings. The objectives of the preload are as follows [41];

1) Elimination of the free radial and axial movement

2) Reduced deflection from externally applied loads

3) Assurance that angular contact ball bearings do not run free of load, which may give rise to ball skidding

4) Reduction of the contact angle difference between the inner and outer raceway at very high speeds

The bearings are assembled with a preload gap. The preload gap is reduced by applying the load, and the bearings are fixed (See Fig. 3.12). Mainly, there are two ways to apply the preload. One is called fixed position preload; the other is constant preload.
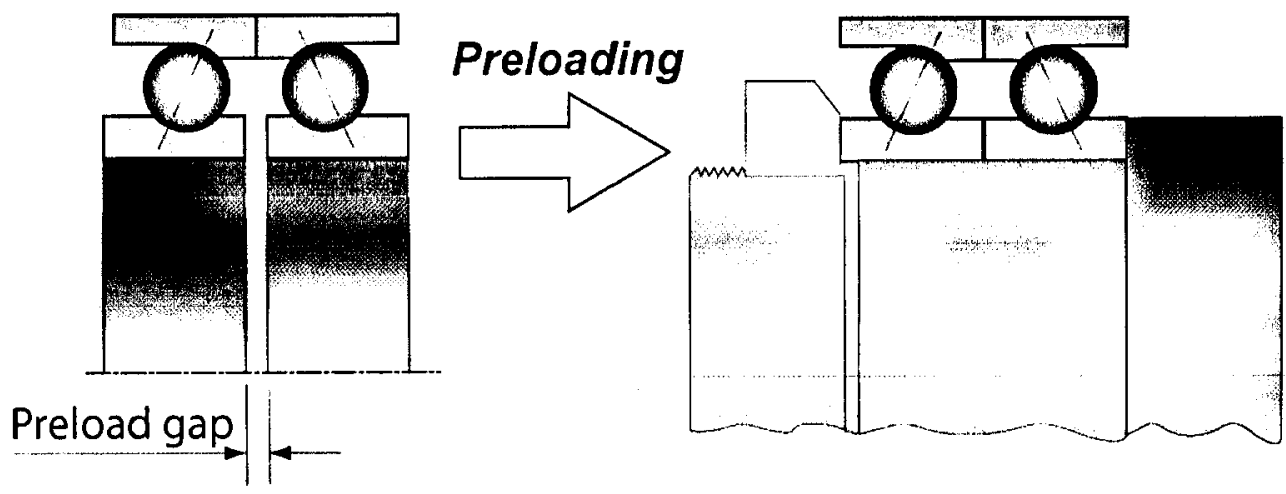

Figure 3.12 : Setting Preload 


\section{(1) Fixed Position Preload}

The fixed position preload method (Fig. 3.13) uses the spacers between both the inner collars and the outer collars. By changing the relative length between outer and inner spacers, the preload amount can be adjusted. In the Fig. 3.13 example, the preload will become higher if the axial length of the outer collar is increased, or that of the inner collar is decreased. The advantage of this type of preload system is that the stiffness can be set high by adjusting the spacer length. However, due to the fixed structure, the preload will increase due to the centrifugal force and temperature rise during spindle rotation. Over preload causes the seizure of the bearings so that, for the high speed spindle, the preload has to be kept down to a certain amount using a better lubrication system and cooling system.

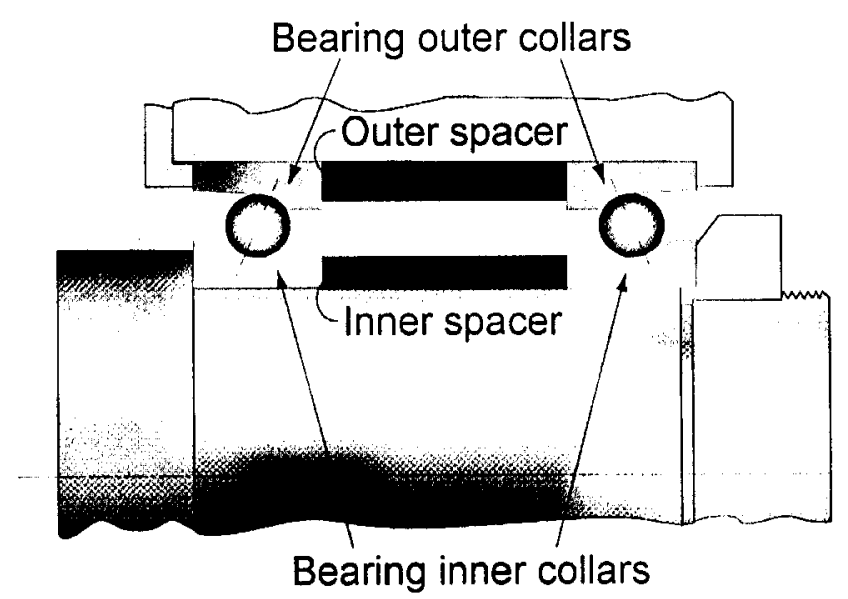

Figure 3.13 : Fixed Position Preload

\section{(2) Constant Preload}

The constant preload system (Fig. 3.14) uses the springs in the axial direction instead of using only the outer collars. The spring absorbs the spindle shaft's axial expansion, which leads to the preload increase, because of temperature rise. Therefore, spring provides relatively constant preload, and over preload can be avoided even in the high speed range. A disadvantage of this preload type is the deflection against the external load (such as cutting forces) becomes larger. Thus, 
the constant preload type spindle is not a suitable for the cutting operation which needs high stiffness.

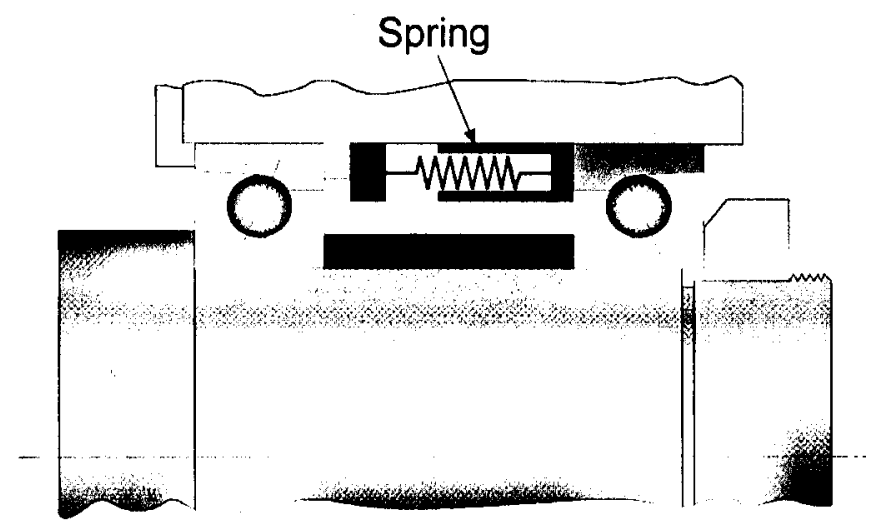

Figure 3.14 : Constant Preload

As another preload method, the different thermal expansion materials are used for the inner and the outer collar. Smaller coefficient of the thermal expansion of the outer collar compared with the inner collar can prevent over preload because the preload is applied with the length difference of the inner collar and the outer collar. Alternatively, the special shape for the outer collar can also curb the over preload, for example, the horseshoe cross section instead of the normal rectangle cross-section.

\subsubsection{Bearing Arrangement}

The bearing arrangement type is also a key issue for the spindle properties. The bearing arrangements are the combination of a set of angular contact ball bearings plus a cylindrical roller bearing. The name of a pair of bearings is designated using "face" and "back", shown in Fig. 3.15. The characteristics of the simple set of bearings can be shown as follows. 


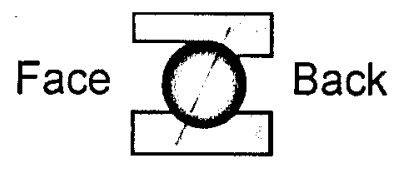

Figure 3.15 : "Face" and "Back"

\section{(1) Back-to-back Type}

Fig. 3.16 shows the back-to-back bearing mounting type. One of the shortages of the angular contact ball bearings, which can carry axial load in only one direction, is covered by alternating the axial direction of each bearing. The lines of the action diverge, and the effective distance $\mathrm{X}$ between bearing centers is increased in this arrangement [41]. Therefore, the back-to-back arrangement has a higher resistance against tilting moments.

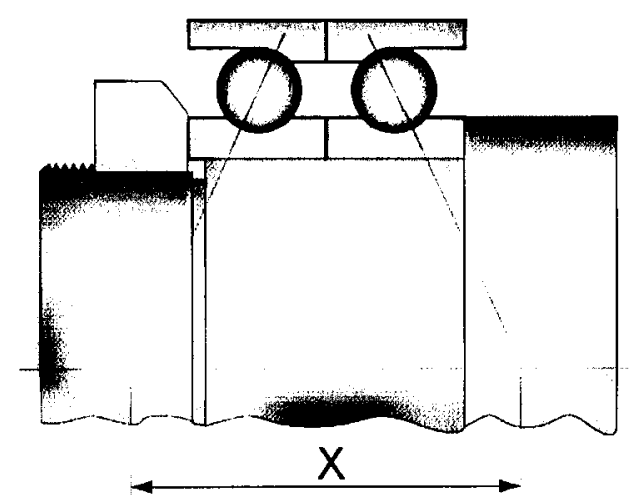

Figure 3.16 : Back-to-back Mounting

\section{(2) Face-to-face Type}

Face-to-face bearing arrangement is shown in Fig. 3.17. This arrangement can carry the axial load in both directions, and the lines of action converge contrary to back-to-back arrangement. Therefore, the resistance to tilting moments is lower than the back-to-back arrangement [41]. The face-to-face bearing arrangement is generally used where precise alignment cannot be achieved, for example, as the supports of the ball screw of $\mathrm{X}, \mathrm{Y}$, and $\mathrm{Z}$ axes. 


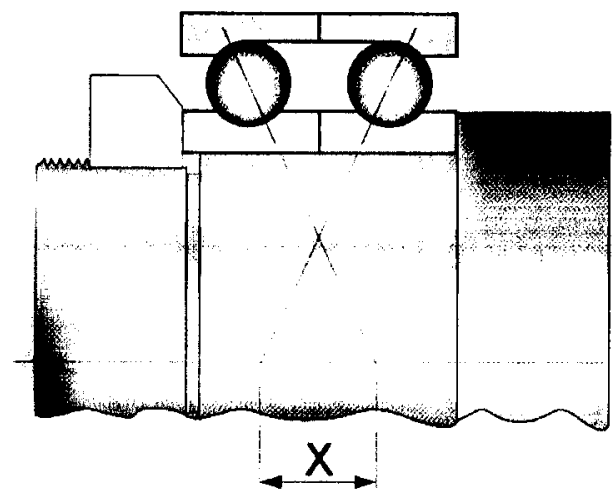

Figure 3.17 : Face-to-face Mounting

\section{(3) Tandem Type}

Tandem arrangement as shown in Fig. 3.18, can only carry the load in one direction. Therefore, this type is usually used with another set of tandem arrangement bearings which is mounted with an inverse direction.

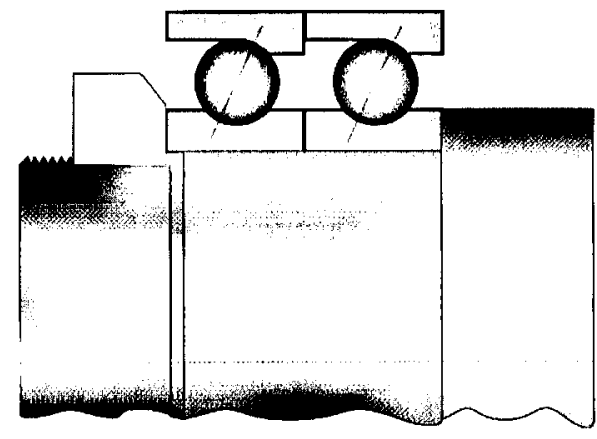

Figure 3.18 : Tandem Mouting

The total number of bearing arrangements is infinite because if the number of bearings changes, the arrangement also changes. However, the number of bearings for the machine tool spindle, especially the milling spindle is limited (Section 3.3.1), and the frequently used bearing arrangement type is also confined. Ten kinds of bearing arrangement are generally used for mill- 
ing spindles. The bearing arrangement can be expressed by using the following symbols cited from the NSK bearing catalog [41].

Table 3.3 : Symbols for Bearing Arrangement

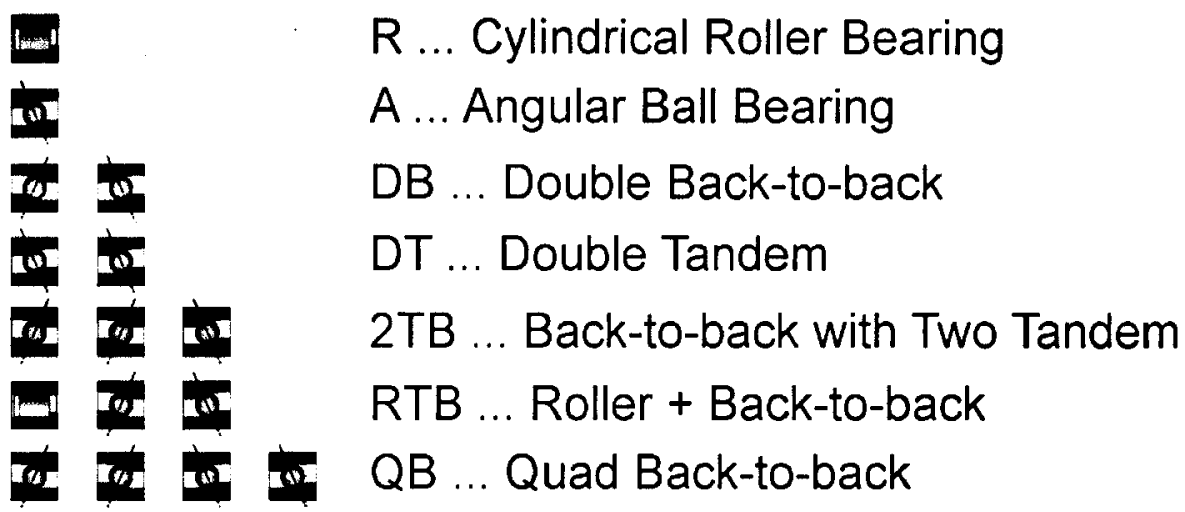

The concept of how to decide the bearing arrangement is that most of the loads are carried with the front bearings, and the rear bearings support the spindle shaft to minimize the bending vibrations and absorb the over preload of the rear bearings because of the thermal expansion of spindle shaft.

The milling spindles usually use the back-to-back arrangement (either the front bearing arrangement is back-to-back, or the total arrangement including rear bearings is back-to-back). The heat generated at the front bearings mostly conducts to the spindle shaft, and the spindle shaft expands axially from the front bearing point. Therefore, the axial deformation of the rear bearings is significant, and the rear bearings are tightened because the outer collars of the rear bearings are fixed. The number of bearing arrangements which are frequently used for the milling spindle is ten. Three types are shown from (a) to (c), and the other bearing arrangement types will be shown in Appendix A.

\section{(a) DB-R Arrangement}

Fig. 3.19 shows the DB-R arrangement in which the front bearings are in the double back-toback arrangement and the rear bearing is a cylindrical roller bearing. Since the rear bearing is a 
roller bearing, which has no capacity to carry axial loads, all axial loads are carried by front bearings. The roller bearing can slide axially slightly, and absorbs the thermal expansion of the spindle shaft. Thus, it can avoid the over preload situation up until the middle rotation speed range.

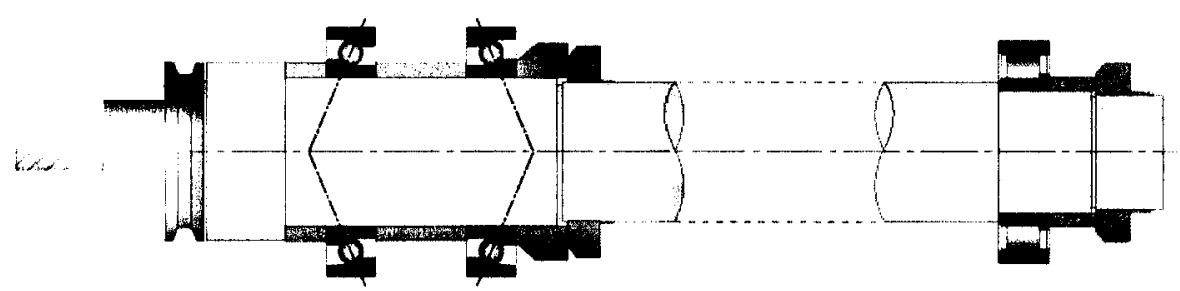

Figure 3.19 : Bearing Arrangement (DB-R)

\section{(b) 2TB-DB Arrangement}

Fig. 3.20 shows the 2TB-DB bearing arrangement. The load capacity of this spindle is more than that of DB-R arrangement due to three bearings at the front. The rear bearing set is the backto-back arrangement. The problem of the 2TB-DB is that the rear bearing set cannot absorb the thermal spindle shaft expansion. Therefore, a sliding device, which prevents the over preload, has to be implemented at the rear bearing set. Once the sliding device is applied, the DB arrangement for the rear bearing arrangement is appropriate for a high speed spindle.

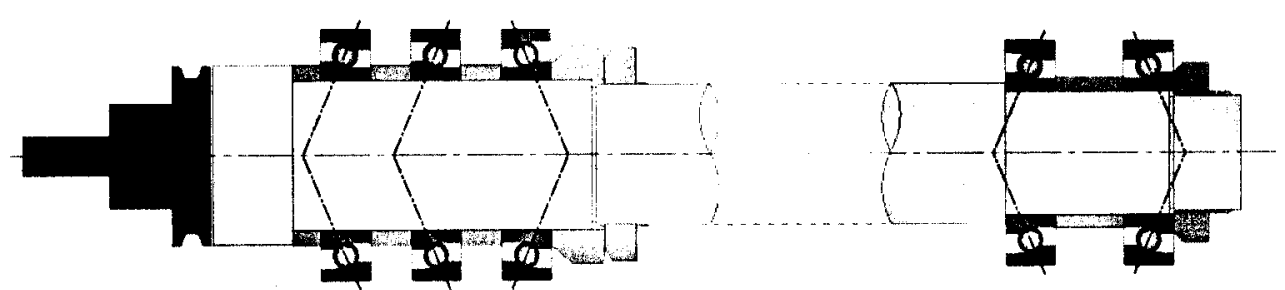

Figure 3.20 : Bearing Arrangement (2TB-DB)

\section{(c) QB-DT Arrangement}

The arrangement type shown in Fig. 3.21 is the QB-DT type, which can carry more load than the 2TB-DB type arrangement. The DT rear bearing arrangement can absorb the thermal expan- 
sion of the spindle shaft. However, too much expansion causes the loosening of the bearings, and if the worst happens, rear balls will run free and huge vibrations will occur. Therefore, the device used to increase the preload of the rear bearings, contrary to the DB arrangement for the rear bearing set, is required for high speed spindle.

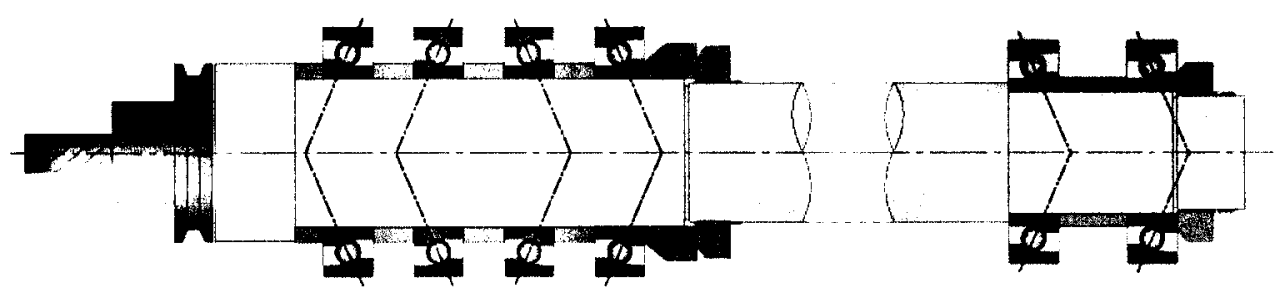

Figure 3.21 : Bearing Arrangement (QB-DT)

\subsubsection{Lubrication System}

Bearing lubrication can significantly increase the rotation capacity and bearing life increased. Generally, two types of lubricant are used for the milling spindle; grease type and oil air type.

\section{(1) Grease Lubrication}

Grease lubrication (Fig. 3.23) is the type where a proper amount of grease is enclosed when the bearings are assembled into spindle. The rotation capability or life is all dependent on the grease quality.

The main reasons that designers use the grease lubrication are its cost-effectiveness. Once the grease is enclosed into the bearings, the lubrication is completed; there is no device to supply the lubricant. Therefore, this type of lubrication can be simply designed and assembled, and the design and manufacturing cost can be very reasonable. Besides, the amount of lubricant does not reduce almost permanently so that the machine operators do not need to worry about maintenance of the lubrication system. 
The disadvantages of the grease lubrication is that the rotation capacity of the grease lubricated bearings is not as high as that of oil air ones, because the higher viscous resistance of grease makes the temperature inside the bearings rise. Besides, the bearing cooling device, in which the cooling air is directly sprayed onto rolling elements to lower the bearing temperature, cannot be implemented because the cooling air expels the grease. The life of the bearings is shorter than those lubricated by the oil air system. The life of the grease lubrication bearings is mostly dependent on the life of the grease itself; the deteriorated grease causes the bearings seize-up. Since there is no circulation to renew the grease, the grease life is basically not very long. The grease lubrication bearings are prone to contamination, because there is no way to exclude the contaminants.

High quality grease and bearings have been developed these days, and even without the oil air system, it has been possible to rotate up to $\mathrm{DmN} 2,000,000$ [10], which can be rotated at, for example, $20,000[\mathrm{rpm}]$ with a $100[\mathrm{~mm}]$ bearing pitch diameter. $\mathrm{DmN}$ is the bearing ball pitch diameter $d_{m}[\mathrm{~mm}]$ times the spindle speed $n[\mathrm{rpm}]$, as shown in Fig. 3.22.

$$
D m N=d_{m} \times n
$$

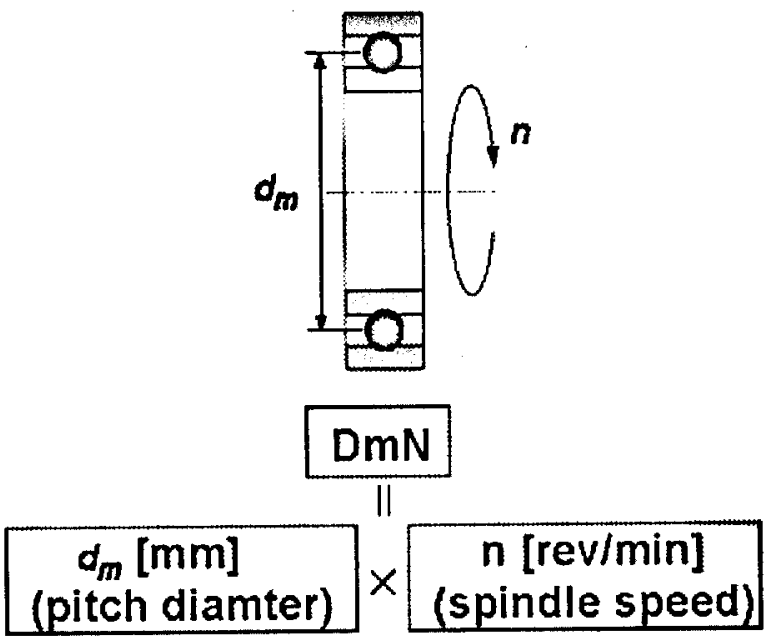

Figure $3.22: \mathrm{DmN}$ 


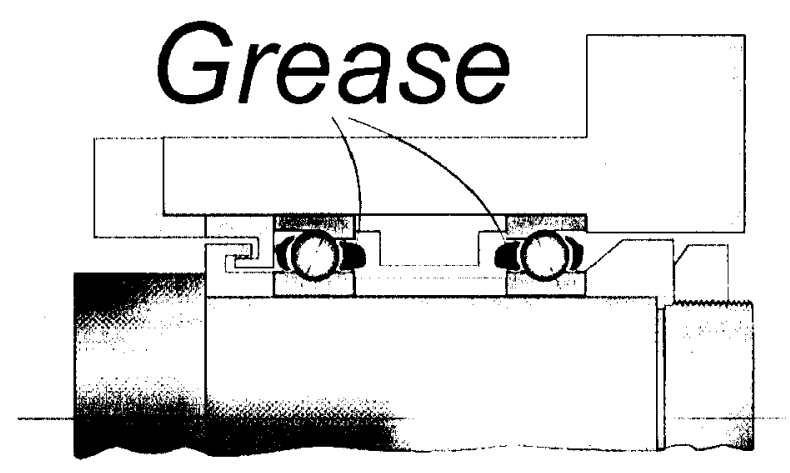

Figure 3.23 : Grease Lubrication

\section{(2) Oil Air Lubrication}

Fig. 3.24 shows the oil air lubrication system. Extremely small amounts oil, such as 0.03 $\left[\mathrm{cm}^{3}\right]$ per $16[\mathrm{~min}][59]$, carried with air are sprayed onto the bearing balls. Too small amounts of grease lead to the lack of lubricant; too much oil causes high viscous resistance which leads to high bearing temperature. Therefore, the amounts of oil have to be adjusted from experience.

The rotation capacity of the oil air lubrication system is much higher than that of grease lubrication system even with advanced grease. The reasons are that the viscous resistance of the oil air system is smaller since the very small amounts of oil are used, and the air mixed with oil can cool the bearings in addition to the role of the oil carriage. Besides, the contaminants hardly reach the bearings because of the exhaust feature of oil air system. Furthermore, since new oil is always supplied to the bearings, the deterioration of the lubricants never occurs.

However, the cost of the oil air system is higher than the grease type. The structure of the oil air system is more complex than that of grease system, and the oil air type needs peripheral devices such as oil supply equipment, and oil/air mixing equipment. Although the oil consumption is very small, the oil is reduced whenever operators use the machine; machine operators must maintain the lubrication system before they start cutting. 
With the oil air lubrication system, the rotation capacity can be $\operatorname{DmN} 3,500,000$ with an advanced bearing. [10]

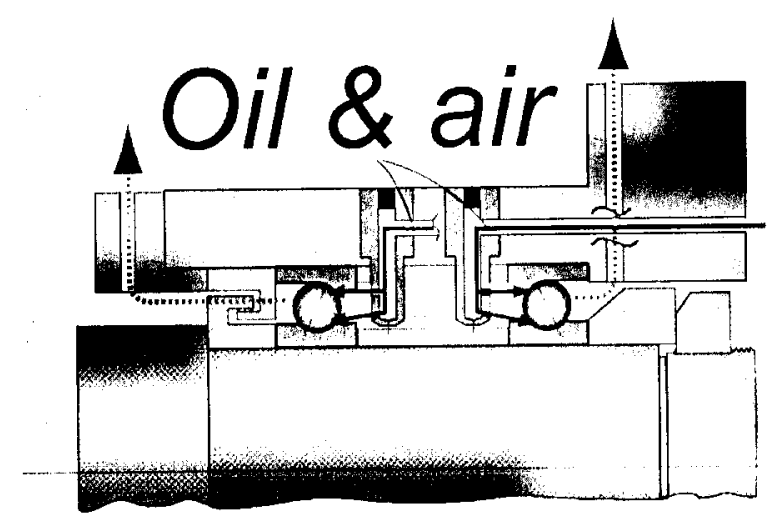

Figure 3.24 : Oil Air Lubrication

\subsection{Tool Interface}

The tool interface is basically decided by users, for depending on the tool that users have, the tool interface will be fixed. There is no compatibility among the different toolholders. In North America and Japan, 7/24 taper type toolholders (CAT/BT) have been used frequently. However, the new toolholders have been developed for high speed spindles. The following toolholders are the example of the cutting toolholders which cutting operators frequently use.

\section{(1) CAT Toolholder}

CAT toolholders (Fig. 3.25) have 7/24 long taper tool and is used in North America and Japan (In Japan, it is called BT type.). Since the users have many CAT toolholders, they do not need to buy the new ones. In addition, the shank of this toolholder is a solid structure, so it is stiffer than the hollow shank toolholders. The cutter can be put into the shank, and the overhang length from the spindle nose to tool tip can be shorter than the other hollow shank type.

However, when it rotates at high speed, the spindle taper expands and the tooling is pulled into the spindle. This causes a dimensional error of the workpiece in the $\mathrm{z}$ axis, and in addition, it 
is hard to remove the tool from the machine. In order to avoid this phenomenon, the type where the toolholder flange contacts the spindle nose was developed. This works at a certain speed range, but at high speed range the spindle taper expands and the gap between the toolholder and the spindle taper appears, and the stiffness reduces extremely because the toolholder contacts only at the spindle nose.

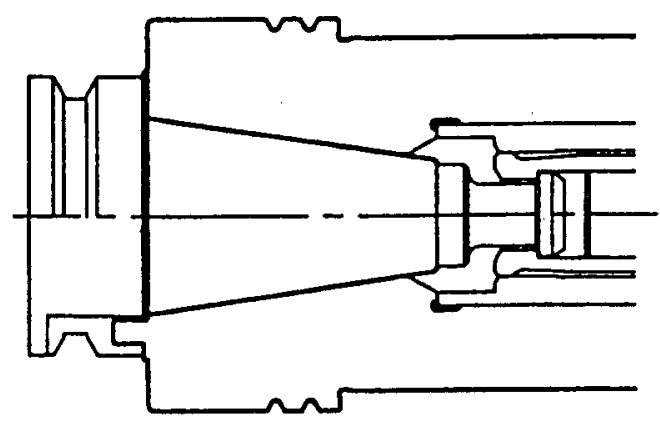

Figure $3.25: \mathrm{CAT}(7 / 24)$ Toolholder

\section{(2) HSK Toolholder}

Figure 3.26 shows the HSK toolholder which is $1 / 10$ short taper. This toolholder is a hollow structure and the collets hook the toolholder from inside the shank and clamp it. This interface type has been standardized by the International Organization for Standardization (ISO).

The advantage of this type is that even if the spindle rotates at a high speed and the spindle taper expands with the centrifugal force, the toolholder will follow suit because of its hollow structure. The toolholder flange can also contact the spindle nose so that the two faces can be contacted at the same time, and the stiffness can be achieved through more than one face contact type. Besides, due to the short taper, the spindle bearing at the front end of the spindle can be positioned closer to the tool side; therefore, the stiffness of the spindle can be improved compared with that of the long taper interface spindle. 
However, the cutter overhang tends to be longer than the solid tool shank type because there is no space to put the cutter into the taper. The inserting angle into the spindle of HSK is 90 to 100 degrees, which is wider compared with the CAT and NC5 type so that HSK is clamped unsteadily (Appendix B). In addition, due to the hollow structure, the tool shank is easily broken compared with the other solid tool shank types.

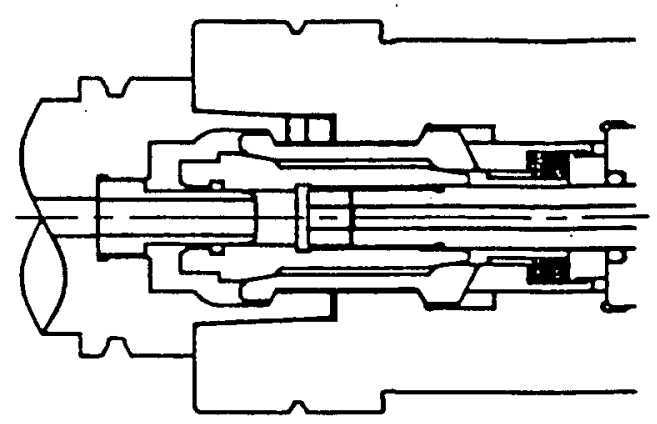

Figure 3.26 : HSK Toolholder

\section{(3) KM Toolholder}

The KM toolholder [32], shown in Fig. 3.27, has a short taper and hollow shank similar to HSK. Initially, KM was applied to lathe tools, but later it was adopted for some machining center tooling interfaces. Therefore, this tooling type is not frequently used for milling spindles. The biggest difference to HSK is the ball-wedge axial force enhancer is in KM. This results in very significant radial force amplification [45]. The stiffness, therefore, of this interface becomes very high. However, because of the high contact pressure, the spindle shaft is deformed radially so the position of the front end bearing needs to be enough distance from taper area. 


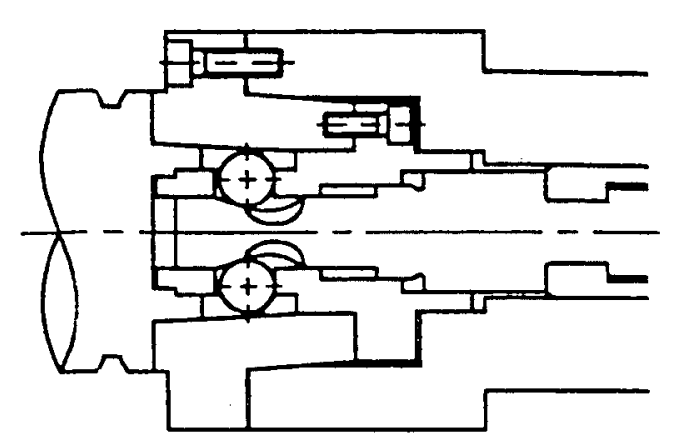

Figure $3.27:$ KM Toolholder

\section{(4) NC5 Toolholder}

Figure 3.28 shows the NC5 tool interface which has been developed by Nikken Kosakusho, Japan. This has a short taper and a solid shank, and in order to overcome the disadvantage of the solid shank, a slit is put in the taper so that even if the spindle taper expands due to the centrifugal force, the tool shank can fit to the spindle taper. The slit taper cone also contributes to high damping [28]. However, since this has not become widespread, it may be costly for users to buy all required toolholders.

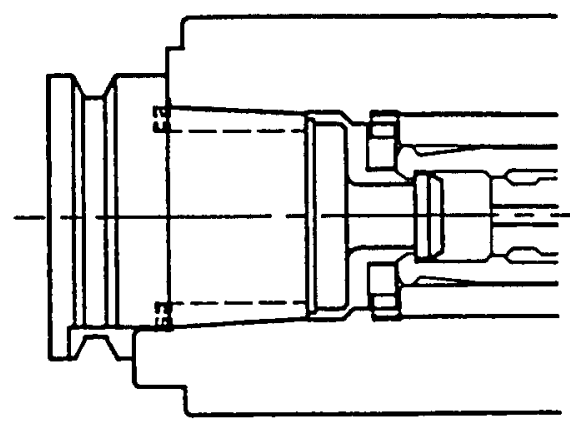

Figure $3.28:$ NC5 Toolholder

All tool interface types have advantages and disadvantages. Users need to select the tool interface by considering the total influences. For example, comparing the CAT type and the HSK 
type, the cutter overhang of the HSK is going to be longer than that of the CAT type; the front end bearing position of the HSK, however, can be closer than that of the CAT. Therefore, the stiffness superiority cannot completely conclude. Besides, the real property of each toolholder is in process of investigation. The contact dynamics between toolholder and spindle taper are especially difficult to define, because they depend on how the toolholder is clamped, that is, the contact dynamics change each time the toolholder is changed. 


\section{Chapter 4}

\section{Expert System for Spindle Design}

\subsection{Introduction}

During the growth of computer technologies in the 1960's, John McCarthy developed Artificial Intelligence (AI). AI is based on algorithms which can think and make decisions by using accumulated expertise. Knowledge-based expert systems like MYCIN have been widely adopted by Shortliffe [52, 53]. MYCIN, which is one of the first practical expert systems, is the system used to diagnose and recommend therapy for infectious blood diseases. For the computational decisions, the ideal answer for the diagnosis is yes or no to make the system simple; in reality, however, there are always some uncertainties in the diagnosis. There are several ways to deal with this uncertainty, such as certainty factors, neural networks and fuzzy logic. The certainty factors are used in MYCIN. The uncertainties are expressed as a number between -1 and 1 for each fact. The neural network represents the uncertainty based on the models of biological neurons, learning schemes, and activation functions. The neural network needs a training process based on past experience and results. The fuzzy logic deals with the uncertainties based on fuzzy sets with membership functions. The uncertain facts in the spindle design process are the terms such as high spindle speed, low cutting torque, etc.

In 1965, Lotfi A. Zadeh [67] introduced fuzzy logic that can cope with the concept of partial truth. He argued that general matters are not always determined satisfactorily by "yes/no", or "true/false" but often require vagueness. Fuzzy logic has been widely applied in electrical appliances as power control and in cameras as auto focusing. 
Vagueness is required for the decisions in the spindle design process. This thesis introduces an Expert Spindle Design System based on a set of fuzzy logic rules which are created using the design experience accumulated from a rage of articles and the author's industrial experience.

\subsection{Expert System for Spindle Design}

One of the difficulties of spindle design is the selection of specific spindle component combinations from the significant number of configurations presented in Chapter 1. Currently, the spindles are designed by experts who have accumulated training and experience in the field. However, once the experts retire or move to another position, the important knowledge of spindle design is lost, and the new designers have to rebuild the knowledge from the beginning. The expert system for spindle design is introduced here to facilitate the process using past experience and knowledge.

Expert systems are collected as rules of thumb and human experience in a computer algorithm. For example, when operating a machine tool and checking its condition, how can one decide about the next action? If the machine starts exhibiting a faulty operation, the operator pushes the STOP button; else if the machine runs normally, the operator will just keep monitoring it. This can be expressed by using the "IF THEN ELSE" expression, which is frequently used to build rules in the expert system algorithms.

IF the machine behaves in the wrong way THEN stop the machine ELSE keep monitoring

The rule base used for the expert system consists of a vast collection of similar "IF THEN ELSE" rules.

Figure 4.1 shows the internal structure of a basic expert system. Experts can access the engine of the system and can modify or add to the knowledge base of rules and databases. They create an inference engine (also called a rule interpreter), which infers new facts that can be 
accessed by users as well. Users enter the necessary input data to the inference engine and receive the output from the inference engine.

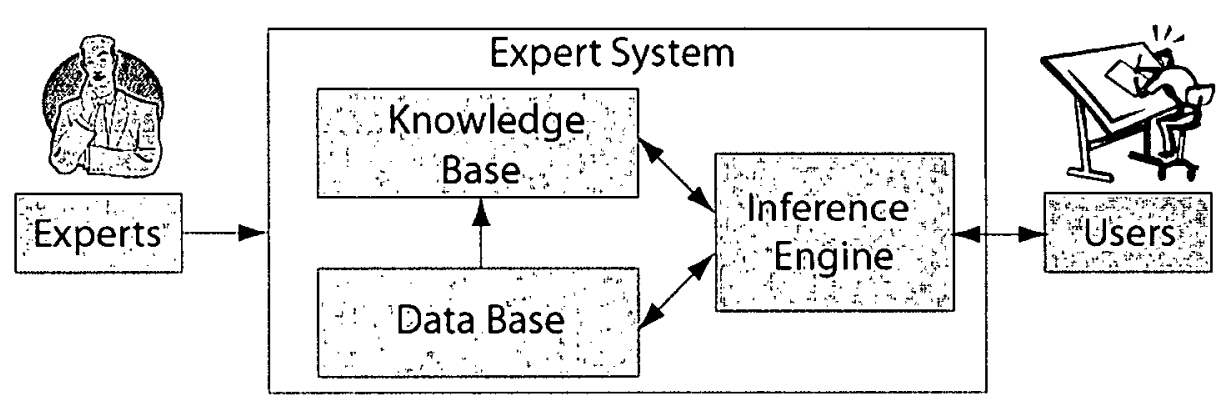

Figure $4.1:$ Internal Structure of Basic Expert System

\subsection{Fuzzy Logic}

Although the expert system is advantageous in an ideal world where the facts are always true or false, in reality facts are mostly expressed with uncertainty, in other words, with fuzziness. The designers seldom use exact numerical data for the spindle design but instead use logical terms. For instance, a gear transmission type is selected when the required cutting torque is high. High is a fuzzy expression that the designers define from their experience and knowledge.

The cutting torque must be expressed in design terms, such as high, middle, and low, and is quantified with a numerical value which can range from 0 to 1000 [Nm]. Fuzzy logic can deal with the uncertainties in the range by using membership functions. In addition, the spindle design process changes as the technology advances, hence the uncertainty rules must be modified progressively.

\section{(1) Fuzzy Sets}

A fuzzy set is a set without a crisp, clearly defined boundary. It can contain a part of the element, and does not need the whole element. Classical sets, in contrast to fuzzy sets, have to include the whole element. Therefore, the boundary is closed as shown in Fig. 4.2. 


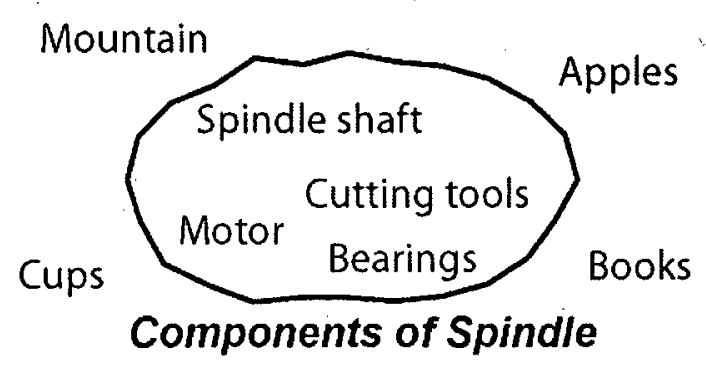

Figure 4.2 : Classical Set

However, sometimes it is not possible to express matters with crisp boundaries. For example, what are the rotating parts of a spindle in a machine tool? Obviously, the cutting tools and the spindle shaft are rotating parts, but how about the bearings and the motor? The balls and inner rings of the bearings rotate, but the outer rings are stationary. Similarly, the shaft and the rotor of the motor rotate, but the other parts, such as the motor housing and the stator are stationary. Therefore, the motor and the bearings cannot be completely defined as a rotating part set, as shown in Fig. 4.3. There is no longer a crisp boundary separating the spindle parts as either rotating or stationary.

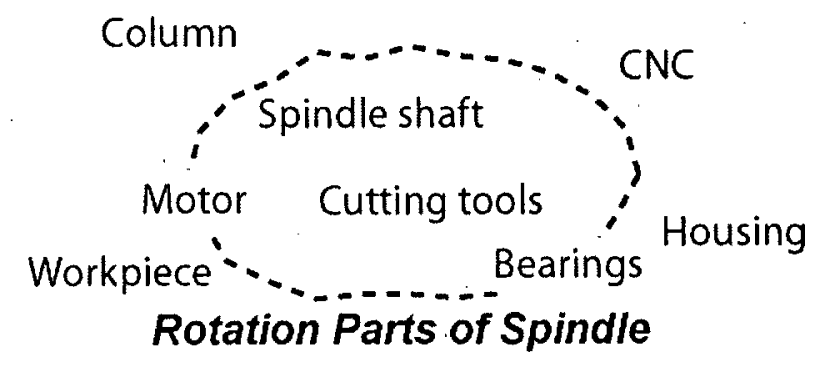

Figure 4.3 : Fuzzy Set

Another classification must be set for the spindle speed range, which can be low, middle or high. Generally, the middle spindle speed range is considered to be between 8,000 [rpm] and 
15,000 [rpm] (See Fig. 4.4). However, whether 7,999 [rpm] can be considered as a low or middle speed is a difficult problem if we use crisp boundaries which can be handled by fuzzy sets.

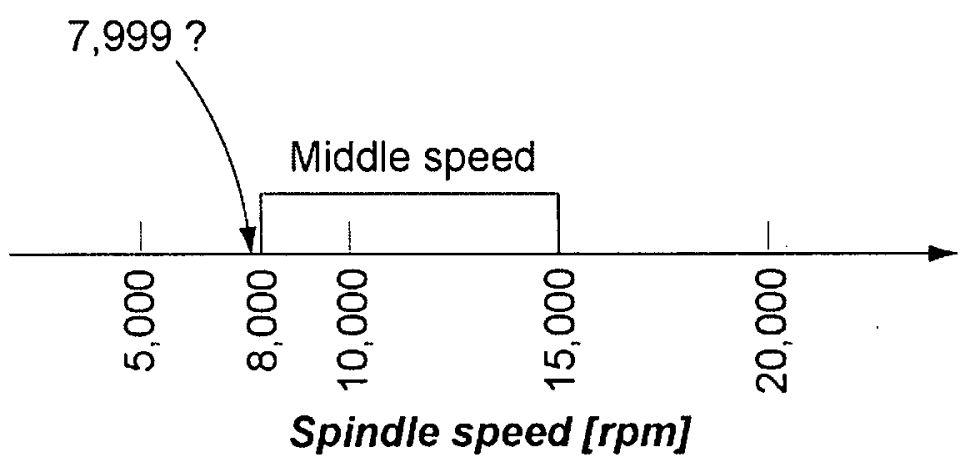

Figure 4.4 : Classical Set for Spindle Speed

As shown in Fig. 4.5, with a fuzzy set, medium spindle speed can be expressed with vague lines, which are dashed in Fig. 4.5. In this case, 7,999 [rpm] does not need to be categorized as a low spindle speed; it may be a middle speed, or it might be a low speed.

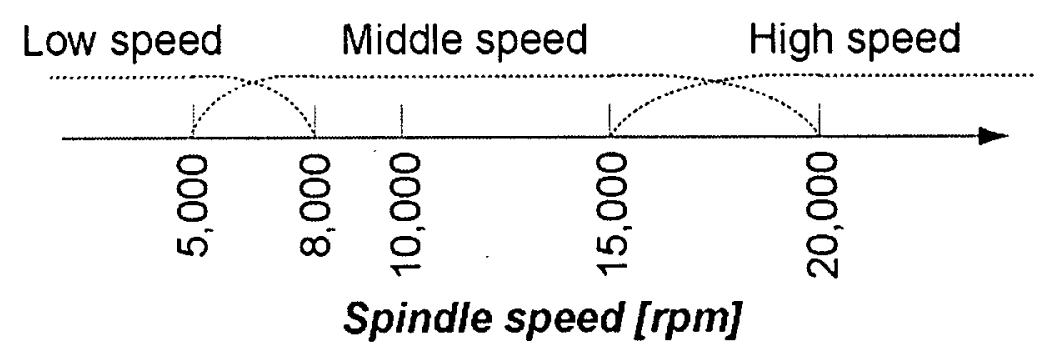

Figure 4.5 : Fuzzy Set for Spindle Speed

\section{(2) Membership Functions}

In order to express the fuzziness of each fuzzy set, such as middle spindle speed, membership functions are applied. A membership function is a curve that defines how each point in the input space is mapped onto a membership value between 0 and 1 [19]. At first, Figure 4.6 illustrates 
characteristic functions of spindle speed with classical sets. In this case, 7,999 [rpm] becomes a low speed because the boundary is crisp.

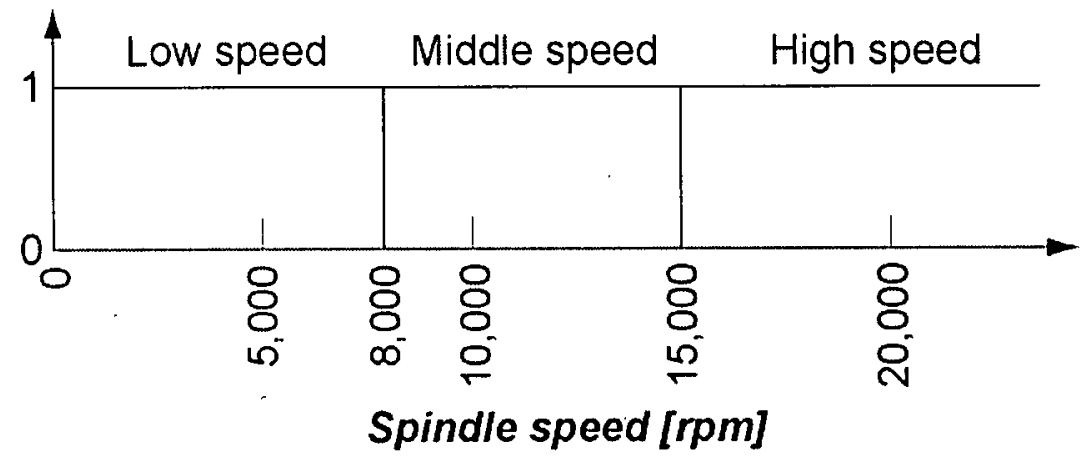

Figure 4.6 : Characteristic Function of Spindle Speed with Classical Sets

Figure 4.7 shows an example of the membership functions of spindle speed with fuzzy sets. These membership functions can express the fuzziness of the spindle speed range. 7,999 [rpm] is, for instance, almost middle spindle speed, but there is still a possibility of falling into a low spindle speed range.

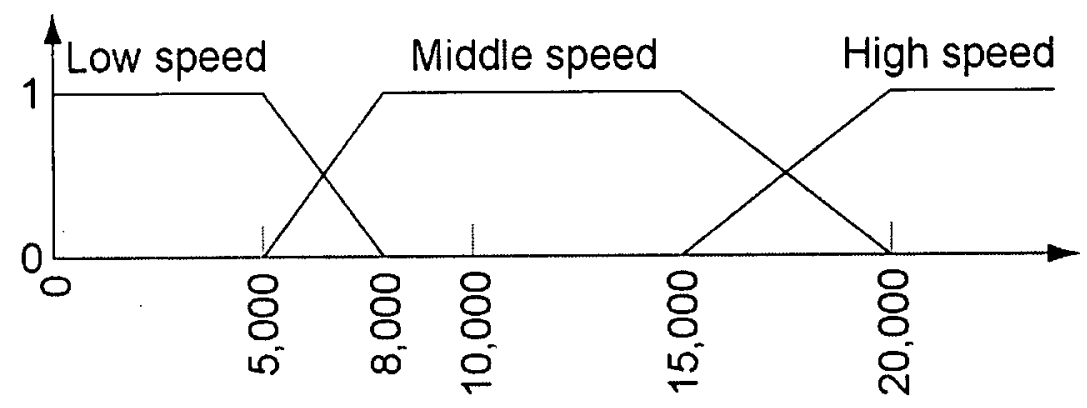

Spindle speed [rpm]

Figure 4.7 : Membership Function of Spindle Speed with Fuzzy Sets

In Figure 4.7, a trapezoid type consisting of linear line membership functions is used. There are several kinds of shapes of membership functions (Fig. 4.8). The singleton is the special case in 
which the base length of a triangle shape is zero. The most commonly used shapes are the triangle, trapezium, and the curve [23].

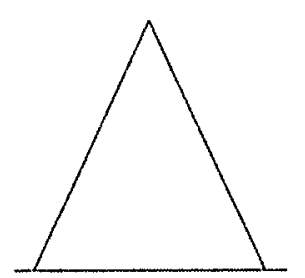

Triangle

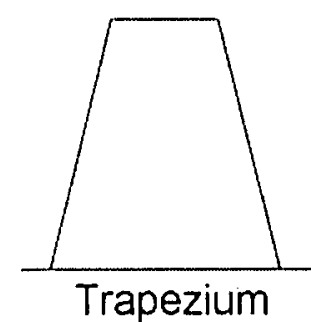

Trapezium

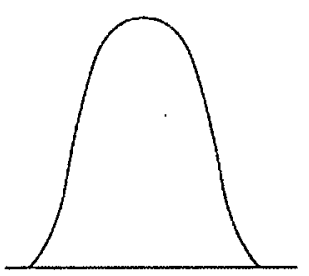

Curve

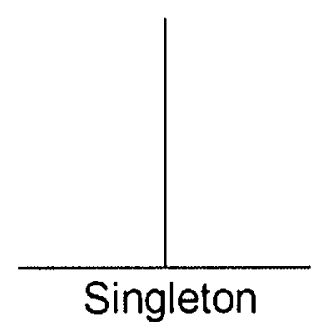

Singleton

Figure 4.8 : Typical Shapes of Membership Functions [23]

\section{(3) Logical Operation}

Table 4.1 shows the basic manipulations of logical connectives. The "min (minimum)" operation shown in Table 4.1 is used to represent the logical "AND" operator. Then, the "max (maximum)" operation represents the "OR" operator. The NOT operation becomes equivalent to "1-A".

Table 4.1 : Logic Connectives in Fuzzy Logic

\begin{tabular}{|ll|l|}
\hline$A$ & $B$ & $\min (A ; B)$ \\
\hline 02 & 0.2 & 0.2 \\
\hline 02 & 0.7 & 0.2 \\
\hline 0.7 & 0.2 & 0.2 \\
\hline 07 & 0.7 & 0.7 \\
\hline & AND \\
\hline
\end{tabular}

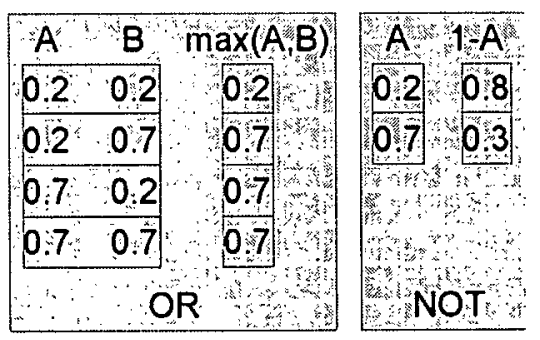

\section{(4) Rule base}

"IF THEN" rules are also used for setting up fuzzy logic rules. A single fuzzy IF-THEN rule can be set as follows:

IF $\mathrm{x}$ is $\mathrm{A}$ THEN $\mathrm{y}$ is $\mathrm{B}$ 
where, A and B are linguistic values defined by fuzzy sets. The rule at the IF-part, " $x$ is A" is called the antecedent; the rule at the THEN-part, "y is B", is called the consequent. As an example of a spindle design rule, the following statement can be shown:

IF cutting torque is high THEN transmission is gear type.

Here, "high" at the antecedent is interpreted as a number between 0 and 1 via membership functions. On the other hand, "gear type" at the consequent is represented as a fuzzy set. The fuzzy sets, which are built by experts, will be defuzzified to produce a single number in the end.

\section{(5) Inference System}

The fuzzy inference process is the process of formulating the mapping from a given input to an output using fuzzy logic. The mapping provides a basis from which decisions can be made, or patterns discerned. The fuzzy inference process involves all of the parts which are shown in the previous sections from (1) to (4). Among the many types of fuzzy inference system, such as the Mamdani-type [33] and the Sugeno-type [54], the Mamdani-type is applied in this research because this method is most commonly used as a fuzzy inference system. The procedure of the Mamdani method is described as follows [19]:

\section{Step 1. Fuzzification}

The inputs, which are all numerical values, have to be fuzzified through membership functions, shown in Fig. 4.9. The input value of 7,000 [rpm], for example, is applied to membership functions at both low speed and middle speed. From a low speed membership function, 7,000 [rpm] is fuzzified to 0.333 , which is a fuzzified number in terms of low speed. From a middle speed membership function, 0.666 can be obtained. So, it can be said that 7,000 [rpm] is more likely to be a middle speed than a low speed. 


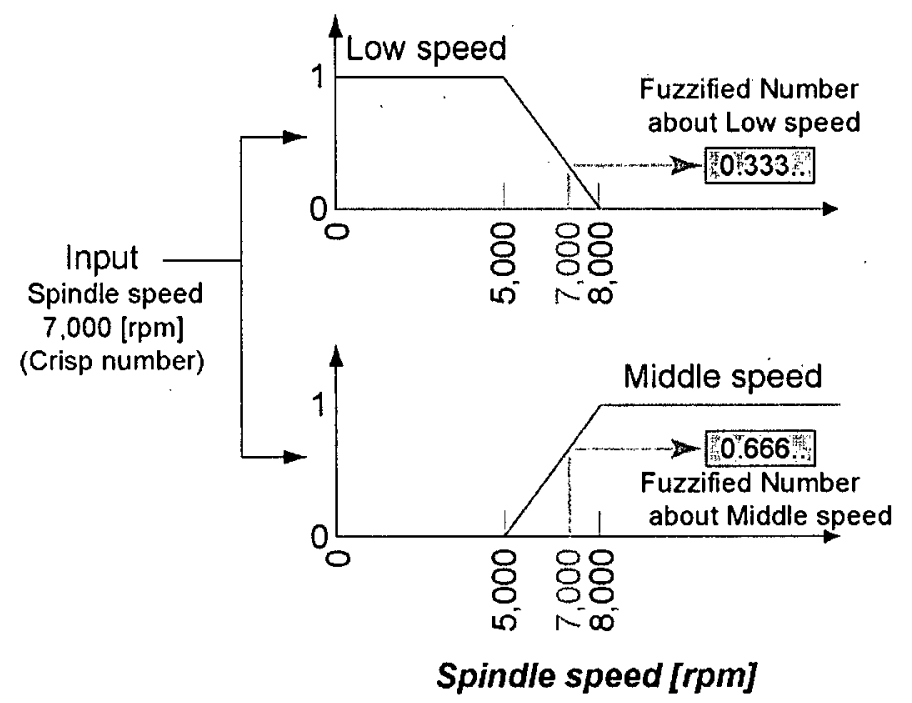

Figure 4.9 : Input Fuzzification

\section{Step 2. Application of Fuzzy Rules}

Implication (fuzzy rules) are applied to the fuzzified numbers using logical operations, which are "AND", "OR", and "NOT" (Fig. 4.10). In the following rules,

IF Spindle speed is Middle AND Torque is Large THEN $z$ is $C$

IF Spindle speed is Middle OR Torque is Large THEN $z$ is $C$

The "AND" operator corresponds to the "min" operator so that "0.2", which is the minimum value between Middle and Large, will be taken as the value of the result of the fuzzy operator. On the other hand, with the "OR" operator, which is equivalent to the "max" operator, "0.666" will be applied as the result of the fuzzy operator.

Implication, which can be said to be the "THEN" part, has several methods, such as "min" and "prod (product)". The "prod" is the method that scales the output fuzzy set. The "min" operator is applied as the implication in this research, as shown in Fig. 4.10. 


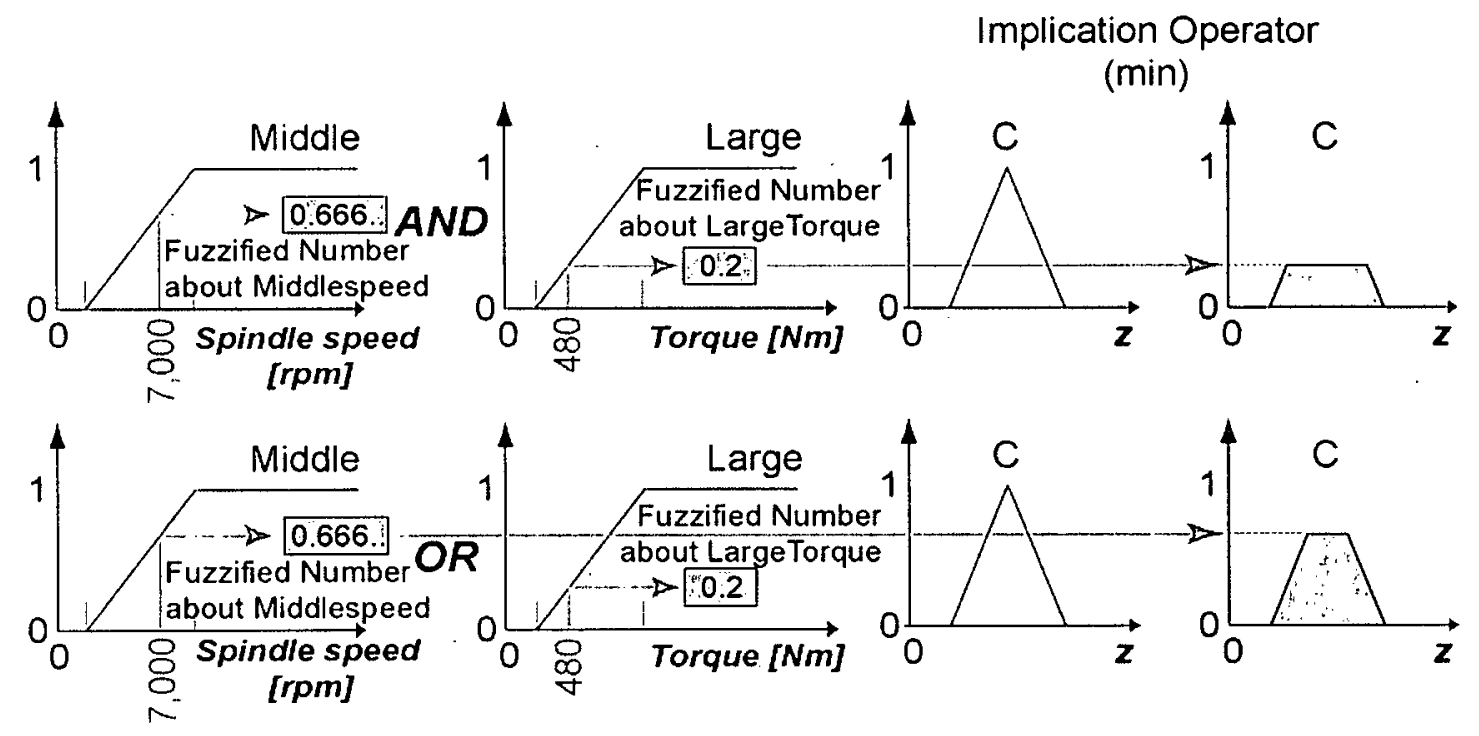

Figure 4.10 : Logic Operation and Implication

\section{Step 3. Aggregation}

Each fuzzy rule results in an implicated set, and those sets are aggregated to make the final set. Among several kinds of aggregation methods, the "max" method is applied in this research. Figure 4.11 shows the "max" method as aggregation. With the "max" method, the fuzzified sets are combined using maximum lines, and the final aggregated set is established.

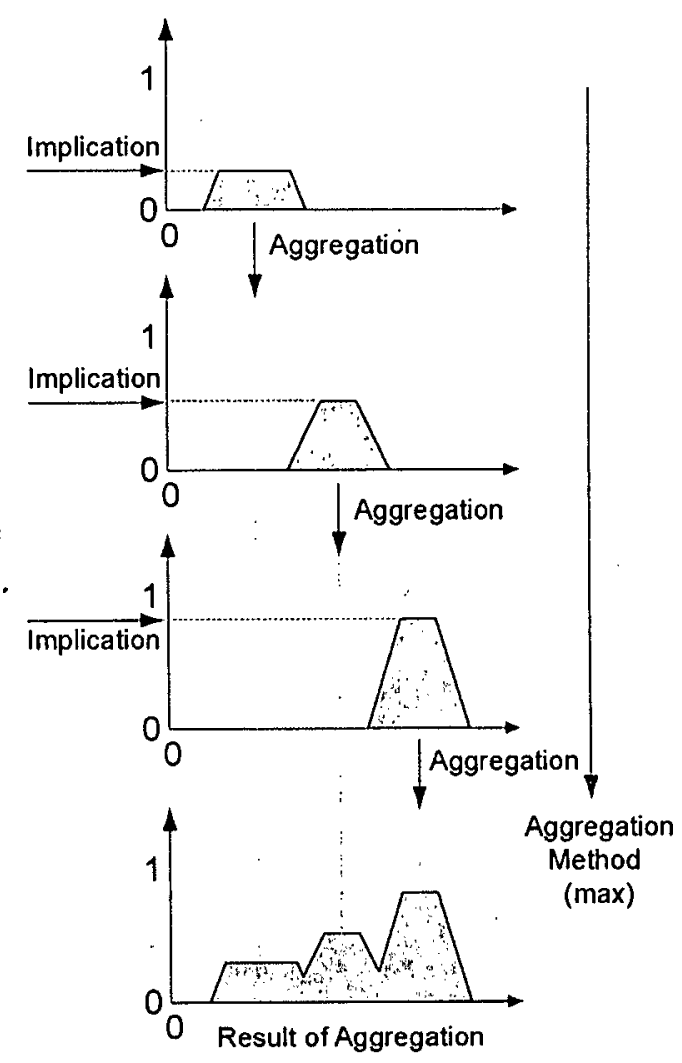

Figure 4.11 : Aggregation [19] 


\section{Step 4. Defuzzification}

The aggregated set shown in step 3 is still a fuzzy set, and the fuzzy sets are not useful for making decisions. Therefore, this fuzzified set must be defuzzified using a certain method. As a defuzzification method, the centroid method is frequently used. Eq. (4.1), called the center-ofgravity formula, is the equation used to compute the centroid of the aggregated fuzzy set. $\hat{y}$ is the defuzzified value, $\mu_{Y}$ is the weight defined as a number between 0 and 1 , and $y_{i}$ is the lateral value. The lateral coordinate, in this case "5.9", is taken as the defuzzified value (See Fig. 4.12).

$$
\hat{y}=\frac{\sum_{i=1}^{N} \mu_{Y}\left(y_{i}\right) \cdot y_{i}}{\sum_{i=1}^{N} \mu_{Y}\left(y_{i}\right)}
$$

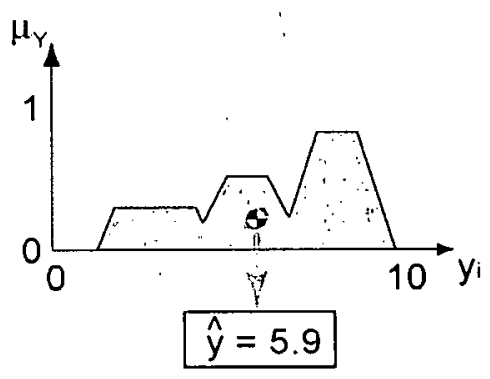

Figure 4.12 : Defuzzification 


\subsection{Application of Expert System to Spindle Design}

Since fuzzy logic is suitable as the uncertainty expression for the spindle design, the expert system combined with the fuzzy logic is used as the components' selection system for the spindle design. The expert system for spindle design is illustrated in Fig. 4.13. The required input values for the spindle design, such as the cutting torque and power, are computed using the laws of cutting mechanics, as described in [2]. Then, the input values are entered into the fuzzy inference system, which is established by experts, and are fuzzified via membership functions. The Mamdani method is used as the inference system. The fuzzified values are applied to the fuzzy rules and aggregated using the max method. The result of the aggregation is defuzzified by using the centroid method, and a defuzzified number is obtained. The simple defuzzified number is applied to the selection rule to select the spindle components. An external database is connected to the fuzzy inference system and users can utilize it. As an example of the database, cutting coefficients for a material, which are required for torque and power calculation, can be cited. The supervising engineer, who is permitted to maintain this expert system, can modify the membership function and database when the tendency of the fuzzy terms, such as "high", "middle", and "low" change. In this research, transmission type and lubrication type are determined using the expert system with fuzzy logic. 


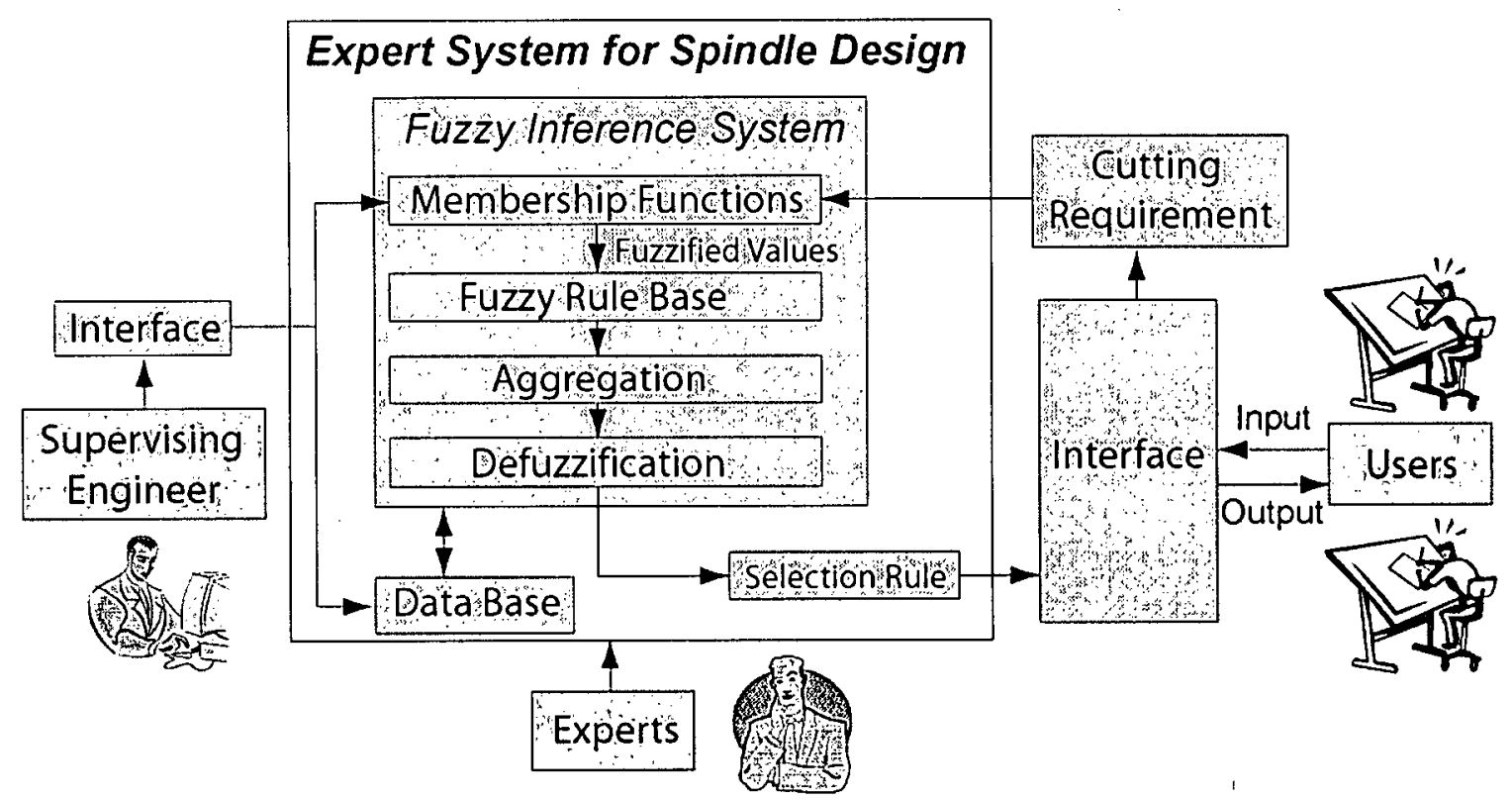

Figure 4.13 : Internal Structure of Expert System for Spindle Design

\subsubsection{Transmission Type Selection}

Figure 4.14 illustrates the process used to determine the type of transmission between spindle shaft and spindle motor. There are four transmission types; Gear type (G), Belt-pulley type (B), Direct coupling type (D), and Motorized type (M). The properties of the transmission options are shown in Section. 1.2. 


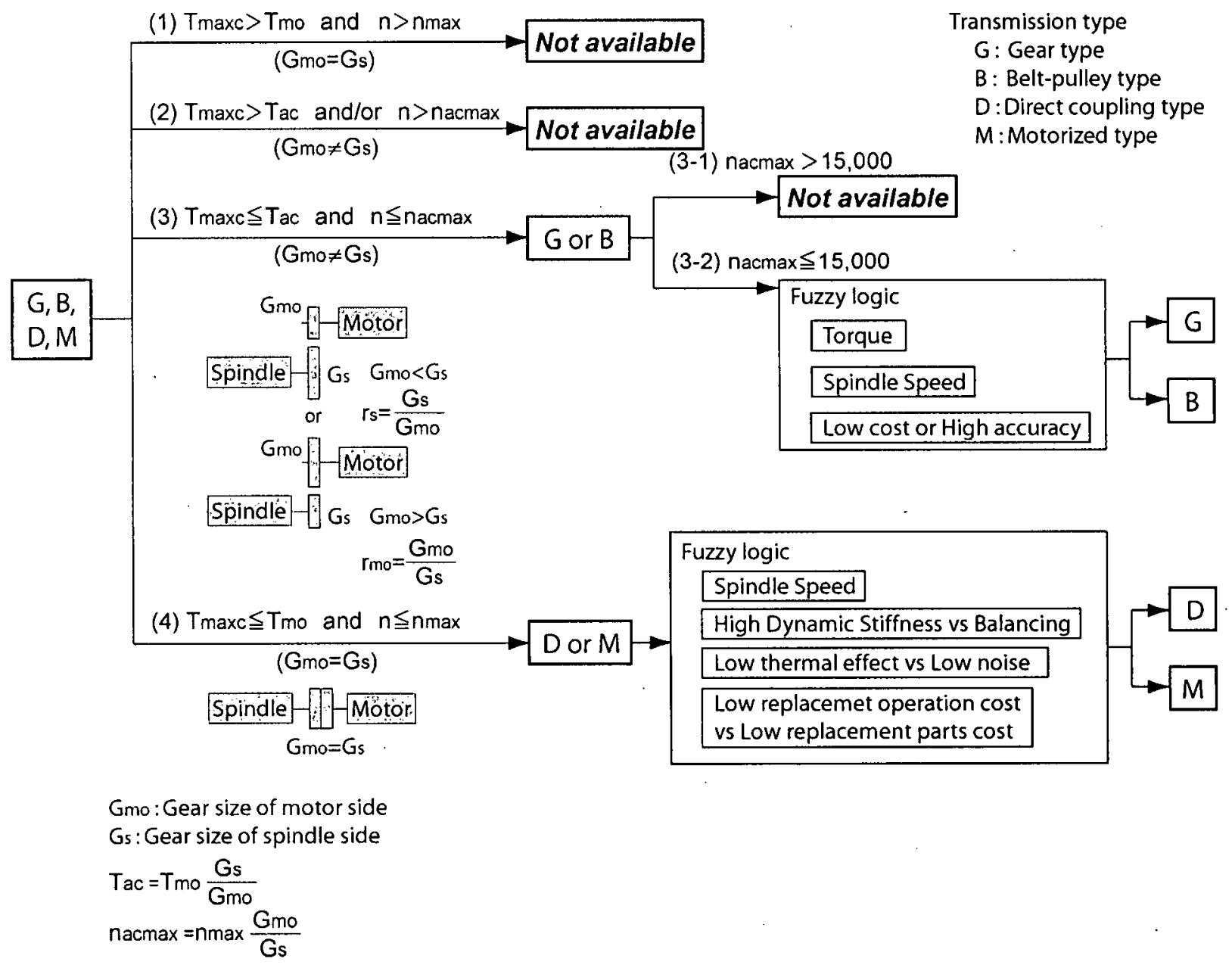

Figure 4.14 : Process of Transmission Type Selection 


\section{Step 1. Evaluation of Required Cutting Torque and Power}

A required cutting torque must be calculated from cutting conditions and be compared with the spindle motor specifications. The spindle must be classified where it requires a torque/speed changing device. The instantaneous cutting torque $T_{c}$ can be calculated [2],

$$
T_{c}=\frac{D}{2} \cdot \sum_{j=1}^{N} F_{t j}\left(\phi_{j}\right) \quad \text { with } \quad \phi_{s t} \leq \phi_{j} \leq \phi_{e x}
$$

where $D$ is the diameter of the milling cutter, and $N$ is the number of teeth of the cutter, $\phi_{j}$ is the instantaneous angle of immersion, $\phi_{s t}$ and $\phi_{e x}$ are the cutter entry and exit angles. $F_{t j}$, which is the tangential cutting force, can be computed using the following equation;

$$
F_{t j}\left(\phi_{j}\right)=K_{t c} a h\left(\phi_{j}\right)+K_{t e} a
$$

where, $K_{t c}$ and $K_{t e}$ are the cutting force coefficient and the edge cutting force coefficient, respectively. The material dependent cutting coefficients are evaluated from cutting experiments, and stored in a database. $a$ is the axial depth of cut, and $h\left(\phi_{j}\right)$ is the chip thickness variation expressed as follows;

$$
h\left(\phi_{j}\right)=c \sin \phi_{j}
$$

where $c$ is the feed rate $[\mathrm{mm} / \mathrm{rev}$-tooth].

Maximum cutting torque $T_{\operatorname{maxc}}$ required for the spindle motor has to be computed from the instantaneous torque $T_{c}$ calculated in Eq. (4.2),

$$
T_{\operatorname{maxc}}=\max \left(T_{c}\right)
$$

The cutting power $P_{t}$ is found from,

$$
P_{t}=V \cdot \sum_{j=1}^{N} F_{t j}\left(\phi_{j}\right) \quad \text { with } \quad \phi_{s t} \leq \phi_{j} \leq \phi_{e x}
$$

where $V=\pi D n$ is the cutting speed and $n$ is the spindle speed. These are inputs set by the spindle designer. 


\section{Step 2. Set Spindle Motor Specifications}

The spindle motor specifications must be determined by users to identify the transmission type. There are, basically, two types of motors; a normal and winding switching type. The power and torque diagrams of both motor types are shown in Fig. 4.15. The relation between motor power $P_{m o}$ and motor torque $T_{m o}$ can be expressed as follows;

$$
P_{m o}=\frac{2 \pi}{60} \cdot n_{m o} \cdot T_{m o}
$$

where $n_{m o}$ is the motor rotation speed. $n_{\max }$, shown in Fig. 4.15, is the maximum motor speed. Torque becomes constant when power increases proportionally. When power becomes constant, torque decreases inverse-proportionally. The winding switching type motor has two step power/ torque switching mechanisms compared with the normal motor. The winding switching type can keep more torque in a high speed spindle range than the normal motor. The designers who want a low cost motor may choose a normal motor, and the winding switching type may be selected by the designers who need a high speed spindle motor.

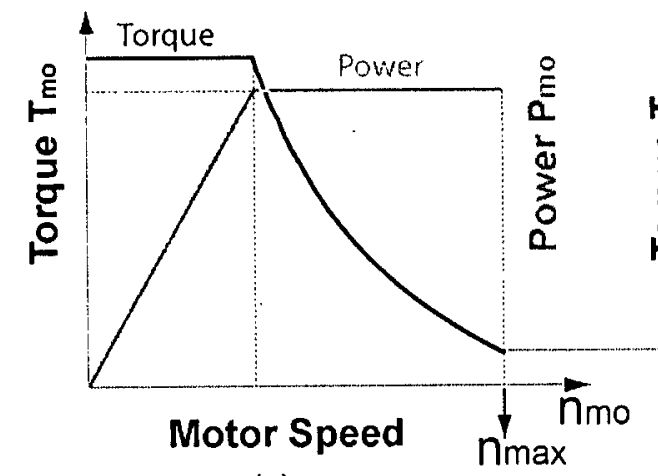

(a)

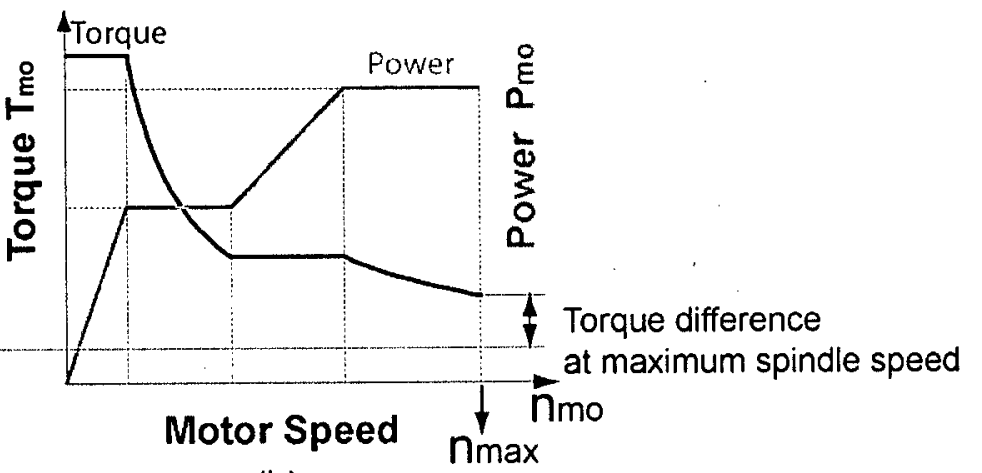

(b)

Figure 4.15 : Power and Torque Diagrams, (a) Normal Type, (b) Winding Switching Type 


\section{Step 3. Classify}

The spindle motor specifications are checked by applying the maximum cutting torque $T_{\text {maxc }}$ and the required cutting spindle speed $n$ to Fig. 4.15. The system will check if the maximum cutting torque is below the motor torque $T_{m o}$, as shown in Step. 2, or above. The system will also check whether the maximum speed $n_{\max }$ of the motor is greater than the cutting spindle speed. $T_{a c}$ and $n_{a c m a x}$ are the actual spindle torque and actual maximum spindle speed, respectively. These can be expressed as follows;

$$
\begin{gathered}
T_{a c}=T_{m o} \cdot \frac{G_{s}}{G_{m o}} \\
n_{a c \max }=n_{\max } \cdot \frac{G_{m o}}{G_{s}}
\end{gathered}
$$

where $G_{m o}$ and $G_{s}$ are the gear sizes of the motor side and spindle side, respectively. When $G_{s}=G_{m o}, T_{a c}=T_{m o}$ and $n_{a c m a x}=n_{\max }$.

If the required speed and torque are higher than the capacity of the motor, the designers must be warned or asked to make changes in the design. The following confinements from (1) to (4) link to the numbered process in Fig. 4.14.

(1) $T_{\text {maxc }}>T_{m o}$ and $n>n_{\max }$, (where $G_{s}=G_{m o}$ )

Since both torque and spindle speed exceed the spindle motor capacity, there is no available spindle.

(2) $T_{\text {maxc }}>T_{a c}$ and/or $n>n_{\text {acmax }}$, (where $G_{s} \neq G_{m o}$ )

There is no available spindle because the gear ratio cannot deal with this case. Even by changing the gear ratio, either required torque or required motor speed exceed the capacity of the motor.

(3) $T_{\operatorname{maxc}} \leq T_{a c}$ and $n \leq n_{a c m a x}$, (where $G_{s} \neq G_{m o}$ ) 
The transmission type can be either the gear type or the belt-pulley type. The spindle cutting torque and speed can be changed by changing the gear ratio $\frac{G_{m o}}{G_{s}}\left(\frac{G_{s}}{G_{m o}}\right)$.

(3-1) $n_{\text {acmax }}>15,000$

There is no available transmission type because the belt expands and it does not transmit enough torque if the rotation speed is more than $15,000[\mathrm{rpm}]$ (see Section 1.2.2).

(3-2) $n_{\text {acmax }} \leq 15,000$

The transmission possibility becomes either the gear type or the belt-pulley type.

(4) $T_{\operatorname{maxc}} \leq T_{m o}$ and $n \leq n_{\max }$, (where $G_{s}=G_{m o}$ )

The transmission type can be the direct coupling type or the motorized type. Both the motor torque $T_{m o}$ and the maximum motor speed $n_{\max }$ are greater than the cutting requirements $T_{\operatorname{maxc}}$ and $n$, so no gear reduction devices are required. 


\section{Step 4. Apply Fuzzy Logic}

In the classification process at step 3 , the transmission possibilities were reduced from the gear, belt-pulley, direct coupling, and motorized type, to just "gear/belt-pulley" or "direct-coupling/motorized" type. Fuzzy logic selects a specific transmission type from among these possibilities. Step. 4-1 is the fuzzy logic process for the transmission selection between the gear and belt-pulley types; Step. 4-2 is the fuzzy logic process for the transmission selection between the direct coupling and motorized types.

\section{Step. 4-1 Selection Between Gear Type and Belt-Pulley Type}

As a selection of transmission between gear type and belt-pulley type, the following fuzzy sets are implemented. These functions are set by referring to bearing catalogs $[16,40,41]$ and the author's five years of experience in a Japanese machine tool company.

(1) Torque

The belt-pulley type cannot transmit large torque compared to the gear type as shown in Section 1.2. The membership function of the torque set is shown in Fig. 4.16. The torque can be classified with "Small", "Middle", and "Large".

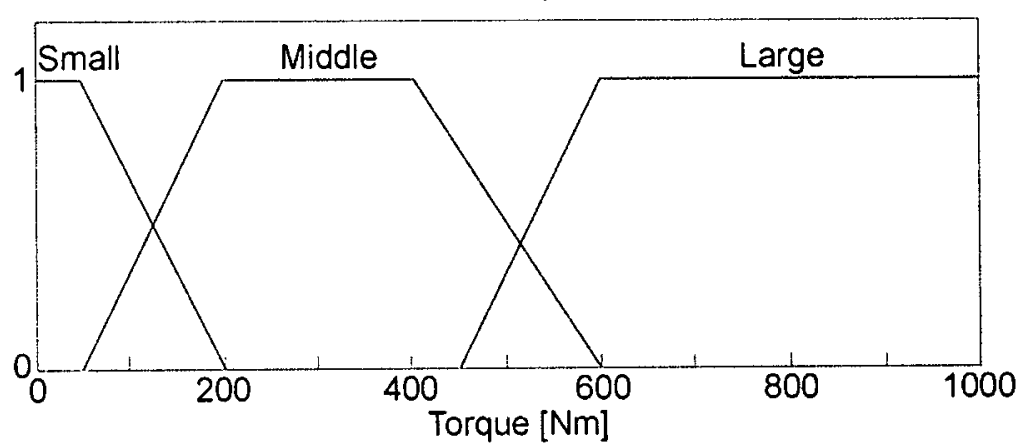

Figure 4.16: Membership Function of Torque

(2) Spindle speed

The belt may expand due to the centrifugal force at a high speed range, which prevents the transmission of torque. Figure 4.17 shows the membership functions 
of the spindle speed. The belt and gear type transmissions are usually not available at a spindle speed range higher than 15,000 [rpm]. As a result, the membership functions of "Low", and "Middle" are used when the gear or belt-pulley type transmission is selected.

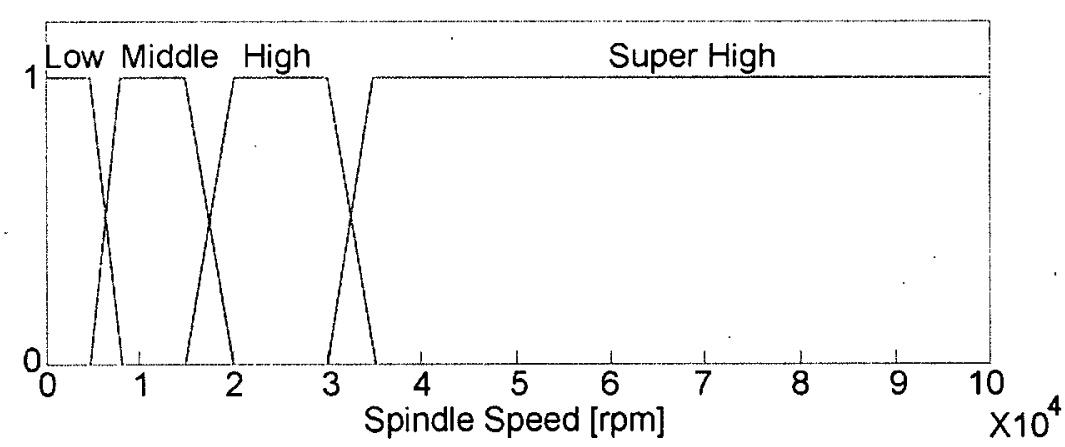

Figure 4.17: Membership Function of Spindle Speed

(3) Low cost vs. High accuracy

The belt-pulley transmission parts can be manufactured at a low cost because of their simplicity. In contrast, the gears are more costly due to the design and manufacturing complexity involved. On the other hand, due to the belt tension applied at the pulley point, the spindle shaft deflects and the rotation accuracy of its spindle becomes worse than that of the gear type.

The membership functions of low cost or high accuracy sets are shown in Fig. 4.18. The users have to select an integer weighting number, which indicates the conflict between the cost and accuracy with an integer number between 1 and 10 . 


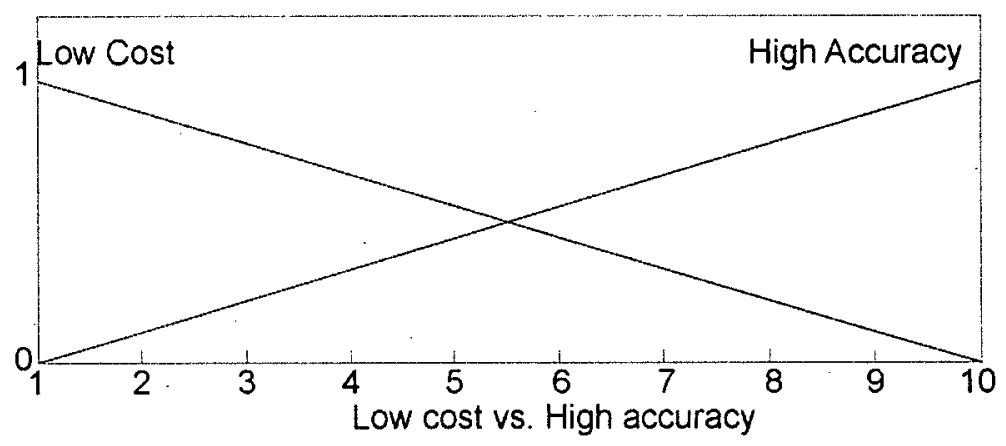

Figure 4.18 : Membership Function of Low Cost vs. High Accuracy

(4) Gear vs. Belt-pulley

The transmission type also must be fuzzified. The membership functions of gear or belt-pulley are shown in Fig. 4.19. This membership functions are used in implication process (Section 4.3 (5) Step 2)

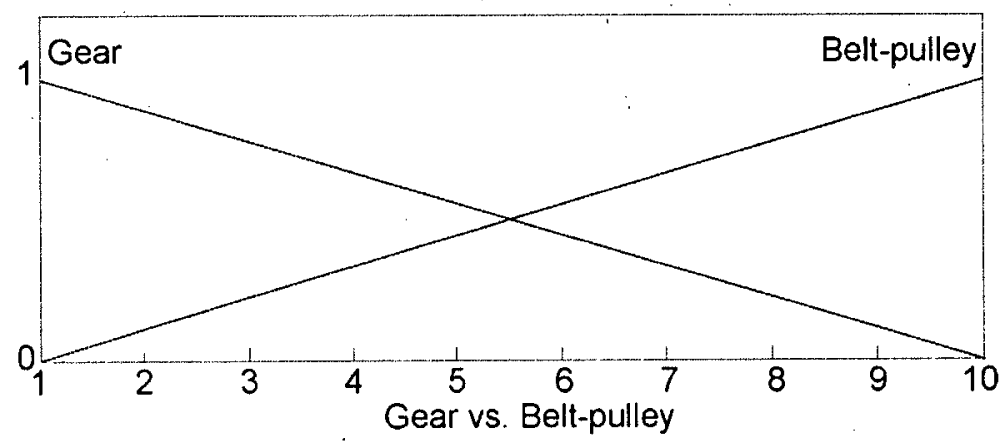

Figure 4.19: Membership Function of Gear vs. Belt-pulley

Fuzzy rules (Table 4.2) are applied to the fuzzified values of torque, speed, cost versus accuracy, and gear/belt transmission type via membership functions. These rules are defined from design principles, machine tool books [36], papers [3, 42] and the author's experience. 
Table 4.2 : Rules for Transmission Selection (Gear/Belt-pulley)

\begin{tabular}{|c|c|c|c|c|c|c|c|c|}
\hline & & Torque & & Spindle speed & & Cost/Accuracy & & Gear/Belt \\
\hline & \multirow{3}{*}{ IF } & Small & \multirow{3}{*}{ AND } & Low & \multirow{3}{*}{ AND } & Low cost & \multirow{3}{*}{ THEN } & Gear \\
\hline 1 & & Middle & & & & & & \\
\hline & & Large & & Middle & & High accuracy & & Belt \\
\hline \multirow{3}{*}{2} & \multirow{3}{*}{ IF } & Small & \multirow{3}{*}{ AND } & Low & \multirow{3}{*}{ AND } & Low cost & \multirow{3}{*}{ THEN } & Gear \\
\hline & & Middle & & & & & & \\
\hline & & Large & & Middle & & High accuracy & & Bèlt \\
\hline \multirow{3}{*}{3} & \multirow{3}{*}{ IF } & Small & \multirow{3}{*}{ AND } & Low & \multirow{3}{*}{ AND } & Low cost & \multirow{3}{*}{ THEN } & Gear \\
\hline & & Middle & & & & & & \\
\hline & & Large & & Middle & & High accuracy & & $\therefore$ Belt \\
\hline \multirow{3}{*}{4} & \multirow{3}{*}{ IF } & Small & \multirow{3}{*}{ AND } & Low & \multirow{3}{*}{ AND } & Low cost & \multirow{3}{*}{ THEN } & Gear \\
\hline & & Middle & & & & & & \\
\hline & & Large & & Middle & & High accuracy & & Beilt \\
\hline \multirow{3}{*}{5} & \multirow{3}{*}{ IF } & Small & \multirow{3}{*}{ AND } & Low & \multirow{3}{*}{ AND } & Low cost & \multirow{3}{*}{ THEN } & Gear \\
\hline & & Middle & & & & & & \\
\hline & & Large & & Middle & & High accuracy & & $\therefore$ Belt \\
\hline \multirow{3}{*}{6} & \multirow{3}{*}{ IF } & Small & \multirow{3}{*}{ AND } & Low & \multirow{3}{*}{ AND } & Low cost & \multirow{3}{*}{ THEN } & Gear \\
\hline & & "Middle & & & & & & \\
\hline & & Large & & Middle & & High accuracy & & Belt \\
\hline \multirow{3}{*}{7} & \multirow{3}{*}{ IF } & Small & \multirow{3}{*}{ AND } & $\therefore \therefore$ Low & \multirow{3}{*}{ AND } & Low cost & & Gear \\
\hline & & Middle & & & & & THEN & \\
\hline & & Large & & Middle & & High accuracy & & Belt \\
\hline
\end{tabular}

The whole process of transmission type selection is shown in Fig. 4.20. The Mamdani method is implemented as the inference engine. The rules are all connected with "AND", and "min" is used as the implication type. The aggregation uses the "max" type. For defuzzification, the centroid method is used.

The final defuzzified value $G B$ becomes "4.19", as shown in Fig. 4.20. And the transmission type is determined with the following selection rule:

IF $G B \geq 5$ THEN transmission is Belt-pulley type

ELSE IF $G B<5$ THEN transmission is Gear type

Therefore, the gear type is chosen for the transmission since $G B$ is equal to 4.19 . 


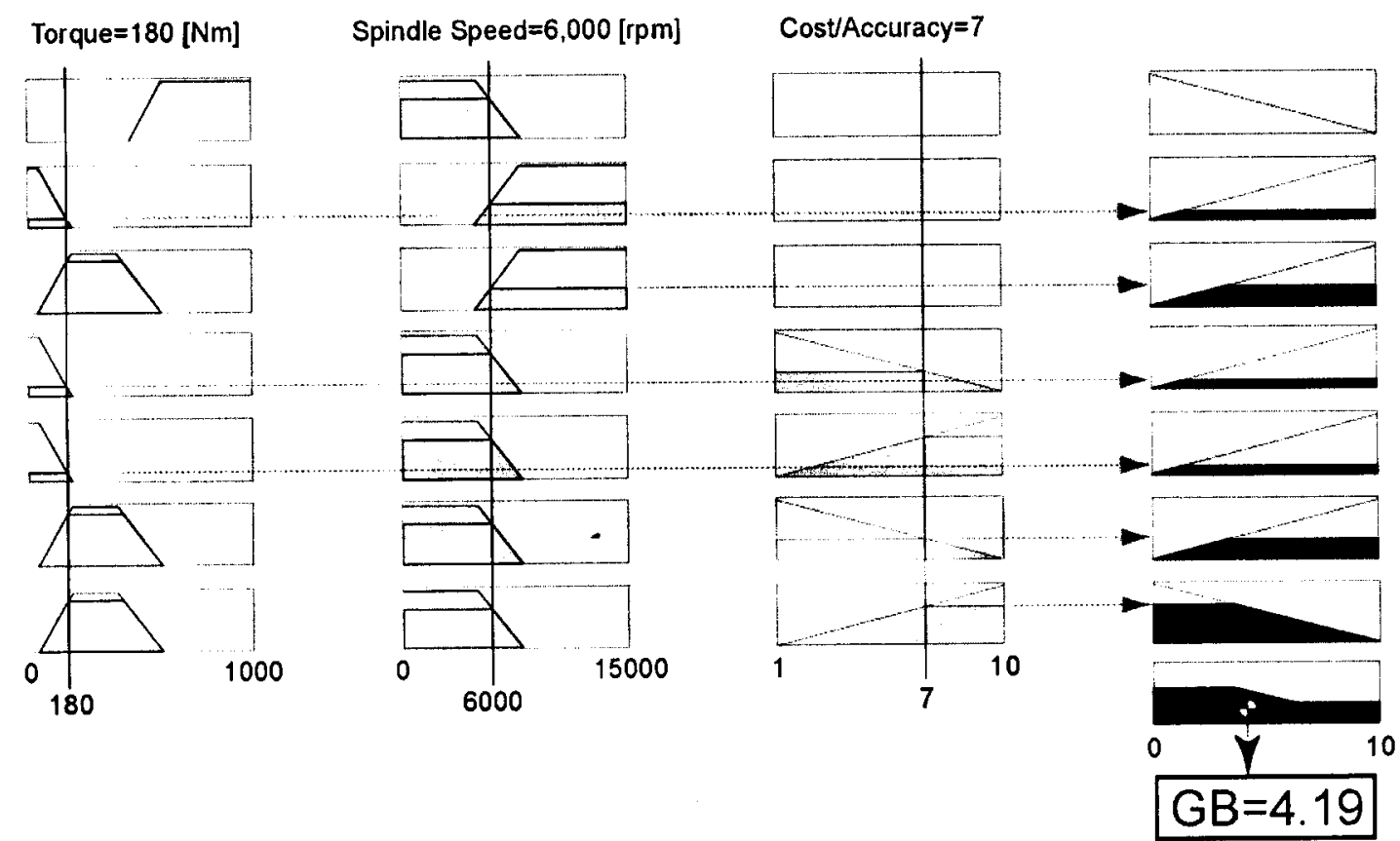

Figure 4.20: Whole Process for Transmission Selection

\section{Step 4-2. Selection Between Direct Coupling Type and Motorized Type}

The transmission between the direct coupling type and the motorized type is achieved by using the following fuzzy sets. Membership functions are shown in Appendix D.

(1) Spindle Speed

At a super high speed range, the direct coupling type is no longer available due to the influence of a misalignment of the spindle and motor shafts. The membership functions are the same, as shown in Fig. 4.17.

(2) High Dynamic Stiffness vs. Low Balancing Vibration

Due to the structure of the motorized spindle, which includes the motor in the spindle unit, the spindle shaft tends to be longer than the other transmission types. 
Hence, the stiffness of the motorized type spindle is dynamically weaker than that of the direct coupling type.

The balance of the spindle in the motorized spindle is advantageous because there is no transmission device; the motor rotates the spindle shaft directly. The direct coupling type is harder to balance than the motorized type because of the difficulty in aligning the spindle and motor shafts with the coupling device.

(3) Low Thermal Effect vs. Small Noise

The motorized spindle generates heat which is conducted to the integrated shaft. The heated spindle shaft grows and causes dimensional errors in the part. While the cooling device is set on the spindle, it cools the motor down from outside of the motor, so the rotor and shaft are not cooled enough to avoid expansion of the shaft. On the other hand, the motor connected to the spindle shaft with a coupling element allows easy installation of a cooling unit between the motor unit and spindle unit. Therefore, the heat generated from the motor can be shut down by the cooling unit. However, the coupling element generates noise in addition to the misalignment problems.

(4) Low Replacement Operation Cost vs. Low Replacement Parts Cost

Since the motorized type is a single unit, the replacement time is much shorter than that of the direct coupling type, which has the separated spindle and motor units. On the other hand, even if only one bearing is broken in the spindle, the whole motorized spindle unit must be replaced. The direct coupling type needs only the replacement of either the spindle unit or the motor unit when one of the bearings is damaged. 
The fuzzy rules shown in Table 4.3 are used for the transmission selection of the direct coupling type or motorized type.

Table 4.3 : Rules for Transmission Selection (Direct Coupling/Motorized)

\begin{tabular}{|c|c|c|c|c|c|c|c|c|c|c|}
\hline ) & & $\begin{array}{l}\text { Spindle } \\
\text { speed }\end{array}$ & & $\begin{array}{l}\text { High D. S."1 } \\
\text { /Balancing }\end{array}$ & & $\begin{array}{l}\text { Low Thermal } \\
\text { /Small Noise }\end{array}$ & & $\begin{array}{l}\text { LROC }^{* 2} \\
\text { /LRPC }^{* 3}\end{array}$ & & $\begin{array}{l}\text { D. coupling } \\
\text { /Motorized }\end{array}$ \\
\hline \multirow{2}{*}{1} & & Low & \multirow{3}{*}{ AND } & Hiah D. S. & \multirow{3}{*}{ AND } & Low thermal & \multirow{3}{*}{ AND } & LROC & \multirow{3}{*}{ THEN } & Dcoupling \\
\hline & IF & Middle & & & & & & & & \\
\hline & & \begin{tabular}{|c|} 
High \\
SuperHigh \\
\end{tabular} & & Balancing & & Small noise & & LRPC & & Motorized \\
\hline \multirow{4}{*}{2} & \multirow{4}{*}{ IF } & \begin{tabular}{|l|} 
Low \\
\end{tabular} & \multirow{4}{*}{ AND } & High D. S. & \multirow{4}{*}{ AND } & Low thermal & \multirow{4}{*}{ AND } & LROC & \multirow{4}{*}{ THEN } & Dcoupling \\
\hline & & Middle & & & & & & & & \\
\hline & & High & & Balancina & & Small noise & & LRPC & & Motorized \\
\hline & & SuperHigh & & Balancing & & Smail nutse & & & & \\
\hline \multirow{3}{*}{3} & \multirow{3}{*}{ IF } & Low & \multirow{4}{*}{ AND } & Hiah D. $\mathrm{S}$. & \multirow{4}{*}{ AND } & Low thermal & \multirow{4}{*}{ AND } & LROC & \multirow{4}{*}{ THEN } & Dcoupling \\
\hline & & Middle & & & & & & & & \\
\hline & & \begin{tabular}{|c|} 
High \\
S
\end{tabular} & & Balancing & & Small noise & & LRPC & & Motorized \\
\hline \multirow{4}{*}{4} & & $\frac{\text { SuperHign }}{\text { Low }}$ & & & & & & & & \\
\hline & \multirow{3}{*}{ IF } & Middle & \multirow{3}{*}{ AND } & High D. S. & \multirow{3}{*}{ AND } & Low thermal & \multirow{3}{*}{ AND } & LROC & \multirow{3}{*}{ THEN } & Dcoupling \\
\hline & & High & & & & & & & & \\
\hline & & SuperHigh & & Balancing & & Small noise & & LRPC & & Motorized \\
\hline \multirow{4}{*}{5} & \multirow{4}{*}{ IF } & Low & \multirow{4}{*}{ AND } & High D. S. & & Low thermal & & LROC & & Dcoupling \\
\hline & & Middle & & . & AND & LUW themainal & AND & 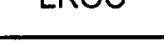 & THEN & \\
\hline & & \begin{tabular}{|l|} 
High \\
\end{tabular} & & Balancing & & Small noise & & LRPC & & Motorized \\
\hline & & SuperHigh & & & & & & & & \\
\hline & & \begin{tabular}{|l|} 
Low \\
\end{tabular} & & Hiah D. S. & & Low thermal & & LROC & & Dcoupling \\
\hline 6 & IIF & Middle & AND & & AND & & AND & & THEN & \\
\hline 0 & II & High & AIND & Balancina & AIV & Small noise & & LRPC & & Motorized \\
\hline & & SuperHigh & & & & & & & & \\
\hline & & Low & & Hiah D $S$. & & Low thermal & & LROC & & Dcoupling \\
\hline 7 & IF & Middle & AND & nignt & AND & LOW Hetmal & AND & & THEN & \\
\hline & IF & High & MIND & Balancina & & Small noise & & LRPC & & Motorized \\
\hline & & SuperHigh & & & & & & & & \\
\hline & & Low & & Hiah D. S. & & Low thermal & & LROC & & Dcoupling \\
\hline 8 & IF & Middle & AND & . & AND & Lurv tientiat & AND & & THEN & \\
\hline 8 & It & High & & Balancina & & Small noise & & LRPC & & Motorized \\
\hline & & SuperHigh & & Balancing & & Smail nulse & & Lente & & \\
\hline & & Low & & High D. S. & & Low thermat & & LROC & & Dcoupling \\
\hline 9 & IF & Middle & AND & & AND & & AND & & THEN & \\
\hline (5) & & $\begin{array}{c}\text { High } \\
\text { SuperHigh }\end{array}$ & AIVD & Balancing & & Small noise & & LRPC & & Motorized \\
\hline
\end{tabular}

*1 High D. S. ... High Dynamic Stiffness

*2 LROC... Low Replacement Operation Cost

*3 LRPC... Low Replacement Parts Cost 
The transmission type is, finally, determined by the following selection rules using $D M$, which is the defuzzified number for direct-coupling/motorized selection using the centroid method, similar to the number $G B$ shown in Fig. 4.20:

IF $D M \geq 5$ THEN transmission type is Motorized type

ELSE IF $D M<5$ THEN transmission type is Direct coupling type

\subsubsection{Lubrication Type Selection}

Figure 4.21 illustrates the lubrication type selection process. The lubrication is grouped under either grease $(G)$ or oil air $(O)$ type.

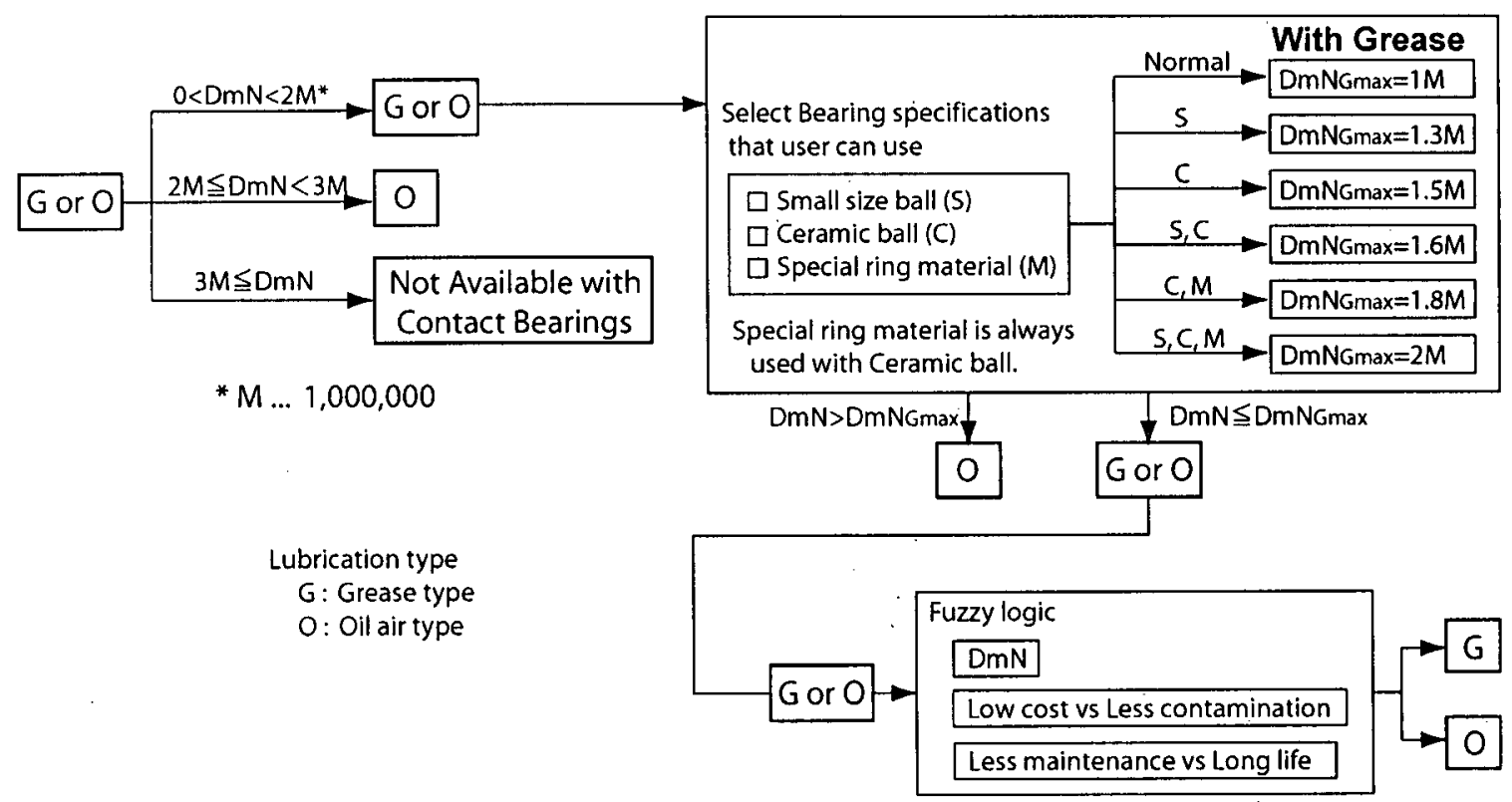

Figure 4.21 : Process of Lubrication Type Selection

The lubrication type needs to be decided based on the bearing type, speed range, and cost. The process of lubrication type selection is examined by the following logic steps:

\section{Step 1. Examine the Availability of Contact Bearings}

The system examines an availability of contact bearings based on the rotational speed range. Generally, if DmN, which expresses the rotation capacity as shown in Eq. (3.3), is no less than 
three million, contact bearings cannot be used. Instead non-contact bearings like air bearings, have to be used. Also, if the $\mathrm{DmN}$ is no less than two million or less than three million, the oil air type must be used because grease lubrication is not effective at high speeds. At up to two million DmN, either grease or oil-air lubrication systems can be selected.

\section{Step 2. Extract Oil Air type}

When the DmN value is under two million, there are still two possibilities; both grease and oil air. Depending on the bearing properties, the necessity for oil air can be reduced. As shown in Section 1.3.4, three main properties for high speed bearings can be described; small ball size, ceramic balls, and special material for bearing rings. Here, $\mathrm{DmN}_{\mathrm{Gmax}}$ is the maximum $\mathrm{DmN}$ value with grease lubrication. As shown in Table 4.4, the maximum DmN capacity of the normal bearings (steel balls, normal ball size, and steel ring) is one million, that is, $\mathrm{DmN}_{\mathrm{Gmax}}$ for the normal bearings is one million. Other $\mathrm{DmN}_{\mathrm{Gmax}}$ values are shown in Table 4.4 [16].

Table 4.4 : Bearing Types and $\mathrm{DmN}_{\mathrm{Gmax}}$ Values

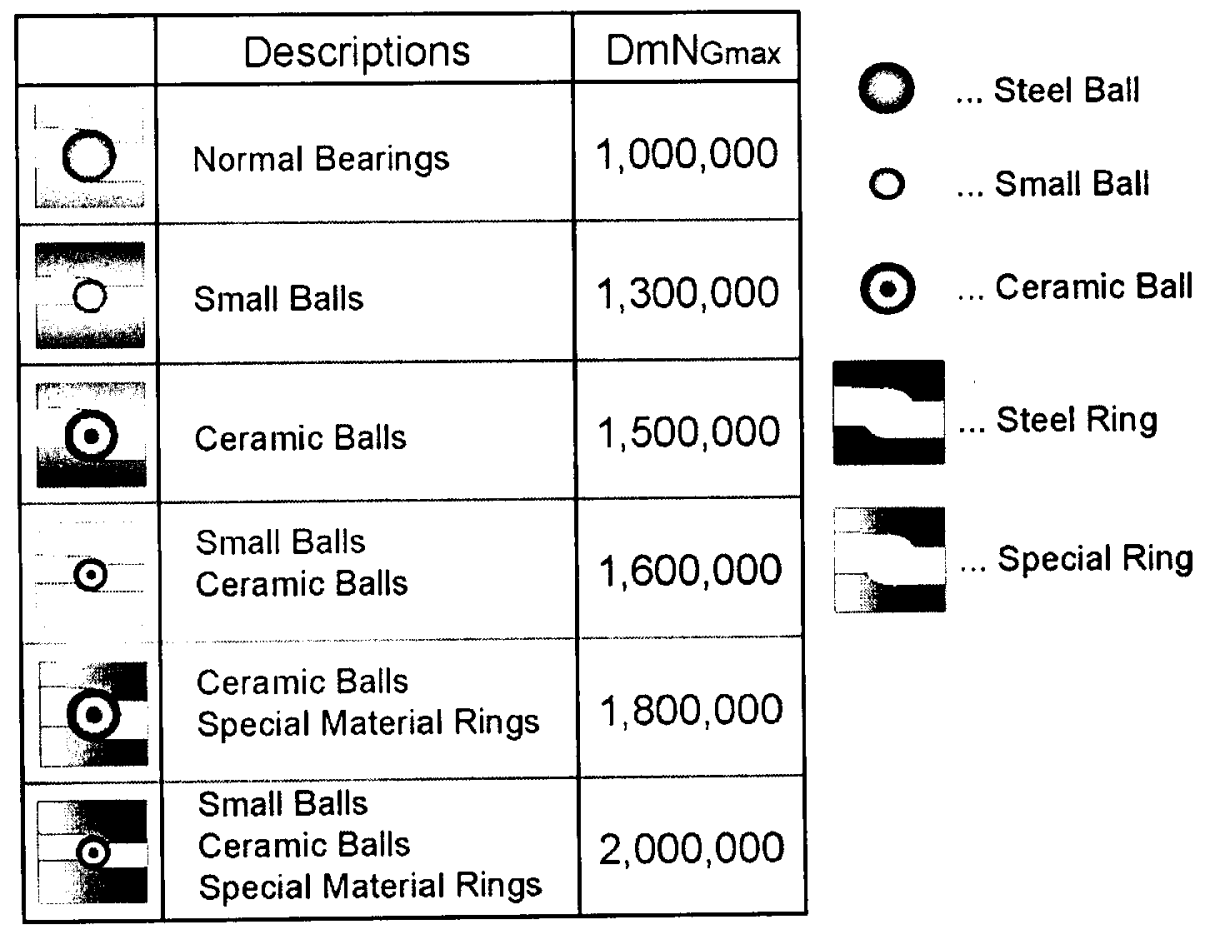


Here special material used for the bearing rings is, for example, Cronidur ${ }^{\circledR} 30$ or an equivalent. Cronidur ${ }^{\circledR} 30$ is only compatible with the ceramic ball bearings.

If the necessary $\mathrm{DmN}$ is greater than $\mathrm{DmN}_{\mathrm{Gmax}}$, the lubrication must be oil air type as the bearings have no rotation capacity with grease lubrication. On the other hand, in the case where the necessary $\mathrm{DmN}$ is greater or equal to $\mathrm{DmN}_{\mathrm{Gmax}}$, the choice of either grease or oil air as lubricator is available. Depending on the concepts of the spindle design, the lubrication type is selected using the following fuzzy logic:

\section{Step 3. Apply Fuzzy Logic}

After reducing the choice of lubrication type to either grease or oil air type, fuzzy logic is used to make the selection. Membership functions are shown in Appendix D.

(1) $\mathrm{DmN}$

The DmN number is a very important value for lubrication selection because lubrication type is dependent, not on spindle speed, but on DmN. Basically, as a lubricator, the oil air type is more suitable for the high speed spindles than the grease type.

(2) Low Cost vs. Less Contamination

With grease lubrication, the spindle structure can be simple. With the oil air lubrication, however, the spindle structure becomes complicated because it needs an air feeding device and an oil/air mixing device. Nevertheless, the air is continuously sprayed onto the bearings from the oil air system, so that contaminations hardly reach the bearings. Therefore the oil air system is more effective in preventing contamination compared to the grease system. 


\section{(3) Less Maintenance vs. Long Life}

Once the grease is set into the bearings, there is nothing else to do for the grease lubrication spindle. The stuffed grease will lubricate the bearings. However, with the oil air type, machine operators have to check the remaining amount of oil every time the machine is used. Also, the air device needs to be maintained.

On the other hand, with the oil air system the life of the bearings tends to be longer than with the grease system. The life of the bearings using grease lubrication is almost dependent on the life of the grease, which is not very long. However, with the oil air system, new oil is always supplied to bearings so that their life is longer.

The fuzzy rules shown in Table 4.5 are then applied. The process is similar to the gear/beltpulley selection shown in Fig. 4.20. 
Table 4.5 : Rules for Lubrication Selection

\begin{tabular}{|c|c|c|c|c|c|c|c|c|}
\hline & & DmN & & $\begin{array}{l}\text { Cost } \\
\text { /Comtamination }\end{array}$ & & $\begin{array}{c}\text { Maintenance } \\
\text { /Life }\end{array}$ & & $\begin{array}{l}\text { Grease } \\
\text { IOil Air }\end{array}$ \\
\hline & \multirow{2}{*}{ IF } & Low & \multirow{2}{*}{ AND } & Low Cost & \multirow{2}{*}{ AND } & Less Maintenance & \multirow{2}{*}{ THEN } & Grease \\
\hline r & & High & & Less Contamination & & Long Life & & Oll Alr \\
\hline \multirow{3}{*}{2} & \multirow{3}{*}{ IF } & Low & \multirow{3}{*}{ AND } & Low Cost & \multirow{3}{*}{ AND } & Less Maintenance & \multirow{3}{*}{ THEN } & Greace \\
\hline & & Middle & & (2) & & 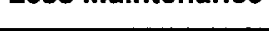 & & or \\
\hline & & High & & Less Contamination & & Long Life & & Oil Air \\
\hline \multirow{2}{*}{3} & \multirow[b]{2}{*}{ IF } & Low & \multirow{2}{*}{ AND } & Low Cost & \multirow{2}{*}{ AND } & Less Maintenance & \multirow{2}{*}{ THEN } & Grease \\
\hline & & High & & Jesc Contamination & & Longlife & & Oil Air \\
\hline \multirow{3}{*}{4} & \multirow{3}{*}{ IF } & Low & \multirow{3}{*}{ AND } & I ouk rost & \multirow{3}{*}{ AND } & I ase Maintananco & \multirow{3}{*}{ THEN } & Grease \\
\hline & & Middle & & Low cost & & Less Malntenance & & Grease \\
\hline & & High & & Less Contamination & & Long Life & & Oil Air \\
\hline \multirow{3}{*}{5} & \multirow{3}{*}{ IF } & Low & \multirow{3}{*}{ AND } & Low Cost & \multirow{3}{*}{ AND } & Less Maintenance & \multirow{3}{*}{ THEN } & Grease \\
\hline & & Middle & & & & & & \\
\hline & & High & & Less Contamination & & Long Life & & Oil Air \\
\hline \multirow{3}{*}{6} & \multirow{3}{*}{ IF } & Low & \multirow{3}{*}{ AND } & Low Cost & \multirow{3}{*}{ AND } & Less Maintenance & \multirow{3}{*}{ THEN } & Grease \\
\hline & & Middle & & & & & & \\
\hline & & High & & Less Contamination & & Long Life & & Oil Air \\
\hline \multirow{3}{*}{7} & \multirow{3}{*}{ IF } & Low & & Low Cost & & Less Maintenance & & Grease \\
\hline & & Middle & AND & & AND & & THEN & \\
\hline & & Hign & & Less Contamination & & Long Life & & Oil Air \\
\hline & & Low & & Low Cost & & Less Maintenance & & Grease \\
\hline 8 & IF & Middle & AND & & AND & & THEN & \\
\hline & & Algn & & Less Contamination & & Long Life & & Oil Air \\
\hline & & Low & & Low Cost & & Less Maintenance & & Grease \\
\hline 9 & IF & Middle & AND & & AND & & THEN & \\
\hline & & High & & Less Contamination & & Long Life & & Oil Air \\
\hline
\end{tabular}

The lubrication type is determined by the following selection rules using $L U B$, which is the defuzzified number for lubrication selection through the centroid method, similar to the number $G B$ shown in Fig. 4.20.

IF $L U B \geq 5$ THEN lubrication type is Oil Air type

ELSE IF $L U B<5$ THEN lubrication type is Grease type 


\subsection{Validation}

The selection of spindle components is illustrated as an example of the proposed expert system. The list of the sample spindles borrowed from commercial CNC machine tools is shown in Table 4.6.

Table 4.6 : Validation List

\begin{tabular}{|c|l|}
\hline Case No. & Spindle Name \\
\hline Case 1 & Mori Seiki SH-403 \\
\hline Case 2 & Starragheckert 260-50-24 \\
\hline Case 3 & Weiss Spindle MAL UBC Version \\
\hline Case 4 & Mitsui Seiki VU65A \\
\hline Case 5 & Matsuura H.Max-500 \\
\hline
\end{tabular}

\section{Case 1 : Mori Seiki Horizontal CNC Machining Center (Model: SH-403)}

\section{Step 1. Set Input Data}

The main spindle specifications of SH-403 are shown in Fig. 4.22 [47]. The spindle has a motorized transmission with an oil-air type lubrication. The spindle has four bearings at the front and one bearing is placed at the rear. The maximum spindle speed is $20,000[\mathrm{rpm}]$ and the power and torque properties of the spindle motor are shown in Fig. 4.22. 


\section{OHl-air lubrication}

- Provents bearing wear and doterioration.

- Reduced frictional loss with minimat lubrication.
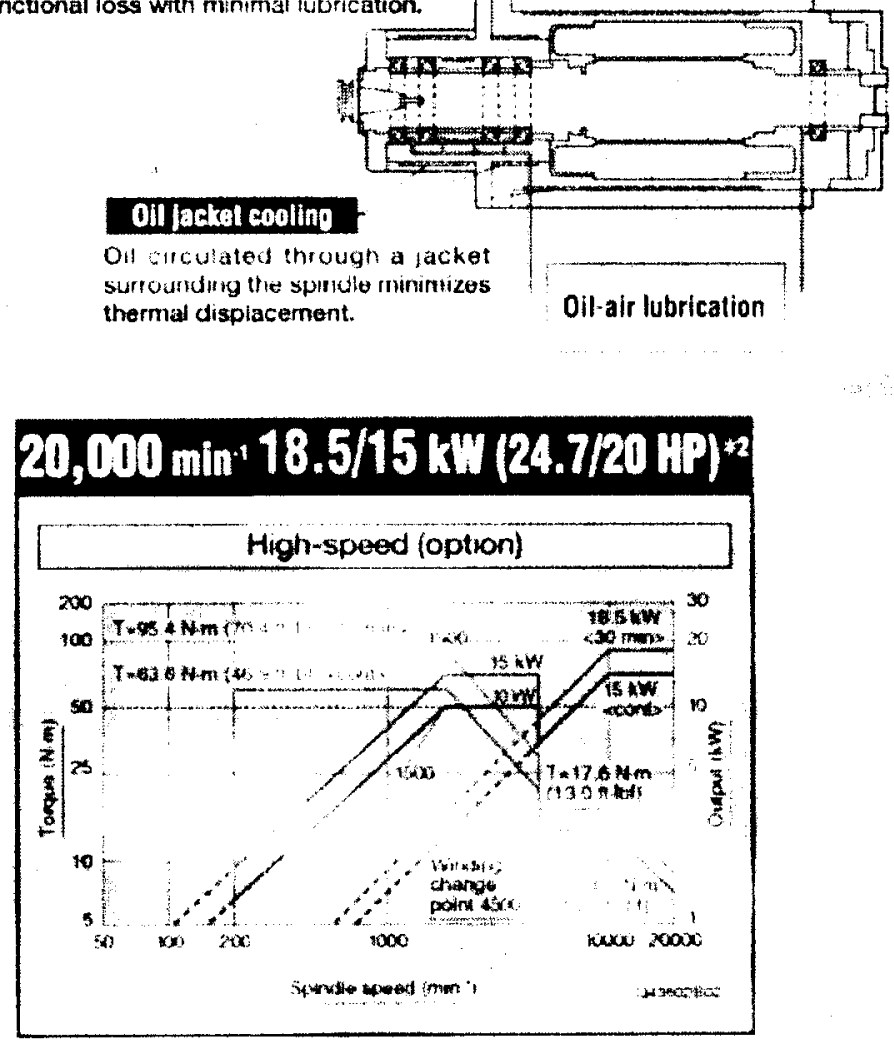

Figure 4.22 : Spindle Specifications of SH-403 [47]

Table 4.7 : Most common cutting conditions for SH-403

\begin{tabular}{|l|c|}
\hline Cutter Diameter & $19.05[\mathrm{~mm}]$ \\
\hline Number of Flutes & 4 \\
\hline Material to Be Cut & AL7075-T6 \\
\hline Cutting Spindle Speed & $15,000[\mathrm{rpm}]$ \\
\hline Depth of Cut & $3[\mathrm{~mm}]$ \\
\hline Width of Cut & $19.05[\mathrm{~mm}]$ (Slotting) \\
\hline Feed Rate & $0.1[\mathrm{~mm} /$ flute] \\
\hline
\end{tabular}


It is assumed that the user wishes to use the machine predominantly in cutting aircraft parts made from Al7075-T6 with a 4 fluted end mill at $3 \mathrm{~mm}$ depth and 15,000 rev/min spindle speed. The most common cutting conditions are listed in Table 4.7.

The cutting conditions and the motor specifications are given as input to the Expert Spindle Design System interface. Sample user interface and inputs are given in Fig. 4.23 to Fig. 4.26

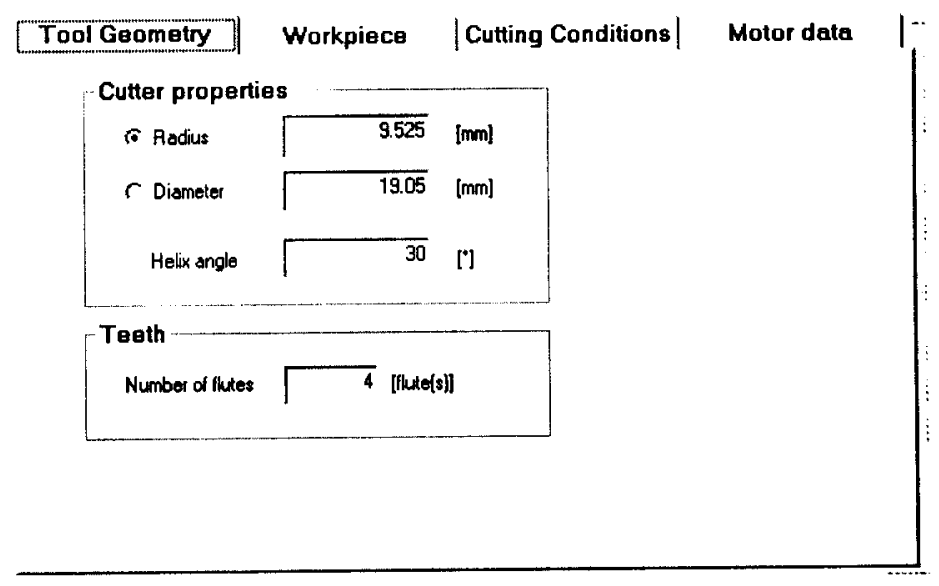

Figure 4.23: Tool Geometry Input Interface

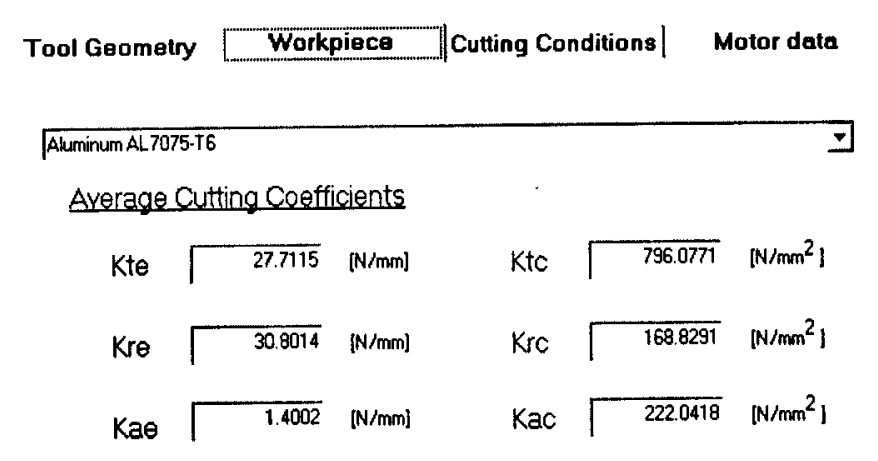

Figure 4.24 : Workpiece Database 


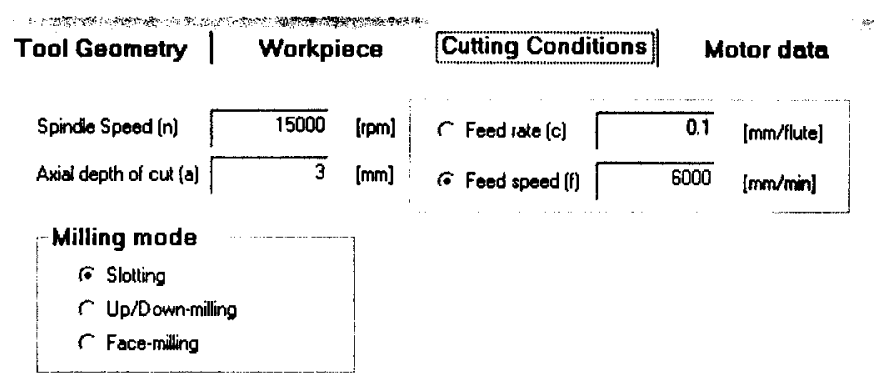

Figure 4.25 : Cutting Conditions Input Interface

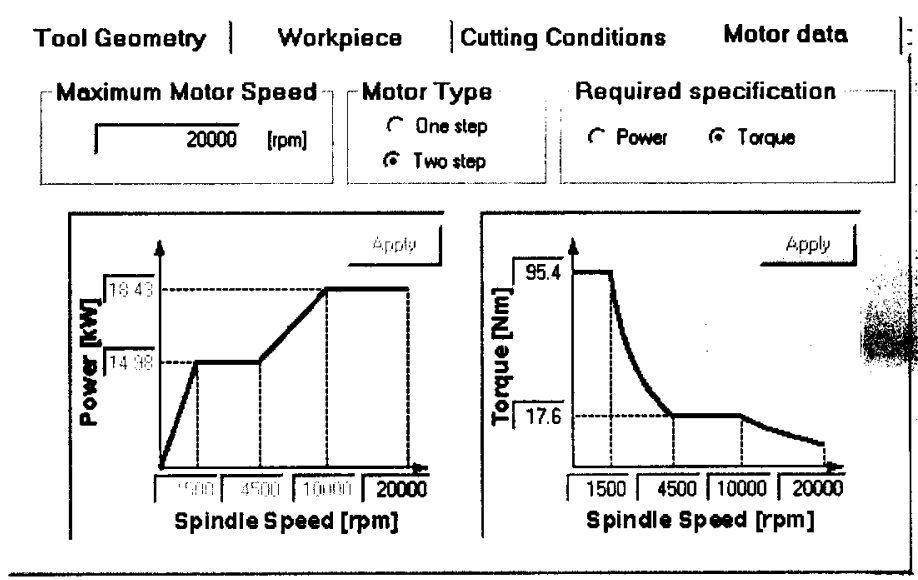

Figure 4.26 : Motor Specification Input Interface

\section{Step 2. Calculate the Required Specifications}

The required specifications, such as the cutting torque and power, are calculated as shown in Fig. 4.27. Part (i), (ii), (iii), and (iv) are $T_{\operatorname{maxc}}, n, T_{m o}$, and $n_{\max }$, respectively. In this case, $T_{\operatorname{maxc}}<T_{m o}$ and $n<n_{\max }$ so that no gear reduction devices are required. Since the motor specifications are more than the required cutting specifications, either the direct coupling type or the motorized type is possible transmission type (Section 4.4.1 Step. 3 (4)). 


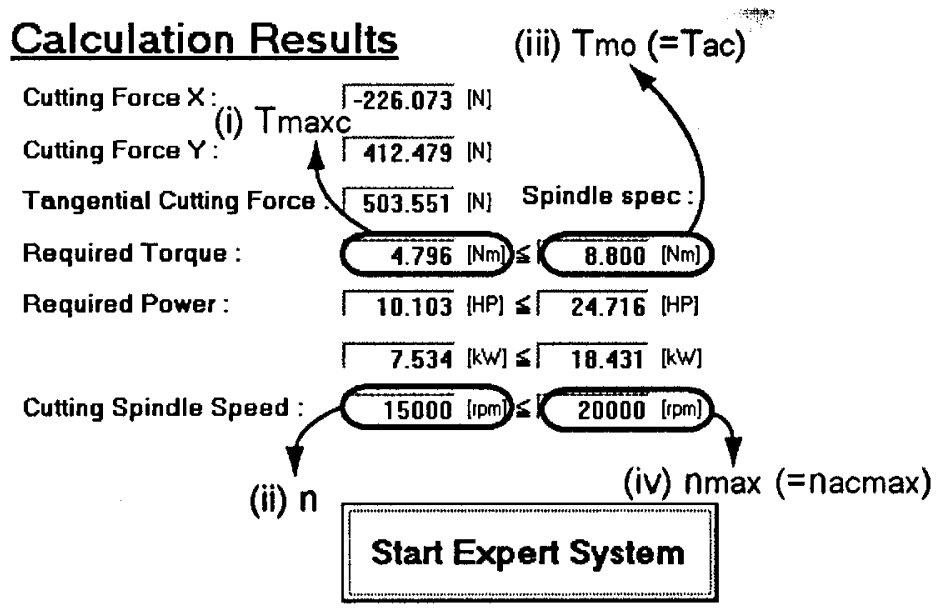

Figure 4.27 : The Specifications for Spindle Design (Available Case)

If the motor specifications are not set properly, the system warns users as shown in Fig. 4.28. The actual spindle torque $T_{a c}$ is not high enough compared to the cutting torque $T_{\operatorname{maxc}}$. The gear size of the spindle side must be larger than that of the motor side, in other words, the gear ratio $\frac{G_{s}}{G_{m o}}$ must be greater than one. At part (ix), the upper and lower bounds of the gear ratio $\frac{G_{s}}{G_{m o}}$ can be computed from the spindle speed and torque. There is, however, no available gear ratio in this case. Part (x) and (xi) show the motor specifications, which are set in Fig. 4.26. Since the gear ratio is set as "1.3", the motor specifications and the spindle specifications are different. The change of the gear size cannot make the actual spindle torque and spindle speed high enough compared to the cutting requirements. Therefore, there is no available spindle because the gear ratio cannot deal with this case (Section 4.4.1 Step 3. (2)). 


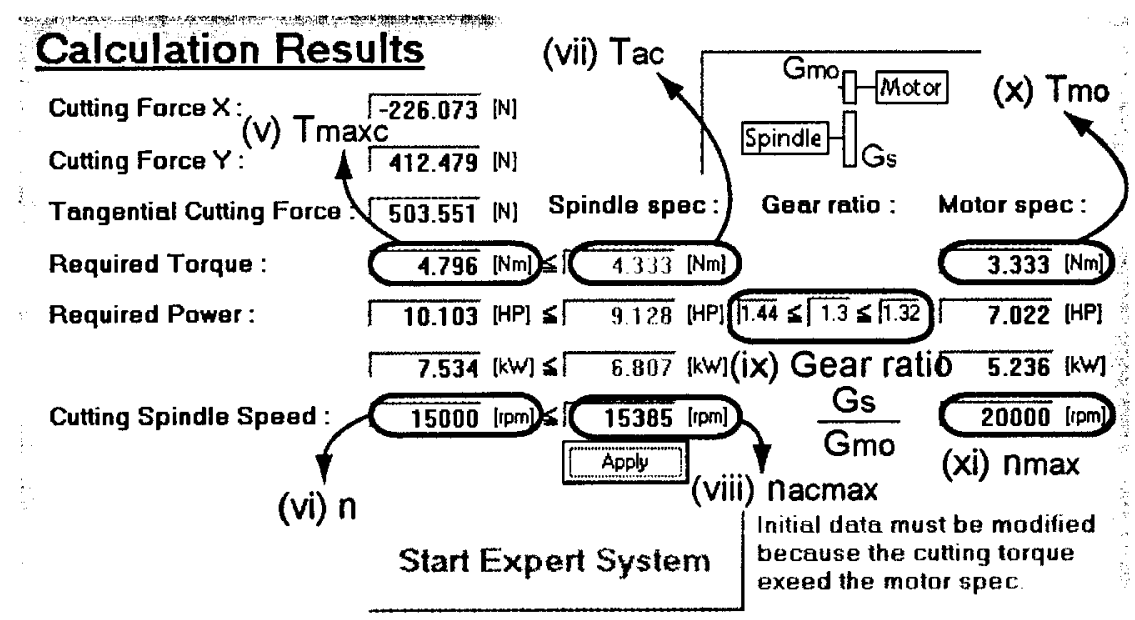

Figure 4.28: The Specifications for Spindle Design (Not Available Case)

The following process is applied to the case described in Fig. 4.27.

\section{Step 3. Transmission Selection}

There are four different transmission types. If the users have already selected a transmission type they can select "Selective" and choose one of the transmission types (Fig. 4.29). If the user is not sure about the transmission type, the "Automatic" option can be selected.

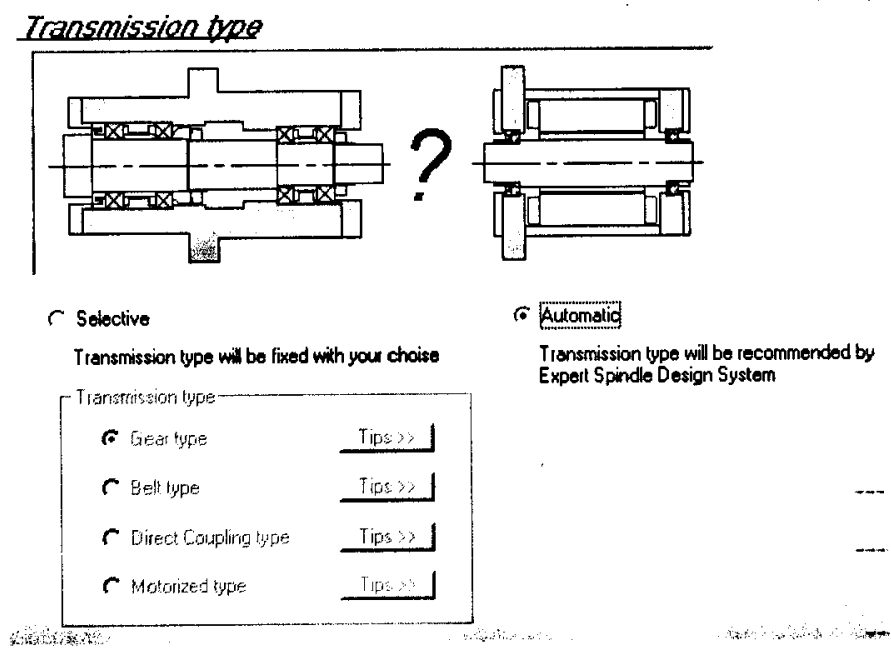

Figure 4.29: Transmission Selection 
In order to select the transmission type from either the direct coupling type or the motorized type, "Spindle Speed", "High Dynamic Stiffness vs. Low Balancing Vibration", "Low Thermal Effect vs. Small Noise", and "Low Replacement Operation Cost vs. Low Replacement Parts Cost" need to be input (see Section 4.4.1 Step. 4-2). The spindle speed is automatically set from the maximum motor speed (Fig. 4.26). The three other factors then have to be entered with the aid of the user interface (Fig. 4.30). In this case, the numbers are assumed from the concepts of the machine written in the SH-403 catalog [47].
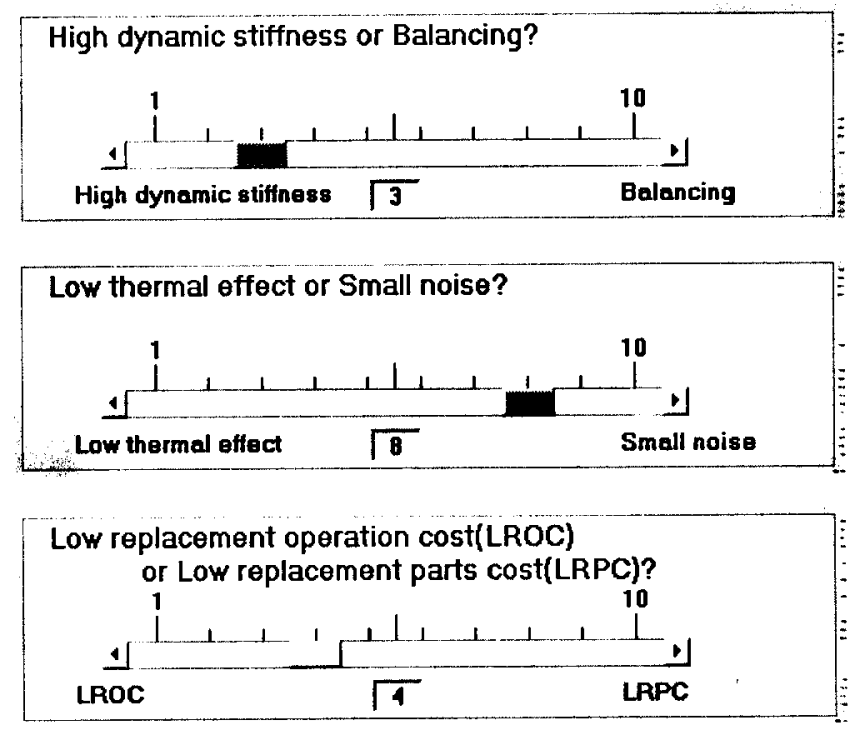

Figure 4.30 : Design Factor Input Interface for Transmission Selection

\section{Step 4. Lubrication Selection}

The lubrication type will be determined after the spindle bearing spans' optimization is completed because the bearing size is one of the most important factors for the lubrication selection, which will be set during the bearing spans' optimization process. 


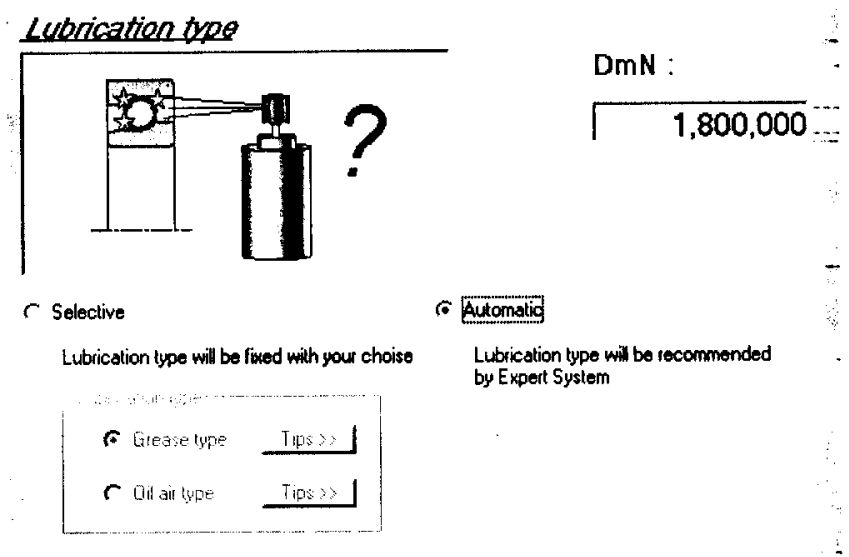

Figure $4.31:$ Lubrication Selection

The bearing specification has to be set by the users (Section 4.4.2 Step. 2). For this spindle, ceramic balls and special material rings are selected as shown in Fig. 4.32. The DmN number is computed using the pitch diameter of the largest bearing times the maximum spindle speed. The pitch diameter of the largest bearing is set as 90 [mm], and the maximum spindle speed is 20,000 [rpm]. So, the DmN number is $1,800,000$ (see Fig. 4.31). The $\mathrm{DmN}_{\mathrm{Gmax}}$ with ceramic balls and special material rings is $1,800,000$ (Table 4.4), so that there are still two possibilities available of either grease or oil air as the lubricator.

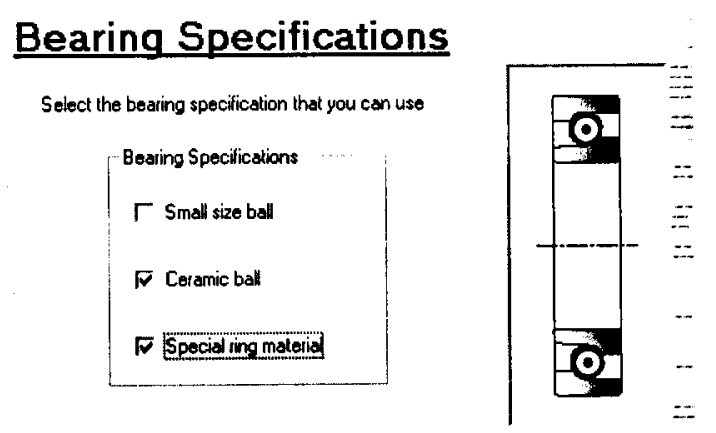

Figure 4.32 : Bearing Specification Set Interface 
For the lubrication selection, the "DmN", "Low Cost vs. Less Contamination", and "Less Maintenance vs. Long Life" data are required, as shown in Section 4.4.2, step 3. The DmN is already calculated from the bearing size and the maximum spindle speed. The factors of "Low Cost vs. Less Contamination" and "Less Maintenance vs. Long Life" are estimated from the machine design concepts of SH-403 [47], as shown in Fig. 4.33.
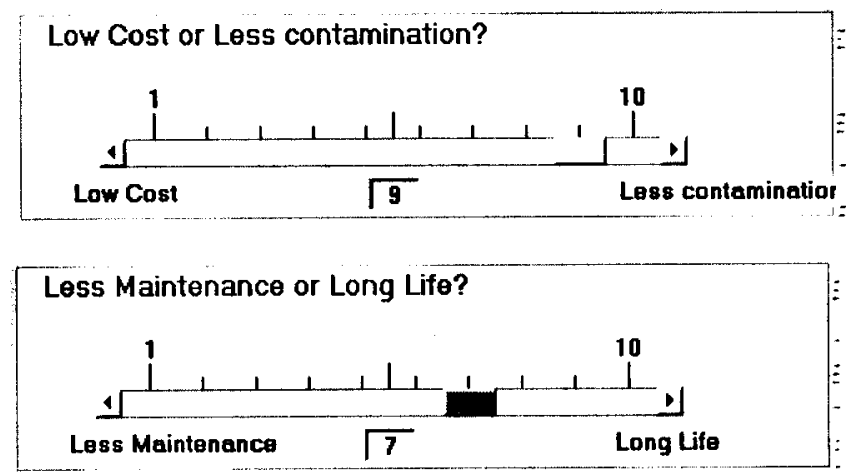

Figure 4.33 : Design Factor Input Interface for Lubrication Selection

\section{Step 5. Result}

Fig. 4.34 shows the component selection result using the expert system. By comparing these to the actual spindle components of Mori Seiki SH-403 (Fig. 4.22), the correct components are chosen. The motorized type is selected as the transmission type, and the oil air system is selected as the lubricant. Although the design concept numbers for Fig. 4.30 and Fig. 4.33 are assumed from the catalog, both results of the transmission type and lubrication type completely match those of the actual spindle. The selection of the HSK as the tool interface is made by users because this expert system has no feature for the tool interface selection. 


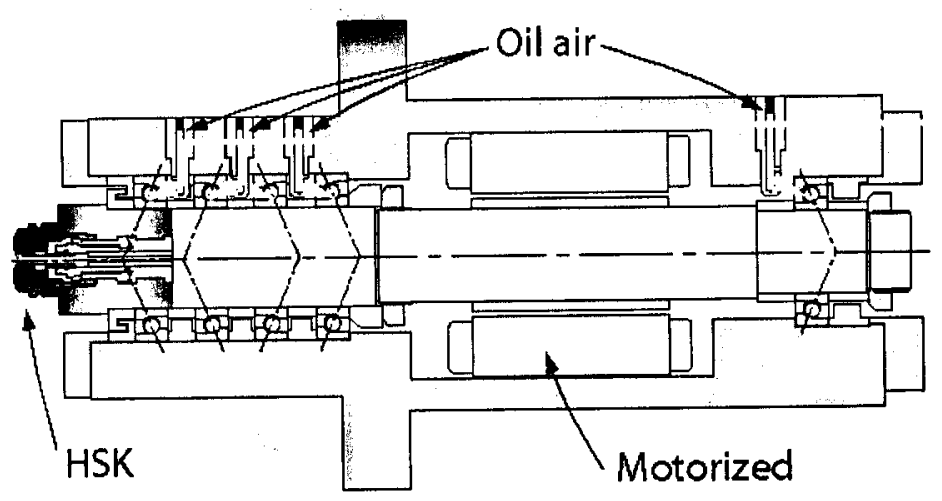

Figure 4.34 : Result from Expert System

\section{Case 2 : Starragheckert 260-50-24}

Using the same process as that used in case 1, the Starragheckert spindle is applied to the expert system. The Starragheckert $260-50-24$ is the spindle built by Starragheckert, Switzerland. Since Starragheckert manufactures a spindle that is not customized and commonly used by the other companies, it can be considered as the universal spindle for any machine. Therefore, reducing replacement operation cost must be a priority. The data and factors are set from the Starragheckert catalog [25]. The components are selected properly, as shown in Fig. 4.35.

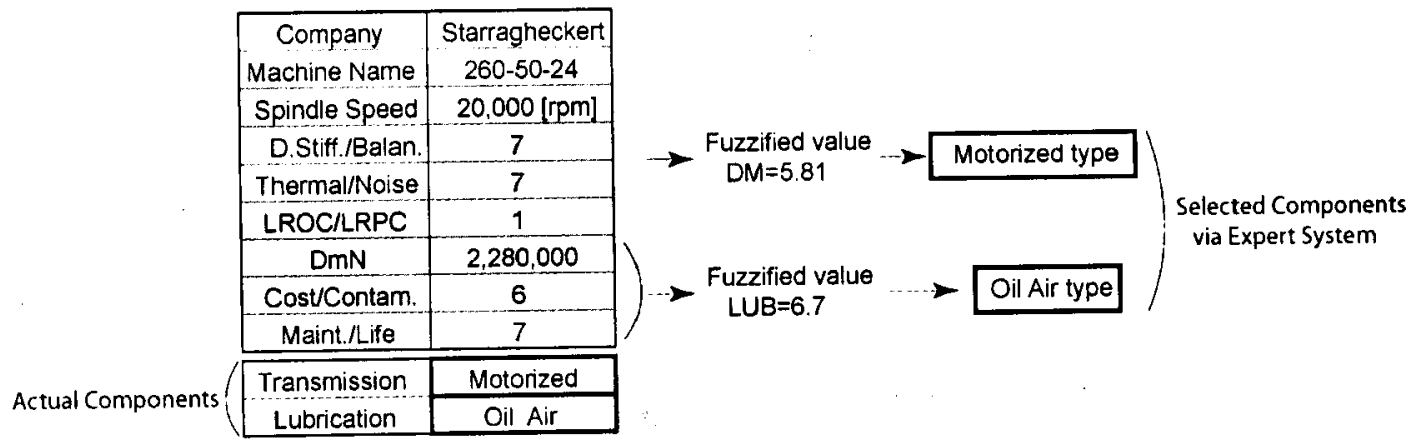

Figure 4.35 : Selection Results for Starragheckert 260-50-24 


\section{Case 3 : Weiss MAL UBC Version}

The Weiss MAL UBC Version is a special spindle which is manufactured for research in MAL, UBC by Weiss Spindle Technology Inc. The expert system achieves the right results, as shown in Fig. 4.36. The design concept of this spindle is to achieve a quite high torque spindle without high expense. In addition, easy maintenance is required rather than a long life because this spindle is used in a laboratory and is therefore not used as frequently as in industry.

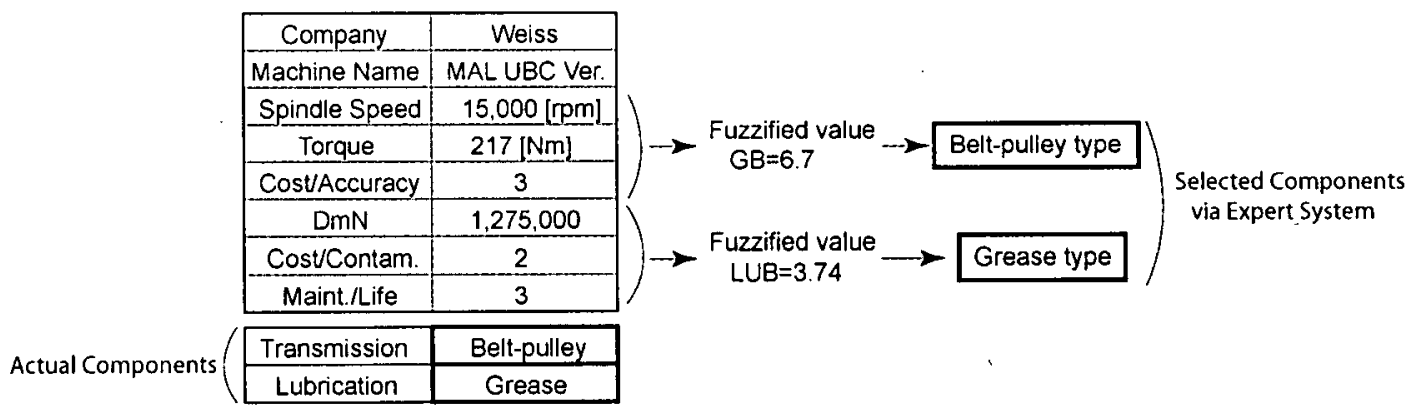

Figure 4.36 : Selection Results for Weiss MAL UBC Version

\section{Case 4 : Mitsui Seiki VU65A}

Mitsui Seiki VU65A 6,000 [rpm] type spindle is for the users who need high precision, high reliability, and high load [61]. Accuracy, less contamination, and low cost are therefore important factors when selecting the transmission and lubrication types for this spindle. Note that the DmN number is computed using the bearing pitch diameter which is assumed from the spindle shaft diameter written in the catalog [61]. 


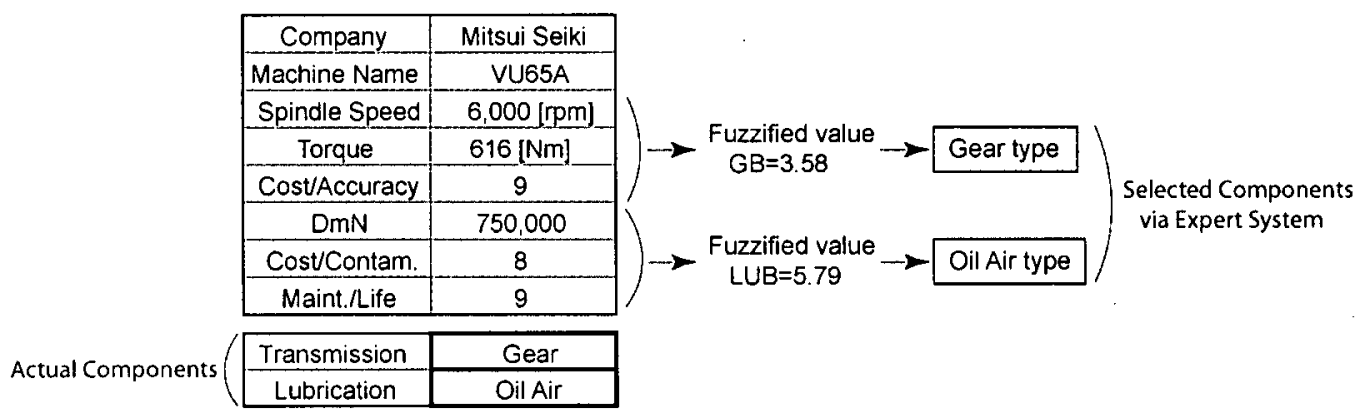

Figure 4.37 : Selection Results for Mitsui Seiki VU65A

\section{Case 5 : Matsuura H.Max-500}

Matsuura H.Max-500 15,000 [rpm] type spindle is manufactured to achieve low maintenance and high rigidity [27], by Matsuura Machinery Co: Note that the $\mathrm{DmN}$ number is computed with the bearing pitch diameter which is assumed from the spindle shaft diameter written in the catalog [27].

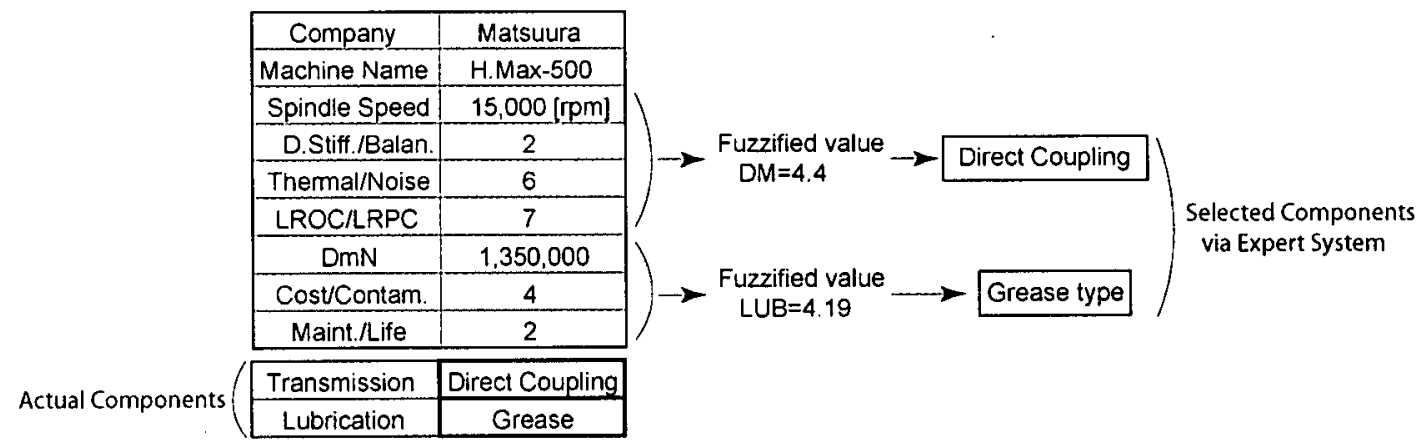

Figure 4.38 : Selection Results for Matsuura H.Max-500

Table 4.8 shows the list of agreements between the actual design and the design that uses this expert system. The results attained via the expert system match those of the actual design in all five cases. Therefore, the proper spindle components can be selected with this expert system, that is, the rule base and the membership functions of this system are defined properly. These results indicate that this expert system for spindle design is validated. 
Table 4.8 : The Results of the Expert System for Spindle Design

\begin{tabular}{|c|c|c|c|c|}
\hline & & & T... Transmissior & L ... Lubrication \\
\hline Case No. & Spindle Name & & Actual Design & Expert System \\
\hline \multirow{2}{*}{ Case 1} & \multirow{2}{*}{ Mori Seiki SH-403 } & $\mathrm{T}$ & Motorized & Motorized \\
\hline & & $\mathrm{L}$ & Oil Air & Oil Air \\
\hline \multirow{2}{*}{ Case 2} & \multirow{2}{*}{ Starragheckert 260-50-24 } & $T$ & Motorized & Motorized \\
\hline & & $\mathrm{L}$ & Oil Air & Oil Air \\
\hline \multirow{2}{*}{ Case 3} & \multirow{2}{*}{ Weiss Spindle MAL UBC Version } & $T$ & Belt-Pulley & Belt-Pulley \\
\hline & & $\mathrm{L}$ & Grease & Grease \\
\hline \multirow{2}{*}{ Case 4} & \multirow{2}{*}{ Mitsui Seiki VU65A } & $\mathrm{T}$ & Gear & Gear \\
\hline & & $\mathrm{L}$ & Oil Air & Oil Air \\
\hline \multirow{2}{*}{ Case 5} & \multirow{2}{*}{ Matsuura H.Max-500 } & $\mathrm{T}$ & D. Coupling & D.Coupling \\
\hline & & $\mathrm{L}$ & Grease & Grease \\
\hline
\end{tabular}




\section{Chapter 5}

\section{Bearing Spans' Optimization}

\subsection{Introduction}

After selecting on the components of the spindle, designers concentrate on the design details such as the dimensions and positions of the parts. Recently, finite element (FE) analysis techniques have become popular, which allow designers to predict part properties, such as static and dynamic stiffness. For example, the designers can analyze the static stiffness of a part many times by changing the part dimensions until a satisfactory design dimensions are achieved. However, the designers can never know if the design is an optimum or not. The need to optimize part dimensions and locations has increased, and some commercial optimization software is in fact available.

In order to apply the optimization to the spindle design, an objective and design variables must first be identified. As shown in Section 3.1, the chatter vibration is an important issue for machine tool operators, as it may cause the spindle to break, resulting in expensive repairs. Therefore, designing a chatter free spindle is the main objective selected in this research.

In a spindle design, there are many design parameters, such as the dimensions of the spindle shaft, housing, and collars. However, it is not realistic to optimize all of these dimensions because the process is time consuming and there is no guarantee that the results will converge due to too many variables. Therefore, in practice, there should not be too many design variables, and most efficient design parameters need to be selected to optimize the objectives. There are numerous constraints on the geometric design of spindle parts, and design dimensions are usually coupled with each other; if the diameter of the spindle shaft changes, the bore diameter of the housing also has to be changed. In this case more parameters need to be taken into account, and the iterative optimization result may not be accomplished with a convergence. The dimensions that are inde- 
pendent from other parts and affect the dynamic properties of the spindle for a chatter free spindle are bearing positions. A detailed explanation of why the bearing spans are important in regard to the chatter property of the spindle will be detailed later. Before describing optimization, the concept of the chatter free spindle, which is the objective of the bearing spans' optimization, will be shown in the next section.

\subsection{Chatter Free Spindle}

As shown in Section 2.4, one of the factors of chatter stability is the dynamic property at the tool tip, which includes the structural properties of the cutting tool, tool holder, spindle, and the components of the machine tool which are connected to the spindle. The intention of this research topic, Expert Spindle Design System, is to automate the spindle design against certain cutting conditions. The cutting conditions include the tool geometry and workpiece material so that the dynamic properties of the cutting tool and the tool holder themselves are invariable. The only variable factors are the dynamic properties of the spindle, especially, the bearing locations, which will be optimized, as shown in Section 5.1.

In order to avoid chatter vibrations, the cutting condition must lie under the stability lobes as shown in Figure 5.1 where stable (a) and unstable (b) cutting points are marked. With a fixed cutting condition, the dynamic property at the tool tip of the spindle system affects the cutting stability only. In other words, if the designers are able to tune the structural dynamics of the spindle system, the chatter vibrations can be prevented at the desired operating conditions.

The parameters that change the dynamic properties of the spindle are the spindle diameter, spindle shaft length, bearing stiffness, mass on the spindle, and bearing position. If the spindle diameter is changed, the bearing size must also be changed. This causes a change in bearing stiffness so that the bearing properties also have to be taken into account. The spindle shaft length must be as short as possible since a longer shaft causes low dynamic stiffness. The bearing stiffness can be manipulated by changing the preload, but if the preload is too large, the bearings seize 
up. The criterion for the maximum preload is dependent on many factors, such as the cooling type, lubrication system, and bearing geometry. Therefore, the bearing stiffness is not suitable as a design parameter in optimizing the dynamic properties of the spindle. However, the bearing positions are not coupled with other design factors and are critical factors for spindle dynamic properties, although many constraints may still exist.

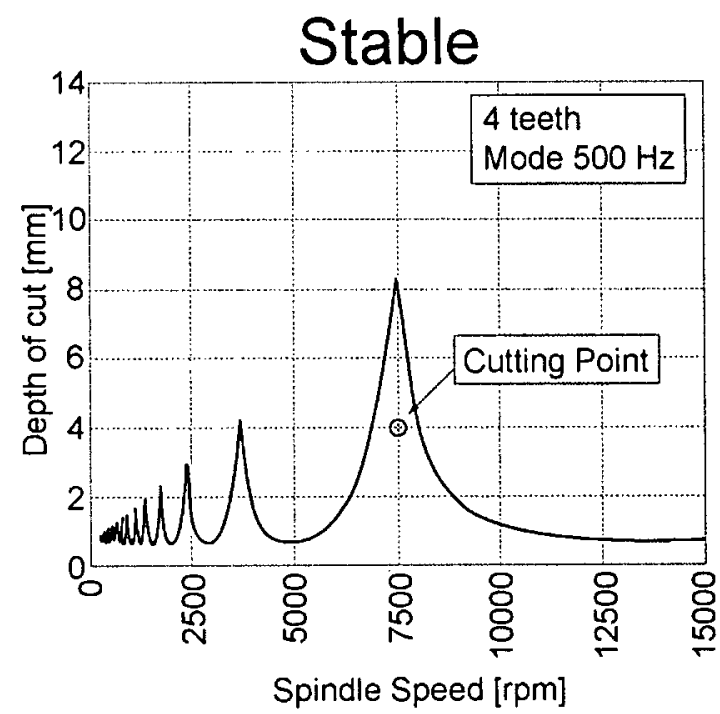

(a)

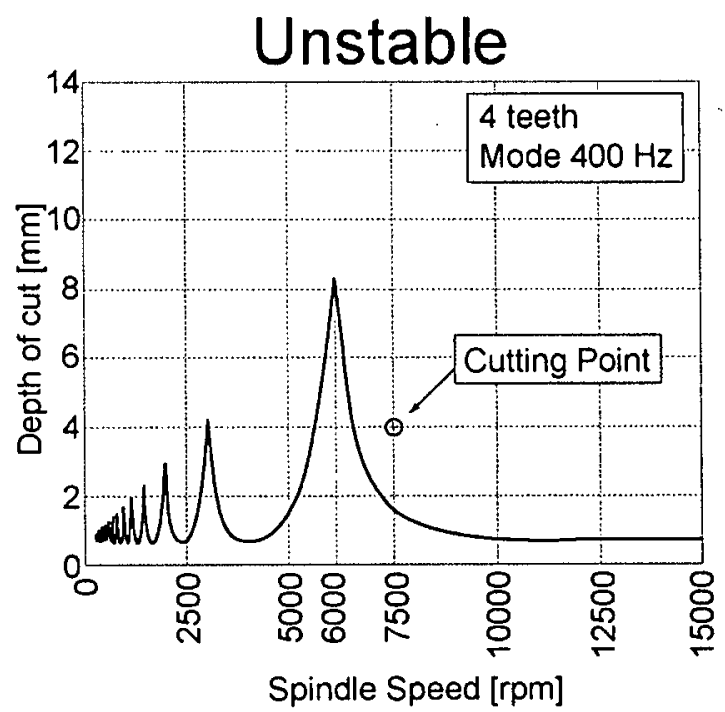

(b)

Figure 5.1 : Stable and Unstable Conditions (a) Stable Cutting, (b) Unstable Cutting

Figure 5.2 shows the simplified spindle model for bearing spans' optimization. From the design principle, the front end bearing must be as close as possible to the spindle nose in order to increase the static stiffness of the spindle at the tool tip. While it is the most critical bearing in terms of the dynamic stiffness of the spindle, changing the position of the front end bearing is practically now viable. The rear bearings must be smaller than the front bearings so that the spindle shaft diameter must have a step between the front bearings and the rear bearings, as shown in Fig. 5.2. The position of this step is also an important factor for spindle dynamics, therefore it is included in the optimization. 


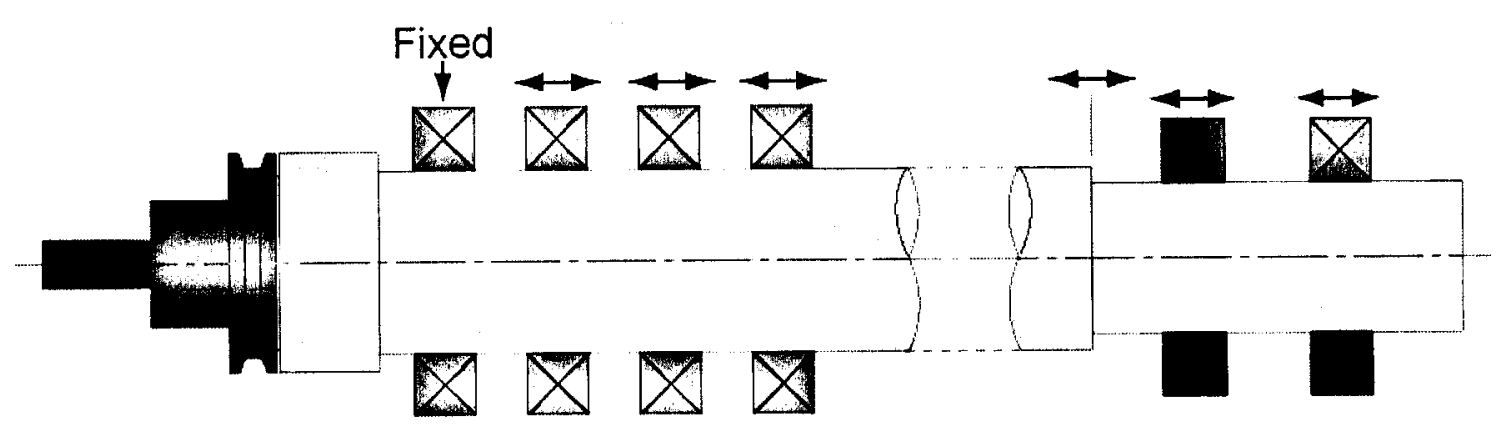

Figure 5.2 : Variable Parameters

In order to understand the dynamic properties regarding chatter stability, a frequency response function at the tool tip must be obtained. Generally, the frequency response function at the tool tip can be measured by picking up the vibrations at the tool tip with the excitation force generated by a hammer, as shown in Section 2.4. However, designs have to be completed without access to actual machines, therefore the frequency response function must be predicted theoretically. A finite element method (FEM), which is frequently used for structural analysis, is used to calculate the dynamic properties of the spindle.

\subsection{Finite Element Analysis for Bearing Spans' Optimization}

\subsubsection{Beam Elements}

There are several element types used for FE analysis; solid, plane, and beam elements. For the spindle analysis for the bearing spans' optimization, beam elements are the most suitable, because the shapes of the spindle and the cutting tool are roughly cylindrical. Besides, a time consuming iteration method will be used for the optimization, so the calculation time for the dynamic properties in each iteration step must be as short as possible. In order to shorten the calculation time, the simplest elements (the beam elements) are the most suitable type. 
There are several types of beam element. Regarding the chatter vibrations in milling, the dynamics in the radial direction are the most important so that axial terms and torsional terms are negligible.

\section{(1) Euler-Bernoulli Beam}

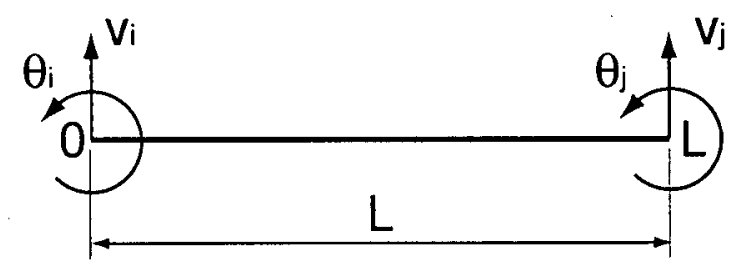

Figure 5.3 : Degree of Freedom of Euiler-Bernoulli Beam Element

The Euler-Bernoulli beam only takes bending effects into account. It can be described by the following equation;

$$
E I \frac{\partial^{4} v}{\partial x^{4}}+\rho A \frac{\partial^{2} v}{\partial t^{2}}=0
$$

where, $E$ is the modulus of elasticity of the spindle shaft, $I$ is the moment of inertia, $\rho$ is the density of the spindle shaft material, $A$ is the section area of the spindle shaft, and $v$ is the deflection in y direction. The manipulation of this equation using FEM is shown in Appendix E.1. $E I \frac{\partial^{4} v}{\partial x^{4}}$ term comes from the bending effects, and $\rho A \frac{\partial^{2} v}{\partial t^{2}}$ term comes from the inertia force applied to the small segment of the spindle shaft.

\section{(2) Euler-Bernoulli Beam + Rotary Inertia Effects}

In addition to the Euler-Bernoulli beam, the rotary inertia effects are taken into account, and the equation becomes;

$$
E I \frac{\partial^{4} v}{\partial x^{4}}+\rho A \frac{\partial^{2} v}{\partial t^{2}}-\rho I \frac{\partial^{4} v}{\partial x^{2} \partial t^{2}}=0
$$


where, $\rho I \frac{\partial^{4} v}{\partial x^{2} \partial t^{2}}$ term expresses the rotary inertia effects. The details of the calculation process are shown in Appendix E.2.

\section{(3) Timoshenko Beam}

The Timoshenko beam element includes the bending, rotary inertia, and shear effects. The equation is formulated as follows;

$$
E I \frac{\partial^{4} v}{\partial x^{4}}+\rho A \frac{\partial^{2} v}{\partial t^{2}}-\rho I \frac{\partial^{4} v}{\partial x^{2} \partial t^{2}}-\frac{E I \rho}{k_{c} G} \frac{\partial^{4} v}{\partial x^{2} \partial t^{2}}-\frac{I \rho^{2}}{k_{c} G} \frac{\partial^{4} v}{\partial x^{4}}=0
$$

where, $k_{c}$ is the cross section factor which depends on the shape of the cross section. In this case, the shape of the cross section is circular; therefore $k_{c}$ can be defined as $9 / 10[48,56]$. Since the rotary effects and shear effects are coupled with each other, two more terms are added to Eq. (5.2). The detailed calculation process is shown in Appendix E.3. The Timoshenko beam element is used in this research because of the reason mentioned in Section 5.3.3.

\subsubsection{Frequency Response Function}

The equations from (5.1) to (5.3) can be transformed into the following equation;

$$
[M]\{\ddot{y}\}+[C]\{\dot{y}\}+[K]\{y\}=\{F(x)\}
$$

where $[M]$ is the mass matrix, $[C]$ is the damping matrix, and $[K]$ is the stiffness matrix. $\{\ddot{y}\}$, $\{\dot{y}\}$, and $\{y\}$ are the acceleration, velocity and displacement of each node, respectively. In order to obtain the undamped natural frequencies and mode shapes, the damping term can be neglected and Eq. (5.4) is considered as free vibration;

$$
[M]\{\ddot{y}\}+[K]\{y\}=0
$$

The natural frequencies $\omega_{n}$ can be obtained solving the following eigenvalue;

$$
\left.[K]-\omega_{n, k}{ }^{2}[M]\right\}\{P\}_{k}=0 \rightarrow \operatorname{det}\left|[K]-\omega_{n, k}{ }^{2}[M]\right|=0
$$


where, $k$ is the number of the modes. Substituting $\omega_{n, k}$ into Eq (5.6), the eigenvectors $\{P\}_{k}$, which are also called the mode shapes, can be computed. The eigenvectors can be expressed by the matrix form as follows [2]:

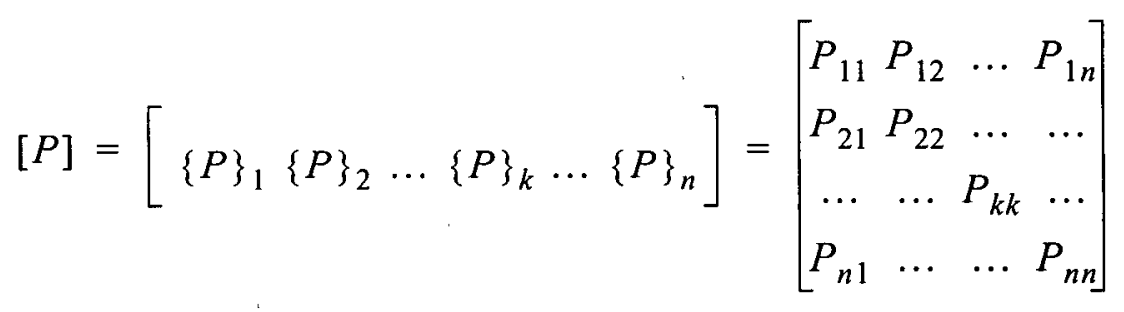

Using the generalized coordinates $\{q\}$,

$$
\{y\}=[P]\{q\} \rightarrow\{q\}=[P]^{-1}\{y\}
$$

the coupled equation Eq. (5.4) is generalized to calculate the frequency response function as follows;

$$
\left[M_{q}\right]\{\ddot{q}\}+\left[C_{q}\right]\{\dot{q}\}+\left[K_{q}\right]\{q\}=\{R\}
$$

where $\left[M_{q}\right]$ is the generalized mass matrix, $\left[C_{q}\right]$ is the generalized damping matrix, and $\left[K_{q}\right]$ is the generalized stiffness matrix. Note that when the system has a proportional damping, the transformed damping matrix is also a diagonal matrix;

$$
\begin{aligned}
{\left[M_{q}\right]=[P]^{T}[M][P] } & =\left[\begin{array}{cccc}
M_{q, 1} & 0 & 0 & 0 \\
0 & M_{q, 2} & 0 & 0 \\
0 & 0 & \ldots & 0 \\
0 & 0 & 0 & M_{q, n}
\end{array}\right] \\
{\left[C_{q}\right] } & =[P]^{T}[C][P] \\
{\left[K_{q}\right] } & =[P]^{T}[K][P] \\
\{R\} & =[P]^{T}\{F(t)\}
\end{aligned}
$$

Now, Eq. (5.9) is a decoupled equation, and it can be expressed as the following equations. 


$$
\begin{gathered}
m_{q 1} \ddot{q}_{1}+c_{q 1} \dot{q}_{1}+k_{q 1} q_{1}=R_{1} \\
m_{q 2} \ddot{q}_{2}+c_{q 2} \dot{q}_{2}+k_{q 2} q_{2}=R_{2} \\
\cdots \\
m_{q, k} \ddot{q}_{k}+c_{q, k} \dot{q}_{k}+k_{q, k} q_{k}=R_{k}
\end{gathered}
$$

Eq. (5.14) can be normalized as the following form:

$$
\ddot{q}_{k}+2 \xi_{k} \omega_{n, k} \dot{q}_{k}+\omega_{n, k}^{2} q_{k}=\frac{R_{k}}{m_{q, k}}
$$

Eq. (5.15) can be expressed in the Laplace domain as follows:

$$
\left(s^{2}+2 \xi_{k} \omega_{n, k} s+\omega_{n, k}^{2}\right)\{Q(s)\}=\frac{1}{m_{q, k}}\{R(s)\}
$$

The transfer function of the Eq. (5.16) is;

$$
\left[\Phi_{q}(s)\right]=\frac{\{Q(s)\}}{\{R(s)\}}=\sum_{k=1}^{n} \frac{1}{m_{q, k}} \cdot \frac{1}{s^{2}+2 \xi_{k} \omega_{n, k} s+\omega_{n, k}^{2}}
$$

where, $\xi_{k}$ is the modal damping that is defined from the experiments or users' experiences.

Eq. (5.4) can also be expressed in the Laplace domain as follows:

$$
\left([M] s^{2}+[C] s+[K]\right)\{Y(s)\}=\{F(s)\}
$$

The transfer function of Eq. (5.18) is:

$$
[H(s)]=\frac{\{Y(s)\}}{\{F(s)\}}
$$

Eq. (5.8) and (5.13) can be expressed with the Laplace operator as follows:

$$
\{Y(s)\}=[P]\{Q(s)\} \text { and }\{R(s)\}=[P]^{T}\{F(s)\}
$$

Substituting Eq. (5.20) into Eq. (5.19): 


$$
[H(s)]=[P]\left[\Phi_{q}\right][P]^{T}=\sum_{k=1}^{n} \frac{\{P\}_{k}\{P\}_{k}^{T}}{m_{q, k}} \cdot \frac{1}{s^{2}+2 \xi_{k} \omega_{n, k} s+\omega_{n, k}^{2}}
$$

In case of $s=j \omega$, Eq. (5.21) becomes the frequency response function:

$$
[H(j \omega)]=\sum_{k=1}^{n} \frac{\{P\}_{k}\{P\}_{k}^{T}}{m_{q, k}} \cdot \frac{1}{\omega_{n, k}^{2}-\omega^{2}+2 j \xi_{k} \omega_{n, k} \omega}=\left[\begin{array}{cccc}
h_{11} & h_{12} & \ldots & h_{1 n} \\
h_{21} & h_{22} & \ldots & \ldots \\
\ldots & \ldots & h_{k k} & \ldots \\
h_{n 1} & \ldots & \ldots & h_{n n}
\end{array}\right]
$$

The direct frequency response function at position 1 can be expressed as follows:

$$
h_{11}=\frac{P_{11} P_{11}}{m_{q, 1}} \cdot \frac{1}{\omega_{n, 1}^{2}-\omega^{2}+2 j \xi_{1} \omega_{n, 1} \omega}+\ldots+\frac{P_{1 n} P_{n 1}}{m_{q, n}} \cdot \frac{1}{\omega_{n, n}^{2}-\omega^{2}+2 j \xi_{n} \omega_{n, n} \omega}
$$




\subsubsection{Suitable Beam Element for Spindle Analysis}

In order to identify the most suitable beam element type for the spindle analysis, the mode shapes and frequency response functions of a simple steel pipe are measured and compared with the analysis results of three different beam elements.

Figure 5.4 shows the experiment setup. An accelerometer is attached at position 1, and excitation forces are applied from position 1 to 8 . The mode shapes and the direct frequency response functions at position 1 are compared.

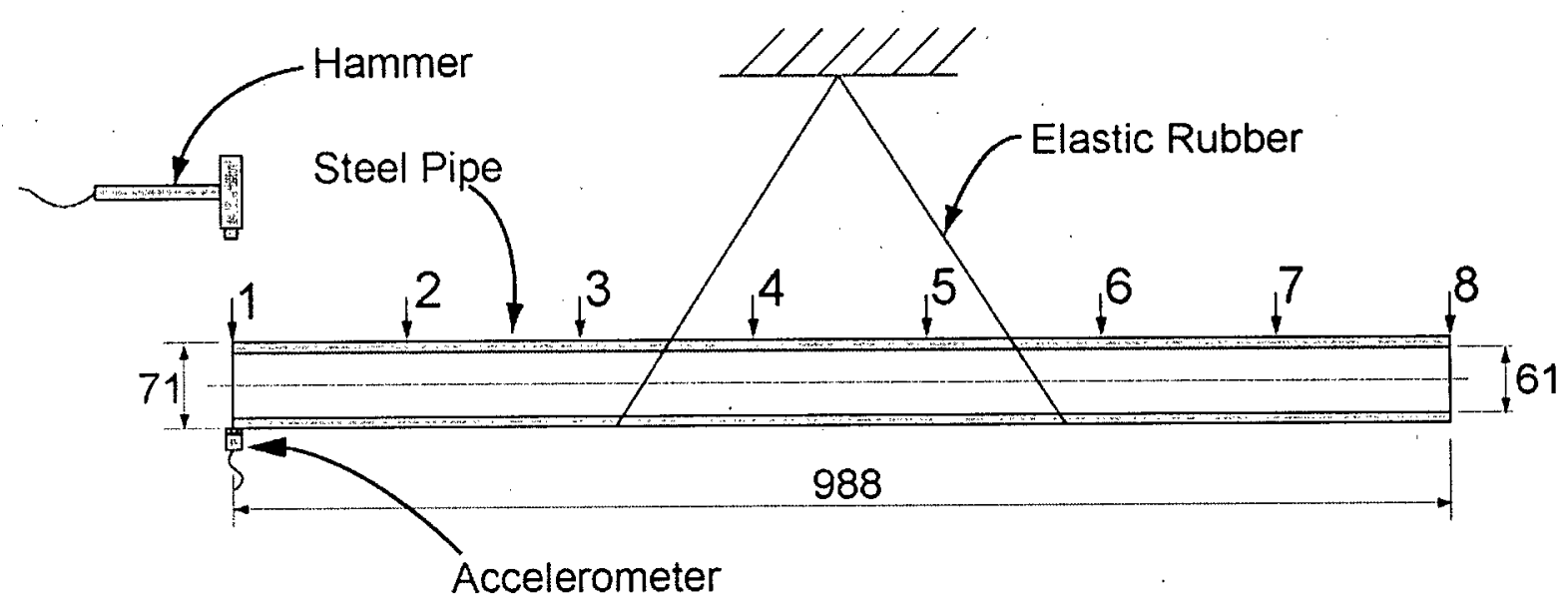

Figure 5.4 : Simple Pipe Test

Having implementing each FE model to this pipe model, the results can be compared regarding the mode shapes and the direct frequency response function (FRF) at position 1. As shown in Fig.5.5, the first to third mode shapes are very similar among all the results, both experimental and predicted results, although the natural frequencies are different. 


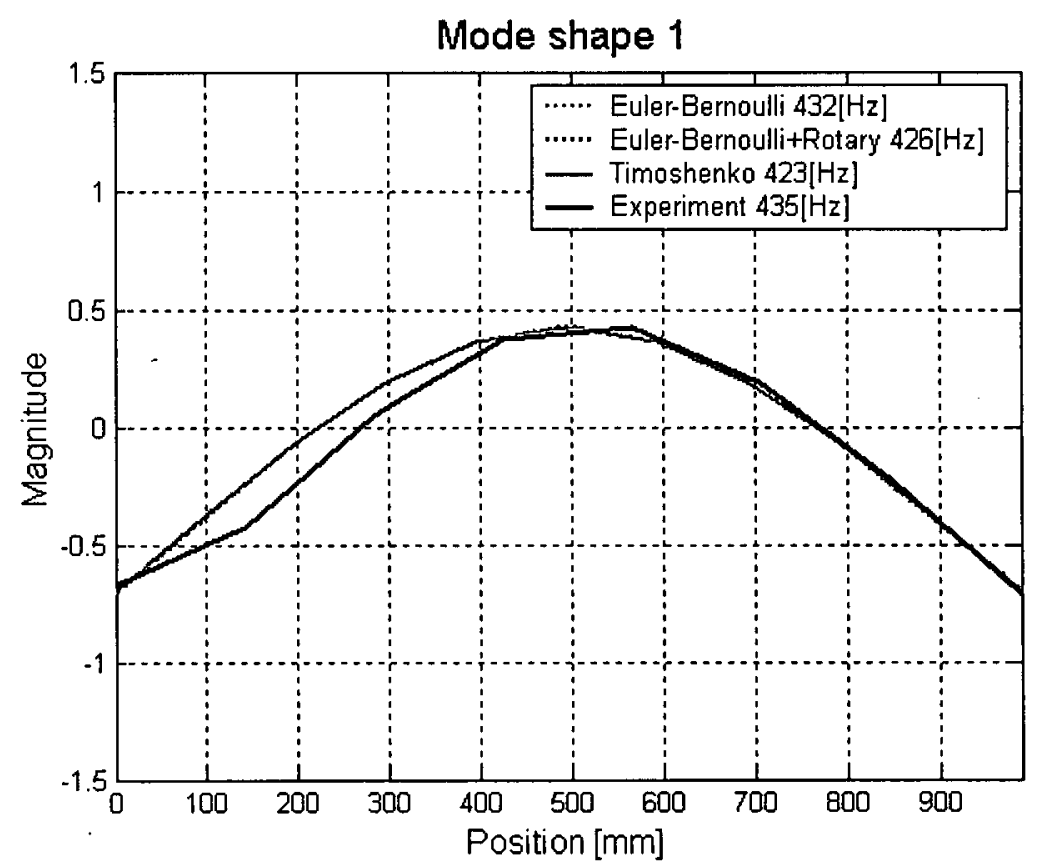

(a)

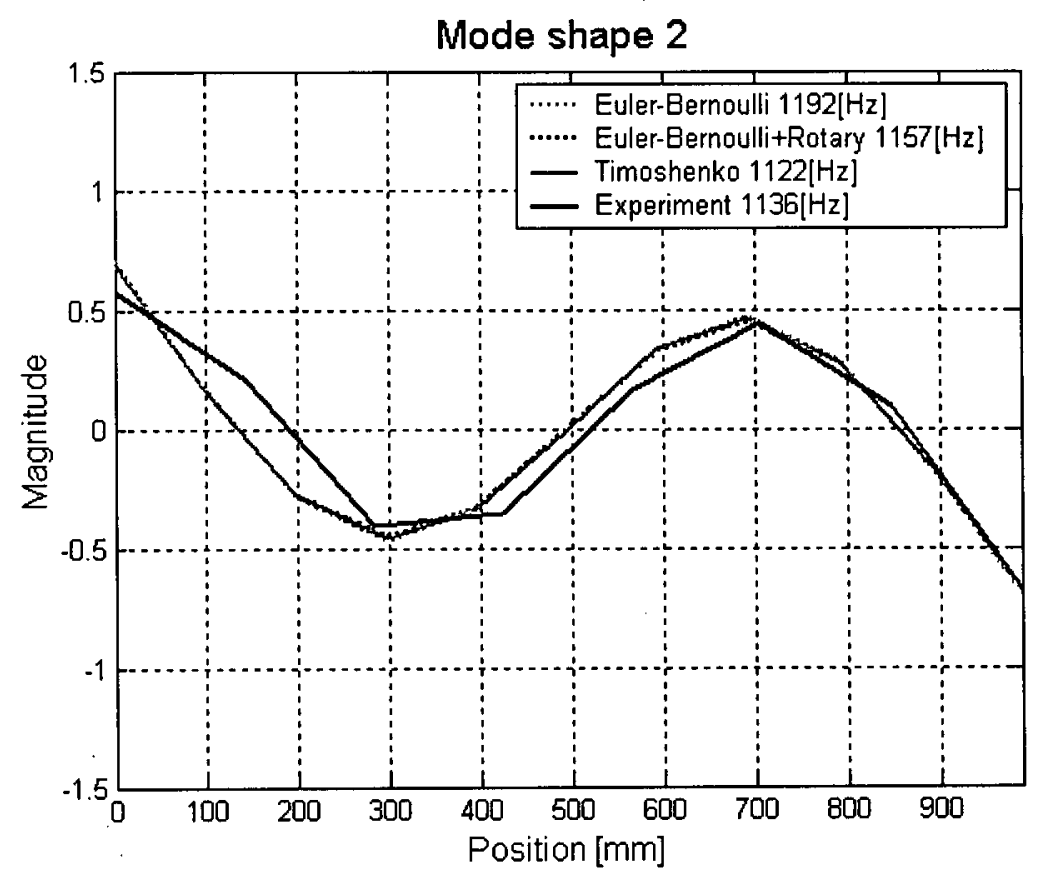

(b) 


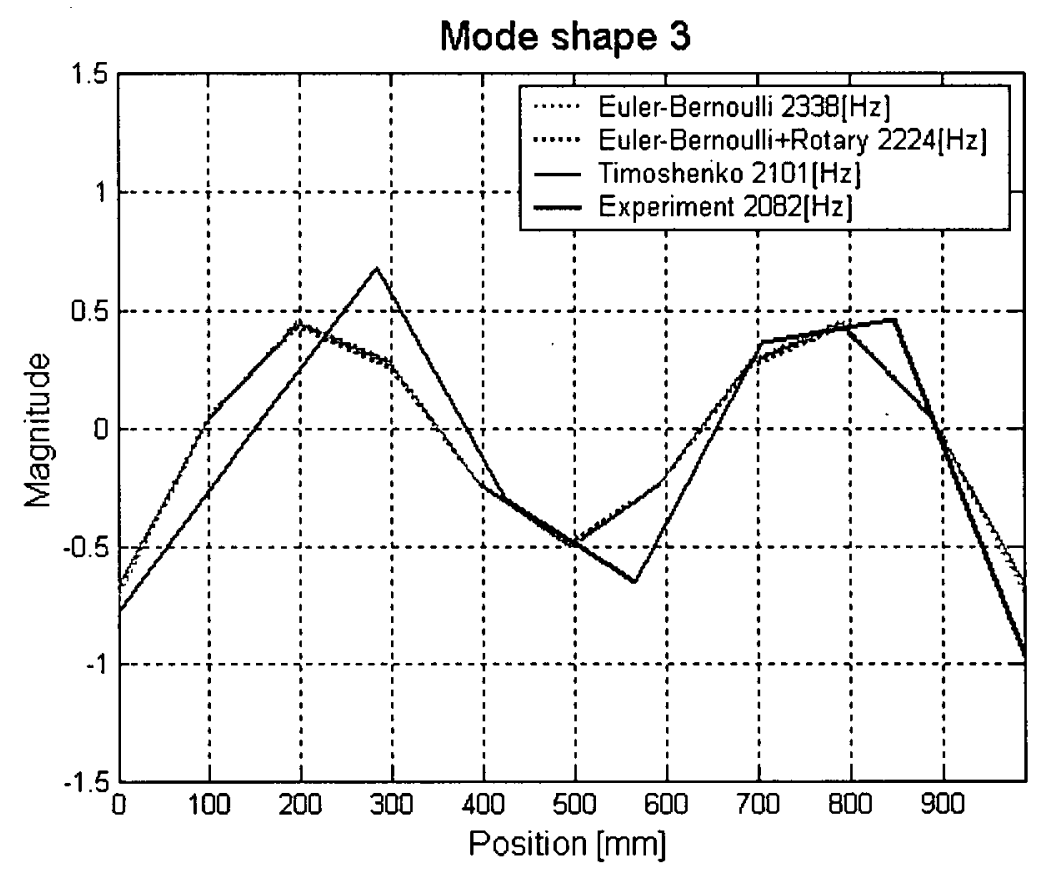

(c)

Figure 5.5 : Comparison of Measured Mode Shapes against FE Models with the EulerBernoulli Beam, the Euler-Bernoulli Beam + Rotary Inertia, and Timoshenko Beam, (a) Mode 1, (b) Mode 2, (c) Mode 3

Figure 5.6 shows the comparison of FRFs. Damping ratios of each mode are computed from the experimental FRF and applied as the damping ratios for analytical FRFs. The first modes around $430[\mathrm{~Hz}]$ are in good agreement, and the deviations increase at higher in the frequencies. The most reliable element type is the Timoshenko beam model, which is in good agreement even at a high frequency range. The Euler-Bernoulli beam, which only considered the bending effects, is not effective at a high frequency range. Therefore, as a FE model takes more effects into account, a simulation result becomes more accurate. The speed range of the machine tool spindles becomes increasingly higher, that is, the machine can be excited using forces with higher frequency content. Therefore, in order to consider chatter, the dynamic properties at a high frequency range must be taken into account to model high speed spindles. Hence, the Timoshenko beam is selected to be the most suitable model for spindle analysis. 


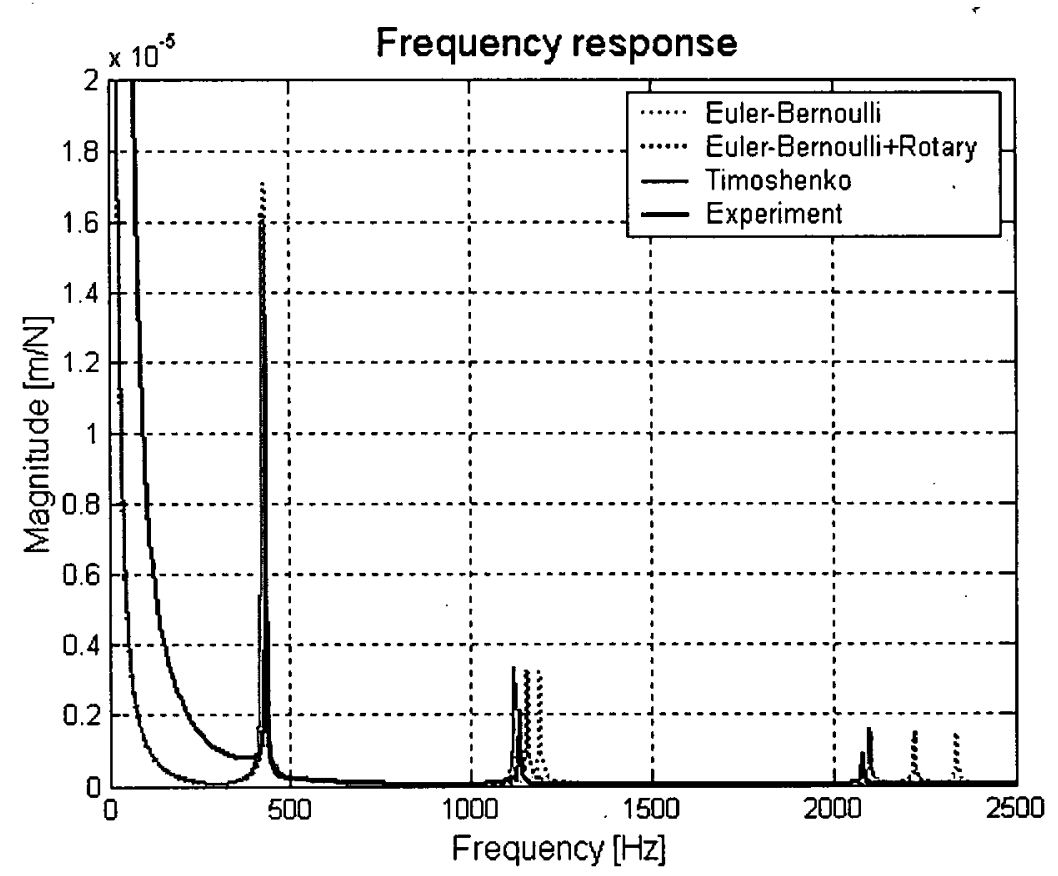

Figure 5.6 : Comparison of FRFs

\subsubsection{Spindle Analysis}

Since time consuming iteration method will be used for the bearing spans' optimization, the FE model must be as simple as possible. In order to simplify the spindle model, the FE model is constructed using the following criteria;

(1) The spindle housing is neglected.

(2) The bearings are expressed as spring elements, and one side of the spring element is connected to the spindle shaft and the other side is fixed.

(3) The stiffness of each bearing, which can be obtained from bearing catalogs $[16,40,41]$, is constant.

(4) The large masses that affect the spindle dynamics are expressed as mass elements.

(5) The Timoshenko beam model is applied to the spindle analysis model. 
As shown in Chapter 1, there are more than a hundred types of the spindles. However, the required elements for the FEM are the transmission type, the number of bearings, and the arrangement of bearings. The transmission type defines the place of the masses. The masses considered in the FE analysis are gear elements for the gear transmission type, pulley elements for belt-pulley transmission type, coupling elements for the direct coupling transmission type, and rotor elements of the spindle motor for the motorized transmission type. Among these, the rotor mass of the motorized type must be between the front bearings and the rear bearings. The other masses are located after the rear bearings. Using the differences in the number and arrangement of bearings, which are defined by the users, the number and location of the spring elements representing the bearings are decided. Figure 5.7 illustrates an example of the conversion from the spindle model to the FE model. The spindle motor is separately fixed at the cast iron housing so that FE model considers only the main spindle shaft. The motor is connected to the housing and does not affect the spindle shaft inertia except contact stiffness at the gear connection.

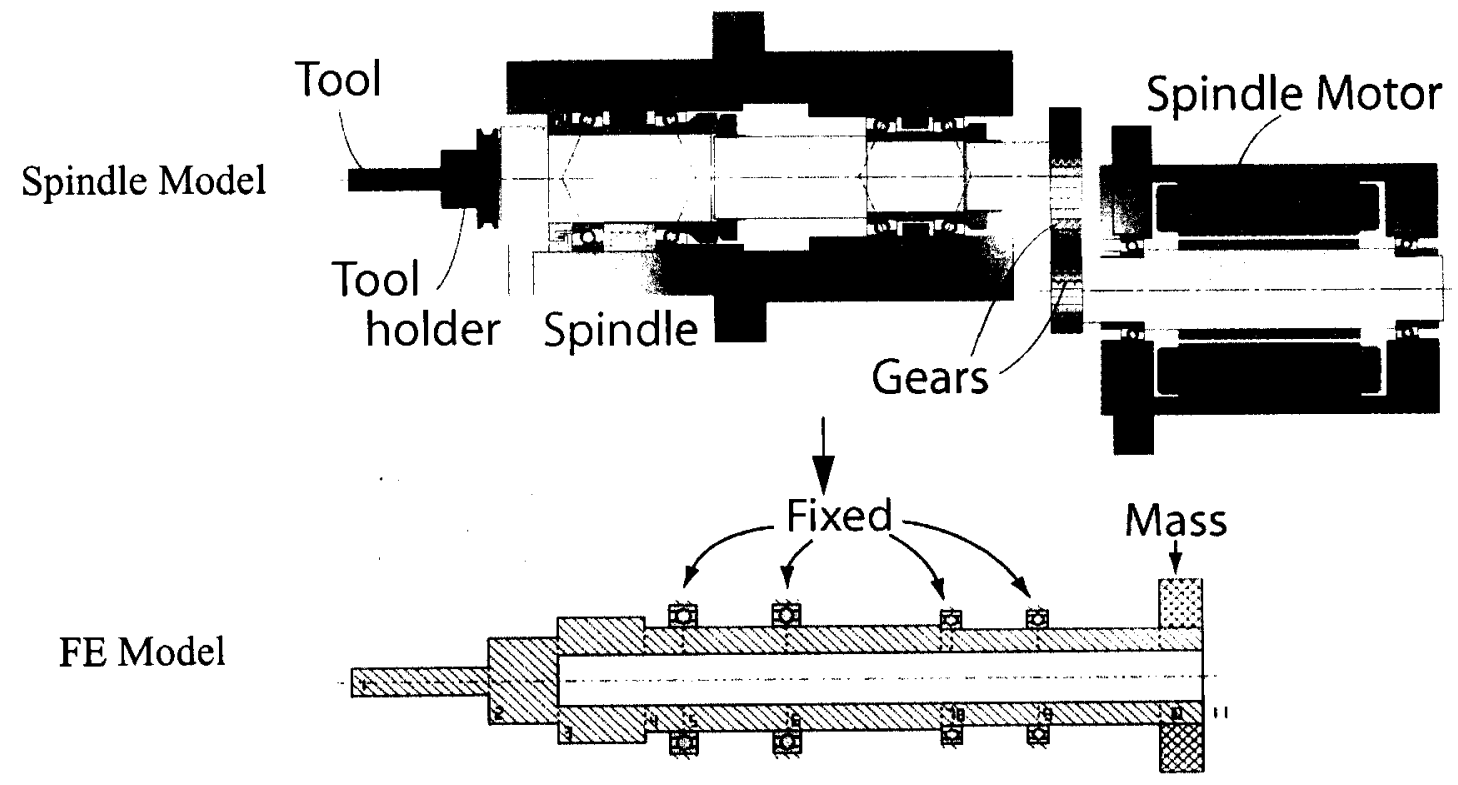

Figure 5.7 : FE Model for Spindle Model 
In order to compute the dynamic properties at the tool tip, which are required for the chatter stability analysis, the tool holder and cutter are taken into account in the FE model. However, the mode shape of the cutter itself will not be considered in the chatter stability calculation. The modes from the tool itself cannot be changed by the changes in bearing spans. In the case that the tool modes cause the chatter vibrations, the tool overhang can be adjusted by the users.

As shown in Fig. 5.8, an FE based modal analysis is conducted using the model shown in Fig. 5.7. The third mode can be identified as the tool mode from Fig. 5.8 because node 1 is the only one deflected compared to the other nodes. Therefore, the third mode is neglected in this case. A criterion, which checks whether the displacement at the tool tip is five times more than elsewhere, is used to distinguish neglected tool modes. This rule is decided from the trial cases.

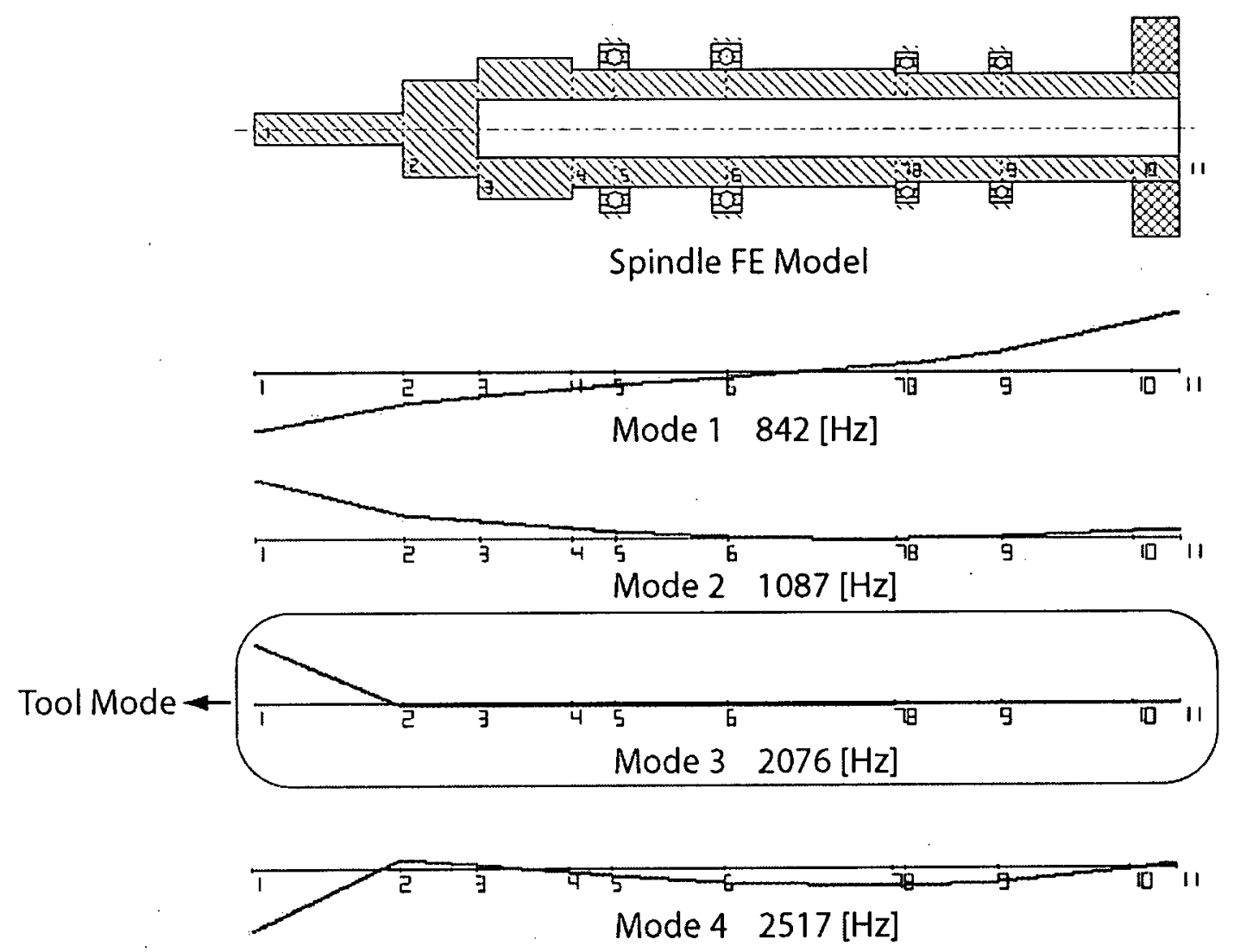

Figure 5.8 : Tool Mode Shape 
Fig. 5.9 shows the direct FRF at the tool tip of the original model and neglected tool mode model. The third mode $(2076[\mathrm{~Hz}])$ of the original FRF is neglected and the number of peaks of the modified FRF are three. This FRF that is neglected the tool mode, is used for the chatter stability analysis.
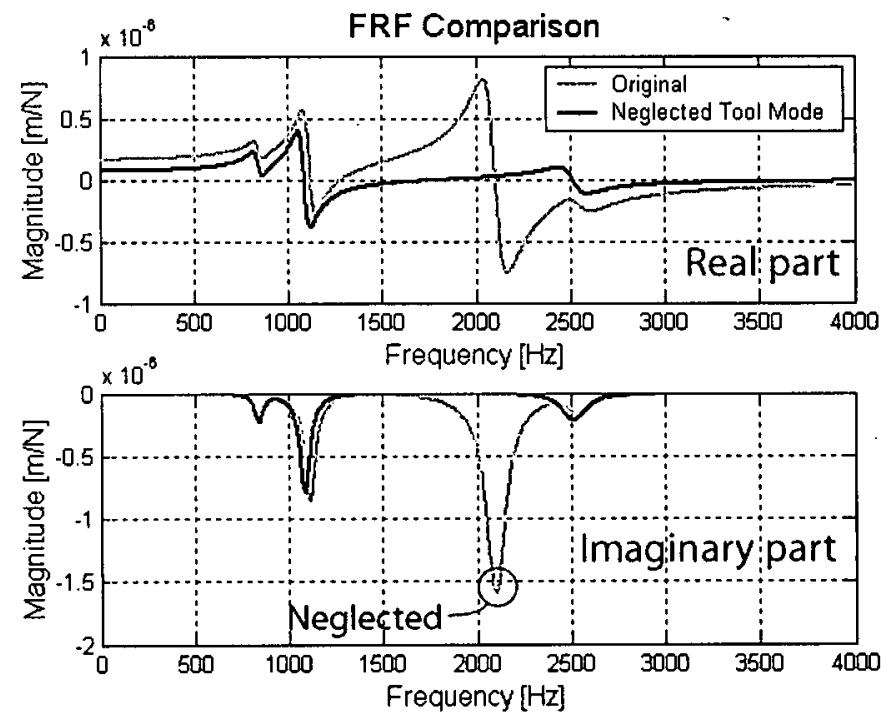

Figure 5.9 : Direct FRF Comparison at the Tool Tip Between Original Model and Neglected Tool Mode Model

With the motorized spindle (Fig. 5.10), the rotor is expressed as the mass, and it is axially longer than the masses of the other transmission devices, such as the gear, pulley, and coupling. The rotor mass is therefore divided into five elements, as shown in Fig. 5.10, in order to improve the accuracy of the predictions. 


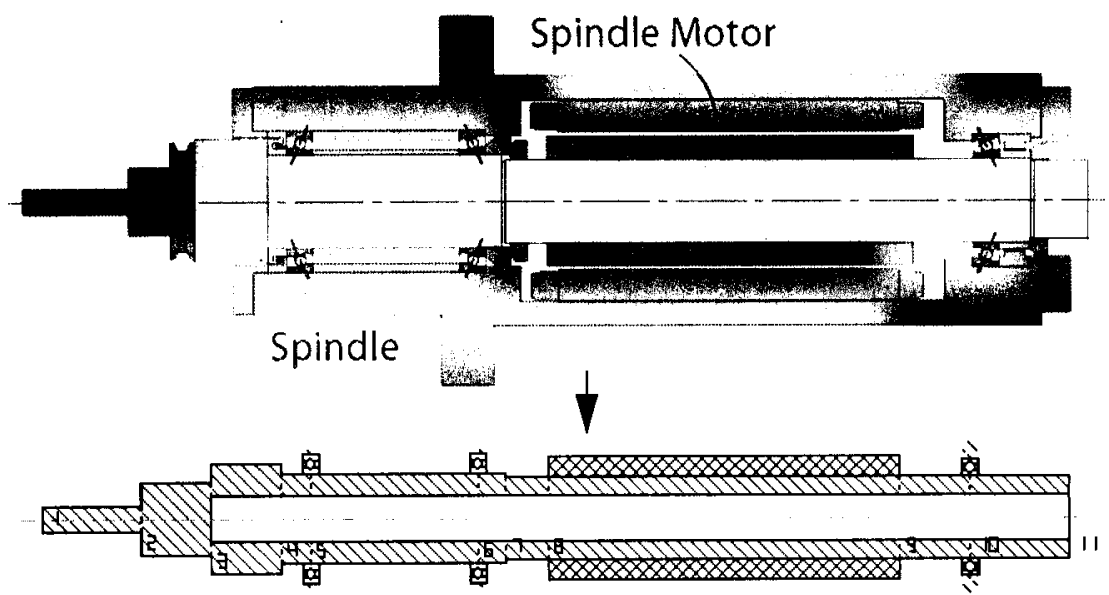

(a)

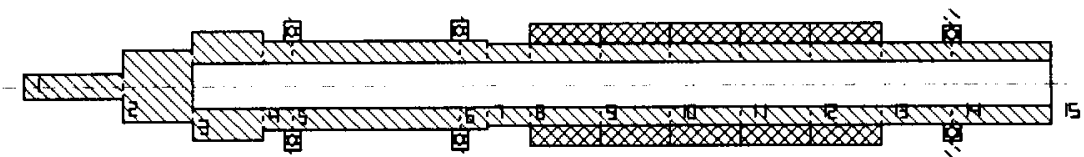

(b)

Figure 5.10 : Rotor Mass Division, (a) One Mass, (b) Five Divided Mass

Figure 5.11 shows the FRF comparison between the spindle model with one rotor mass and with five divided rotor mass. Mode shapes are shown in Fig. 5.12. With the one mass model, the mode shape from nodes 8 to 13 become a straight line. Therefore, the one mass model is no longer useful for the complicated mode shapes at these nodes (for example, mode 4 and 5). Thus, the five divided mass model is used in this research. 

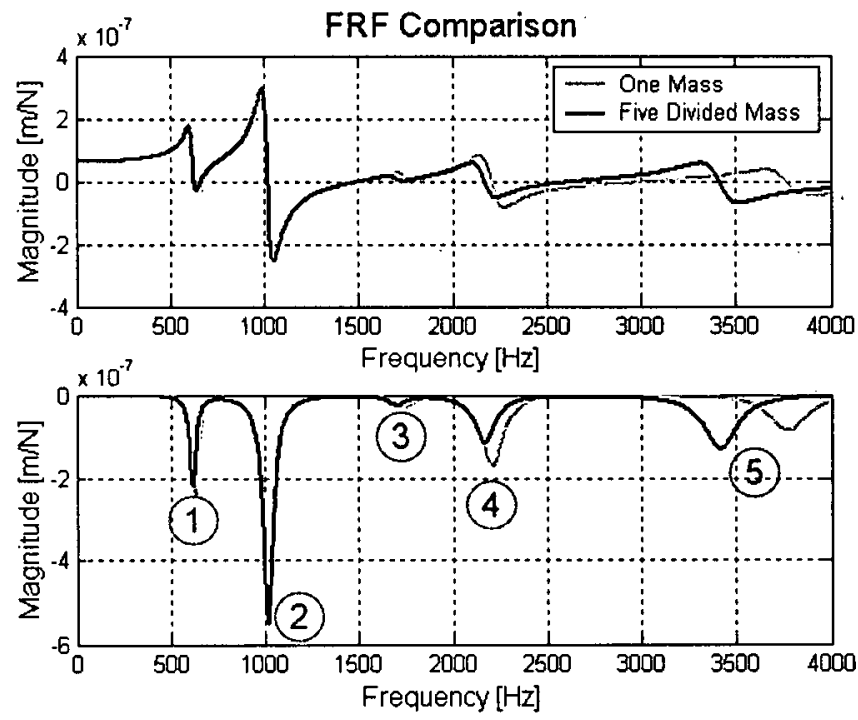

Figure 5.11 : FRF Comparison With Different Mass Divisions
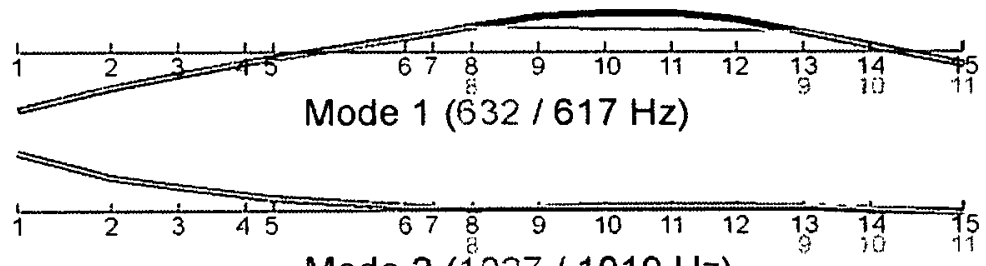

Mode $2(1027 / 1019 \mathrm{~Hz})$

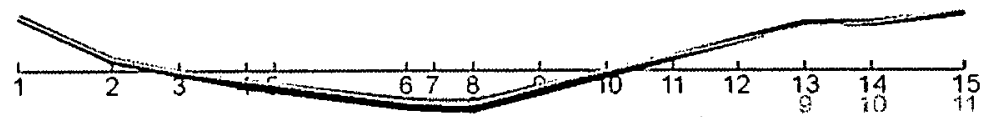

Mode $3(1748 / 1703 \mathrm{~Hz})$

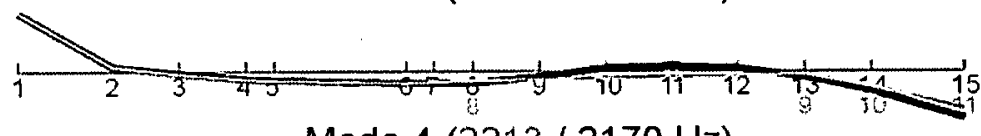

Mode $4(2213 / 2170 \mathrm{~Hz})$

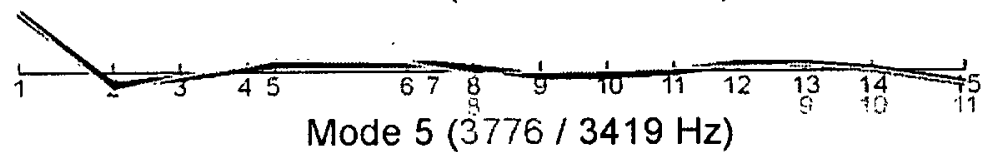

Figure 5.12: Modes Comparison 


\subsection{Optimization Methods}

\subsubsection{Introduction}

The concept of optimization can be found in our daily lives. People usually suppose that they want to have the best quality products. "Best" depends on their demands, for example lower cost, longer life, and so on. In order to achieve these demands, the design is important. Numerical optimization is one of the tools used to accomplish the "best" design.

The design can be defined as the process of finding the minimum or maximum of some parameters (objective function) by changing the variable parameters (design variables). For the design to be acceptable, it must also satisfy a certain set of specified requirements (constraints). That is, we wish to find the constrained minimum or maximum of the objective function by changing the design variables.

Optimization methods are roughly classified into two types; an indirect and a direct method. The indirect method (Appendix F) is based on the derived properties of the objective and constraint functions at the minimum value. Basically, the minimum value of this method can be obtained with only one set of calculations. The direct method, which is also called the iterative method, is more direct from an engineering perspective. To calculate the minimum values for simple problems, the indirect method is fine, but for complex problems and highly nonlinear problems, the indirect method is no longer suitable in practice, and the direct method must be applied instead.

The advantage of the numerical optimization is that it can deal with a wide variety of design variables and constraints. In addition, the results obtained by the numerical optimization are not solved from intuition or experience. Therefore, the improved non-traditional results can be obtained. The disadvantage is that the computational time increases as the number of design variables increases. However, for spindle optimization, the design variables can only be the bearing spans, so the number of design variables is not large. The biggest disadvantage for the numerical optimization is that the global minimum (the minimum value among the local minimums) is sel- 
dom obtained, that is, the local minimum (one of the extremums of the minimum sides) is set as the minimum value of the objective function. Depending on an initial value, the final minimum may be changed, that is, the different local minimums are obtained (Fig. 5.13). The only thing we can do is set multi-initial values, comparing the results and selecting the minimum value among the results [60].

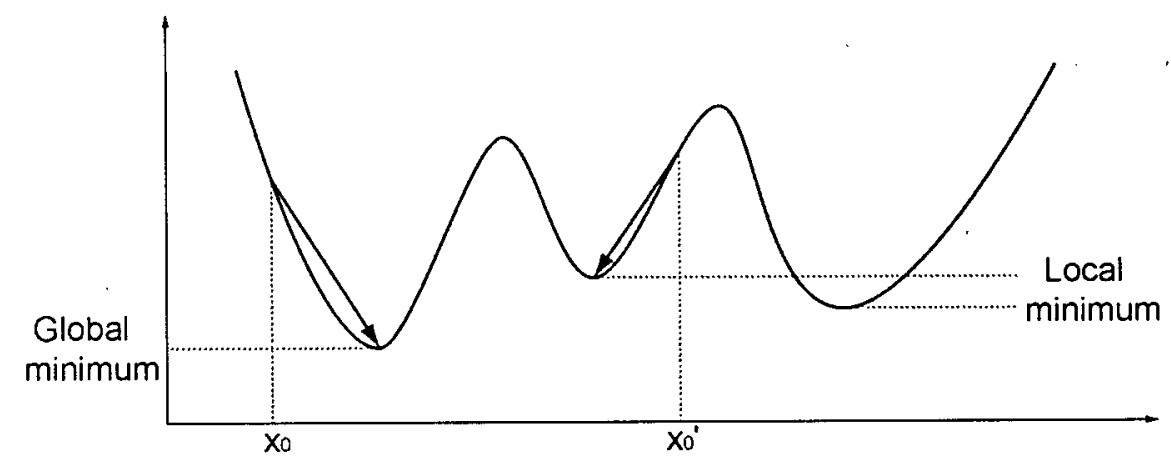

Figure 5.13 : Global Minimum and Local Minimum 


\subsubsection{Sequential Quadratic Programming}

The direct methods are used for the design optimization because the objective function for the mechanical design tends to be highly nonlinear and the indirect methods are not suitable. The direct methods are called iterative methods as well. Most of the iterative operations can be expressed as the following equation;

$$
x_{k+1}=x_{k}+\alpha^{*} d
$$

where $k$ is the iteration number, $x_{k+1}$ is the new design variable vector, $x_{k}$ is the current design variable vector, $d$ is a vector search direction, and $\alpha^{*}$ is the scalar quantity that defines the distance moving in direction $d$.

The definition of $d$ and $\alpha^{*}$ in Eq. (5.24) is a key issue needed to find the design variable which optimizes the objective function. The basic procedure to define $d$ and $\alpha^{*}$ is to first set vector $d$ using a certain method, and then find scalar value $\alpha^{*}$. The number of the row of $d$ is equal to the number of the design variables. The process used to find $\alpha^{*}$ is called the one-dimensional search because $\alpha^{*}$ is a scalar number, and only one variable $\alpha^{*}$ needs to be defined.

There are many direct methods, and the objective of those methods is to find $d$ and $\alpha^{*}$. The indirect methods can be categorized as zero-order methods, first-order methods, and second-order methods [60]. Random search method, steep descent method, and Newton's method are the zeroorder, first-order, and second-order method, respectively. Newton's method, which is shown in Appendix F.1, is the method in which the second order Taylor series expansion is implemented to the objective function, and the search direction $d$ is defined from this process. The Hessian matrix, which is the second partial derivative of the objective with respect to the design variables, exists in the equation. However, it is usually hard to calculate the second derivatives in practical problems; therefore, the Hessian matrix is updated by using approximation techniques, which is called the Quasi-Newton method. There are several approximation techniques, such as the BFGS 
method [18] and DFP method [17]. Since the BFGS method is the most popular, it is used as the approximation technique for the Hessian matrix updating in this thesis.

Sequential Quadratic Programming (SQP) is commonly expressed as the Kuhn-Tucker equation using the Quasi-Newton updating procedure. The SQP is named from the calculation process in which the QP sub-problem is solved at each major iteration. The QP sub-problem can be expressed as follows.

Minimize : $\quad q(d)=\frac{1}{2} d^{T} H_{k} d+\nabla f\left(x_{k}\right)^{T} d$

Subject to : $\quad \tilde{g}_{j}=\nabla g_{j}\left(x_{k}\right)^{T} d+g_{j}\left(x_{k}\right) \leq 0 \quad j=1, \ldots, \mathrm{m}$ (Number of constraints)

Since the equality constraints do not exist in the spindle optimization process, only inequality constraints are shown in Eq. (5.25). $d$ is the vector, which has $n$ rows. $n$ is the number of design variables. $d$ can be expressed as follows.

$$
d=[d(1) d(2) \ldots d(i) \ldots d(n)]^{T}, \quad i=1, \ldots, \mathrm{n}
$$

In order to solve Eq. (5.25), the Kuhn-Tucker conditions are applied as follows.

$$
\begin{gathered}
\frac{\partial q(d(i))}{\partial d(i)}+\sum_{j=1}^{m} \lambda_{j} \frac{\partial \tilde{g}_{j}}{\partial d(i)}=0 \\
\lambda_{j} \tilde{g}_{j}=0, j=1, \ldots, \mathrm{m} \\
\tilde{g}_{j} \leq 0, j=1, \ldots, \mathrm{m} \\
\lambda_{j} \geq 0, j=1, \ldots, \mathrm{m}
\end{gathered}
$$

All possibilities, which come from Eq. (5.28), must be considered for a feasible solution. By solving Eq. (5.27) to (5.30), the search direction $d$ for Eq. (5.24) can be obtained.

Having solved the direction $d$, the step length $\alpha^{*}$ must be determined without violating the constraints. As a first assumption of $\alpha^{*}$ can be one $\left(\alpha^{1}=1\right)$. If the initial objective value 
$f_{o b}\left(x_{0}\right)$ is greater than $f_{o b}\left(x_{1}\left(d, \alpha^{1}\right)\right)$, the step size is modified to half of $\alpha$. In this case, the next $\alpha=\alpha^{0.5}=0.5 . \alpha$ is updated until $f_{o b}\left(x_{0}\right)$ becomes less than $f_{o b}\left(x_{1}(d, \alpha)\right)$.

For next iteration, the Hessian matrix $H_{k}$ is computed by using the Quasi-Newton method with the approximation updating technique, BFGS method. The BFGS method formulated by Broyden, Fletcher, Goldfarb, and Shanno [17, 18, 21, 49] can be expressed as:

$$
H_{k+1}=H_{k}+\frac{q_{k} q_{k}^{T}}{q_{k}^{T} s_{k}}-\frac{H_{k}^{T} s_{k}^{T} s_{k} H_{k}}{s_{k}^{T} H_{k} s_{k}}
$$

where

$$
\begin{gathered}
s_{k}=x_{k+1}-x_{k} \\
q_{k}=\nabla f\left(x_{k+1}\right)-\nabla f\left(x_{k}\right)
\end{gathered}
$$

As the starting point of the Hessian matrix $H_{0}$, the identity matrix $I$ is a good definition since it is a symmetric positive definite matrix. The first partial derivatives $\nabla f\left(x_{k}\right)$ are either supplied through analytically calculated gradients, or derived by using a numerical differentiation method using finite differences. 


\subsubsection{SQP Application to Bearing Spans' Optimization}

Fig. 5.14 illustrates the flow chart of the SQP optimization algorithm for the bearing spans' optimization.

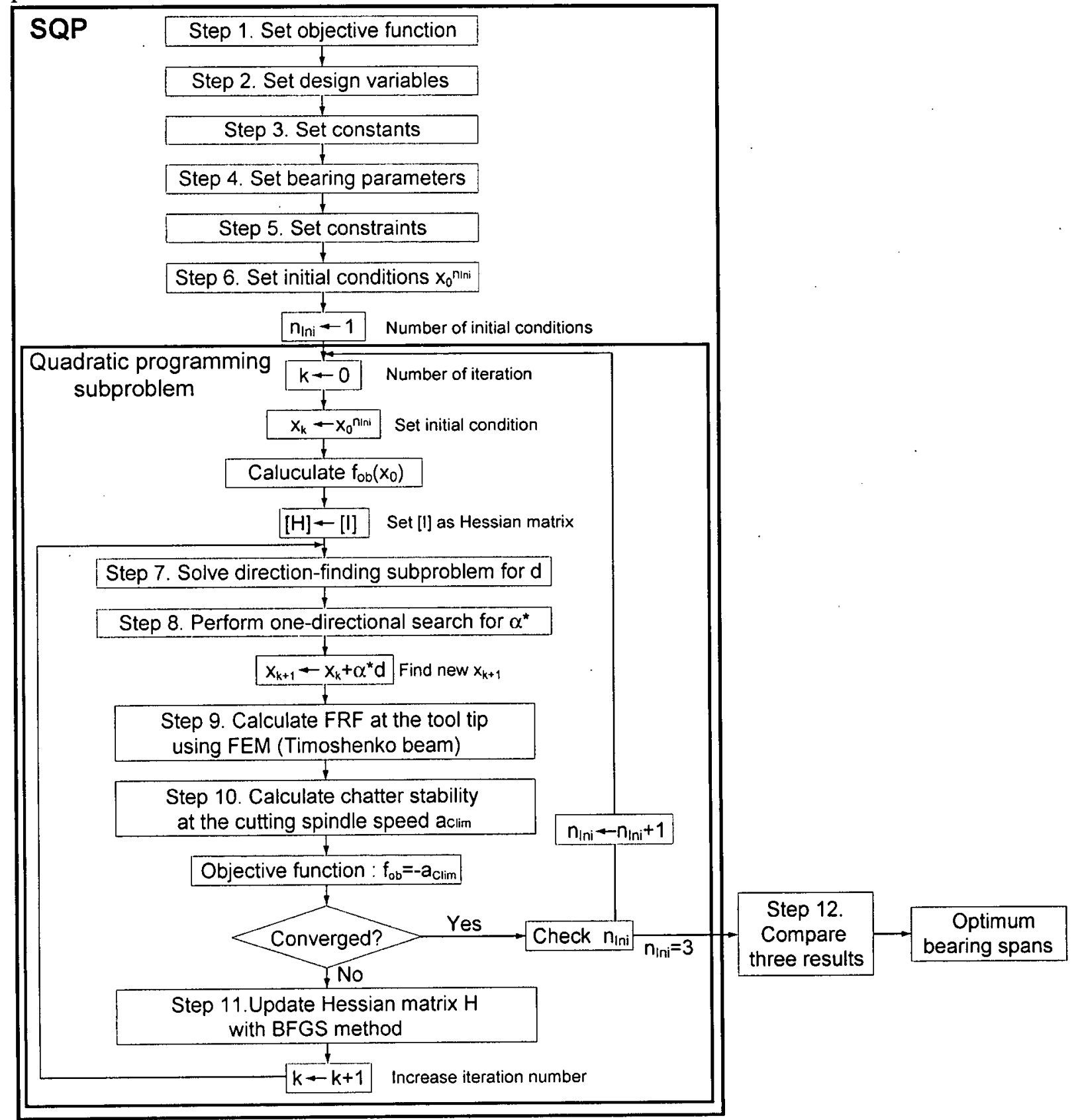

Figure 5.14 : Optimization Algorithm with SQP for Bearing Spans' Optimization 


\section{Step 1. Set Objective Function}

As shown in Section 5.2, chatter vibrations do not occur when the point of a cutting condition is below the chatter stability lobes. In other words, a chatter free spindle can be accomplished by changing the shape of the stability lobes using spindle dynamics modification.

When the critical depth of cut of the stability lobes at the cutting spindle speed ( $a_{C l i m}$ ) (Fig. $5.15)$ is maximized, the cutting status is the most stable. Therefore, the objective function $\left(f_{o b}\right)$, can be defined simply as follows:

$$
\text { Minimize : } f_{o b}=-a_{\text {Clim }}
$$

In order to calculate the $a_{\text {Clim }}$, the FRF at the tool tip is required. The FRF calculation process is shown in Section 5.3.2.

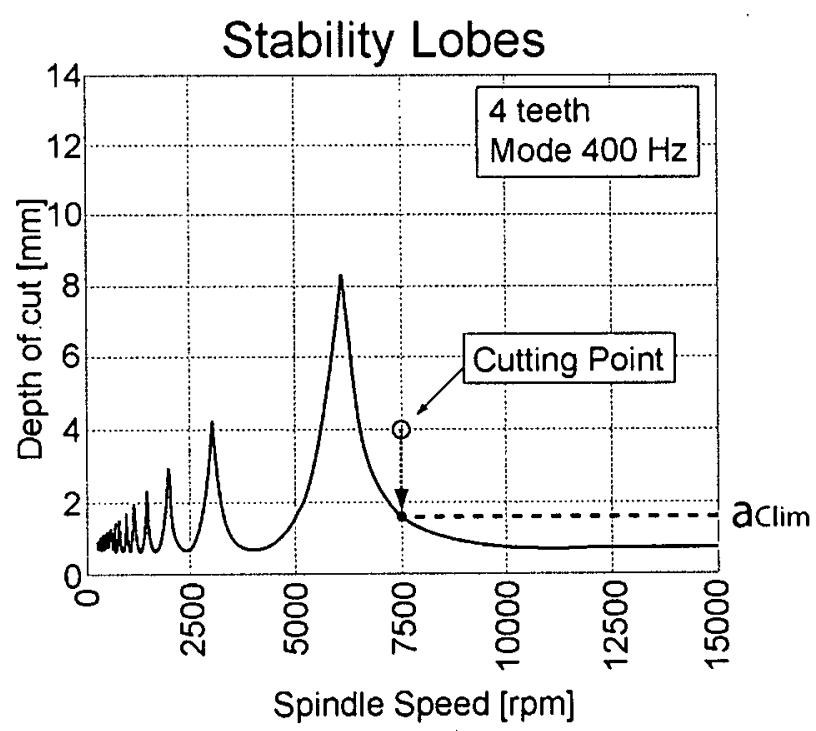

Figure 5.15 : Stability Lobes

\section{Step 2. Set Design Variables}

The design variables for the chatter free spindle design are the bearing spans (see Section 5.2). The number of the design variables changes depending on the bearing arrangement and the transmission type. Fig. 5.16 shows the design variables of the motorized spindle with five bear- 
ings (four front and one rear bearings). The $\mathrm{x}(1)$ to $\mathrm{x}(6)$ are the design variables. The $\bar{x}$ is also optimized, but it is determined automatically with the subtraction of the other known length from the total spindle length.

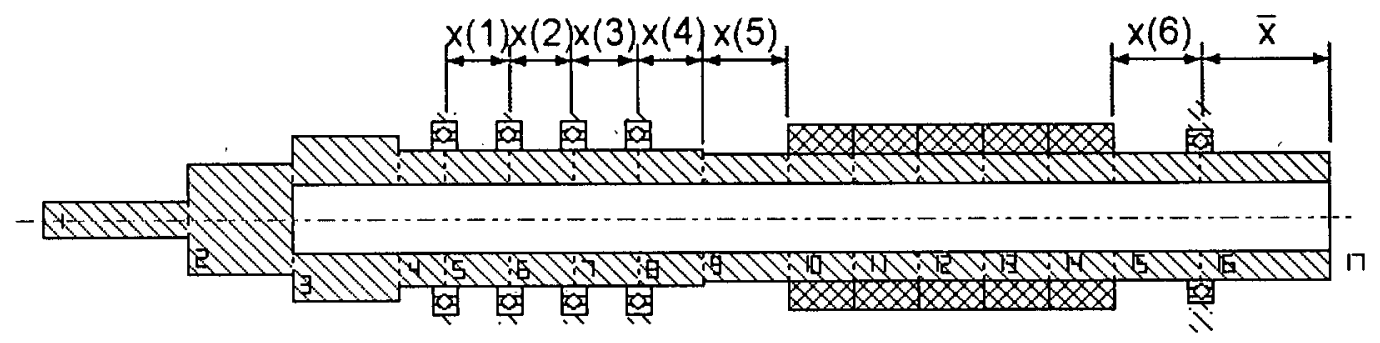

Figure 5.16 : Design Variables

Therefore, the design variables in Eq. (5.24) $x_{k+1}=x_{k}+\alpha^{*} d$ becomes,

$$
x=\left[\begin{array}{l}
x(1) \\
x(2) \\
x(3) \\
x(4) \\
x(5) \\
x(6)
\end{array}\right]
$$

\section{Step 3. Set Design Constants}

Design constants must be defined by the users from their design demands. All shaft and mass dimensions are required, and the front end bearing position needs to be set as well as shown in Fig. 5.17. Figure 5.16 illustrates the motorized spindle with four front bearings and one rear bearing. The mass, which expresses the rotor, is divided by five because the rotor is generally a long part and the long one-mass element causes inaccurate FE analysis results. (Section 5.3.4) 


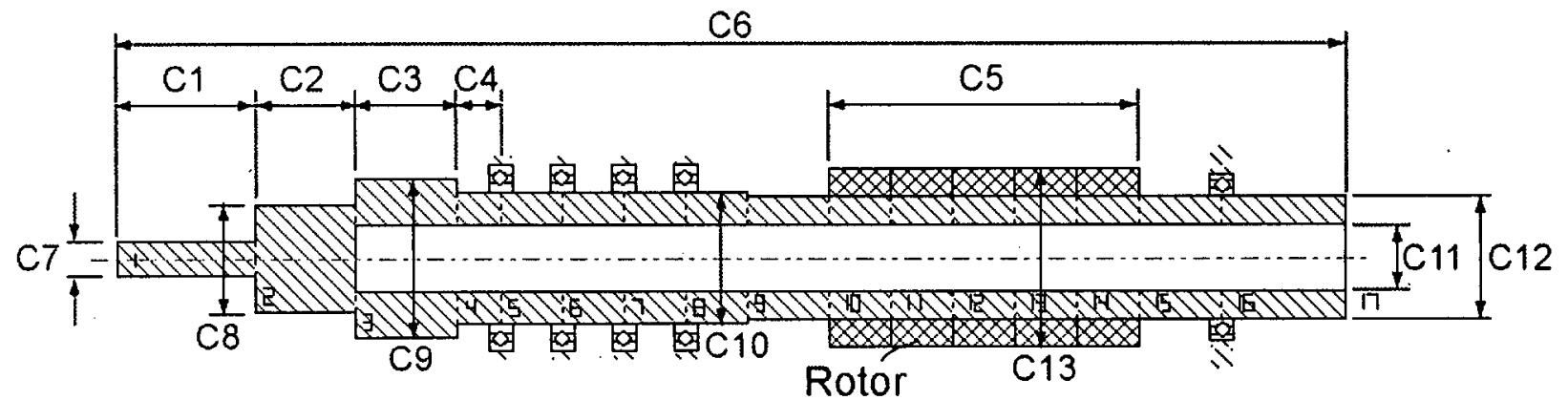

Figure 5.17 : Design Constants

\section{Step 4. Set Bearing Parameters}

Bearing parameters must be set as shown in Fig. 5.18. B1 to B7 are the size of the bearings. $\mathrm{Kr}$ and $\mathrm{Ka}$ are the radial and axial bearing stiffness, respectively. The bearing stiffness values are obtained from bearing manufacturers $[16,40,41]$.

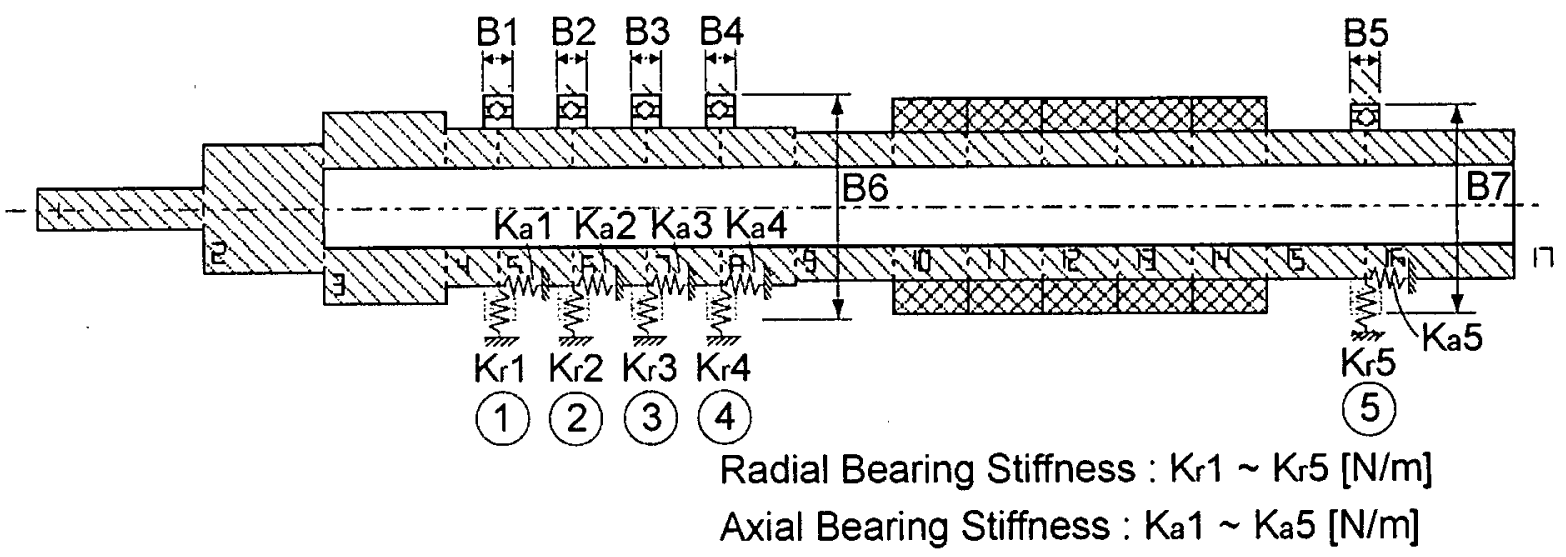

Figure 5.18 : Bearing Dimensions and Stiffnesses

\section{Step 5. Set Design Constraints}

The design constraints must be set to the design variables $\mathrm{x}(1)$ to $\mathrm{x}(6)$ and $\bar{x}$ in Fig. 5.16. Therefore, the design constraints $\mathrm{S} 1$ to $\mathrm{S} 7 \mathrm{can}$ be set as shown in Fig. 5.19. These $\mathrm{S}$ values are greater than or equal to the bearing widths. Depending on the design concepts, the users can set 
the constraints; for example, since the lubrication nozzle must be between the front end and the second front bearing, S1 must be greater than ten millimeters plus bearing widths.

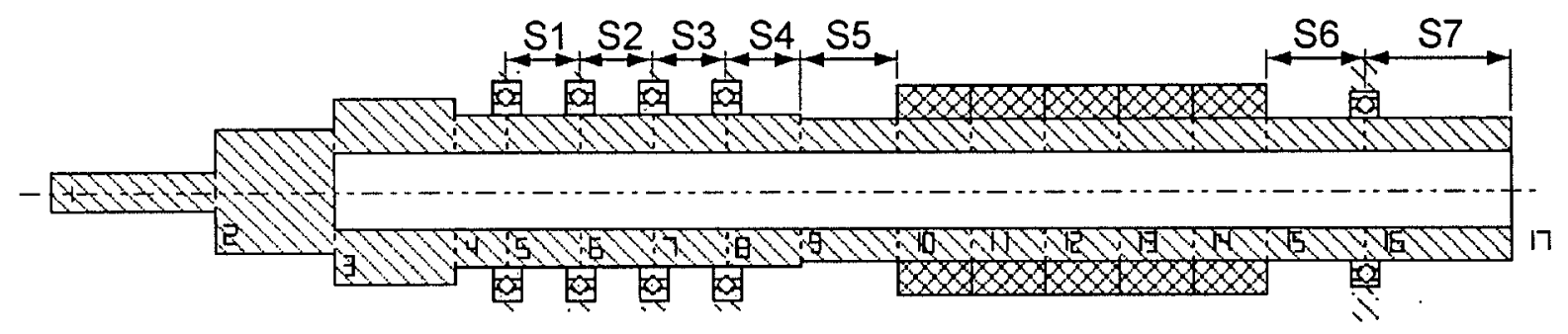

Figure 5.19 : Design Constraints

\section{Step 6. Set Initial Conditions}

Three initial conditions are set as shown in Fig. 5.20. It is important to try optimization using more than one initial condition. This is necessary to prevent optimization to converge to one local minimum as opposed to global minimum. Using the initial conditions $x_{0}^{1}(x), x_{0}^{2}(x)$, and $x_{0}^{3}(x)$, the quadratic programming subproblem is solved.

$$
x_{0}^{1}(x)=\left[\begin{array}{c}
x_{0}^{1}(1) \\
x_{0}^{1}(2) \\
x_{0}^{1}(3) \\
x_{0}^{1}(4) \\
x_{0}^{1}(5) \\
x_{0}^{1}(6)
\end{array}\right], x_{0}^{2}(x)=\left[\begin{array}{c}
x_{0}^{2}(1) \\
x_{0}^{2}(2) \\
x_{0}^{2}(3) \\
x_{0}^{2}(4) \\
x_{0}^{2}(5) \\
x_{0}^{2}(6)
\end{array}\right], x_{0}^{3}(x)=\left[\begin{array}{c}
x_{0}^{3}(1) \\
x_{0}^{3}(2) \\
x_{0}^{3}(3) \\
x_{0}^{3}(4) \\
x_{0}^{3}(5) \\
x_{0}^{3}(6)
\end{array}\right]
$$

As the first computation, the initial condition $x_{0}^{1}(x)$ is used $\left(x_{0}(x)=x_{0}^{1}(x)\right)$. 


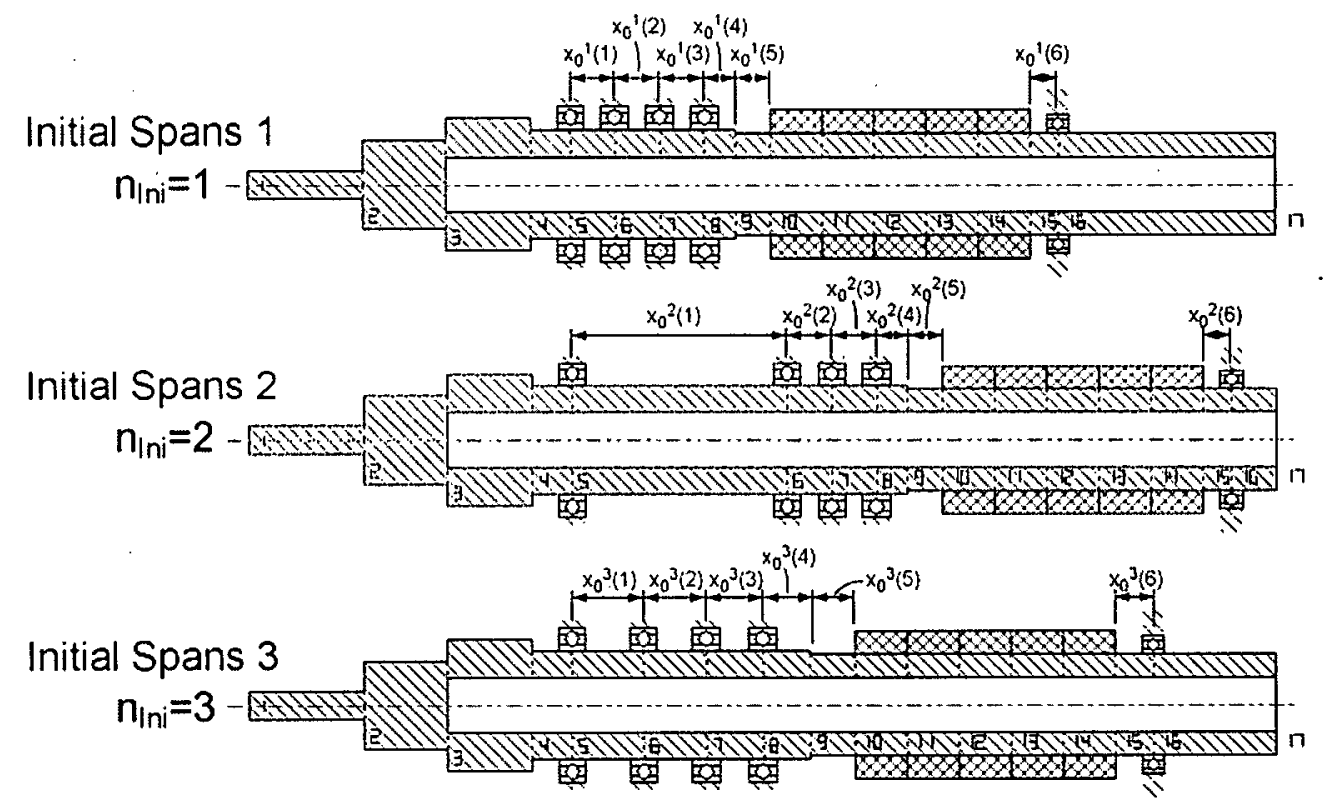

Figure 5.20 : Initial Conditions

\section{Quadratic Programming Subproblem}

\section{Step 7. Solve direction-finding subproblem for $d$}

From Eq. (5.25),

$$
\begin{aligned}
& \text { Minimize : } q(d)=\frac{1}{2} d^{T} H_{k} d+\nabla f\left(x_{k}\right)^{T} d \\
& \text { Subject to : } \quad \tilde{g}_{j}=\nabla g_{j}\left(x_{k}\right)^{T} d+g_{j}\left(x_{k}\right) \leq 0 \quad j=1, \ldots, \mathrm{m}
\end{aligned}
$$

The solution $d$, which minimizes the subproblem shown in Eq. (5.34), is the search direction.

$$
d=[d(1) d(2) d(3) d(4) d(5) d(6)]^{T}
$$

The detail solution of the quadratic programming subproblem is shown in Appendix H. 


\section{Step 8. One-directional search for step size $\alpha^{*}$}

Having set the search direction $d$, the step size $\alpha^{*}$ is found. The first assumption of $\alpha^{*}$ can be one $\left(\alpha^{1}=1\right)$. If the initial objective value $f_{o b}\left(x_{0}\right)$ is greater than $f_{o b}\left(x_{1}\left(d, \alpha^{1}\right)\right)$, the step size is modified to half of $\alpha$. In this case, the next $\alpha=\alpha^{0.5}=0.5$. Until $f_{o b}\left(x_{0}\right)$ becomes less than $f_{o b}\left(x_{1}(d, \alpha)\right), \alpha$ is updated.

\section{Step 9. Calculate FRF at the Tool Tip Using FEM}

Using the new bearing spans $x\left(x_{1}=x_{0}+\alpha^{*} d\right)$, the FRF at the tool tip is calculated (Section 5.3.2).

$$
x_{1}(x)=\left[\begin{array}{l}
x_{0}(1) \\
x_{0}(2) \\
x_{0}(3) \\
x_{0}(4) \\
x_{0}(5) \\
x_{0}(6)
\end{array}\right]+\alpha^{*} \cdot\left[\begin{array}{l}
d(1) \\
d(2) \\
d(3) \\
d(4) \\
d(5) \\
d(6)
\end{array}\right]
$$

The FRF calculated here is the one that the tool mode is neglected (Section 5.3.4). The damping ratio of each mode is set as 0.03 , which is typical damping ratio of the mechanical system.
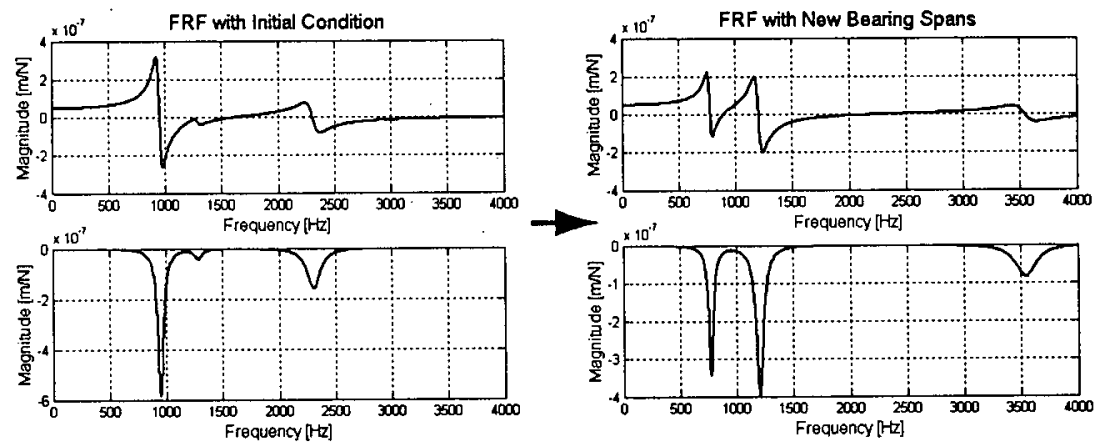

Figure 5.21 : Change of FRF 


\section{Step 10. Calculate Chatter Stability $a_{\text {Clim }}$ at the Cutting Spindle Speed}

The chatter stability is calculated using new FRF computed in the step 9. Budak-Altintas chatter theory for milling [1] is used for the chatter stability calculation as shown in Section 2.4.

$$
a_{\text {lim }}=\frac{-2 \pi \Lambda_{R}}{N K_{s}}\left(1+\left(\frac{\Lambda_{I}}{\Lambda_{R}}\right)^{2}\right)
$$

where, $K_{s}$ is the cutting coefficient, and $N$ is the number of teeth. $\Lambda_{R}$ and $\Lambda_{I}$ are real and imaginary values of an eigenvalue $\Lambda$, which is obtained using FRF at the tool tip. The details of the chatter stability lobes can be found in $[1,2]$.

\section{Step 11. Update Hessian Matrix H with BFGS Method}

The Hessian matrix $H_{k}$ is updated using BFGS method. The BFGS method formulated by Broyden, Fletcher, Goldfarb, and Shanno can be expressed as:

$$
H_{1}=H_{0}+\frac{q_{0} q_{0}^{T}}{q_{0}^{T} s_{0}}-\frac{H_{0}^{T} s_{0}^{T} s_{0} H_{0}}{s_{0}^{T} H_{0} s_{0}}
$$

where

$$
\begin{gathered}
s_{0}=x_{1}-x_{0} \\
q_{0}=\nabla f\left(x_{1}\right)-\nabla f\left(x_{0}\right)
\end{gathered}
$$

The initial Hessian matrix $H_{0}$ is defined as the identity matrix $I$. The first partial derivatives $\nabla f\left(x_{1}\right)$ are either supplied through analytically calculated gradients, or derived by using a numerical differentiation method using finite differences.

\section{Step 12. Compare Three Results}

Having computed the quadratic programming subproblem three times, the results are compared, and the most minimized condition is chosen as the optimum bearing spans. 


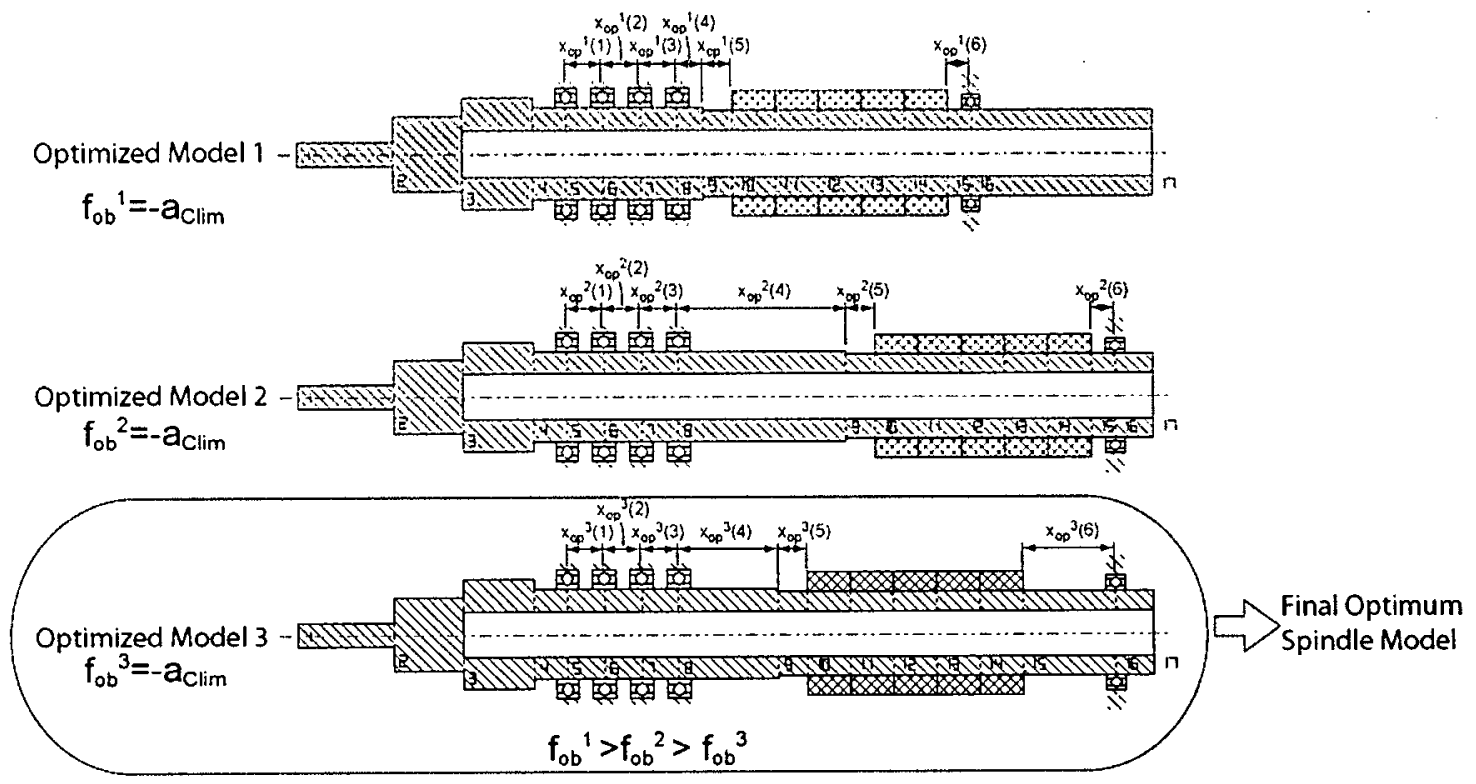

Figure 5.22 : Comaprison of the Three Results 


\subsubsection{Bearing Spans' Optimization with Expert Spindle Design System}

The transmission selection process must be accomplished before the optimization process because the mass type changes depending on the transmission type. Therefore, the procedures from Section 4.5, Step 1 to Step 3, are completed before the following process. The cutting speed and depth of cut are set at 9,000[rpm] and $3[\mathrm{~mm}]$, respectively.

\section{Set Number and Arrangement of Bearings}

The number of both front (Fig. 5.23) and rear bearings (Fig. 5.24) must be defined by the users because the bearing number corresponds to the number of spring elements in the spindle FE model. The arrangement type needs to be set depending on the users' design concepts.

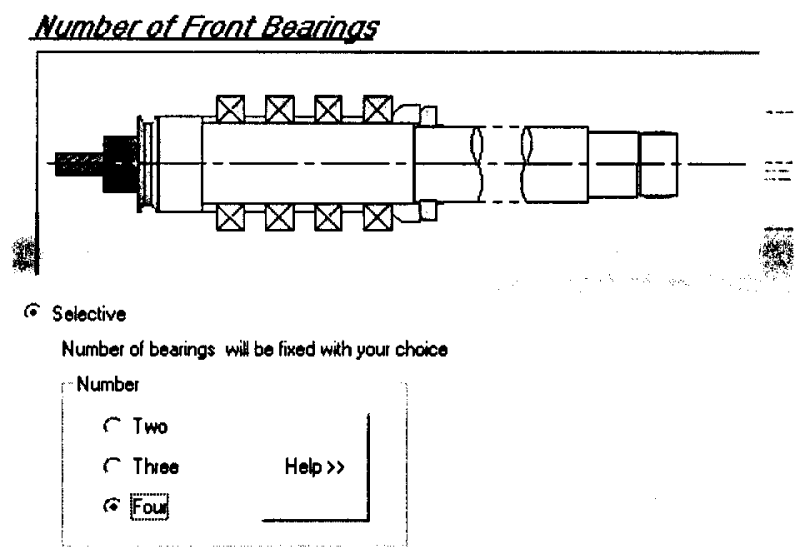

Figure $5.23:$ Interface for Setting Number of Front Bearings

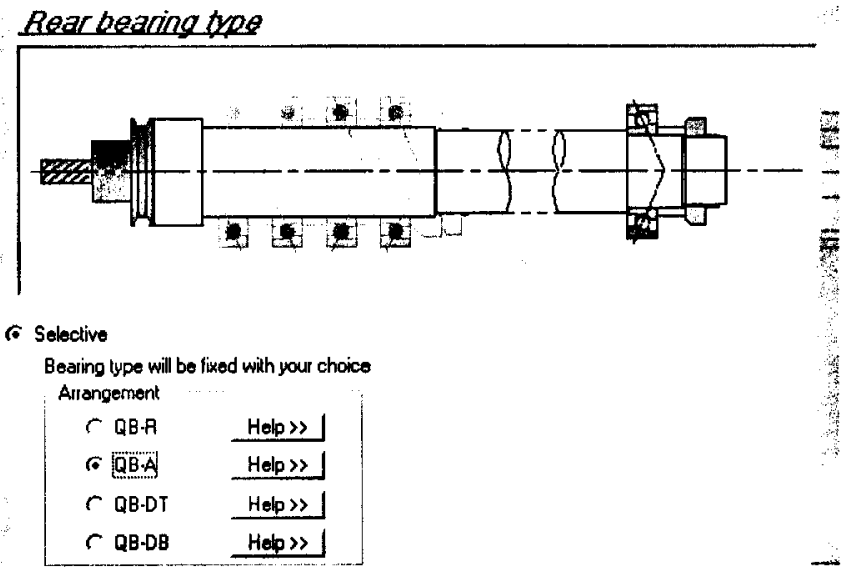

Figure 5.24 : Interface for Setting Rear Bearings 


\section{Set Spindle Shaft Dimensions}

Spindle shaft dimensions are used as the beam element size in the FE analysis, and need to be selected by the designer.

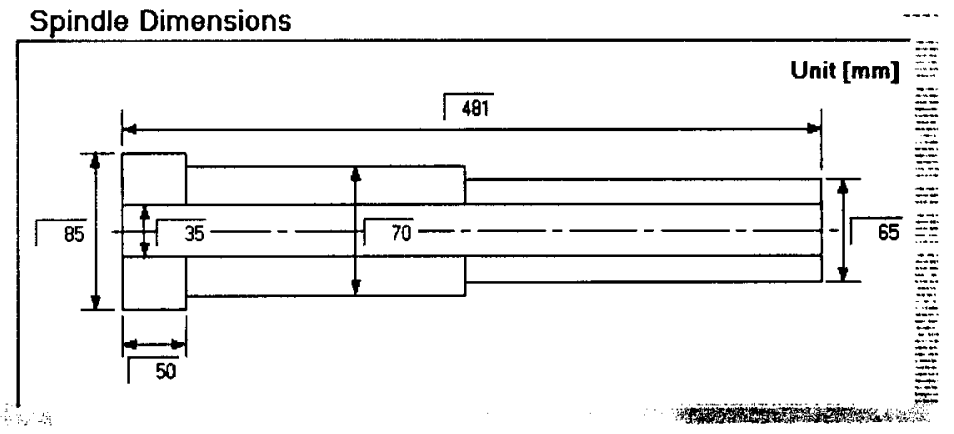

Figure 5.25 : Interface for Setting Spindle Shaft Dimensions

\section{Set Bearing Parameters}

The dimensions of the bearings are used to compute the constraints. The stiffness of the bearings is used as the spring element in the FE analysis. The bearing properties are obtained from the bearing catalogs $[16,40,41]$. The position of the front end bearing must also be defined (Fig. 5.2) by the designer.

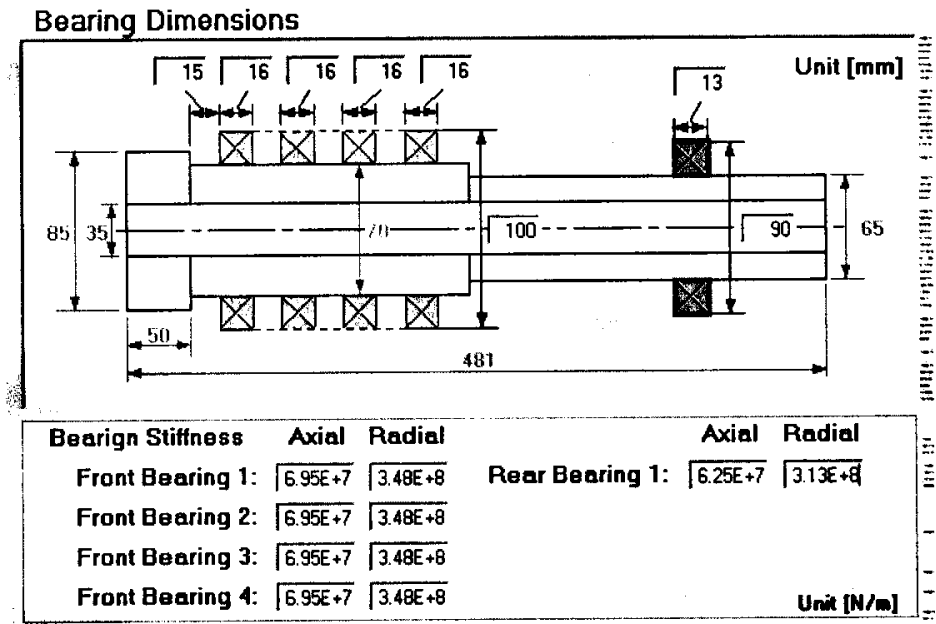

Figure 5.26 : Interface for Setting Bearing Parameters 


\section{Set Mass Properties}

The properties of the mass, such as gear, pulley, coupling, and rotor of the spindle motor, must be set at this interface. The properties include the outer diameter, width, and density of the mass.

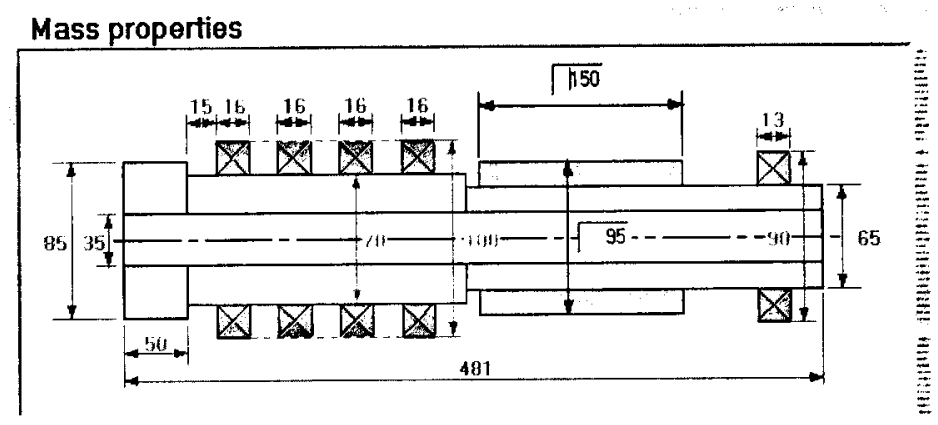

$$
\begin{aligned}
& \text { Mass Properties } \\
& \text { Density: } 7800\left[\mathrm{~kg} / \mathrm{m}^{3}\right]
\end{aligned}
$$

Figure 5.27: Interface for Setting Mass Properties

\section{Set Constraints}

Although the constraints are set to the bearing gaps, as shown in Fig. 5.28, the system computes the constraints, so the node spans, in the FE model.

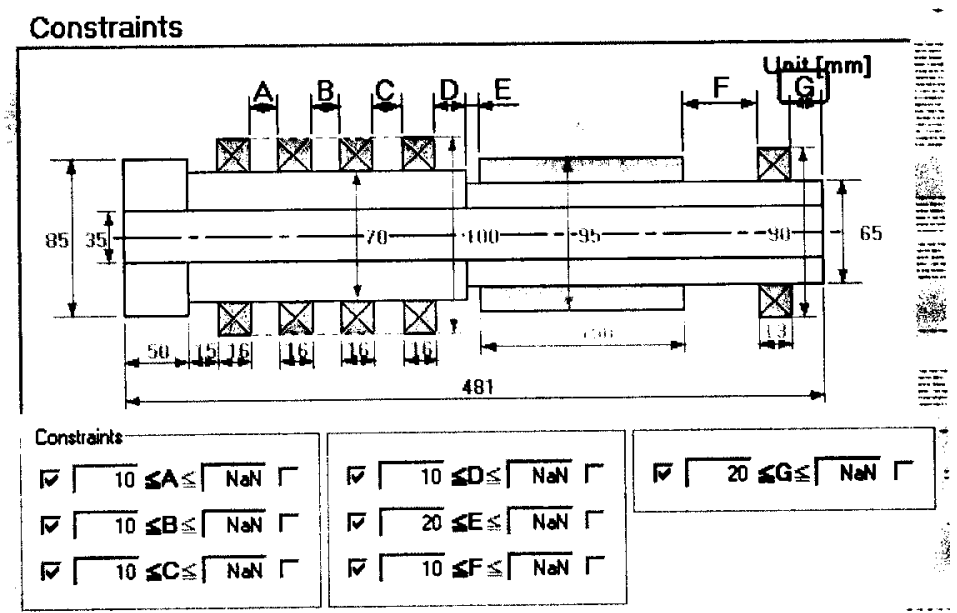

Figure 5.28 : Interface for Setting Bearing Span Constraints 


\section{Set Tool Dimensions and Initial Bearing Spans}

Since the FRF must be calculated at the tool tip to compute chatter vibrations, the dimensions of the tool and toolholder are required. The value set in Section 4.5, Step. 1 is used as the cutter diameter.

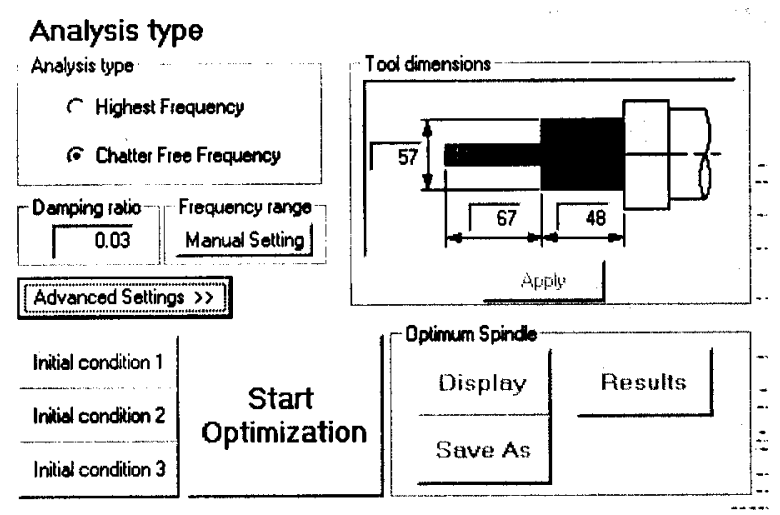

Figure 5.29 : Interface for Setting Analysis Type

Three types of initial bearing spans are set without violating the constraints set at Step. 5. The following three spans are used as the initial spans (Fig. 5.30).

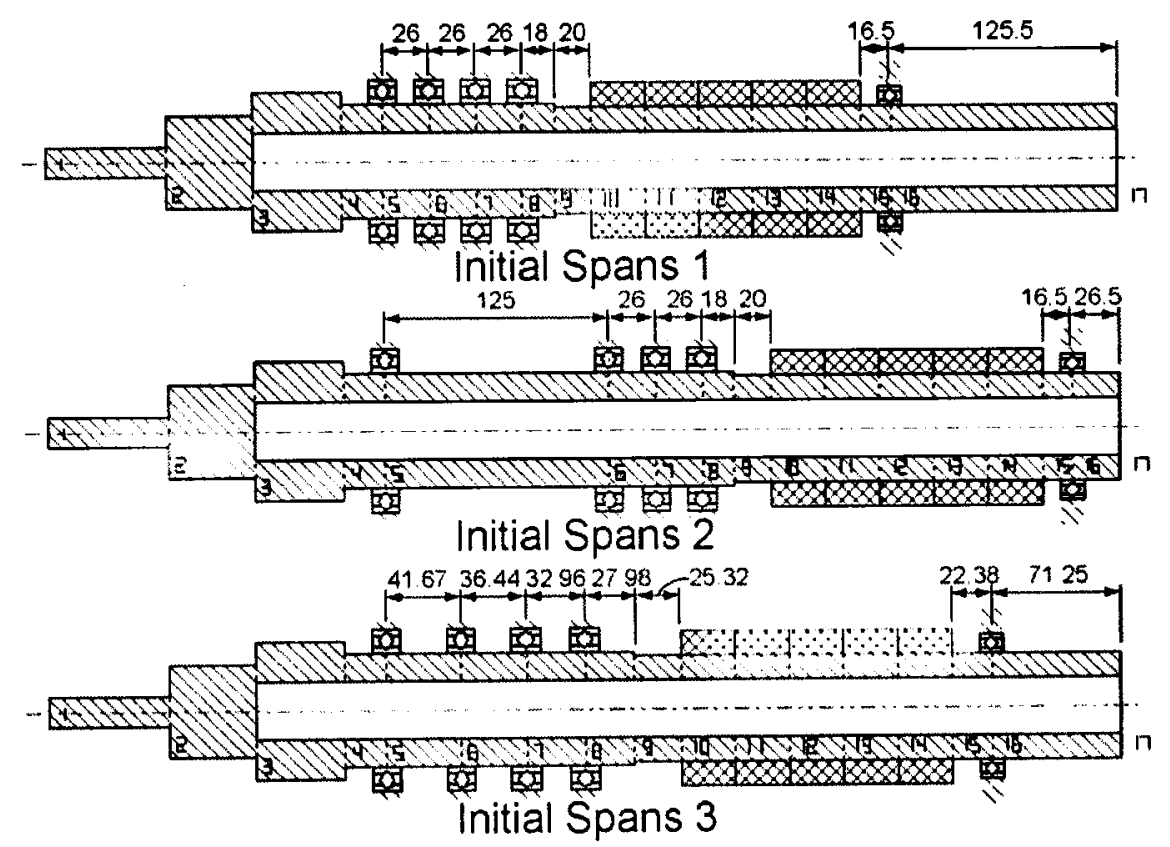

Figure 5.30 : Initial Spans 


\section{Calculation}

The SQP is used to optimize the bearing spans. The process used to calculate the objective function $f_{o b}$ is not simple, and the gradients and Hessian matrix cannot be calculated analytically. Therefore, these are derived numerically using a numerical differentiation method and a Quasi-Newton method, respectively. The minimum change in the design variables for finite difference gradients is set to $0.01[\mathrm{~mm}]$ so that the first partial derivative $\nabla f$ is derived by subtracting $0.01[\mathrm{~mm}]$ from the bearing spans. The BFGS approximation technique is used to update the Hessian matrix.

The termination tolerance of the objective function values is set to 0.0001 . In the case that the optimized value difference between the previous and current values is less than 0.0001 , the calculation stops computing and the final value is shown as the optimized value.

The optimization calculations are examined with three kinds of initial spans. The results of each calculation are compared and the minimum value of the objective function is taken as the optimum result.

\section{Results}

Table 5.1 shows the iteration process of each model. Model 1 is at the local minimum with the initial bearing spans, so the optimization calculation is terminated with only one iteration. The calculation of model 2 terminated with three iterations. Model 3 requires eight iterations. The values at the lower right of each model table are compared, and the minimum value is chosen as the final optimum value. In Table 5.1, the value of model 3 is the smallest value, therefore, the optimized bearing spans of model 3 are the final optimum bearing spans. 
Table 5.1 : Iteration Process to Identify Optimized Bearing Spans

(See Fig. 5.16 for $\mathrm{x}(1), \ldots, \mathrm{x}(6)$, and $\bar{x}$ )

Model 1

\begin{tabular}{|c|c|c|c|c|c|c|c|c|}
\hline Iteration No. & $x(1)$ & $x(2)$ & $x(3)$ & $x(4)$ & $x(5)$ & $x(6)$ & $\bar{x}$ & Objective \\
\hline Initial Vari. & 26 & 26 & 26 & 18 & 20 & 16.5 & 125.5 & -1.404916 \\
\hline 1 & 26 & 26 & 26 & 18 & 20 & 16.5 & 125.5 & -1.404916 \\
\hline
\end{tabular}

Model 2

\begin{tabular}{|c|c|c|c|c|c|c|c|c|}
\hline Iteration No. & $x(1)$ & $x(2)$ & $x(3)$ & $x(4)$ & $x(5)$ & $x(6)$ & $\bar{x}$ & Objective \\
\hline Initial Vari. & 125 & 26 & 26 & 18 & 20 & 16.5 & 26.5 & -1.089992 \\
\hline 1 & 26 & 26 & 26 & 97.30 & 39.70 & 16.5 & 26.5 & -4.024501 \\
\hline 2 & 26 & 26 & 26 & 117.00 & 20 & 16.50 & 26.5 & -4.037782 \\
\hline 3 & 26 & 26 & 26 & 117.00 & 20 & 16.50 & 26.5 & -4.037811 \\
\hline
\end{tabular}$\quad 0.0000029<0.0001$

Model 3

\begin{tabular}{|c|c|c|c|c|c|c|c|c|}
\hline Iteration No. & $x(1)$ & $x(2)$ & $x(3)$ & $x(4)$ & $x(5)$ & $x(6)$ & $\bar{x}$ & Objective \\
\hline Initial Vari. & 41.67 & 36.44 & 32.96 & 27.98 & 25.32 & 22.38 & 71.25 & -1.237261 \\
\hline 1 & 26 & 26 & 26 & 117 & 20 & 16.5 & 26.5 & -4.037744 \\
\hline 2 & 26 & 26 & 26 & 116.34 & 20 & 17.16 & 26.5 & -4.063706 \\
\hline 3 & 26 & 26 & 26 & 18 & 89.89 & 45.61 & 26.5 & -4.665540 \\
\hline 4 & 26 & 26 & 26 & 32.69 & 60.67 & 60.14 & 26.5 & -4.982496 \\
\hline 5 & 26 & 26 & 26 & 65.48 & 20 & 68.02 & 26.5 & -5.185286 \\
\hline 6 & 26 & 26 & 26 & 68.47 & 20 & 65.03 & 26.5 & -5.197738 \\
\hline 7 & 26 & 26 & 26 & 69.55 & 20 & 63.95 & 26.5 & -5.198566 \\
\hline 8 & 26 & 26 & 26 & 69.43 & 20 & 64.07 & 26.5 & -5.198582 \\
\hline
\end{tabular}

Figure 5.31 (a) shows the chatter stability lobes computed from the initial bearing spans (Fig.5.30). The desired spindle speed is 9,000 [rpm], and the depth of cut is 3 [mm]. The three initial bearing span models yield to an unstable cutting with chatter vibrations.

The SQP optimization is implemented, and the bearing spans are optimized as shown in Fig. 5.32. The chatter stability lobes are modified as shown in Figure 5.31 (b). The three optimum stability lines 1 to 3 are calculated from the optimized models 1 to 3 , respectively. The optimized stability lobes are different depending on the initial bearing spans. The optimum results 2 and 3 
make the cutting stable at the desired speed and depth while it is unstable at the optimum solution $\# 1$.

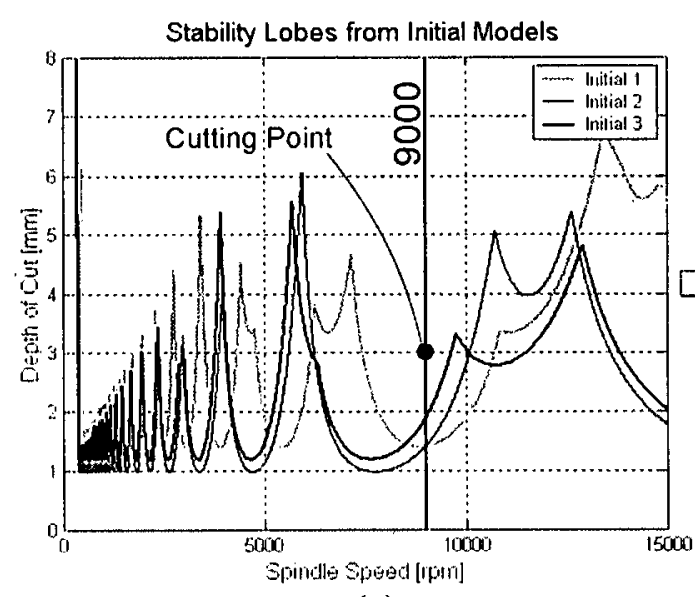

(a)

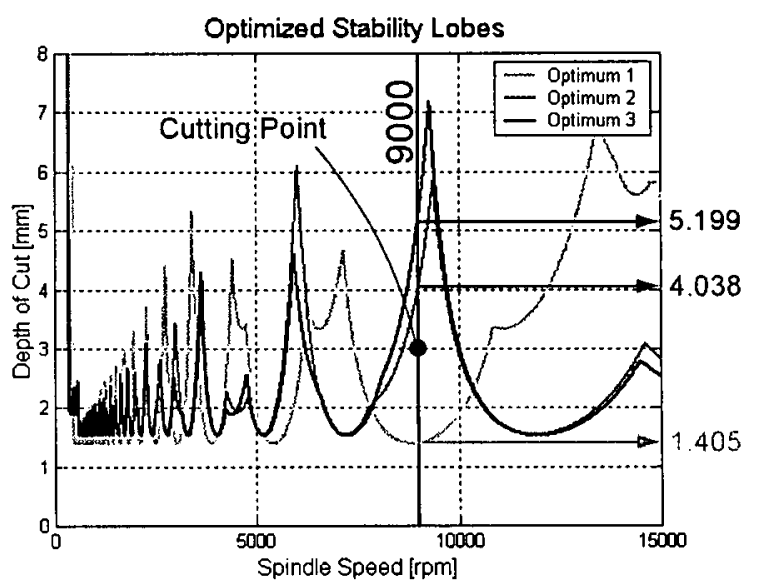

(b)

Figure 5.31 : Initial (a) and Optimized (b) Chatter Stability Lobes

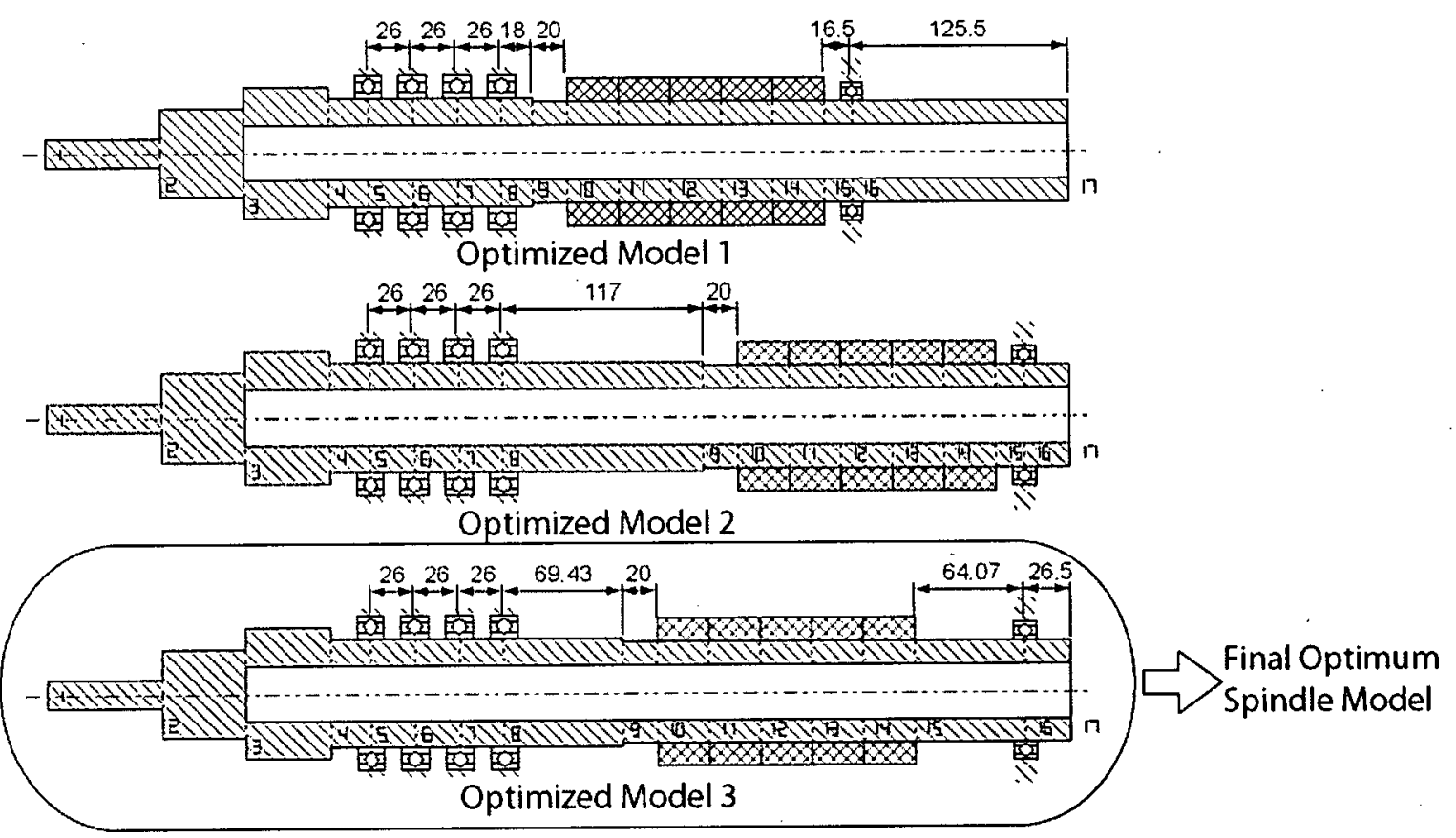

Figure 5.32 : Optimized Models 


\subsubsection{Validation}

In order to validate the optimization, two design variables, $\mathrm{x}(4)$ and $\mathrm{x}(6)$, are changed slightly (Fig. 5.33) by one millimeter each (Table. 5.2), and all stabilities are checked by using the final optimum bearing spans model.

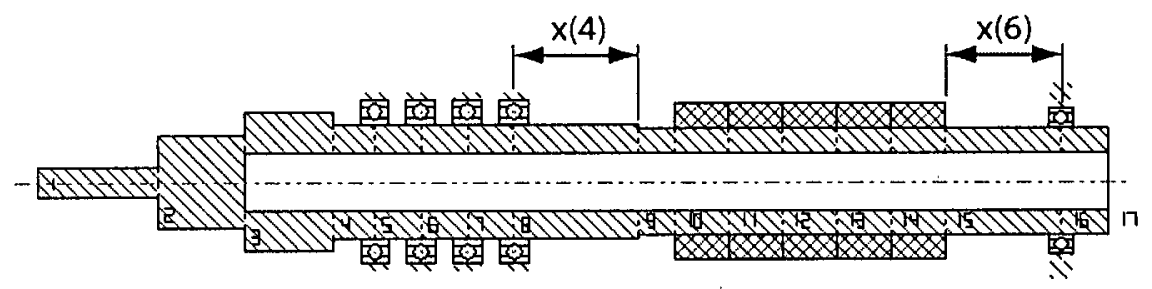

Figure 5.33 : Modifying Design Variables

Table 5.2 : Modification Parameters

\begin{tabular}{|c|c|c|}
\hline & $x(4)$ & $x(6)$ \\
\hline Optimum & 69.43 & 64.07 \\
\hline Modified 1 & 70.43 & 63.07 \\
\hline Modified 2 & 68.43 & 65.07 \\
\hline
\end{tabular}

Figure 5.34 (a) shows the comparison among the stability lobes of the final optimum bearing spans and the modified bearing spans. Since there is little difference between the bearing spans, the stability lobes are very similar. Figure 5.34 (b) is the figure that zooms in the rectangle box at (a). The depth of cut of the final optimum model at the spindle speed of 9,000 [rpm] is 5.1988 , and those of both modified models are 5.1979. Thus, it can be concluded that the final result is the optimized model. 


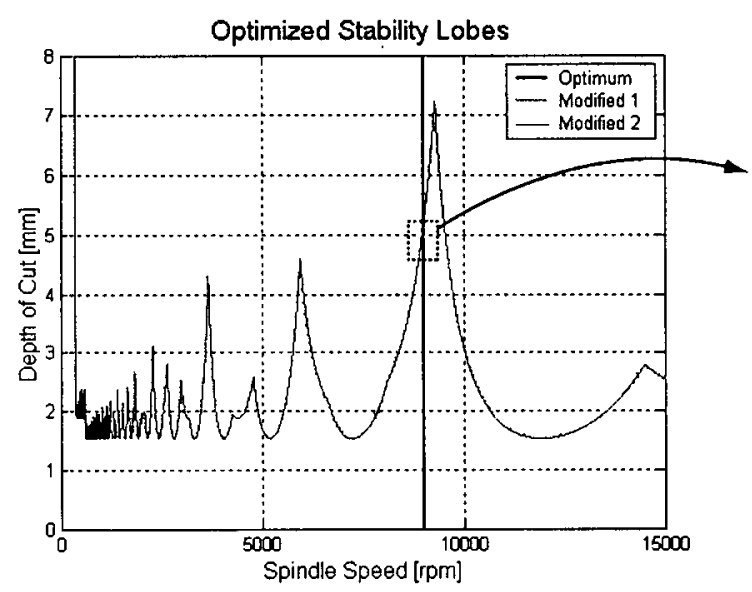

(a)

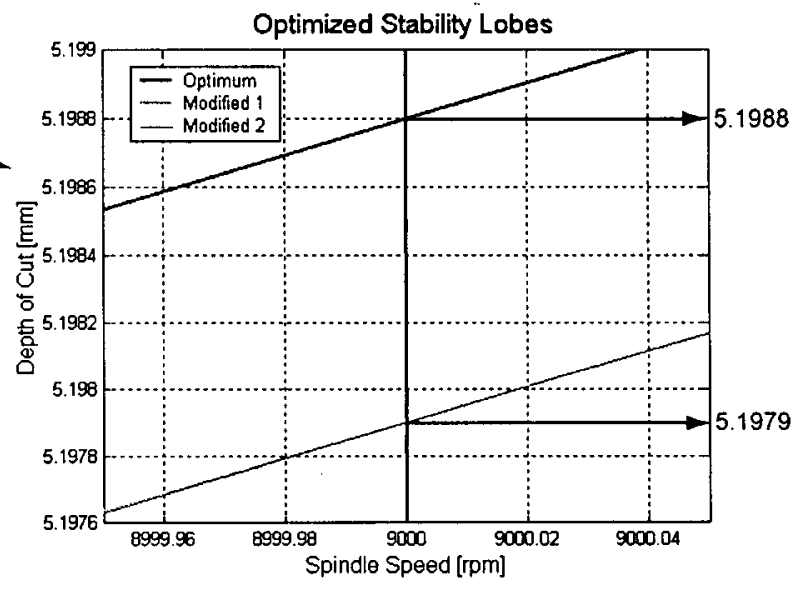

(b)

Figure 5.34 : (a) Validation of Final Optimum Stability Lobes, (b) Figure That Zooms in the Rectangle Box at (a) 


\section{Chapter 6}

\section{Conclusions}

This thesis presents an Expert Spindle Design system for machine tool engineers. It proposes an alternative method to the present design practice which is based on the past experience of individual designers, while attempting to eliminate costly trials by using the laws of machine design, solid mechanics, and metal cutting dynamics in an integrated fashion.

The author of this thesis has industrial experience as a machine tool designer. He compiled additional design data from the existing machine tool spindles and contacts from major international spindle builders in various countries. The design configurations and membership functions are stored in a knowledge base using sets of design rules based on the past experience and laws of cutting mechanics. Fuzzy logic is used as an inference engine in the proposed expert system. The fuzzy logic can deal with design uncertainties such as high, medium and low speeds or large/small torque required from the spindles where the exact numerical values are difficult to set rigidly by the designers. The membership functions can be updated by the designers as the rules change due to technological advances in industry. The expert system leads to automatic generation of spindle configuration which includes drive shaft, motor type and size, transmission mechanism between the motor and shaft, and tool holder style.

While the configuration and sub-components of the spindle are based on the torque, power, and speed requirements from the machine tool, the exact spacing of the bearings must be determined based on the chatter vibration stability of the spindle. The thesis proposes a bearing spacing optimization strategy for the spindles configured by the expert system or designed by the engi-

neers. The designer provides initial estimates of the bearing spacings including constraints. The configured spindle is analyzed by a proposed Finite Element Analysis (FEA) algorithm based on 
Timoshenko Beam elements. Since the chatter stability in milling is affected by the dynamic flexibilities of the spindle shaft in the radial plane, the axial freedom of the system is neglected. The Frequency Response Function (FRF) of the spindle at the tool tip is obtained by the modal analysis module of the FEA algorithm. The FRF is required by the chatter stability law which indicates whether the spindle with the proposed bearing spacing would cut the desired work material without chatter vibrations. The bearing spacings are optimized iteratively until the designed spindle satisfies chatter vibration free cutting constraints. Sequential Quadratic Programming (SQP) is used as an optimization method in identifying optimal bearing locations. The proposed expert spindle design strategy is demonstrated in designing several industrial size spindles used in industry.

The proposed system is an initial attempt to create an expert and optimal system for the design of machine tool spindles, and additional research is needed before it can be more effectively used in industry. One of the difficulties is to model a tool holder and spindle interface. The contact stiffness and damping at the tool holder-spindle depends on the axial preload of the drawbar which pulls the tool towards the hollow spindle taper. The surface finish quality, the shape, and area of the contact also affect the contact stiffness, which in turn influences the dynamic stiffness of the spindle. In addition, the connection of the spindle to the machine tool column, and the boundary conditions between the machine tool bed and foundation need to be considered since they affect the overall dynamic stiffness of the spindle. A database containing the damping coefficients at the tool holder, bearing, and any other assembly junctions needs to be measured and added to the knowledge base of the expert system. More than one cutting conditions, such as variable tools, spindle speeds, workpiece materials, and depth of cut must be added to the optimization of bearing spacing so that wider range of spindle applications can be considered. It must be noted that addition of multiple variables such as speed, number of teeth and shaft dimensions may 
have difficulties. The future research is recommended to focus on widening the objective function while ensuring the convergence to an optimum spindle design for high performance machining. 
Appendix A

\section{A.1. Bearing Arrangement for Milling Spindles}

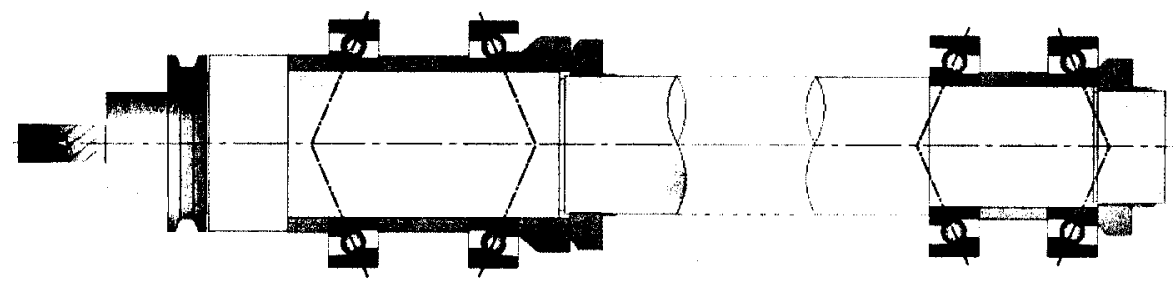

Figure A.1 : DB-DB

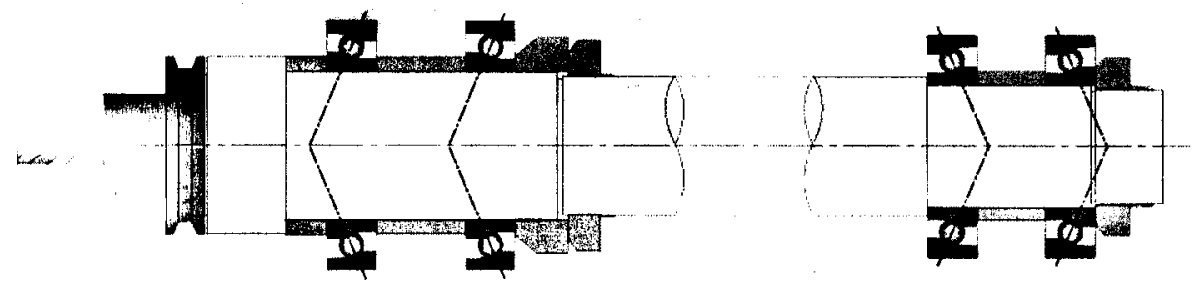

Figure A.2 : DT-DT

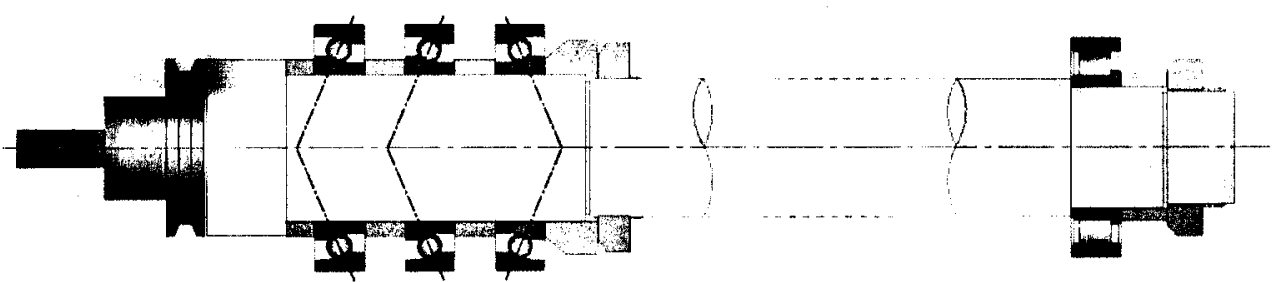

Figure A.3 : 2TB-R

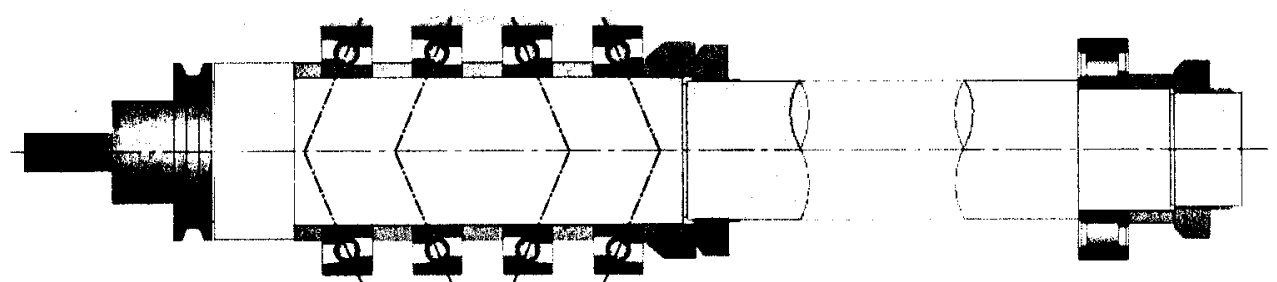

Figure A.4 : QB-R 


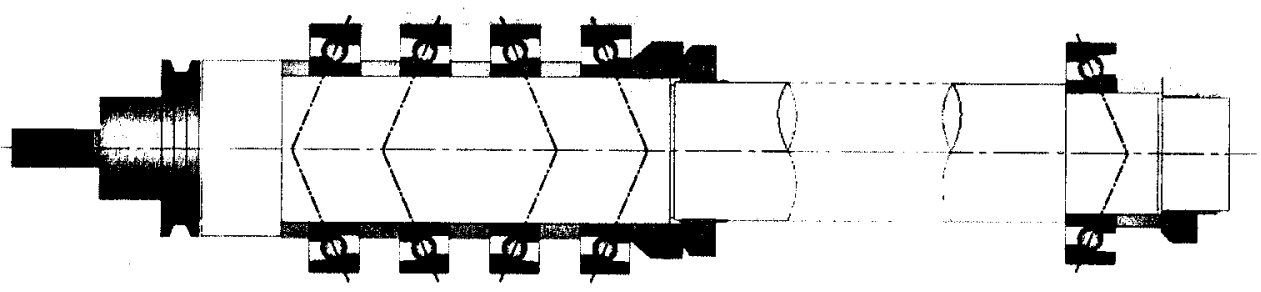

Figure A.5 : QB-A
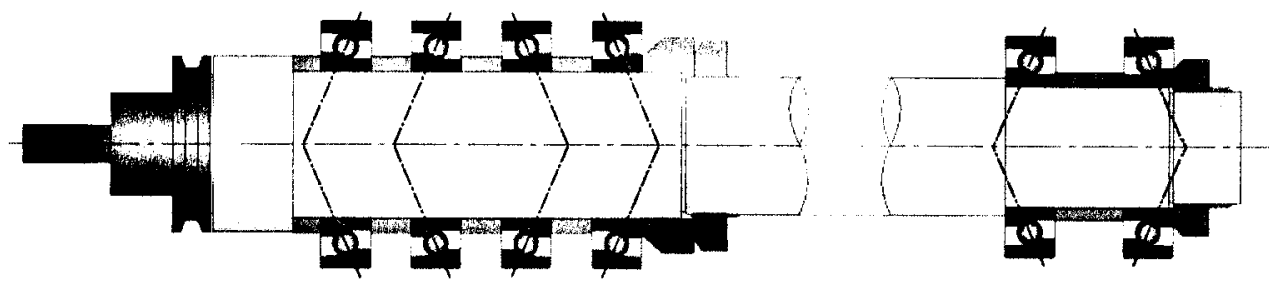

Figure A.6 : QB-DB

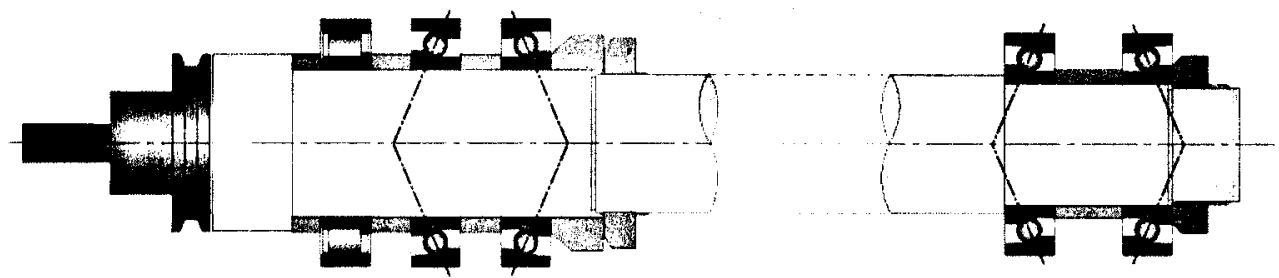

Figure A.7 : RDB-DB 


\section{Appendix B}

\section{B.1 Comparison of Inserting Angles}
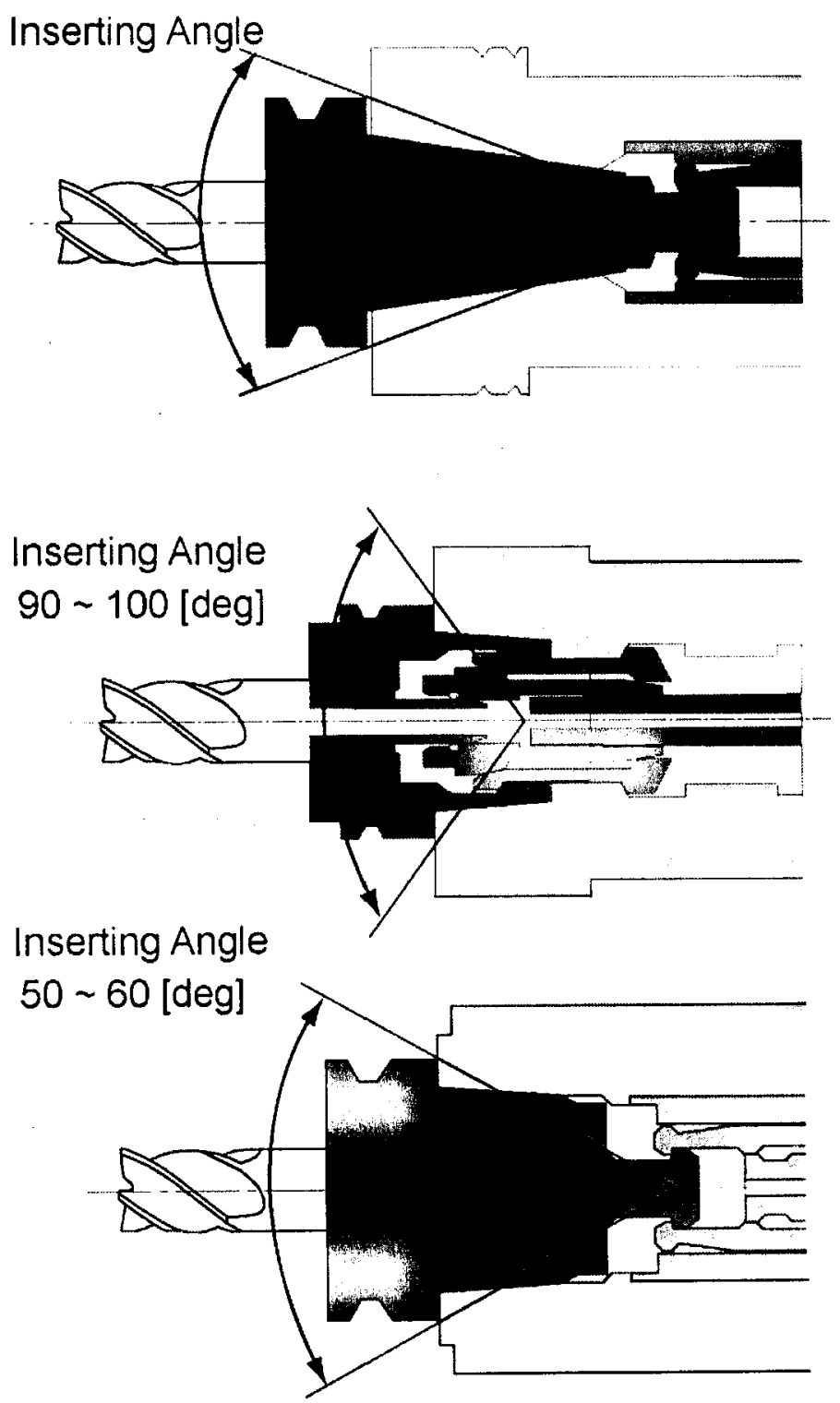

Figure B.1 : Inserting Angle Comparison 


\section{Appendix C}

\section{C.1 Specifications of Fadal VMC 2216}

Table C.1 : Specifications of VMC 2216

\begin{tabular}{|c|c|}
\hline \multicolumn{2}{|c|}{ SPECIFICATIONS } \\
\hline Table Size & $39^{\prime \prime} \times 16^{\prime \prime}$ \\
\hline Floor to Table Surface & $31^{\prime \prime}$ \\
\hline T-Slots (No. x Width x Span) & $3 \times .562^{\prime \prime} \times 4.33^{\prime \prime}$ \\
\hline Cutting Feed Rate $(\mathrm{X} / \mathrm{Y} / \mathrm{Z})$ & $.01-400 \mathrm{ipm}$ \\
\hline Rapid Travel Rate (X/Y/Z) & $900(X / Y) 700(Z)$ ipm \\
\hline Max. Weight on Table & 2,006 lbs. \\
\hline AC Axis Drive Motor (X/Y/Z) & 3,800 lbs. $^{\star}$ thrust \\
\hline Ball Screw Size $(X / Y / Z)$ & $40 \mathrm{~mm}$ dia. \\
\hline Longitudinal (X-Axis) & $22^{\prime \prime}$ \\
\hline Cross (Y-Axis) & $16^{\prime \prime}$ \\
\hline Vertical (Z-Axis) & 20" (Opt.28") \\
\hline Spindle Nose to Table & 4"-24" \\
\hline Spindle Center to Column Ways & $16^{\prime \prime}$ \\
\hline Main Motor - Spindle Horse Power & $15 \mathrm{HP} / 22.5 \mathrm{HP}$ \\
\hline Spindle Torque* & $160 / 220 \mathrm{ft}$-Ibs. \\
\hline Accuracy, Axis Positioning ${ }^{\star \star}$ & $+/-.0002 "$ \\
\hline Accuracy, Axis Repeatability** & $+1-.0001^{\prime \prime}$ \\
\hline Glass Scales (X/Y/Z) & Optional \\
\hline Spindle Speed & $10 \mathrm{~K} / 15 \mathrm{~K}$ Opt. \\
\hline Spindle Orientation & Electromechanical \\
\hline Spindle Taper & No. 40 \\
\hline ATC, Number of Tools & 21 \\
\hline ATC, Tool selection & Random / Bi-directional \\
\hline Max. Tool diameter & 3" \\
\hline (Without Adjacent Tools) & $4.5^{\prime \prime}$ \\
\hline Max. Tool Length & $15^{\prime \prime}$ \\
\hline Max. Tool Weight & 15 lbs. \\
\hline Machine Width x Depth & $98 " \times 77^{\prime \prime}$ \\
\hline Machine Maximum Height & $103^{\prime \prime}$ \\
\hline Machine Weight & $8,300 \mathrm{lbs}$. \\
\hline Air Pressure Requirement (Momentary) & 80 PSI, 15 SCFM \\
\hline Power Requirement (3-Phase) & $40 / 45$ Amps, 230 VAC \\
\hline CoolPower System & Spindle $/ X, Y, Z$ Ballscrews \\
\hline
\end{tabular}




\section{Appendix D}

\section{D.1 Membership Functions for Transmission Selection (Direct Coupling / Motorized)}

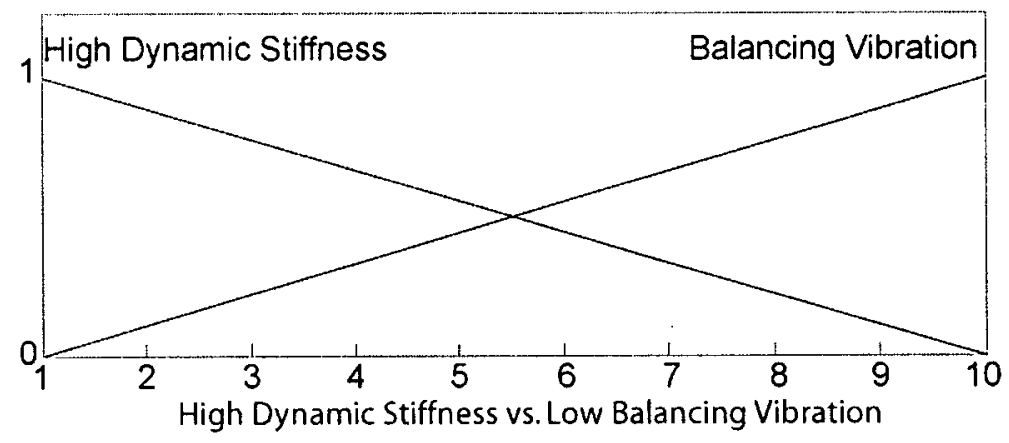

Figure D.1 : Membership Function of High Dynamic Stiffness vs. Balancing Vibration

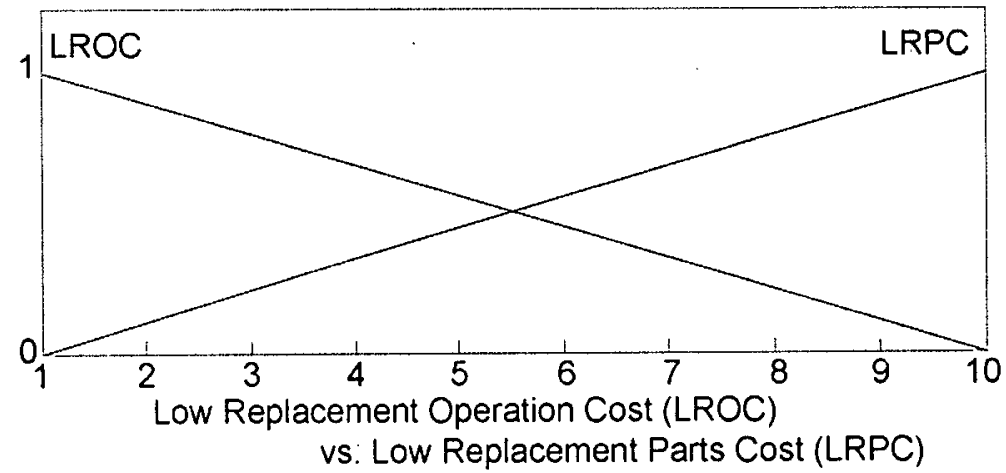

Figure D.2 : Membership Function of Low Replacement Operation Cost vs. Low Replacement Parts Cost 


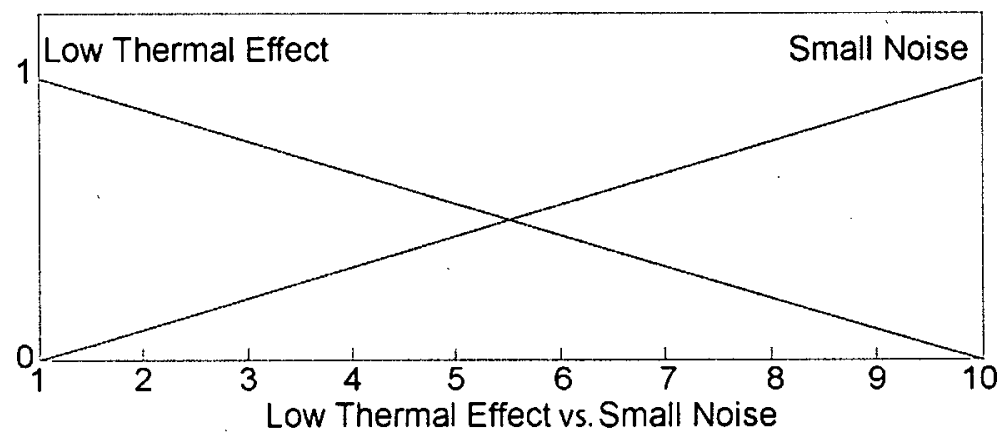

Figure D.3 : Membership Function of Low Thermal Effect vs. Small Noise

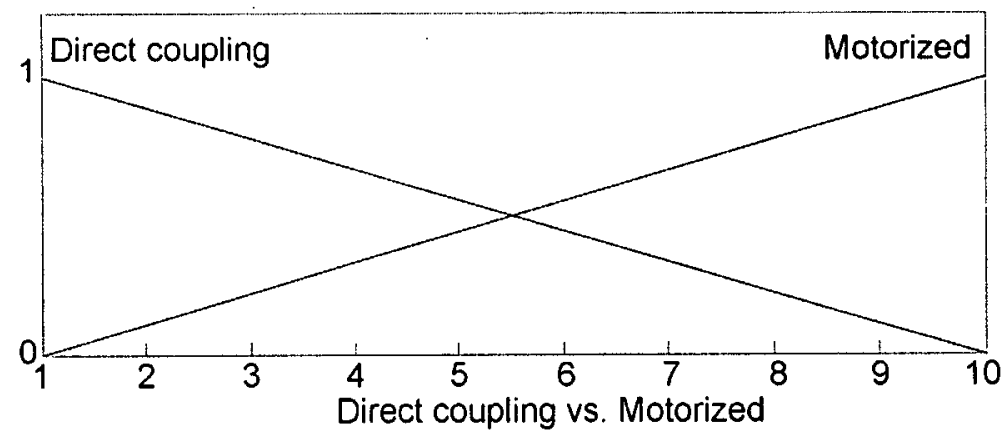

Figure D.4 : Membership Function of Direct Coupling vs. Motorized

\section{D.2 Membership Functions for Lubrication Selection}

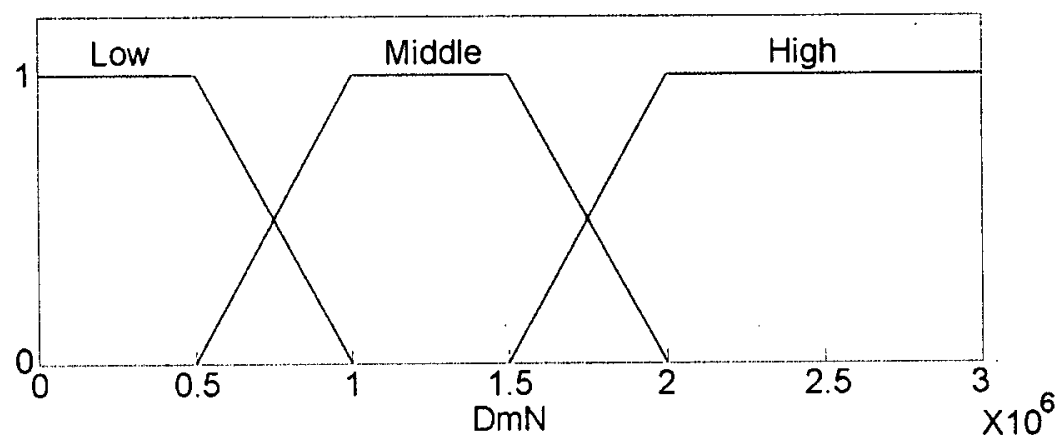

Figure D.5 : Membership Function of DmN 


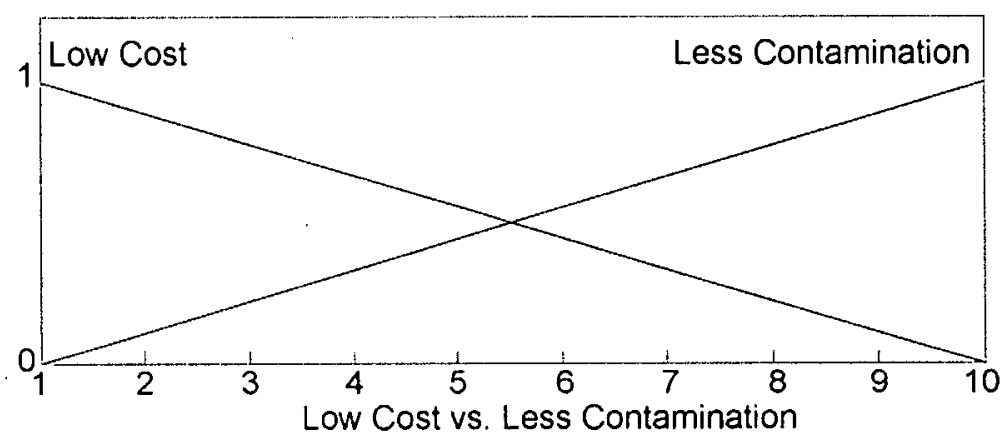

Figure D.6 : Membership Function of Low Cost vs. Less Contamination

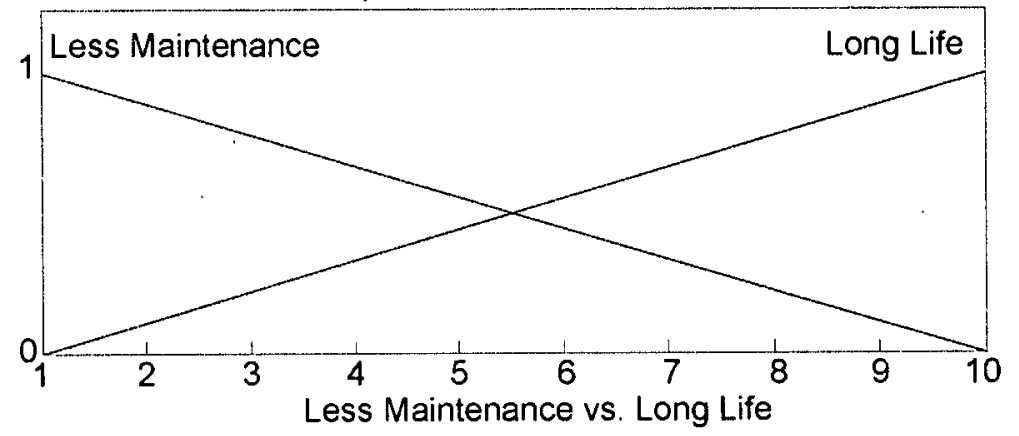

Figure D.7 : Membership Function of Less Maintenance vs. Long Life

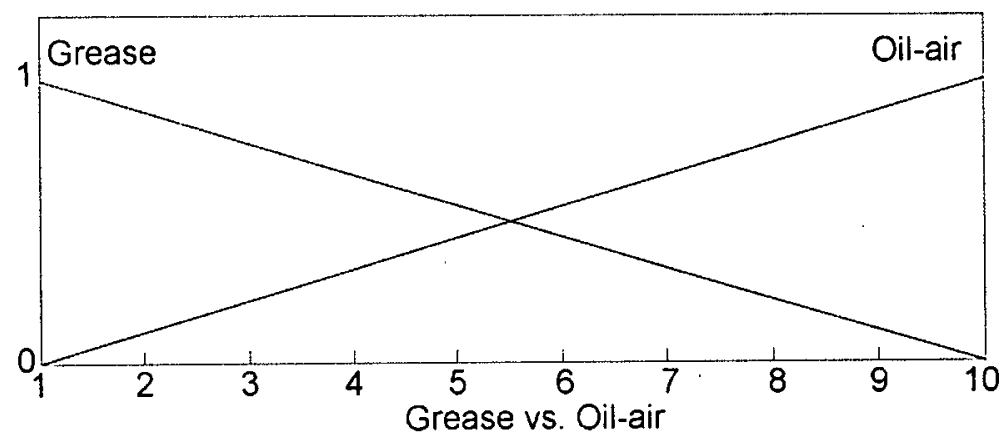

Figure D.8 : Membership Function of Grease vs. Oil-air 


\section{Appendix E}

\section{E.1 Euler-Bernoulli Beam Model}

\section{Shape Function}

Since the translational and torsional effects can be negligible, only bending and rotational effects will be taken into account.

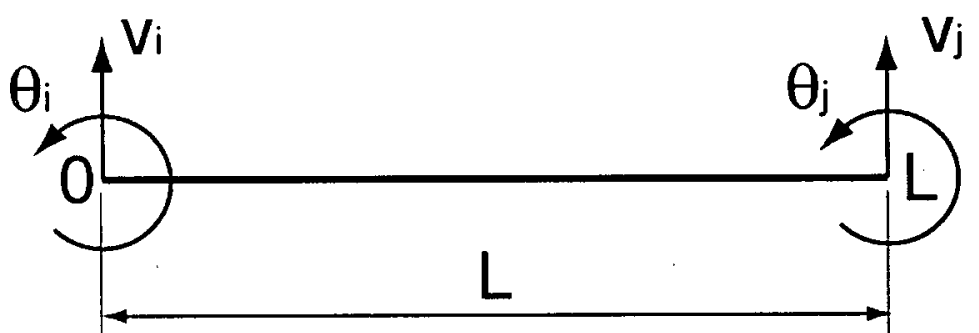

Figure E.1 : Degree of Freedom of Euiler-Bernoulli Beam Element

The solution must be a cubic polynomial because there are four boundary conditions show in Figure E.1. Therefore, the solution should be the following form,

$$
v(x)=a_{0}+a_{1} x+a_{2} x^{2}+a_{3} x^{3}
$$

where, constants $a_{0}$ through $a_{3}$ are determined from the required four support conditions. Then, the first derivative of $v(x)$ corresponds to rotational angle $\theta(x)$.

$$
\nu^{\prime}(x)=\theta(x)=a_{1}+2 a_{2} x+3 a_{3} x^{2}
$$

Substituting the boundary conditions at the position, $x=0$ and $x=L$, into Eq. (E.1) and (E.2),

$$
\begin{aligned}
& v(0)=a_{0}=v_{i} \\
& \theta(0)=a_{1}=\theta_{i}
\end{aligned}
$$




$$
\begin{gathered}
v(L)=a_{0}+a_{1} L+a_{2} L^{2}+a_{3} L^{3}=v_{j} \\
\theta(L)=a_{1}+2 a_{2} L+3 a_{3} L^{2}=\theta_{j}
\end{gathered}
$$

Transforming Eq. (E.3) to (E.6), the displacement $v(x)$ can be expressed as follows.

$$
v(x)=N_{v 1} v_{i}+N_{v 2} \theta_{i}+N_{v 3} v_{j}+N_{v 4} \theta_{j}
$$

where,

$$
\begin{gathered}
N_{v 1}=1-3 \xi^{2}+2 \xi^{3} \\
N_{v 2}=L\left(\xi-2 \xi^{2}+\xi^{3}\right) \\
N_{v 3}=3 \xi^{2}-2 \xi^{3} \\
N_{v 4}=L\left(\xi^{3}-\xi^{2}\right) \\
\xi=x / L
\end{gathered}
$$

With matrix form, Eq. (E.7) can be expressed as follows.

$$
\begin{gathered}
v=N_{v}^{T} \cdot a \\
\delta v=\delta a^{T} \cdot N_{v}
\end{gathered}
$$

where,

$$
N_{v}=\left[\begin{array}{c}
N_{v 1} \\
N_{v 2} \\
N_{v 3} \\
N_{v 4}
\end{array}\right]=\left[\begin{array}{c}
1-3 \xi^{2}+2 \xi^{3} \\
L\left(\xi-2 \xi^{2}+\xi^{3}\right) \\
3 \xi^{2}-2 \xi^{3} \\
L\left(\xi^{3}-\xi^{2}\right)
\end{array}\right], a=\left[\begin{array}{c}
v_{i} \\
\theta_{i} \\
v_{j} \\
\theta_{j}
\end{array}\right]
$$

For convenience of later calculations, 


$$
N_{v}^{\prime}=\frac{d N_{v}}{d x}=\frac{d N_{v}}{d \xi} \cdot \frac{d \xi}{d x}=\left[\begin{array}{c}
N_{v 1}^{\prime} \\
N_{v 2^{\prime}} \\
N_{v 3^{\prime}} \\
N_{v 4}^{\prime}
\end{array}\right]=\left[\begin{array}{c}
\frac{1}{L}\left(-6 \xi+6 \xi^{2}\right) \\
1-4 \xi+3 \xi^{2} \\
\frac{1}{L}\left(6 \xi-6 \xi^{2}\right) \\
3 \xi^{2}-2 \xi
\end{array}\right], N_{v}^{\prime \prime}=\frac{d^{2} N_{v}}{d x^{2}}=\left[\begin{array}{c}
\frac{1}{L^{2}}(-6+12 \xi) \\
\frac{1}{L}(-4+6 \xi) \\
\frac{1}{L^{2}}(6-12 \xi) \\
\frac{1}{L}(6 \xi-2)
\end{array}\right]
$$

\section{Internal Virtual Work}

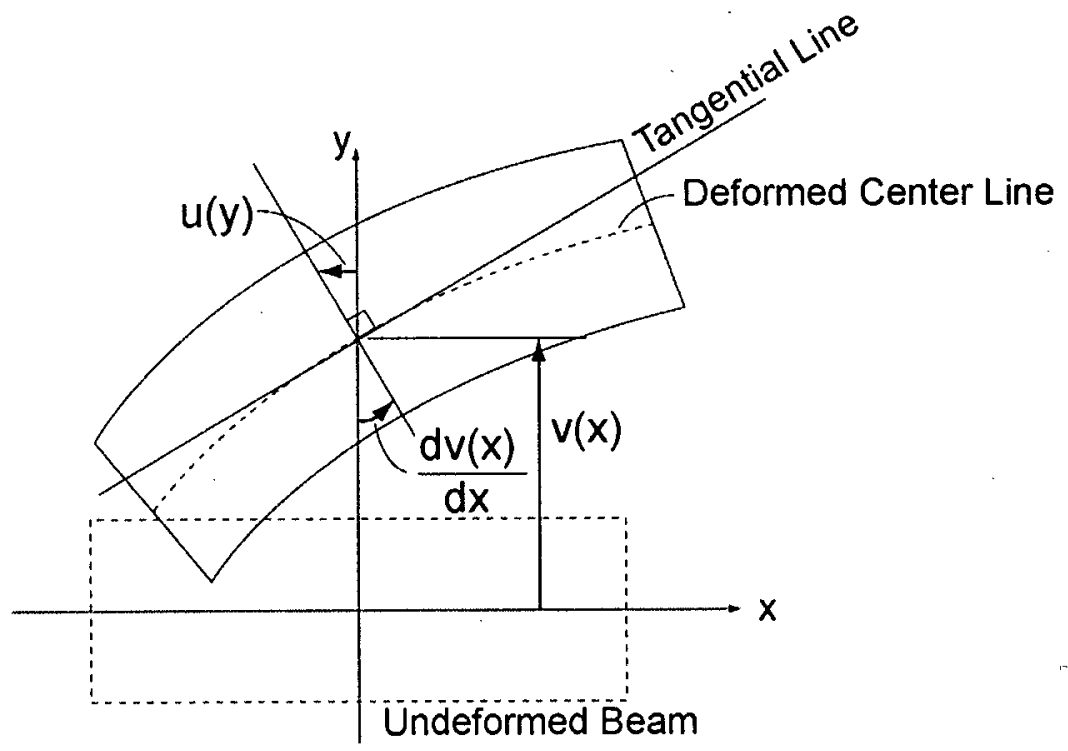

Figure E.2 : Deformation of Euler-Bernoulli Beam

The deformation of the Euler-Bernoulli beam can be expressed as follows.

$$
\begin{gathered}
u(z)=-y \frac{d v}{d x}=-y v^{\prime} \\
v(x)=v
\end{gathered}
$$

Strain and stress can be formulated, 


$$
\begin{gathered}
\text { Strain : } \varepsilon(y)=\frac{\partial u}{\partial x}=-y v^{\prime \prime}, \text { Virtual strain : } \delta \varepsilon(z)=-y \delta v^{\prime \prime} \\
\text { Stress : } \sigma(y)=E \varepsilon(y)=-E y v^{\prime \prime}
\end{gathered}
$$

Internal virtual work $\delta W_{\text {int }}$ can be expressed with the stress $\sigma(y)$ and virtual strain $\delta \varepsilon$ as follows.

$$
\begin{aligned}
\delta W_{\text {int }} & =\int_{v o l} \sigma \delta \varepsilon \\
& =\int_{v o l} E\left(-y v^{\prime \prime}\right)\left(-y \delta v^{\prime \prime}\right) \\
& \left.=E I \int_{0}^{L} v^{\prime \prime} \delta v^{\prime \prime} \quad \text { (since, } I=\int_{\text {area }} y^{2} d A \quad\right) \\
& =E I \delta a^{T}\left(\int_{0}^{L} N_{v}{ }^{\prime \prime}{ }^{T} N_{v}{ }^{\prime \prime}\right) a
\end{aligned}
$$

\section{External Virtual Work}

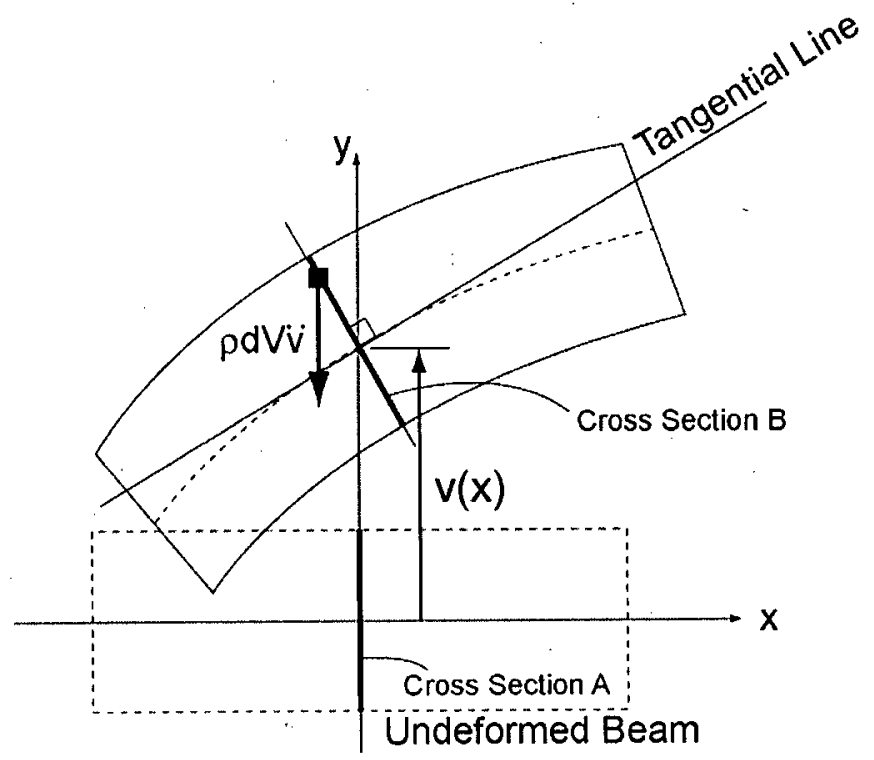

Figure E.3 : Inertia Force Worked in Euler-Bernoulli Beam 
Along the cross section $\mathrm{A}$ and $\mathrm{B}$, the deformation in $\mathrm{z}$ direction is always $v(x)$. Therefore, the inertia force in $\mathrm{z}$ direction worked in small amount volume $d V$ can be,

$$
\delta F_{y}=-\rho d V \ddot{v}
$$

External virtual work is,

$$
\begin{aligned}
\delta W_{e x t} & =-\int_{v o l} \rho \ddot{v} \cdot \delta v \\
& =-\rho A \int_{0}^{L} \ddot{v} \cdot \delta v \\
& =-\delta a\left(\rho A \int_{0}^{L} N_{v}^{T} \cdot N_{v}\right) \ddot{a}
\end{aligned}
$$

Since, the internal virtual work is equal to the external virtual work,

$$
\delta W_{\text {int }}=\delta W_{\text {ext }}
$$

Substituting Eq. (E.8) and (E.9) into Eq. E.10),

$$
\begin{aligned}
& E I \delta a^{T}\left(\int_{0}^{L} N_{v}{ }^{\prime \prime} N_{v}{ }^{\prime \prime}\right) a=-\delta a^{T}\left(\rho A \int_{0}^{L} N_{v}^{T} \cdot N_{v}\right) \ddot{a} \\
& \left(\rho A \int_{0}^{L} N_{v}^{T} \cdot N_{v}\right) \ddot{a}+E I\left(\int_{0}^{L} N_{v}{ }^{\prime \prime}{ }^{T} N_{v}{ }^{\prime \prime}\right) a=0
\end{aligned}
$$

Eq. (E.11) can be expressed with the mass matrix $\left[M_{E B}\right]$ and the stiffness matrix $\left[K_{E B}\right]$ of the Euler-Bernoulli beam as follows.

$$
\left[M_{E B}\right] \ddot{a}+\left[K_{E B}\right] a=0
$$


where,

$$
\left[M_{E B}\right]=\frac{\rho A L^{2}}{420}\left[\begin{array}{cccc}
\frac{156}{L} & 22 & \frac{54}{L} & -13 \\
\ldots & 4 L & 13 & -3 L \\
\ldots & \ldots & \frac{156}{L} & -22 \\
S Y M & \ldots & \ldots & 4 L
\end{array}\right]\left[K_{E B}\right]=\frac{E I}{L^{3}}\left[\begin{array}{cccc}
12 & 6 L & -12 & 6 L \\
\ldots & 4 L^{2} & -6 L & 2 L^{2} \\
\ldots & \ldots & 12 & -6 L \\
S Y M & \ldots & \ldots & 4 L^{2}
\end{array}\right]
$$

\section{E.2 Euler-Bernoulli Beam + Rotary Inertia Effects Model}

\section{Shape Function}

The shape function is exactly same as that of the Euler-Bernoulli beam.

\section{Internal Virtual Work}

The internal virtual work is exactly same as that of the Euler-Bernoulli beam, as well.

\section{External Virtual Work}

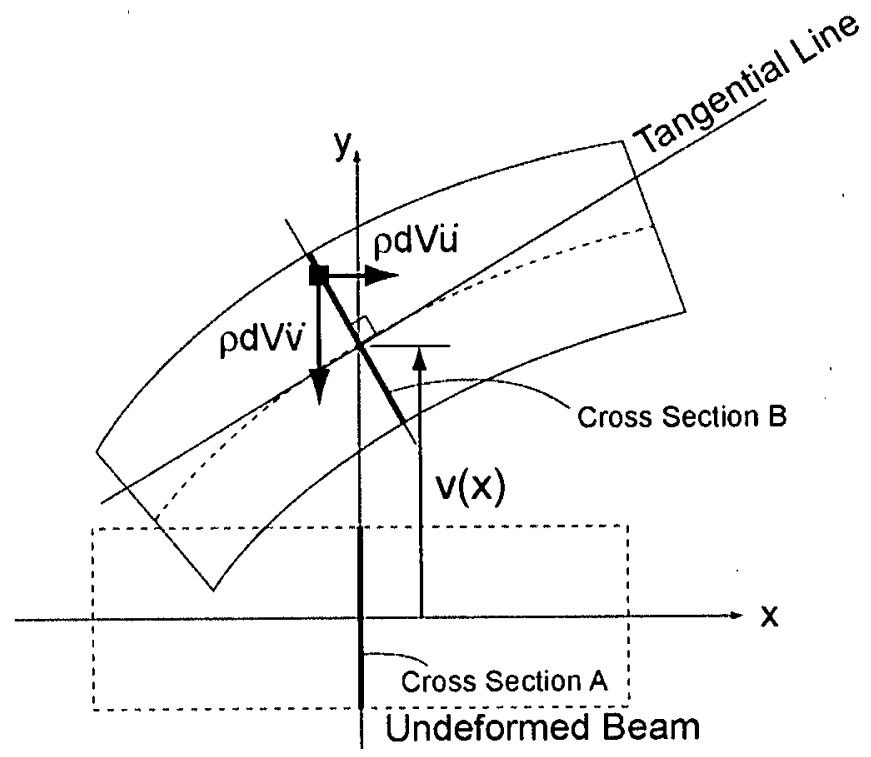

Figure E.4 : Inertia Force Worked in Euler-Bernoulli + Rotary Effects Beam 
The acceleration inside the beam element can be expressed as follows.

$$
\ddot{u}(y)=\frac{d^{2} u(y)}{d t^{2}}=-y \ddot{v}^{\prime}
$$

Along the cross section $\mathrm{A}$ and $\mathrm{B}$, the deformation in $\mathrm{z}$ direction is always $v(x)$. Therefore, the inertia force worked in small amount volume $d V$ can be,

$$
\delta F_{y}=-\rho d V \ddot{v}
$$

The inertia force in $\mathrm{x}$ direction, which expresses the rotary effects can be formulated as,

$$
\delta F_{x}=-\rho d V \ddot{u}
$$

External virtual work becomes,

$$
\begin{aligned}
\delta W_{e x t} & =-\int_{v o l} \rho \ddot{u} \cdot \delta u-\int_{v o l} \rho \ddot{v} \cdot \delta v \\
& =-\rho \int_{v o l}\left(-y \ddot{v} \ddot{v}^{\prime}\right) \cdot \delta\left(-y v^{\prime}\right)-\int_{v o l} \rho \ddot{v} \cdot \delta v \\
& =-\rho I \int_{0}^{L} \ddot{v}^{\prime} \cdot \delta v^{\prime}-\rho A \int_{0}^{L} \ddot{v} \cdot \delta v \\
= & \delta a^{T}\left(-\rho I \int_{0}^{L} N_{v}{ }^{T} N_{v}{ }^{\prime}-\rho A \int_{0}^{L} N_{v}^{T} N_{v}\right) \ddot{a}
\end{aligned}
$$

Since, the internal virtual work is equal to the external virtual work,

$$
\delta W_{i n t}=\delta W_{\text {ext }}
$$

Substituting Eq. (E.8) and (E.12) into (E.13),

$$
\begin{aligned}
& E I \delta a^{T}\left(\int_{0}^{L} N_{v}{ }^{\prime \prime} N_{v}{ }^{\prime \prime}\right) a=\delta a^{T}\left(-\rho I \int_{0}^{L} N_{v}{ }^{T} N_{v}{ }^{\prime}-\rho A \int_{0}^{L} N_{v}^{T} N_{v}\right) \ddot{a} \\
& \left(\rho A \int_{0}^{L} N_{v}^{T} \cdot N_{v}+\rho I \int_{0}^{L}{N_{v}{ }^{\prime T}}^{T} N_{v}{ }^{\prime}\right) \ddot{a}+E I\left(\int_{0}^{L} N_{v}{ }^{\prime \prime}{ }^{T} N_{v}{ }^{\prime \prime}\right) a=0
\end{aligned}
$$

Eq. (E.11) can be expressed with the mass matrix $\left[M_{E B R}\right]$ and the stiffness matrix $\left[K_{E B R}\right]$ of the Euler-Bernoulli beam as follows. 


$$
\left[M_{E B R}\right] \ddot{a}+\left[K_{E B R}\right] a=0
$$

where,

$$
\begin{gathered}
{\left[M_{E B R}\right]=\left[M_{T}^{E B R}\right]+\left[M_{R}^{E B R}\right]} \\
{\left[M_{T}^{E B R}\right]=\frac{\rho A L^{2}}{420}\left[\begin{array}{cccc}
\frac{156}{L} & 22 & \frac{54}{L} & -13 \\
\ldots & 4 L & 13 & -3 L \\
\ldots & \ldots & \frac{156}{L} & -22 \\
S Y M & \ldots & \ldots & 4 L
\end{array}\right]\left[M_{R}^{E B R}\right]=\frac{\rho I}{30}\left[\begin{array}{cccc}
\frac{36}{L} & 3 & -\frac{36}{L} & 3 \\
\ldots & 4 L & -3 & -L \\
\ldots & \ldots & \frac{36}{L} & -3 \\
S Y M & \ldots & \ldots & 4 L
\end{array}\right]} \\
{\left[K_{E B}\right]=\frac{E I}{L^{3}}\left[\begin{array}{cccc}
12 & 6 L & -12 & 6 L \\
\ldots & 4 L^{2} & -6 L & 2 L^{2} \\
\ldots & \ldots & 12 & -6 L \\
S Y M & \ldots & \ldots & 4 L^{2}
\end{array}\right]}
\end{gathered}
$$

\section{E.3 Timoshenko Beam Model}

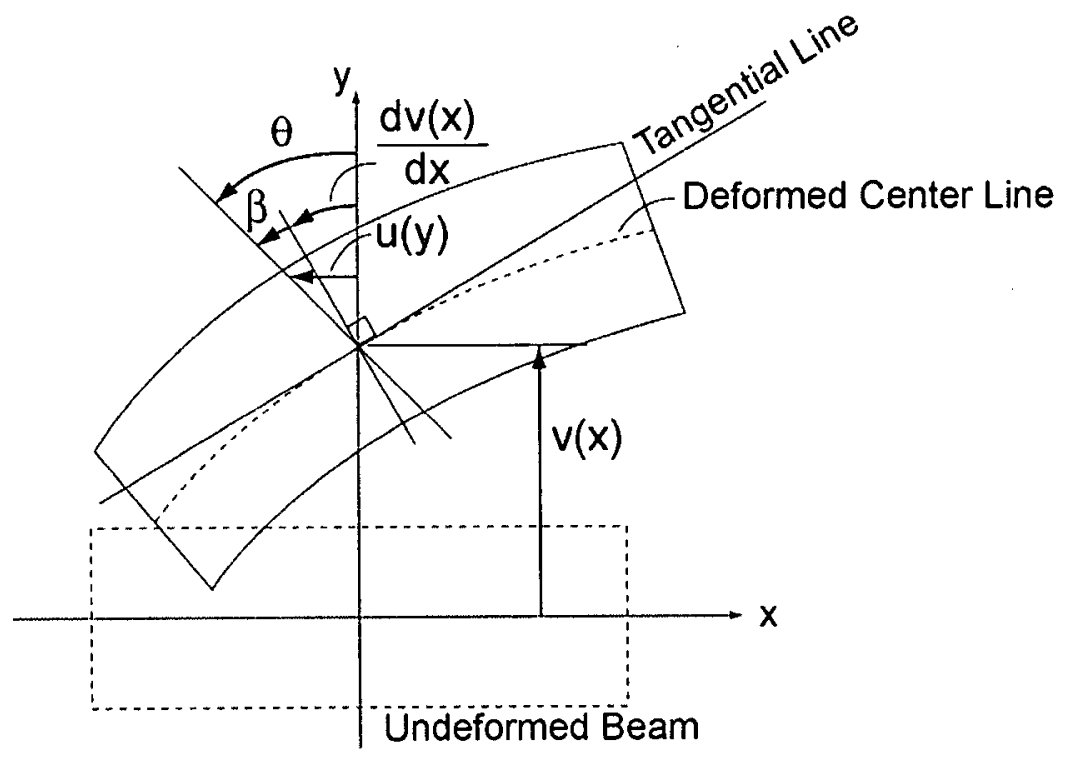

Figure E.5 : Deformation of Timoshenko Beam 


\section{Shape Function}

Deformation of the Timoshenko beam includes the shear angle $\beta$ that is independent on the deformation angle of the bending effects $\frac{d v}{d x}$. Therefore, the translational deformation $v(x)$, and the rotational deformation $\theta$ must be defined separately as follows.

$$
\begin{gathered}
v(x)=a_{0}+a_{1} x+a_{2} x^{2}+a_{3} x^{3} \\
\theta(x)=b_{0}+b_{1} x+b_{2} x^{2}
\end{gathered}
$$

Substituting the boundary conditions at the position, $x=0$ and $x=L$, into Eq. (E.15)) and (E.16),

$$
\begin{gathered}
v(0)=a_{0}=v_{i} \\
\theta(0)=b_{0}=\theta_{i} \\
v(L)=a_{0}+a_{1} L+a_{2} L^{2}+a_{3} L^{3}=v_{j} \\
\theta(L)=b_{0}+b_{1} L+b_{2} L^{2}=\theta_{j}
\end{gathered}
$$

We have, now, seven unknowns $\left(a_{0}, a_{1}, a_{2}, a_{3}, b_{0}, b_{1}, b_{2}\right)$, and four boundary conditions so that these unknowns cannot be obtained. In order to solve this problem, EulerLagrange equations are used.

$$
\frac{d^{3}}{d x^{3}}\left(\frac{\partial f}{\partial q^{\prime \prime \prime}}\right)-\frac{d^{2}}{d x^{2}}\left(\frac{\partial f}{\partial q^{\prime \prime}}\right)+\frac{d}{d x}\left(\frac{\partial f}{\partial q^{\prime}}\right)-\frac{\partial f}{\partial q}=0
$$

where, $f$ is a certain function, and $q$ is general coordinates.

The deformation $u$, strain $\varepsilon$, and stress $\sigma$ can be expressed as follows.

$$
\begin{gathered}
u(y)=-y \theta \\
\varepsilon=\frac{\partial u}{\partial x}=-y \theta^{\prime} \\
\sigma=-E y \theta^{\prime}
\end{gathered}
$$


The shear strain $\gamma$ and the shear stress $\tau$ can be expressed as follows.

$$
\begin{gathered}
\gamma=\frac{\partial u}{\partial y}+\frac{\partial v}{\partial x}=-\theta+v^{\prime}=-\beta \\
\tau=k G \gamma
\end{gathered}
$$

where, $G$ is the modulus of traverse elasticity, and $k$ is the cross section factor.

The potential energy $U$ for the Timoshenko bean can be formulated as follows.

$$
\begin{aligned}
U & =\frac{1}{2} \int_{v o l} \sigma \varepsilon+\frac{1}{2} \int_{v o l} \tau \gamma \\
& =\frac{1}{2} \int_{v o l} E y^{2}\left(\theta^{\prime}\right)^{2}+\frac{1}{2} \int_{v o l} G k\left(v^{\prime}-\theta\right) \\
& =\int_{0}^{L}\left\{\frac{1}{2} E I\left(\theta^{\prime}\right)^{2}+\frac{1}{2} k G A\left(v^{\prime}-\theta\right)\right\} d x
\end{aligned}
$$

Considering,

$$
f=\frac{1}{2} E I\left(\theta^{\prime}\right)^{2}+\frac{1}{2} k G A\left(v^{\prime}-\theta\right)
$$

and, substituting Eq. (E.22) into Euler-Lagrange equation (E.21),

In case of $q=v$,

$$
\frac{d}{d x}\left(E I \theta^{\prime}\right)+k G A\left(v^{\prime}-\theta\right)=0 \rightarrow E I \theta^{\prime \prime}+k G A\left(v^{\prime}-\theta\right)=0
$$

In case of $q=\theta$,

$$
\frac{d}{d x}\left\{k G A\left(v^{\prime}-\theta\right)\right\}=0 \quad \rightarrow k G A\left(v^{\prime \prime}-\theta^{\prime}\right)=0
$$

From Eq. (E.23) and (E.24),

$$
\begin{gathered}
2 E I b_{2}+k G A\left(a_{1}+2 a_{2} x+3 a_{3} x^{2}-b_{0}-b_{1} x-b_{2} x^{2}\right)=0 \\
2 a_{2}+6 a_{3} x-b_{1}-2 b_{2} x=0
\end{gathered}
$$

In case of $x=0$, 


$$
\begin{gathered}
2 E I b_{2}+k G A\left(a_{1}-b_{0}\right)=0 \rightarrow 2 E I b_{2}+k G A\left(a_{1}-\theta_{i}\right)=0 \\
2 a_{2}-b_{1}=0 \rightarrow b_{1}=2 a_{2}
\end{gathered}
$$

In case of $x=L$,

$$
\begin{gathered}
2 E I b_{2}+k G A\left(a_{1}+2 a_{2} L+3 a_{3} L^{2}-\theta_{i}-b_{1} L-b_{2} L^{2}\right)=0 \\
2 a_{2}+6 a_{3} L-b_{1}-2 b_{2} L=0
\end{gathered}
$$

Substituting Eq. (E.26) into (E.28),

$$
b_{2}=3 a_{3}
$$

Substituting Eq. (E.26) into (E.27),

$$
2 E I b_{2}+k G A\left(a_{1}+3 a_{3} L^{2}-\theta_{i}-b_{2} L^{2}\right)=0
$$

Substituting Eq. (E.29) into (E.20),

$$
b_{1}=\frac{1}{L} \theta_{j}-\frac{1}{L} \theta_{i}-3 a_{3} L
$$

Substituting Eq. (E.26) into (E.31),

$$
a_{2}=\frac{1}{2 L} \theta_{j}-\frac{1}{2 L} \theta_{i}-\frac{3}{2} a_{3} L
$$

Substituting Eq. (E.29) into (E.25),

$$
a_{1}=\theta_{i}-\frac{6 E I}{k G A} a_{3}
$$

Substituting Eq. (E.32) and (E.33) into (E.19),

$$
a_{3}=\frac{1}{1+\Phi}\left(\frac{2}{L^{3}} v_{i}-\frac{2}{L^{3}} v_{j}+\frac{1}{L^{2}} \theta_{i}+\frac{1}{L^{2}} \theta_{j}\right) \text { where, } \Phi=\frac{12 E I}{k G A L^{2}}
$$

Substituting Eq. (E.34) into (E.29), (E.31), (E.32), and (E.33),

$$
a_{1}=\theta_{i}+-\frac{\Phi}{1+\Phi}\left(\frac{1}{L} v_{i}-\frac{1}{L} v_{j}+\frac{1}{2} \theta_{i}+\frac{1}{2} \theta_{j}\right)
$$




$$
\begin{gathered}
a_{2}=\frac{1}{2 L} \theta_{j}-\frac{1}{2 L} \theta_{i}-\frac{1}{1+\Phi}\left(\frac{3}{L^{2}} v_{i}-\frac{3}{L^{2}} v_{j}+\frac{3}{2 L} \theta_{i}+\frac{3}{2 L} \theta_{j}\right) \\
b_{1}=\frac{1}{L} \theta_{j}-\frac{1}{L} \theta_{i}-\frac{1}{1+\Phi}\left(\frac{6}{L^{2}} v_{i}-\frac{6}{L^{2}} v_{j}+\frac{3}{L} \theta_{i}+\frac{3}{L} \theta_{j}\right) \\
b_{2}=\frac{1}{1+\Phi}\left(\frac{6}{L^{3}} v_{i}-\frac{6}{L^{3}} v_{j}+\frac{3}{L^{2}} \theta_{i}+\frac{3}{L^{2}} \theta_{j}\right)
\end{gathered}
$$

Substituting Eq. (E.34) to (E.38) into (E.15), and (E.16),

$$
\begin{aligned}
& v(x)=N_{v 1} \cdot v_{i}+N_{v 2} \cdot \theta_{i}+N_{v 3} \cdot v_{j}+N_{v 4} \cdot \theta_{j}=N_{v}^{T} \cdot a \\
& \theta(x)=N_{\theta 1} \cdot v_{i}+N_{\theta 2} \cdot \theta_{i}+N_{\theta 3} \cdot v_{j}+N_{\theta 4} \cdot \theta_{j}=N_{\theta}^{T} \cdot a
\end{aligned}
$$

where,

$$
\begin{gathered}
N_{v}=\left[\begin{array}{c}
N_{v 1} \\
N_{v 2} \\
N_{v 3} \\
N_{v 4}
\end{array}\right]=\left[\begin{array}{c}
\frac{1}{1+\Phi}\left(2 \xi^{3}-3 \xi^{2}-\Phi \xi+(1+\Phi)\right) \\
\frac{L}{1+\Phi}\left(\xi^{3}-\left(2+\frac{\Phi}{2}\right) \xi^{2}+\left(1+\frac{\Phi}{2}\right) \xi\right) \\
-\frac{1}{1+\Phi}\left(2 \xi^{3}-3 \xi^{2}-\Phi \xi\right) \\
\frac{L}{1+\Phi}\left(\xi^{3}-\left(1-\frac{\Phi}{2}\right) \xi^{2}-\frac{\Phi}{2} \xi\right)
\end{array}\right] \\
N_{\theta}=\left[\begin{array}{c}
N_{\theta 1} \\
N_{\theta 2} \\
N_{\theta 3} \\
N_{\theta 4}
\end{array}\right]=\left[\begin{array}{c}
6 \\
\frac{6}{1+\Phi}\left(3 \xi^{2}-(4+\Phi) \xi+(1+\Phi)\right) \\
\frac{6}{(1+\Phi) L}\left(\xi^{2}-\xi\right) \\
\frac{1}{1+\Phi}\left(3 \xi^{2}-(2-\Phi) \xi\right)
\end{array}\right]
\end{gathered}
$$




$$
\left.a=\left[\begin{array}{c}
v_{i} \\
\theta_{i} \\
v_{j} \\
\theta_{j}
\end{array}\right], \quad \text { where, } \xi=\frac{x}{L} \quad\right\}
$$

From (E.39), the small deflection can be expressed, $\delta v=\delta a^{T} \cdot N_{\nu}$

From (E.40), the small angle can be expressed, $\delta \theta=\delta a^{T} \cdot N_{\theta}$

For convenience of later calculations,

$$
\begin{gathered}
N_{v}^{\prime}=\left[\begin{array}{l}
N_{v 1}{ }^{\prime} \\
N_{v 2^{\prime}} \\
N_{v 3^{\prime}} N_{v 4^{\prime}}^{\prime}
\end{array}\right]=\left[\begin{array}{c}
\frac{1}{(1+\Phi) L}\left(6 \xi^{2}-6 \xi-\Phi\right) \\
\frac{1}{1+\Phi}\left(3 \xi^{2}-2\left(2+\frac{\Phi}{2}\right) \xi+\left(1+\frac{\Phi}{2}\right)\right) \\
-\frac{1}{(1+\Phi) L}\left(6 \xi^{2}-6 \xi-\Phi\right) \\
\frac{1}{1+\Phi}\left(3 \xi^{2}-2\left(1-\frac{\Phi}{2}\right) \xi-\frac{\Phi}{2}\right)
\end{array}\right] \\
N_{\theta}^{\prime}=\left[\begin{array}{l}
N_{\theta 1^{\prime}} N_{\theta 2^{\prime}} \\
N_{\theta 3^{\prime}} \\
N_{\theta 4^{\prime}}
\end{array}\right]=\left[\begin{array}{c}
\frac{6}{(1+\Phi) L^{2}}(2 \xi-1) \\
\frac{1}{(1+\Phi) L}(6 \xi-(4+\Phi)) \\
-\frac{6}{(1+\Phi) L^{2}}(2 \xi-1) \\
\frac{1}{(1+\Phi) L}(6 \xi-(2-\Phi))
\end{array}\right]
\end{gathered}
$$




\section{Internal Virtual Work}

$$
\begin{gathered}
\delta W_{\text {int }}=\int_{v o l} \sigma \delta \varepsilon+\int_{v o l} \tau \delta \gamma=\int_{v o l} E\left(-y \theta^{\prime}\right)\left(-y \delta \theta^{\prime}\right)+\int_{v o l} k G(-\beta)(-\delta \beta) \\
=E I \int_{0}^{L} \theta^{\prime} \delta \theta^{\prime}+k G A \int_{0}^{L}\left(\theta-w^{\prime}\right)\left(\delta \theta-\delta w^{\prime}\right) \\
=E I \delta a\left(\int_{0}^{L} N_{\theta}{ }^{\prime T} N_{\theta}{ }^{\prime}\right) a+k G A \delta a\left(\int_{0}^{L}\left(N_{\theta}^{T} N_{\theta}-N_{v}{ }^{T} N_{\theta}-N_{\theta}^{T} N_{v}{ }^{\prime}+N_{v}{ }^{\prime T} N_{v}{ }^{\prime}\right)\right) a
\end{gathered}
$$

\section{External Virtual Work}

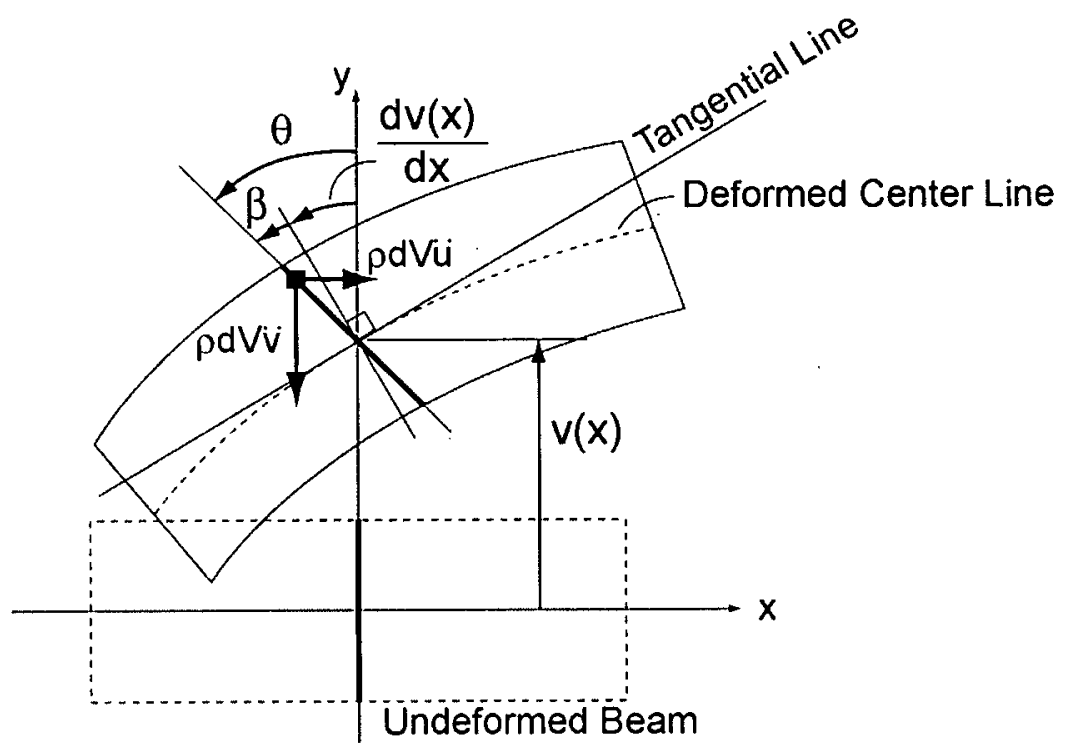

Figure E.6 : Inertia Force Worked in Timoshenko Beam

The acceleration inside the beam element can be expressed as follows.

$$
\ddot{u}(y)=\frac{d^{2} u(y)}{d t^{2}}=-y \ddot{\theta}
$$

Along the cross section $\mathrm{A}$ and $\mathrm{B}$, the deformation in $\mathrm{z}$ direction is always $v(x)$. Therefore, the inertia force worked in small amount volume $d V$ can be,

$$
\delta F_{y}=-\rho d V \ddot{v}
$$

The inertia force in $\mathrm{x}$ direction, which expresses the rotary effects can be formulated as, 


$$
\delta F_{x}=-\rho d V \ddot{u}
$$

External virtual work becomes,

$$
\begin{aligned}
\delta W_{e x t} & =-\int_{v o l} \rho \ddot{u} \cdot \delta u-\int_{v o l} \rho \ddot{v} \cdot \delta v \\
& =-\rho \int_{v o l}(-y \ddot{\theta}) \cdot \delta(-y \ddot{\theta})-\int_{v o l} \rho \ddot{v} \cdot \delta v \\
& =-\rho I \int_{0}^{L} \ddot{\theta} \cdot \delta \theta-\rho A \int_{0}^{L} \ddot{v} \cdot \delta v \\
= & \delta a^{T}\left(-\rho I \int_{0}^{L} N_{\theta}^{T} N_{\theta}-\rho A \int_{0}^{L} N_{v}^{T} N_{v}\right) \ddot{a}
\end{aligned}
$$

Since, the internal virtual work is equal to the external virtual work,

$$
\delta W_{i n t}=\delta W_{e x t}
$$

Substituting Eq. (E.41) and (E.42) into (E.43),

$$
\begin{aligned}
& E I \delta a\left(\int_{0}^{L} N_{\theta}{ }^{T} N_{\theta}{ }^{\prime}\right) a+k G A \delta a\left(\int_{0}^{L}\left(N_{\theta}^{T} N_{\theta}-N_{v}{ }^{T} N_{\theta}-N_{\theta}^{T} N_{v}{ }^{\prime}+N_{v}{ }^{T} N_{v}{ }^{\prime}\right)\right) a \\
& =\delta a\left(-\rho I \int_{0}^{L} N_{\theta}^{T} N_{\theta}-\rho A \int_{0}^{L} N_{v}^{T} N_{v}\right) \ddot{a} \\
& \left(\rho I \int_{0}^{L} N_{\theta}^{T} N_{\theta}+\rho A \int_{0}^{L} N_{v}^{T} N_{v}\right) \ddot{a} \\
& +\left(E I\left(\int_{0}^{L} N_{\theta}{ }^{T} N_{\theta}{ }^{\prime}\right)+k G A\left(\int_{0}^{L}\left(N_{\theta}^{T} N_{\theta}-N_{v}{ }^{T} N_{\theta}-N_{\theta}^{T} N_{v}{ }^{\prime}+N_{v}{ }^{\prime T} N_{v}{ }^{\prime}\right)\right)\right) a=0
\end{aligned}
$$

Eq. (E.44) can be expressed with the mass matrix $\left[M_{\text {Tim }}\right]$ and the stiffness matrix $\left[K_{\text {Tim }}\right]$ of the Euler-Bernoulli beam as follows.

$$
\left[M_{\text {Tim }}\right] \ddot{a}+\left[K_{\text {Tim }}\right] a=0
$$

where,

$$
\left[M_{\text {Tim }}\right]=\left[M_{T}^{T i m}\right]+\left[M_{R}^{T i m}\right]
$$




$$
\left[M_{T}^{T i m}\right]=\frac{\rho A L}{420(1+\Phi)^{2}}\left[\begin{array}{cccc}
m_{T 1}^{T i m} & m_{T 2}^{\text {Tim }} & m_{T 3}^{\text {Tim }} & m_{T 4}^{\text {Tim }} \\
\ldots & m_{T 5}^{\text {Tim }} & -m_{T 4}^{\text {Tim }} & m_{T 6}^{\text {Tim }} \\
\ldots & \ldots & m_{T 1}^{\text {Tim }} & -m_{T 2}^{\text {Tim }} \\
S Y M & \ldots & \ldots & m_{T 5}^{\text {Tim }}
\end{array}\right]
$$

where, $m_{T 1}^{\text {Tim }}=156+294 \Phi+140 \Phi^{2} \quad m_{T 2}^{\text {Tim }}=\left(22+38.5 \Phi+17.5 \Phi^{2}\right) L$

$$
\begin{array}{ll}
m_{T 3}^{T i m}=54+126 \Phi+70 \Phi^{2} & m_{T 4}^{T i m}=-\left(13+31.5 \Phi+17.5 \Phi^{2}\right) L \\
m_{T 5}^{T i m}=\left(4+7 \Phi+3.5 \Phi^{2}\right) L^{2} & m_{T 6}^{T i m}=-\left(3+7 \Phi+3.5 \Phi^{2}\right) L^{2}
\end{array}
$$

$$
\left[M_{R}^{T i m}\right]=\frac{\rho I}{30(1+\Phi)^{2} L}\left[\begin{array}{cccc}
36 & m_{R 1}^{T i m} & -36 & m_{R 1}^{T i m} \\
\ldots & m_{R 2}^{\text {Tim }} & -m_{R 1}^{\text {Tim }} & m_{R 3}^{\text {Tim }} \\
\ldots & \ldots & 36 & -m_{R 1}^{\text {Tim }} \\
S Y M & \ldots & \ldots & m_{R 2}^{\text {Tim }}
\end{array}\right]
$$

where, $m_{R 1}^{\operatorname{Tim}}=(3-15 \Phi) L \quad m_{R 2}^{\operatorname{Tim}}=\left(4+5 \Phi+10 \Phi^{2}\right) L^{2} \quad m_{R 3}^{\operatorname{Tim}}=\left(-1-5 \Phi+5 \Phi^{2}\right) L^{2}$

$$
\left[K_{\text {Tim }}\right]=\frac{E I}{(1+\Phi) L^{3}}\left[\begin{array}{cccc}
12 & 6 L & -12 & 6 L \\
\ldots & (4+\Phi) L^{2} & -6 L & (2-\Phi) L^{2} \\
\ldots & \ldots & 12 & -6 L \\
S Y M & \ldots & \ldots & (4+\Phi) L^{2}
\end{array}\right]
$$




\section{Appendix F}

\section{F.1 Indirect Method}

The basic concept of the optimization method is to compute a minimum value of a certain function. Considering Taylor's expansion for a function $f(x)$ at a point $x^{*}=x+\Delta x$ :

$$
f(x+\Delta x)=f(x)+f(x) \cdot \Delta x+\frac{1}{2 !} \cdot f^{\prime \prime}(x) \cdot(\Delta x)^{2}+R
$$

Transforming Eq. (F.1):

$$
\Delta f=f(x+\Delta x)-f(x)=f^{\prime}(x) \cdot \Delta x+\frac{1}{2 !} \cdot f^{\prime \prime}(x) \cdot(\Delta x)^{2}+R
$$

A necessary condition for the extremum point, maximum or minimum, is:

$$
\nabla f=f^{\prime}(x)=\frac{d f}{d x}=0
$$

Then, as a sufficient condition for the minimum point $\Delta f$ must be positive, so:

$$
\frac{1}{2 !} \cdot f^{\prime \prime}(x) \cdot(\Delta x)^{2}>0 \text { or } f^{\prime \prime}(x)>0
$$

Fig. F.1 (a) shows a simple quadratic curve and (b) shows a high order curve. Both of the minimum values can be obtained by using Eq. (F.3) and Eq. (F.4). The functions shown in Fig. F.1 are unconstrained functions. 


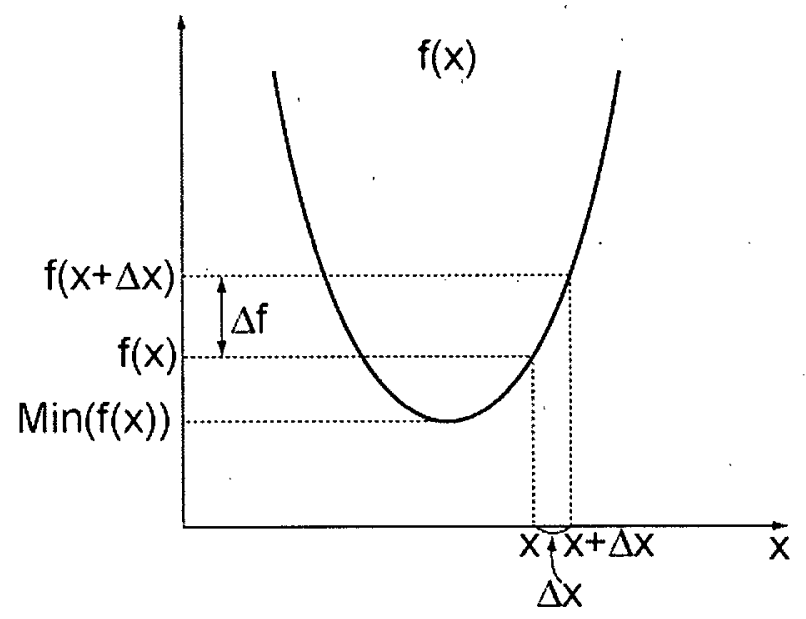

(a)

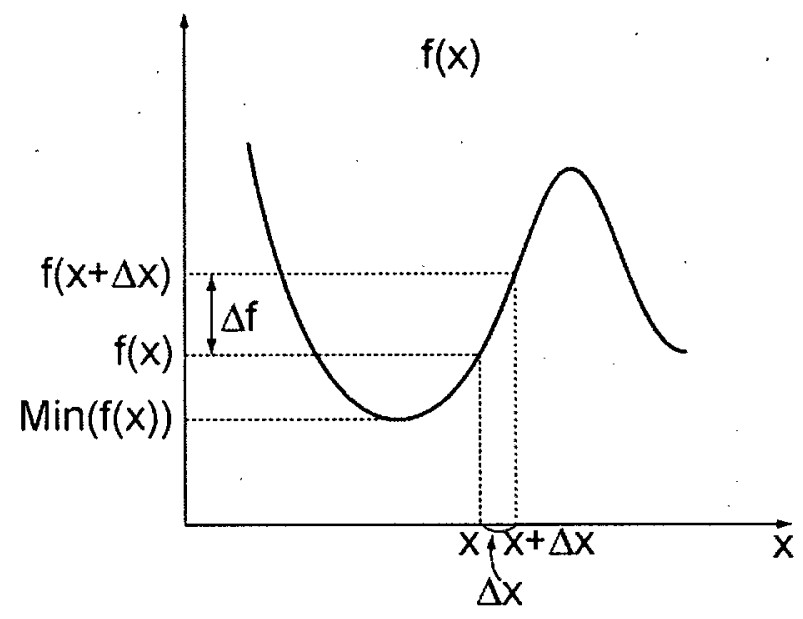

(b)

Figure F.1 : Minimum Value of Curves, (a) Quadratic Function, (b) High Order Function

In general, the unconstrained function can be solved as follows.

The objective function is,

$$
f(x)
$$

and the necessary conditions can be,

$$
\nabla f \equiv \frac{\partial f}{\partial x_{i}}=0 \quad \text { with } \quad i=1, n
$$

the sufficient conditions for the minimization of the objective function are,

$$
\frac{1}{2} \cdot \Delta x^{T} \cdot H \cdot \Delta x>0 \quad \text { or } \quad H \text { is positive definite }
$$

where $H$ is called the Hessian matrix, which is the second order of the partial differentiation. The Hessian matrix can be expressed as follows:

$$
[H]=\left[\begin{array}{cccc}
\frac{\partial^{2} f}{\partial x_{1}^{2}} & \frac{\partial^{2} f}{\partial x_{1} \partial x_{2}} & \cdots & \frac{\partial^{2} f}{\partial x_{1} \partial x_{n}} \\
\cdot & \cdot & \cdot & \cdot \\
\cdot & \cdot & \cdot & \cdot \\
S Y M & \ldots & \ldots & \frac{\partial^{2} f}{\partial x_{n}^{2}}
\end{array}\right]
$$


In practical engineering problems, there are equality and inequality constraints. The KuhnTucker theorem can be applied to the constrained cases. The general form of the Kuhn-Tucker theorem will be shown as follows:

Objective function

$$
f(x)
$$

subject to the equality constraints,

$$
h_{i}(x)=0 \quad \text { with } \quad i=1, n
$$

and the inequality constraints,

$$
g_{j}(x) \leq 0 \quad \text { with } \quad j=1, m
$$

Then the Lagrange function for this condition will be;

$$
L\left(x, \lambda_{i}, \mu_{j}, s_{j}\right)=f(x)+\sum_{i=1}^{n} \lambda_{i} \cdot h_{i}(x)+\sum_{j}^{m} \mu_{j} \cdot\left[g_{j}(x)+s_{j}^{2}\right]
$$

where, $\lambda$ and $\mu$ are the Lagrange multipliers for the equality and inequality constraints, respectively. $s$ is called the "Slack variable" with which the inequality constraint can be considered as the equality constraint functions. The necessary conditions, in which the derivatives (Eq. (F.6)) of the Lagrange function from Eq. (F.5) are equal to zero, lead to the minimum value of $L$.

$$
\nabla L=\left[\begin{array}{l}
\frac{\partial L}{\partial x} \\
\frac{\partial L}{\partial \lambda} \\
\frac{\partial L}{\partial \mu} \\
\frac{\partial L}{\partial s}
\end{array}\right]=0
$$




\section{Appendix G}

\section{G.1 Newton's Method}

The objective function $f(x)$ is expended using Taylor series;

$$
f\left(x_{k+1}\right) \cong f\left(x_{k}\right)+\nabla f\left(x_{k}\right) \cdot \delta x+\Delta x+\frac{1}{2} \delta x \cdot H\left(x_{k}\right) \cdot \delta x
$$

where,

$$
\delta x=x_{k+1}-x_{k}
$$

Solving Eq. (G.1):

$$
\delta x=-\left[H\left(x_{k}\right)\right]^{-1} \cdot \nabla f\left(x_{k}\right)
$$

Rearranging Eq. (G.2) using Eq. (G.3):

$$
\begin{aligned}
x_{k+1} & =x_{k}+\delta x \\
& =x_{k}-\left[H\left(x_{k}\right)\right]^{-1} \cdot \nabla f\left(x_{k}\right)
\end{aligned}
$$

Comparing the last term in Eq. (G.4) to the $d$ vector in Eq. (5.24) (with $\alpha^{*}=1$ ):

$$
d=-\left[H\left(x_{k}\right)\right]^{-1} \cdot \nabla f\left(x_{k}\right)
$$

Therefore, Eq. (G.5) provides a search direction to use in a general one dimensional search. 


\section{Appendix H}

\section{H.1 The Detail Calculation of Spindle Bearing Spans' Optimization}

Fig. H.1 shows the direct coupling type spindle model.

Spindle Model
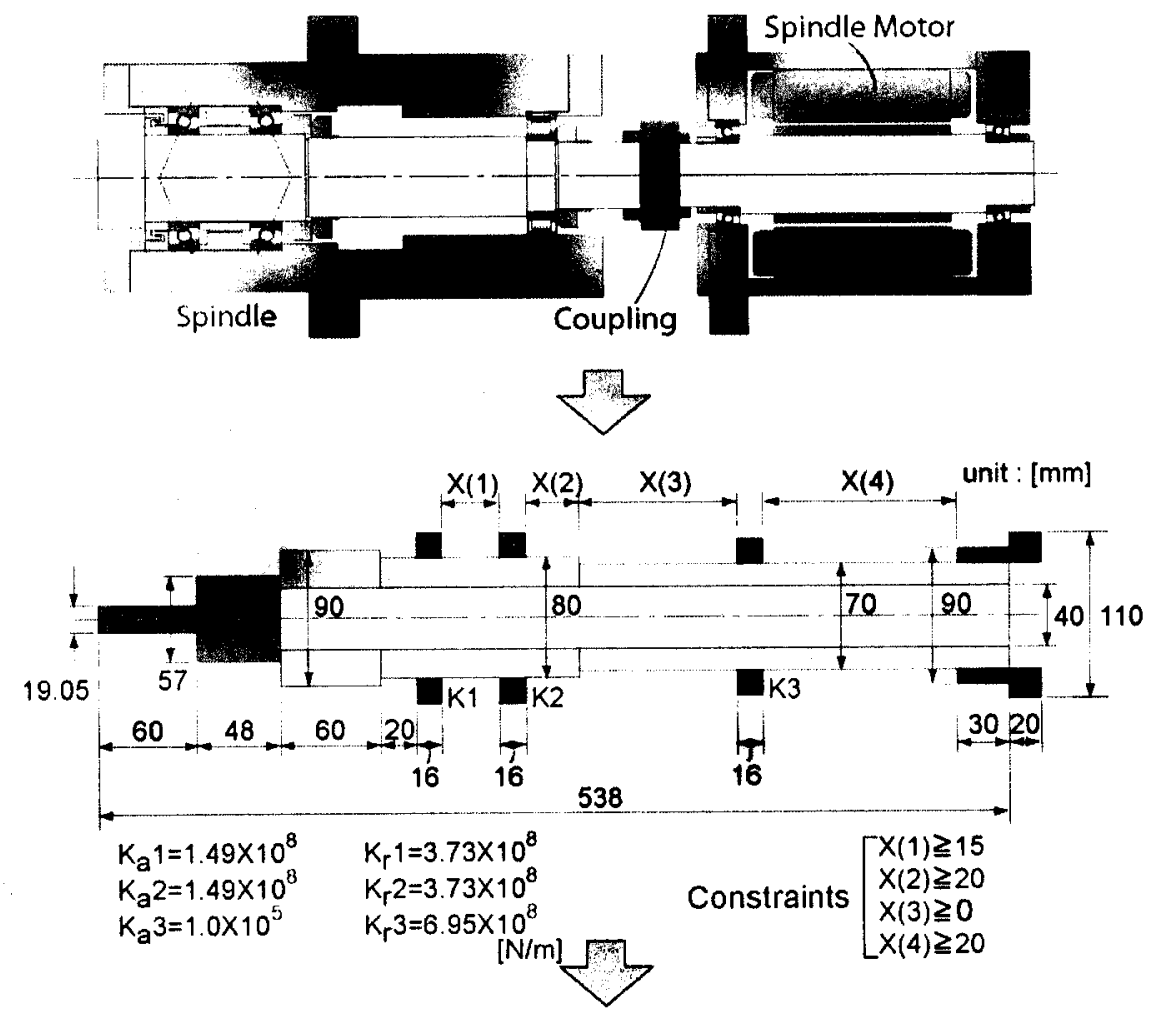

FEM Model

(Design)

FEM Model

(Analysis)

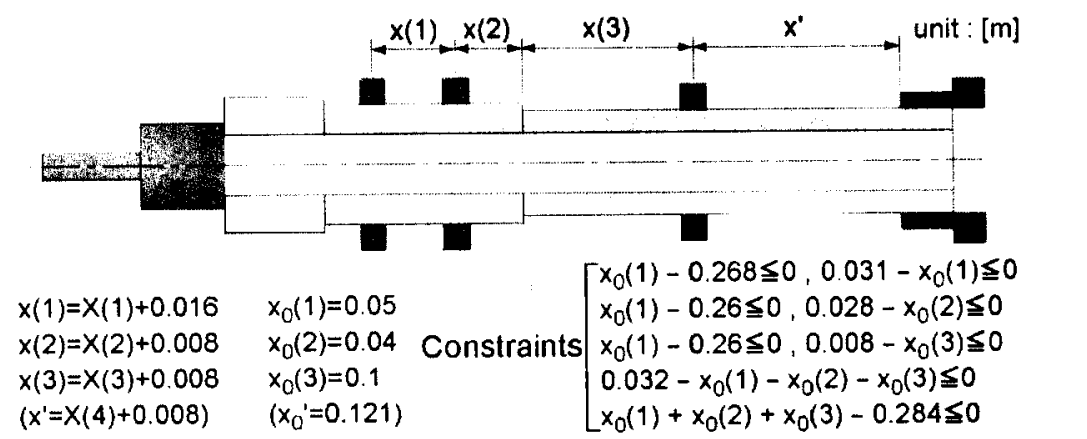

Figure H.1 : Modeling for Spindle Analysis 
The iterative operations can be expressed as the following equation;

$$
x_{k+1}=x_{k}+\alpha^{*} d
$$

where, $d$ is a vector search direction, and $\alpha^{*}$ is the scalar quantity that defines the distance moving in direction $d$.

In order to find $d$, the subproblem $q(d)$ must be minimized;

$$
\begin{aligned}
& \text { Minimize : } q\left(d_{k}\right)=\frac{1}{2} d_{k}^{T} H_{k} d_{k}+\nabla f_{o b}\left(x_{k}\right)^{T} d_{k} \\
& \text { Subject to : } \tilde{g}_{j}=\nabla g_{j}\left(x_{k}\right)^{T} d_{k}+g_{j}\left(x_{k}\right) \leq 0 \quad \mathrm{j}=1, \ldots, 8
\end{aligned}
$$

where,

$$
f_{o b}(x)=-a_{C l i m}
$$

From the sets of constraints described in Fig. H.1,

$$
\begin{gathered}
g_{1}(x)=x(1)-0.268 \leq 0 \\
g_{2}(x)=0.031-x(1) \leq 0 \\
g_{3}(x)=x(2)-0.26 \leq 0 \\
g_{4}(x)=0.028-x(2) \leq 0 \\
g_{5}(x)=x(3)-0.26 \leq 0 \\
g_{6}(x)=0.008-x(3) \leq 0 \\
g_{7}(x)=0.032-x(1)-x(2)-x(3) \leq 0 \\
g_{8}(x)=x(1)+x(2)+x(3)-0.284 \leq 0
\end{gathered}
$$




$$
\begin{gathered}
\nabla g_{i}=\left[\begin{array}{c}
\frac{\partial g_{i}}{\partial x(1)} \\
\frac{\partial g_{i}}{\partial x(2)} \\
\frac{\partial g_{i}}{\partial x(3)}
\end{array}\right], \text { so, } \nabla g_{1}=\left[\begin{array}{l}
1 \\
0 \\
0
\end{array}\right], \nabla g_{2}=\left[\begin{array}{c}
-1 \\
0 \\
0
\end{array}\right], \nabla g_{3}=\left[\begin{array}{l}
0 \\
1 \\
0
\end{array}\right], \nabla g_{4}=\left[\begin{array}{c}
0 \\
-1 \\
0
\end{array}\right] \\
\nabla g_{5}=\left[\begin{array}{l}
0 \\
0 \\
1
\end{array}\right], \nabla g_{6}=\left[\begin{array}{c}
0 \\
0 \\
-1
\end{array}\right], \nabla g_{7}=\left[\begin{array}{c}
-1 \\
-1 \\
-1
\end{array}\right], \text { and } \nabla g_{8}=\left[\begin{array}{l}
1 \\
1 \\
1
\end{array}\right]
\end{gathered}
$$

Now, an initial condition is set as;

$$
x_{0}=\left[\begin{array}{c}
0.05 \\
0.04 \\
0.1
\end{array}\right]
$$

From the initial condition (H.13),

$$
f_{o b}\left(x_{0}\right)=-4.03919
$$

and the first derivative of $f(x)$ at the point (H.13) can be calculated using finite difference method. The difference is defined as $1 \times 10^{-5}$ :

$$
\nabla f_{o b}\left(x_{0}\right)=\left[\begin{array}{l}
\frac{f_{o b}\left(x_{0}\right)_{f d 1}-f_{o b}\left(x_{0}\right)}{1 \times 10^{-5}} \\
\frac{f_{o b}\left(x_{0}\right)_{f d 2}-f_{o b}\left(x_{0}\right)}{1 \times 10^{-5}} \\
\frac{f_{o b}\left(x_{0}\right)_{f d 3}-f_{o b}\left(x_{0}\right)}{1 \times 10^{-5}}
\end{array}\right]=\left[\begin{array}{l}
-109.05 \\
-125.22 \\
-129.03
\end{array}\right]
$$


where,

$$
\begin{gathered}
f_{o b}\left(x_{0}\right)_{f d 1}=f_{o b}\left(\begin{array}{c}
0.04999 \\
0.04 \\
0.1
\end{array}\right)=-4.03810, f_{o b}\left(x_{0}\right)_{f d 2}=f_{o b}\left(\begin{array}{c}
0.05 \\
0.03999 \\
0.1
\end{array}\right)=-4.03794, \\
f_{o b}\left(x_{0}\right)_{f d 3}=f_{o b}\left(\begin{array}{c}
0.05 \\
0.04 \\
0.09999
\end{array}\right)=-4.03790
\end{gathered}
$$

The initial Hessian matrix can be defined as the identity matrix $I$;

$$
H_{0}=[I]=\left[\begin{array}{lll}
1 & 0 & 0 \\
0 & 1 & 0 \\
0 & 0 & 1
\end{array}\right]
$$

Therefore, from (H.2), $q\left(d_{0}\right)$ can be expressed with $d_{0}=\left[d_{0}(1), d_{0}(2), d_{0}(3)\right]^{T}$ as follows:

$$
\begin{array}{r}
q(d)=-109.05 d_{0}(1)-125.22 d_{0}(2)-129.03 d_{0}(3) \\
+0.5 d_{0}(1)^{2}+0.5 d_{0}(2)^{2}+0.5 d_{0}(3)^{2}
\end{array}
$$

Also, the $\tilde{g}_{j}$ can be expressed as;

$$
\begin{gathered}
\tilde{g}_{1}=-0.218+d_{0}(1) \leq 0 \rightarrow d_{0}(1) \leq 0.218 \\
\tilde{g}_{2}=-0.019-d_{0}(1) \leq 0 \rightarrow d_{0}(1) \geq-0.019 \\
\tilde{g}_{3}=-0.22+d_{0}(2) \leq 0 \rightarrow d_{0}(2) \leq 0.22 \\
\tilde{g}_{4}=-0.012-d_{0}(2) \leq 0 \rightarrow d_{0}(2) \geq-0.012 \\
\tilde{g}_{5}=-0.16+d_{0}(3) \leq 0 \rightarrow d_{0}(3) \leq 0.16 \\
\tilde{g}_{6}=-0.092-d_{0}(3) \leq 0 \rightarrow d_{0}(3) \geq-0.092 \\
\tilde{g}_{7}=-0.158-d_{0}(1)-d_{0}(2)-d_{0}(3) \leq 0 \rightarrow d_{0}(1)+d_{0}(2)+d_{0}(3) \geq-0.158
\end{gathered}
$$




$$
\tilde{g}_{8}=-0.094+d_{0}(1)+d_{0}(2)+d_{0}(3) \leq 0 \rightarrow d_{0}(1)+d_{0}(2)+d_{0}(3) \leq 0.094
$$

This quadratic programming problem can be solved with the use of the Kuhn-Tucker conditions. The Kuhn-Tucker conditions are given by;

$$
\begin{gathered}
\frac{\partial q\left(d_{0}\right)}{\partial d_{0}(1)}+\sum_{j=1}^{8} \lambda_{j} \frac{\partial \tilde{g}_{j}}{\partial d_{0}(1)}=0 \\
\frac{\partial q\left(d_{0}\right)}{\partial d_{0}(2)}+\sum_{j=1}^{8} \lambda_{j} \frac{\partial \tilde{g}_{j}}{\partial d_{0}(2)}=0 \\
\frac{\partial q\left(d_{0}\right)}{\partial d_{0}(3)}+\sum_{j=1}^{8} \lambda_{j} \frac{\partial \tilde{g}_{j}}{\partial d_{0}(3)}=0 \\
\lambda_{j} \tilde{g}_{j}=0, j=1, \ldots, 8 \\
\tilde{g}_{j} \leq 0 \quad, \quad j=1, \ldots, 8 \\
\lambda_{j} \geq 0 \quad, \quad j=1, \ldots, 8
\end{gathered}
$$

Eq. (H.26), (H.27), and (H.28) can be expressed as follows:

$$
\begin{aligned}
& -109.05+d_{0}(1)+\lambda_{1}-\lambda_{2}-\lambda_{7}+\lambda_{8}=0 \\
& -125.22+d_{0}(2)+\lambda_{3}-\lambda_{4}-\lambda_{7}+\lambda_{8}=0 \\
& -129.03+d_{0}(3)+\lambda_{5}-\lambda_{6}-\lambda_{7}+\lambda_{8}=0
\end{aligned}
$$

From Eq. (H.29), all possibilities of active constraints will be considered.

(1) $\lambda_{1}=0, \lambda_{2}=0, \lambda_{3}=0, \lambda_{4}=0, \lambda_{5}=0, \lambda_{6}=0, \lambda_{7}=0$, and $\lambda_{8}=0$ From Eq. (H.32), $d_{0}(1)=109.05$. But $d_{0}(1) \leq 0.218$ from Eq. (H.18). Therefore, the constraint is violated and there is no feasible solution. 
(2) $\lambda_{1}=0, \lambda_{2}=0, \lambda_{3}=0, \lambda_{4}=0, \lambda_{5}=0, \lambda_{6}=0, \lambda_{7}=0$, and $\tilde{g}_{8}=0$

$$
d_{0}(1)+\lambda_{8}=109.05, d_{0}(2)+\lambda_{8}=125.22 \text {, and } d_{0}(3)+\lambda_{8}=129.03
$$

From Eq. (H.25), $d_{0}(1)+d_{0}(2)+d_{0}(3)=0.094$.

So, $\lambda_{8}=121.1$, and $d_{0}(1)=-12.05, d_{0}(2)=4.12$, and $d_{0}(3)=7.93$

From Eq. (H.19), (H.20), and (H.22), $d_{0}(1) \geq-0.019, d_{0}(2) \leq 0.22$, and $d_{0}(3) \leq 0.16$, respectively.

Therefore, the constraint is violated and there is no feasible solution.

In order to find the feasible solution, all possibilities, in this case $2^{8}(=256)$ cases, must be computed. In this problem, the following case can lead the feasible solution.

$$
\begin{gathered}
\text { In case, } \lambda_{1}=0, \tilde{g}_{2}=0, \lambda_{3}=0, \tilde{g}_{4}=0, \lambda_{5}=0, \lambda_{6}=0, \lambda_{7}=0 \text {, and } \tilde{g}_{8}=0 \\
-109.05+d_{0}(1)-\lambda_{2}+\lambda_{8}=0 \\
-125.22+d_{0}(2)-\lambda_{4}+\lambda_{8}=0 \\
-129.03+d_{0}(3)+\lambda_{8}=0 \\
d_{0}(1)=-0.019 \\
d_{0}(2)=-0.012 \\
d_{0}(1)+d_{0}(2)+d_{0}(3)=0.094
\end{gathered}
$$

Solving the Eq. (H.35) to (H.40),

$$
d_{0}=\left[\begin{array}{l}
d_{0}(1) \\
d_{0}(2) \\
d_{0}(3)
\end{array}\right]=\left[\begin{array}{c}
-0.019 \\
-0.012 \\
0.125
\end{array}\right]
$$


Now, $\alpha^{*}$ will be found. The first guess of the $\alpha^{*}$ can be one $(\alpha=1)$. Substituting $\alpha=1$ into Eq. (H.1),

$$
x_{1}^{1}=x_{0}+1 \cdot d_{0}=\left[\begin{array}{c}
0.05 \\
0.04 \\
0.1
\end{array}\right]+1 \cdot\left[\begin{array}{c}
-0.019 \\
-0.012 \\
0.125
\end{array}\right]=\left[\begin{array}{l}
0.031 \\
0.028 \\
0.225
\end{array}\right]
$$

However, $f_{o b}\left(x_{1}^{1}\right)=-1.4417$, which is greater than $f_{o b}\left(x_{0}\right)=-4.03919$ (H.14). Therefore, $\alpha$ is changed to half.

$$
x_{1}^{0.5}=x_{0}+0.5 \cdot d_{0}=\left[\begin{array}{c}
0.05 \\
0.04 \\
0.1
\end{array}\right]+0.5 \cdot\left[\begin{array}{c}
-0.019 \\
-0.012 \\
0.125
\end{array}\right]=\left[\begin{array}{c}
0.0405 \\
0.034 \\
0.1625
\end{array}\right]
$$

Now, $f_{o b}\left(x_{1}^{0.5}\right)=-4.14216$, which is less than $f_{o b}\left(x_{0}\right)$. Therefore, $\alpha^{*}$ can be set as 0.5 . If the new value $f_{o b}\left(x_{1}^{0.5}\right)$ is still greater than $f_{o b}\left(x_{0}\right), \alpha$ can be updated as 0.25 .

As the next step, the Hessian matrix is updated using BFGS method:

$$
H_{k+1}=H_{k}+\frac{q_{k} q_{k}^{T}}{q_{k}^{T} s_{k}}-\frac{H_{k}^{T} s_{k}^{T} s_{k} H_{k}}{s_{k}^{T} H_{k} s_{k}}
$$

where,

$$
\begin{gathered}
s_{k}=x_{k+1}-x_{k} \\
q_{k}=\nabla f_{o b}\left(x_{k+1}\right)-\nabla f_{o b}\left(x_{k}\right)
\end{gathered}
$$

In this case,

$$
\begin{gathered}
s_{0}=x_{1}-x_{0}=\left[\begin{array}{lll}
-0.0095 & -0.006 & 0.0625
\end{array}\right]^{T} \\
\nabla f_{o b}\left(x_{1}\right)=\left[\begin{array}{lll}
-31.66 & 52.12 & 20.41
\end{array}\right]^{T} \text {, so that } q_{k}=\left[\begin{array}{lll}
77.39 & 177.34 & 149.44
\end{array}\right]^{T}
\end{gathered}
$$

Substituting Eq. (H.44) and (H.45) into (H.43), 


$$
H_{1}=H_{0}+\frac{q_{0} q_{0}^{T}}{q_{0}^{T} s_{0}}-\frac{H_{0}^{T} s_{0}^{T} s_{0} H_{0}}{s_{0}^{T} H_{0} s_{0}}=\left[\begin{array}{ccc}
794.25 & 1819.98 & 1533.70 \\
1819.98 & 4170.36 & 3514.36 \\
1533.70 & 3514.36 & 2961.55
\end{array}\right]
$$

Having derived the new Hessian matrix, another iteration can be started by defining a new quadratic programming. After the twelve iteration process, the calculation converged. The optimum $x$ 's and the final stability are shown as follows.

$$
x_{12}=x_{\text {final }}=\left[\begin{array}{c}
0.1489 \\
0.028 \\
0.0087
\end{array}\right] \text {, and } f_{o b}\left(x_{\text {final }}\right)=-8.1530
$$

Thus, the optimum bearing spans become,

$$
X_{\text {optimum }}=\left[\begin{array}{c}
X(1) \\
X(2) \\
X(3) \\
X(4)
\end{array}\right]=\left[\begin{array}{c}
x(1)-0.016 \\
x(2)-0.008 \\
x(3)-0.008 \\
x^{\prime}-0.008
\end{array}\right]=\left[\begin{array}{c}
0.1329 \\
0.02 \\
0.0007 \\
0.1184
\end{array}\right]
$$




\section{Bibliography}

[1] Altintas Y., Budak E., 1995, "Analytical Prediction of Stability Lobes in Milling", CIRP Annals - Manufacturing Technology, Vol. 44, No. 1, pp. 357-362

[2] Altintas Y., 2000, Manufacturing Automation - Metal Cutting Mechanics, Machine Tool Vibrations, and CNC Design, Cambridge University Press

[3]. Aronson R.B., 1995, "Machine Tool 102: Spindles", Manufacturing Engineering, Vol. 114, No. 3, 7pp.

[4] The Barden Co., 1996, "Ceramics for Use in Ball Bearings", Precision Bulletin, No. 1

[5] The Barden Co, 1996, "Oil Lubrication", Precision Bulletin, No. 5C

[6] The Barden Co, 1996, "New ZSB Series Spindle Bearings Improve Speedability and Offer Integral Shields", Precision Bulletin, No. 7

[7] The Barden Co, 1996, "Patented "H" Cage Improves Bearing Performance", Precision Bulletin, No. 10

[8] The Barden Co, 1996, "Preloading Bearings", Precision Bulletin, No. 11

[9] The Barden Co, 2000, "The Effects of High Speed on Ball Bearings", Precision Bulletin, No. 17

[10] The Barden Co, 2000, "BARDEN/FAG CRONIDUR ${ }^{\circledR} 30$ Hybrid Spindle Bearings", Precision Bulletin, No. 18

[11] Brandon J.A., Al-Shareef K.J.H., 1990, "On The Validity of Several Common Assumptions in The Design of Machine Tool Spindle-Bearing Systems", International Journal of Machine Tools \& Manufacture, Vol. 31, No. 2, pp. 235-248

[12] Chen C.H., Wang K.W., 1994, "Integrated approach toward the dynamic analysis of highspeed spindles: part II-Dynamics under moving end load", American Society of Mechanical Engineers, Design Engineering Division (Publication) DE, Vol. 60, pp. 347-354

[13] Chen W.J., Rajan M., Rajan S.D., Nelson H.D., 1988, "Optimal Design of Squeeze Film Dampers for Flexible Rotor Systems", Journal of Mechanisms, Transmissions, and Automation in Design, Vol. 110, No. 2, pp. 166-174

[14] Coleman T., Branch M.A., Grace A., 1999, Optimization Toolbox for Use with Matlab ${ }^{\circledR}$ Version 2, The Math Works, Inc. 
[15] Eskicioglu H., Akkok M., Yildiz O.H., 1994, "Computer Aided Selection of Machine Tool Spindle Bearing Arrangements", American Society of Mechanical Engineers, Petroleum Division (Publication) PD, Vol. 64, No. 8-1, pp. 181-187

[16] FAG Ultra High Speed \& Super Precision Spindle Bearings, Fukuda Corp.

[17] Fletcher R., Powell M.J.D., 1963, "A Rapidly Convergent Descent Method for Minimization", Computer Journal, Vol. 6, pp. 163-168

[18] Fletcher R., 1970, "New Approach to Variable Metric Algorithms", Computer Journal, Vol. 13, No. 3, pp. 317-322

[19] · Fuzzy Logic Toolbox for Use with Matlab ${ }^{\circledR}$ Version 2, The Math Works, Inc., 2000

[20] Gill, P.E., Murray W., Wright M.H., 1991, Numerical Linear Algebra and Optimization: Volume 1, Addison-Wesley Publishing Company

[21] Goldfarb D, 1970, "A Family of Variable-Metric Methods Derived by Variational Means", Mathematics of Computation, Vol. 24, Iss. 109, pp. 23-26

[22] Hagiu G., Gafiranu M.D., 1995, "Preload Optimization: A High Efficiency Design Solution for Grinding Machines Main Spindles", ASTM Special Technical Publication, No. 1247 , pp. $74-84$

[23] Harris, John, 2000, An Introduction to Fuzzy Logic Applications, Kluwer Academic Publishers

[24] Harris, T.A., 2001, Rolling Bearing Analysis - 4th Edition, A Wiley-Interscience publication

[25] High Performance Motor Spindles, Starragheckert

[26] Hogan B., 1999, "No Speed Limits", Manufacturing Engineering, Vol. 122, No. 3, pp. 6679

[27] H.Max Series, Matsuura Machinery Co.

[28] "Innovative approach to high-performance system", Machinery and Production Engineering, 1995, Vol. 153, No. 3903

[29] Kang Y., Chang Y.P., Tsai J.W., Chen S.C., Yang L.K., 2001, "Integrated "CAE" Strategies for The Design of Machine Tool Spindle-Bearing Systems", Finite Elements in Analysis and Design, Vol. 37, No. 6-7, pp. 485-511

[30] Lee D., Choi D., 2000, "Reduced Weight Design of A Flexible Rotor With Ball Bearing Stiffness Characteristics Varying with Rotational Speed and Load", Journal of Vibration and Acoustics, Transactions of the ASME, Vol. 122, No. 3, pp. 203-208 
[31] Lewis Walter J., 1990, "Design of High Speed Grease Lubricated Spindles for Machine Tool Production Equipment", SAE (Society of Automotive Engineers) Transactions, Vol. 99, No. Sect 5, pp. 1061-1070

[32] Lewis, David L., 1999, "What's Happening with HSK?", Manufacturing Engineering, No.4, pp.78-82

[33] Mamdani, E.H, S. Assilian, 1975, "An Experiment in Linguistic Synthesis with A Fuzzy Logic Controller", International Journal of Man-Machine Studies, Vol. 7, No. 1, pp. 1-13

[34] Merritt H.E., 1965, "Theory of Self-Excited Machine Tool Chatter", ASME Journal of Engineering for Industry, Vol. 87, pp.447-454.

[35] Minis I., Yanushevsky T., 1993, "A New Theoretical Approach for the Prediction of Machine Tool Chatter in Milling", ASME Journal of Engineering for Industry, Vol. 115, pp.1-8.

[36] Moriwaki T., et al., 1998, Kousakukikai no sekkeigaku (kiso-hen) [The Design for Machine tools (Basics)], Japan Machine Tool Builder's Association

[37] Myung S., Han S., 2001, "Knowledge-Based Parametric Design of Mechanical Products Based on Configuration Design Method", Expert Systems with Applications, Vol. 21, No. 2, p 99-107

[38] Nataraj C., Ashrafiuon H., 1993, "Optimal Design of Centered Squeeze Film Dampers", Journal of Vibration, Acoustics, Stress, and Reliability in Design, Vol. 115, No. 2, pp. 210214

[39] Nelson H.D., 1980, "Finite Rotating Shaft Element Using Timoshenko Beam Theory", Journal of Mechanical Design, Transactions of the ASME, Vol. 102, No. 4, pp. 793-803

[40] NSK Ltd., 1999, Precision Rolling Bearings for Machine Tool Spindles

[41] NSK-RHP, 1998, RHP Super Precision Bearings

[42] Popoli, W.F., 1998, "High Speed Spindle Design and Construction", Technical Paper Society of Manufacturing Engineers. MR, No. MR98-146

[43] Popoli, W.F., 2000, "Spindle-Bearing Basics", Manufacturing Engineering, Vol. 125, No. 5 , pp. $52-57$

[44] Rao S.B., 1997, "Metal Cutting Machine Tool Design - A Review", Journal of Manufacturing Science and Engineering, Transactions of the ASME, Vol. 119, No. 4(B), pp. 713716

[45] Rivin E.I., 2000, "Tooling Structure: Interface Between Cutting Edge and Machine Tool", CIRP Annals - Manufacturing Technology, Vol. 49, No. 2, pp. 591-609 
[46] Ruhl R.L., Booker J.F., 1972, "A Finite Element Model for Distributed Parameter Turborotor Systems", Journal of Engineering for Industry, Vol. 94 Ser. B, No. 1, pp. 126-132

[47] SH-403, MORI SEIKI CO., LTD.

[48] Shames I.H., Dym C.L., 1985, Energy and Finite Element Methods in Structural Mechanics, Hemisphere Publishing Corp.

[49] Shanno D. F., 1970, "Conditioning of Quasi-Newton Methods for Function Minimization", Mathematics of Computation, Vol. 24, Iss. 111, pp. 647-656

[50] Shin Y.C., 1992, "Bearing Nonlinearity and Stability Analysis in High Speed Machining", Journal of Engineering for Industry, Transactions of the ASME, Vol. 114, No. 1, pp. 23-30

[51] Shinno H., Ito, Y. Hashizume H., 1991, "A Decision-Making Methodology for Basic Layout Design of Machine Tools", JSME International Journal, Series 3: Vibration, Control Engineering, Engineering for Industry, Vol. 34, No. 2, pp. 290-294

[52] Shortliffe E.H., 1976, Computer-Based Medical Consultations: MYCIN, American Elsevier Publishing Co., Inc.

[53] Shortliffe E.H., 1977, "MYCIN: A Knowledge-based Computer Program Applied to Infectious Diseases", The First Annual Symposium on Computer Applications in Medical Care, pp. 66-69

[54] Sugeno M., 1985, Industrial Application of Fuzzy Control, Elsevier Science Pub. Co.

[55] Taylor S., Khoo B.T., Walton D., 1990, "Microcomputer Optimisation of Machine Tool Spindle Stiffnesses", International Journal of Machine Tools \& Manufacture, Vol. 30, No. 1, pp. 151-159

[56] Timoshenko S.P., Goodier J.N., 1970, Theory of Elasticity, McGraw-Hill Book Company

[57] Tlusty J., 1965, "A Method of Analysis of Machine Tool Stability", Proceeding MTDR, pp.5-14.

[58] Tobias S.A., 1965, Machine Tool Vibration, Blackie and Sons Ltd.

[59] Tsutsumi M., Tada, K., 1994, "Development of High-Speed Spindle for Machine Tools by Means of Intermittent Oil-Mist Lubrication", Nippon Kikai Gakkai Ronbunshu, C Hen/ Transactions of the Japan Society of Mechanical Engineers, Part C, Vol. 60, No. 577, pp. 2911-2916

[60] Vanderplaats, G.N., 1984, Numerical Optimization Techniques for Engineering Design : With Applications, McGraw Hill Inc.

[61] VU65A Vertical Machining Center, Mitsui Seiki Kogyo Co., Ltd. 
[62] Weck M., Koch A., 1993, "Spindle-Bearing Systems for High-Speed Applications in Machine Tools", CIRP Annals, Vol. 42, No. 1, pp. 445-448

[63] Wang W.R., Chang C.N., 1994, "Dynamic Analysis and Design of A Machine Tool Spindle-Bearing System", Journal of Vibration and Acoustics, Transactions of the ASME, Vol. 116 , No. 3, pp. 280-285

[64] Weck M., Hennes N., Krell M., 1999, "Spindle and Toolsystems with High Damping", CIRP Annals - Manufacturing Technology, Vol. 48, No. 1, pp. 297-302

[65] Wong W.L.D., Atkinson J., 2000, "A Knowledge Cell Approach to Processing Design Information", Journal of Materials Processing Technology, Vol. 107, No. 1-3, pp. 44-52

[66] Yang S., 1981, "A Study of The Static Stiffness of Machine Tool Spindles", International Journal of Machine Tool Design \& Research, Vol. 21, No. 1, pp. 23-40

[67] Zadeh, L.A., 1965, "Fuzzy Sets", Information and Control, Vol. 8, pp. 338-353 